\title{
The London School of Economics and Political Science
}

'As if nobody's reading'?: The imagined audience and socio-technical biases in personal blogging practice in the $U K$

David R. Brake

A thesis submitted to the Department of Media and Communications of the London School of Economics for the degree of Doctor of Philosophy, London, April 2009. 


\section{Declaration}

I certify that the thesis I have presented for examination for the $\mathrm{PhD}$ degree of the London School of Economics and Political Science is solely my own work.

This work is licensed under the Creative Commons Attribution-Noncommercial 2.0 UK: England \& Wales License. To view a copy of this license, visit http://creativecommons.org/licenses/by-nc/2.0/uk/ or send a letter to Creative Commons, 171 Second Street, Suite 300, San Francisco, California, 94105, USA.

I warrant that this authorization does not, to the best of my belief, infringe the rights of any third party. 


\section{Abstract}

This thesis examines the understandings and meanings of personal blogging from the perspective of blog authors. The theoretical framework draws on a symbolic interactionist perspective, focusing on how meaning is constructed through blogging practices, supplemented by theories of mediation and critical technology studies. The principal evidence in this study is derived from an analysis of in-depth interviews with bloggers selected to maximise their diversity based on the results of an initial survey. This is supplemented by an analysis of personal blogging's technical contexts and of various societal influences that appear to influence blogging practices.

Bloggers were found to have limited interest in gathering information about their readers, appearing to rely instead on an assumption that readers are sympathetic. Although personal blogging practices have been framed as being a form of radically free expression, they were also shown to be subject to potential biases including social norms and the technical characteristics of blogging services. Blogs provide a persistent record of a blogger's practice, but the bloggers in this study did not generally read their archives or expect others to do so, nor did they retrospectively edit their archives to maintain a consistent self-presentation.

The empirical results provide a basis for developing a theoretical perspective to account for blogging practices. This emphasises firstly that a blogger's construction of the meaning of their practice can be based as much on an imagined and desired social context as it is on an informed and reflexive understanding of the communicative situation. Secondly, blogging practices include a variety of envisaged audience relationships, and some blogging practices appear to be primarily self-directed with potential audiences playing a marginal role. Blogging's technical characteristics and the social norms surrounding blogging practices appear to enable and reinforce this unanticipated lack of engagement with audiences. This perspective contrasts with studies of computer mediated communication that suggest bloggers would monitor their audiences and present themselves strategically to ensure interactions are successful in their terms. The study also points the way towards several avenues for further research including a more in-depth consideration of the neglected structural factors (both social and technical) which potentially influence blogging practices, and an examination of social network site use practices using a similar analytical approach. 


\section{Acknowledgements}

A thesis is a rite of passage and it is by necessity a solitary one in some respects but I could not have started, continued or completed this journey without the generous help and support of many. My supervisors, of course, have played a key role. Robin Mansell showed faith in my work when I was struggling and kept me on the path to completion. Your calm assurance and sage advice have been invaluable - thank you. Thanks also to Nick Couldry, now at Goldsmiths, whose suggestions and criticism are always stimulating. I am grateful for the interest and support that you generously showed even once your formal supervisory role had ended. Other staff in the department have also been generous with their time - particularly the others on my thesis committee. It has been a privilege to benefit from Sonia Livingstone's advice and to work with her on several projects while completing my thesis. The breadth and depth of your understanding of media theory and practice combined with your warmth and energy are an inspiration to many of us. Shani Orgad's early advice was invaluable. I am grateful to my examiners, Paul Hodkinson and Neil Selwyn, whose balanced and thoughtful assessment of my draft has helped me to clarify my arguments and put my scholarly contribution into perspective.

I also could not have managed without the help and encouragement of my fellow LSE students - Elizabeth, Ellen, Patrick, Zoe, Nancy, Giota and many others. Thank you all from the bottom of my heart. Thank you too to those who made themselves available for the interviews at the core of this thesis - you were unfailingly thoughtful and generous with your time. I am grateful to Knut Lundby for inviting me to join the Mediatized Stories Network and to all the members of that network for the stimulation they provided and the interest that they have shown in my work. Thank you also to all of the other academic friends I have met (mostly) at conferences and who have kept in touch online, particularly Lois Scheidt, Gordon Gow, Maria Bakardjieva, Lynn Schofield Clark and Theresa Senft. Last but not, of course, least, I would like to thank my family. Thank you to Mum and Dad for respecting my decision to pursue this even when I found it hard to explain why I would do such a thing and backing me up through the long struggle. Adrien, my son, your love and laughter kept me sane. Thank you to my father-in-law, Robert - I hope I will also be able to work elephants into my graphs one day. Thank you most of all to my wife Delphine. Your love, support and patience throughout this thesis journey have been exemplary - I dedicate this thesis to you. 


\section{Table of Contents}

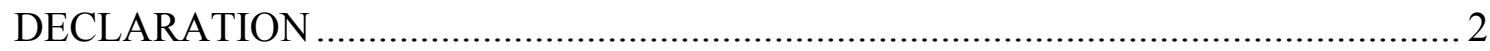

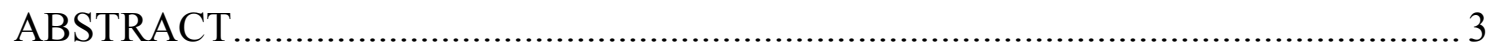

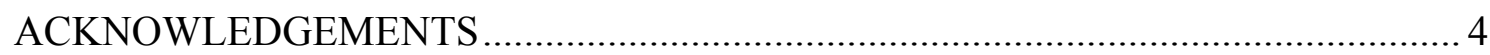

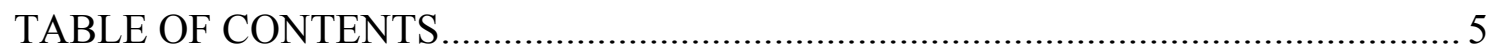

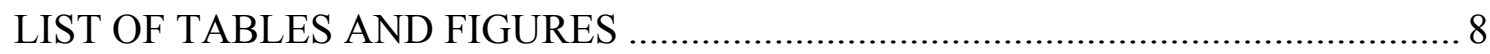

CHAPTER 1: INTRODUCTION

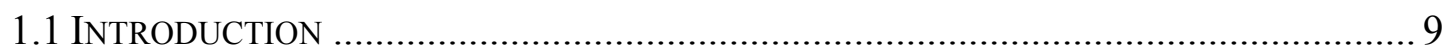

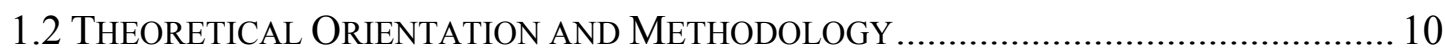

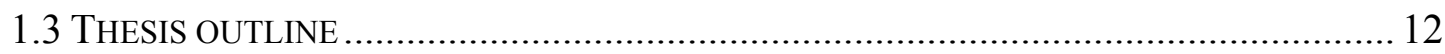

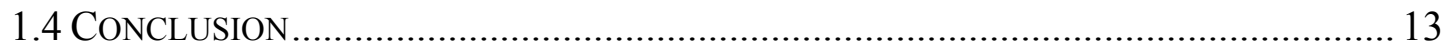

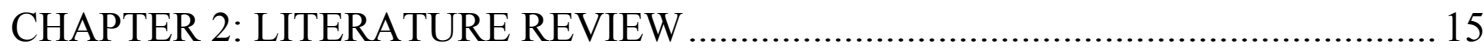

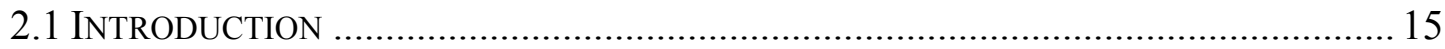

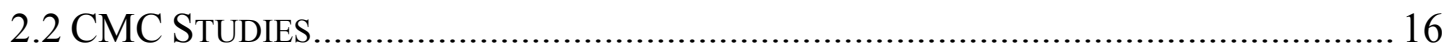

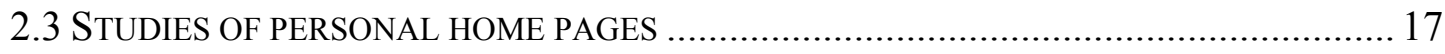

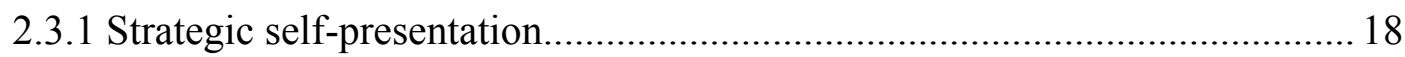

2.3.2 Identity construction ............................................................................ 20

2.3.3 Technological and social influences on home page practices ..................... 22

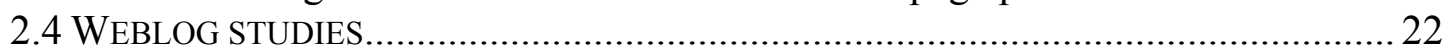

2.4.1 Technological influences on Blogging practices ....................................... 24

2.4.2 Social Influences on Blogging Practices ................................................. 29

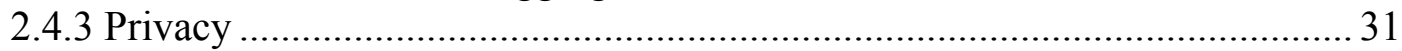

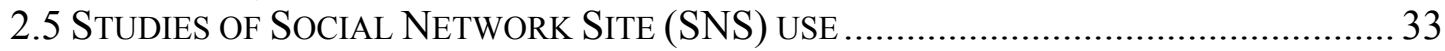

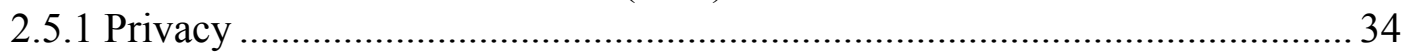

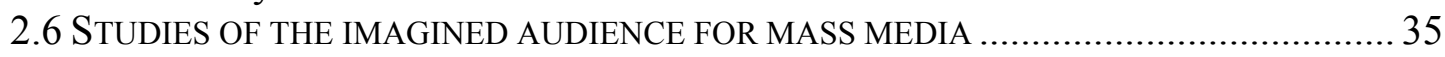

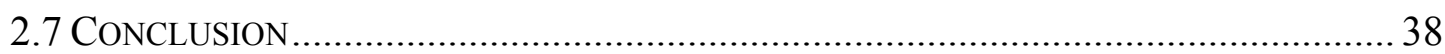

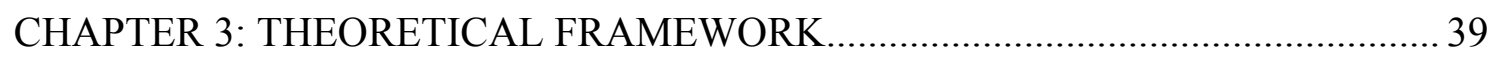

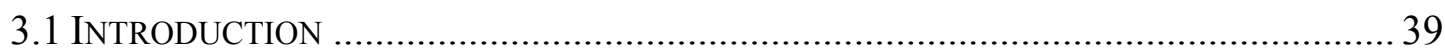

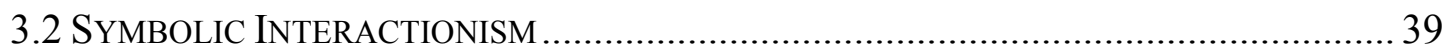

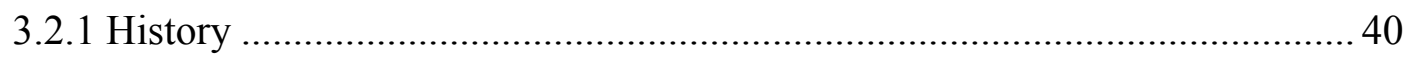

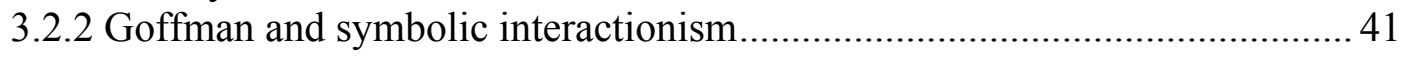

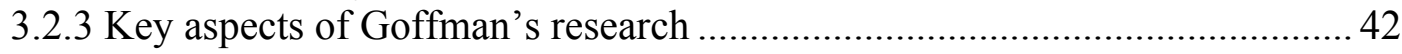

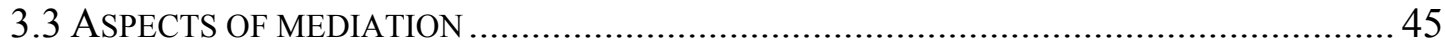

3.3.1 Meyrowitz: the importance of control over social information .................... 46

3.3.2 Thompson: New forms of interaction and the role of the imagination.......... 48

3.4 BLOGGING AS A TECHNOLOGICALLY MEDIATED PRACTICE ................................ 53

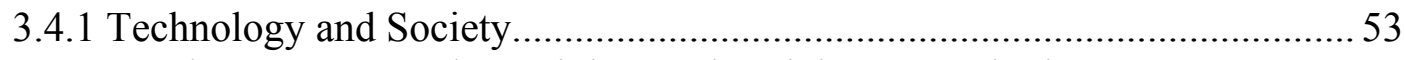

3.4.2 Feenberg: Between determinism and social constructionism...................... 55

3.5 CONCEPTUAL FRAMEWORK - PERSONAL WEBLOGGING AND THE ROLE OF TECHNOLOGICAL

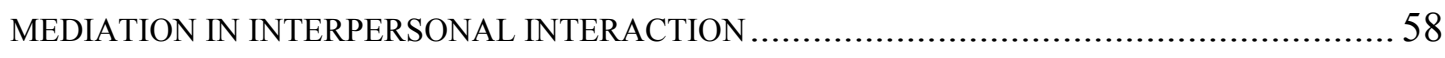

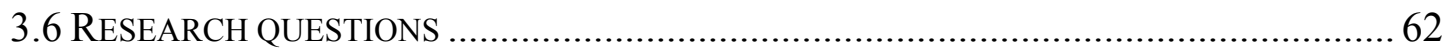

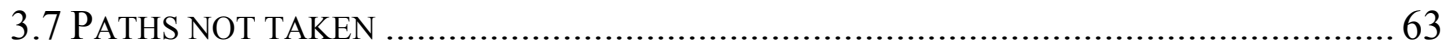

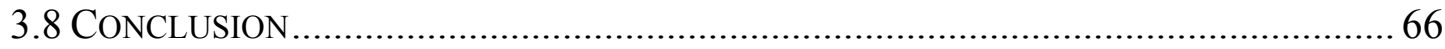

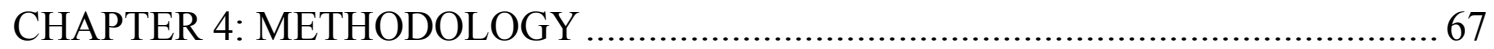

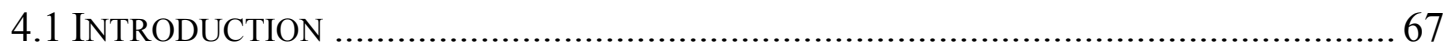

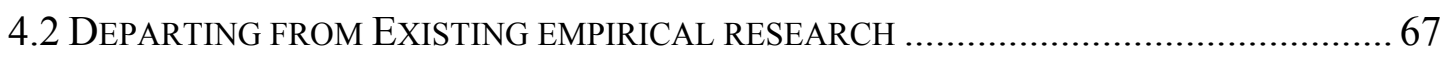

4.2.1 Limitations of prior interview-based and ethnographic research ..................69 69

4.2.2 Towards a methodological reorientation ............................................. 70 
4.3 OPERATIONALISING THE CONCEPTUAL FRAMEWORK …...................................... 71

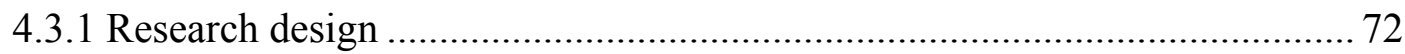

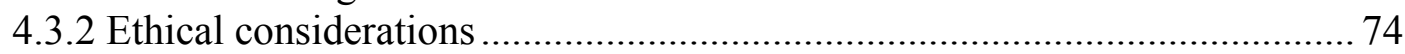

4.4 OVERVIEW OF EMPIRICAL RESEARCH METHODS AND PROCESS .............................. 76

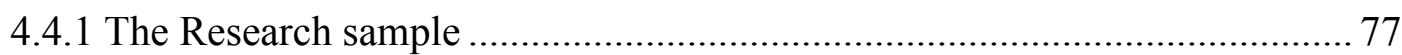

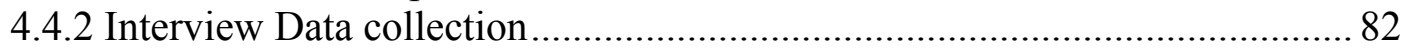

4.4.3 Analysis of technical and social contexts of blogging.............................. 84

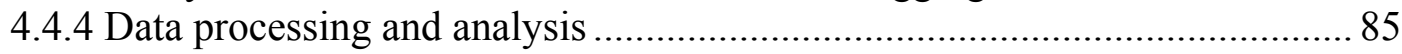

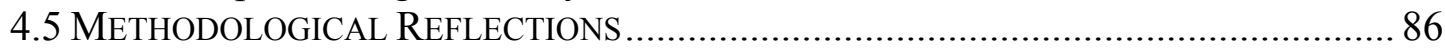

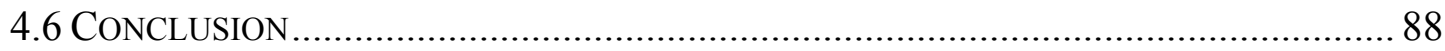

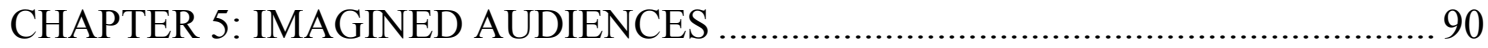

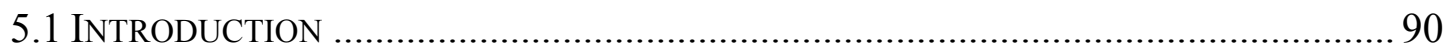

5.2 WHO DO PERSONAL WEBLOGGERS THINK THEY ARE TALKING TO? ......................... 90

5.2.1 How much do bloggers know about their readers?................................... 90

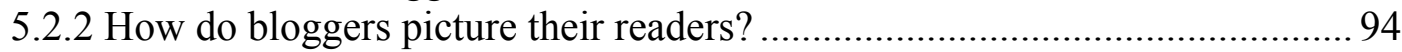

5.3 WHAT RELATIONSHIP TO THEIR READERS DO BLOGGERS SEEK? ............................ 98

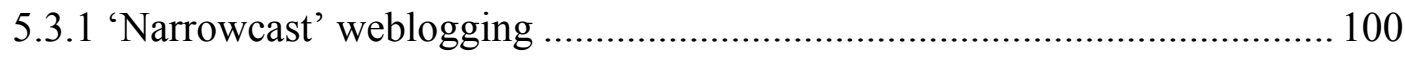

5.3.2 Dialogic Weblogging - Keeping in touch with friends................................ 105

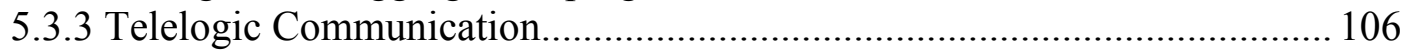

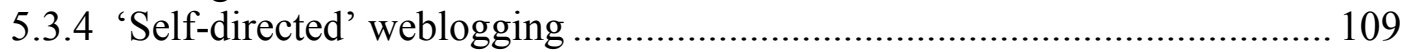

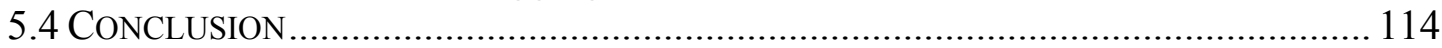

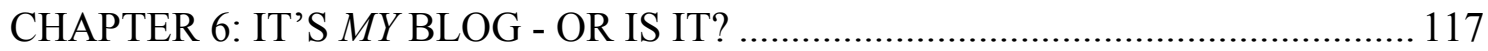

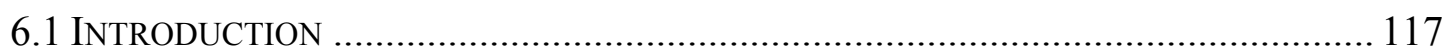

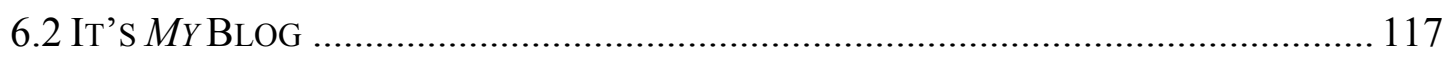

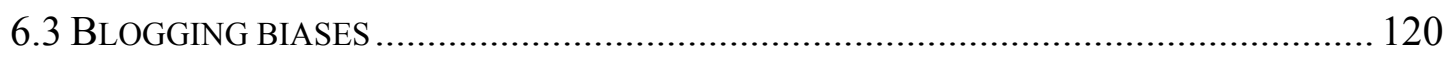

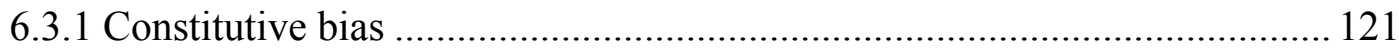

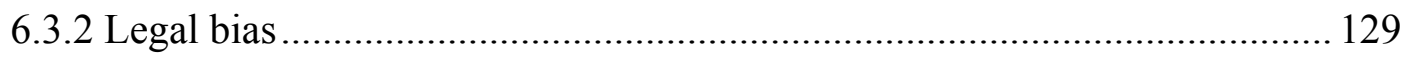

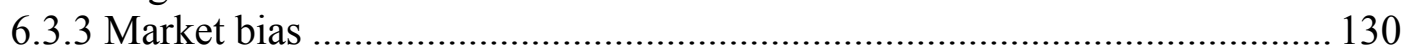

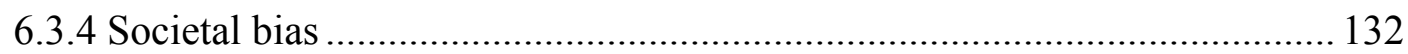

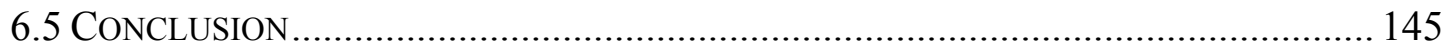

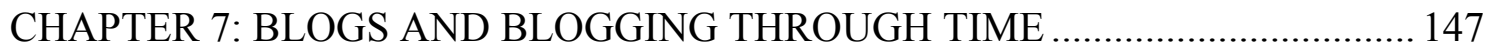

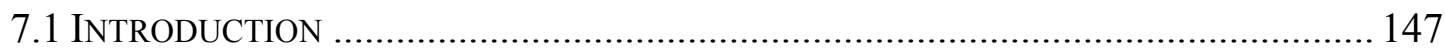

7.2 CHANGING BLOGGING PRACTICE THROUGH TIME .......................................... 148

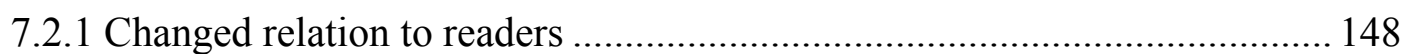

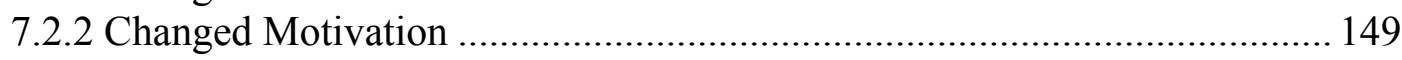

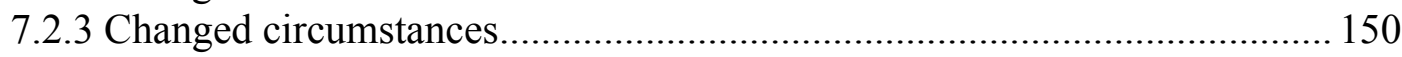

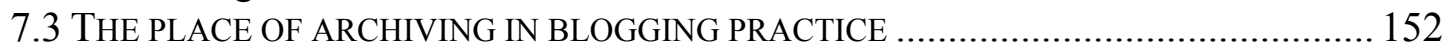

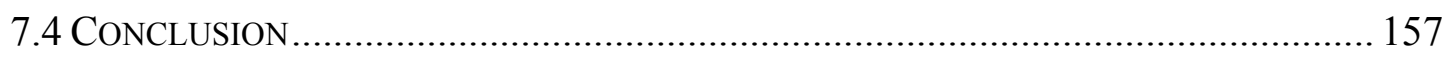

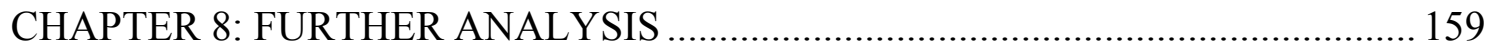

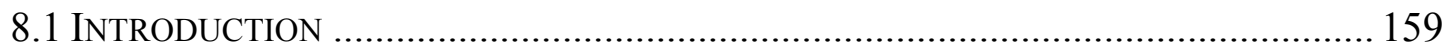

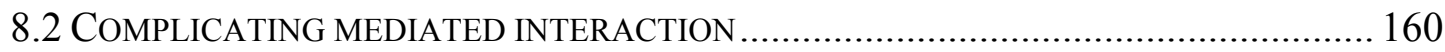

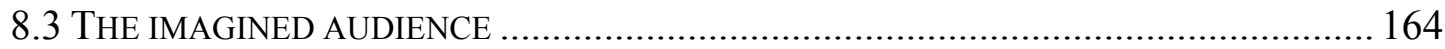

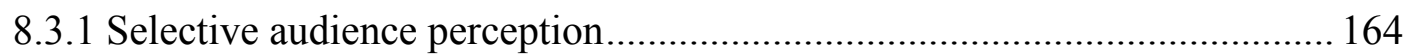

8.3.2 Changing norms of social information disclosure? ................................. 167

8.3.3 The varying roles and importance of the audience ...................................... 170

8.3.4 Alternative academic framings for the audience's role ............................ 171

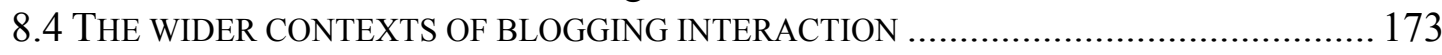

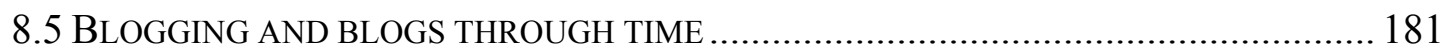

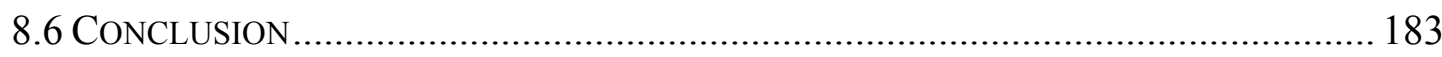

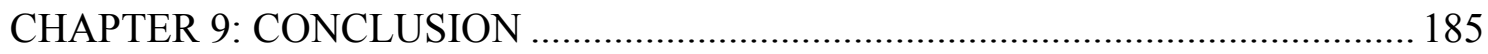




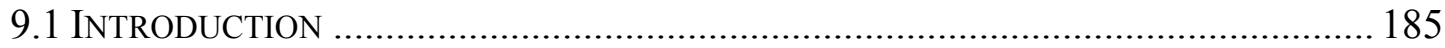

9.2 THEORETICAL INSIGHTS AND KEY EMPIRICAL RESULTS........................................ 185

9.3 THEORETICAL AND METHODOLOGICAL REFLECTIONS............................................... 192

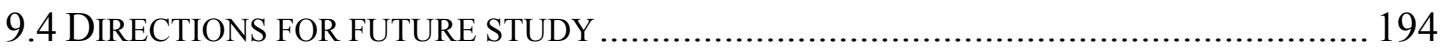

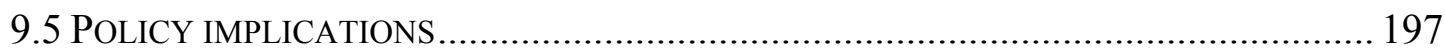

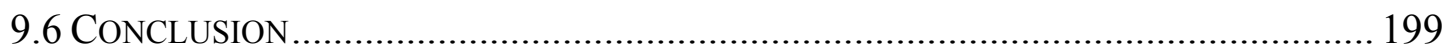

APPENDIX A: BLOG TECHNOLOGIES \& DEFINITIONS …………………….... 200

BLOGGING DEFINED ………………………………………………………..... 200

THE BLOGGING ‘ECOSYSTEM’ - BLOG-RELATED SERVICES ………………………........205

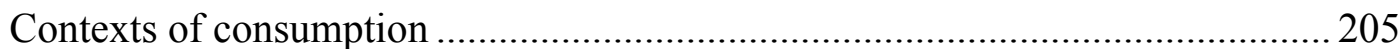

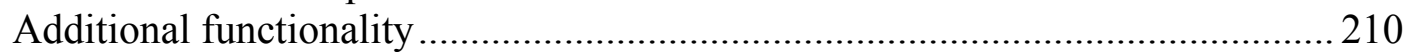

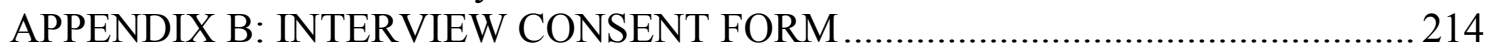

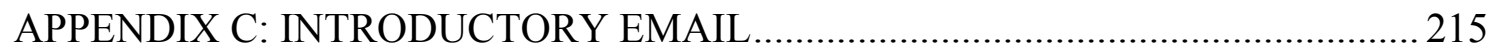

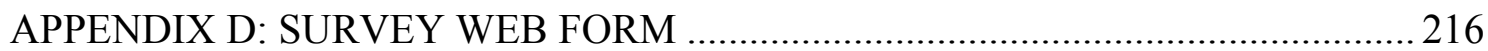

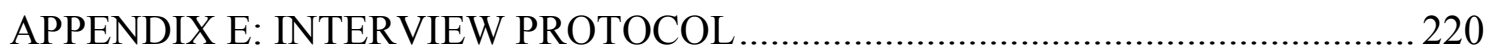

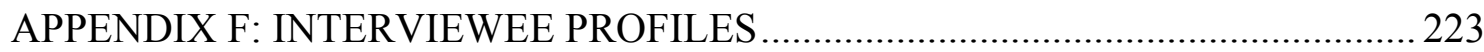

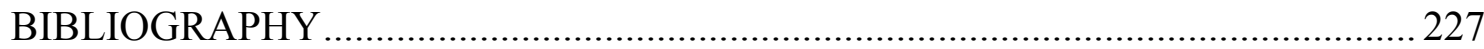




\section{List of Tables and Figures}

Table 4.1 - Phases of Research (p. 85)

Table 4.2 - Response Rate (p. 91)

Table 5.1 - Forms of intended weblog interaction (p. 109)

Table 6.1 - Constraints on mediated practices (p. 132)

Image 6.2 - Blogger navigation bar (p. 134)

Image 6.3 - Livejournal posting interface (p. 140)

Image 6.4 - Blogging-related cartoon (p. 147)

Image 6.5 - Blogging-related cartoon (p. 148)

Table 8.1 - Non-interactive forms of blogging practice (p. 188)

Image 8.2 - Myspace content-posting warning (p. 198)

Image A.1 - Facebook wall (p. 221)

Image A.2 - Flickr photostream (p. 222)

Image A.3 - Youtube user page (p. 223)

Image A.4 - Twitter user page (p. 224)

Image A.5 - Technorati search page (p. 226)

Image A.6 - Google Reader main page (p. 227)

Image A.7 - Friendfeed user page (p. 228)

Image A.8 - Wayback machine weblog archive (p. 229)

Image A.9 - Wayback machine page comparison (p. 230)

Image A.10 - Statcounter visitor location information (p. 231)

Image A.11 - Annotated screenshot of a sample weblog page (p. 233) 


\section{Chapter 1: Introduction}

\subsection{INTRODUCTION}

There is a striking mismatch in academic research on internet-mediated practices between the kind of practices studied by social scientists and their incidence in the general population. A great deal of attention has been paid to the use of the internet as a political tool, as a shopping mall, or as an educational tool. This focus is reflected in most studies of the digital divide, for example, and in policy reports which have focused on the putative educational, economic and political benefits of internet use - particularly of the 'right kind' of internet use (DiMaggio et al. 2004, Hargittai and Hinnant 2008). By comparison, the use of the internet for private, inter-personal communication outside the workplace has received rather less attention among social scientists, although studies of internet use consistently reveal that it is experienced more as a social space by most users than as an informational one - a study of American internet users, for example found 35\% of their internetusing time was spent communicating with people outside a work setting - the largest single use (Nie et al. 2004). The main focus of social scientific attention on such social uses of the internet has been the extensive debate, conducted predominantly using macro-level, quantitative studies, aimed at establishing a positive or negative link between internet use - particularly email and more recently social network sites - and 'social capital' (Ellison et al. 2007, Hlebec et al. 2006, Horrigan et al. 2006, Valenzuela et al. 2008, Wellman and Quan-Hasse 2004). In this study, the aim is to addresses the less-well-charted territory of qualitative analysis of 'social' internet use. Given the empirical research so far that will be highlighted in Chapter 2, the choice has been taken to concentrate on one particular aspect - personal weblogging.

He wanted his posts to be read, and feared that people would read them, and hoped that people would read them, and didn't care if people read them. He wanted to be included while priding himself on his outsider status. And while he sometimes wrote messages that were explicitly public -- announcing a band practice, for instance -- he also had his own stringent notions of etiquette. His crush had an online journal, but J. had never read it; that would be too intrusive, he explained. (Nussbaum 2004)

The quotation above about a teenage personal weblogger's imagined relationship with his readers helps to illustrate some of the apparent contradictions and complexities which informed the choice of personal weblogging as the object of this study. While in some respects this practice resembles an online rendition of earlier forms like diaries and commonplace books, it is novel due to the manner in which it appears to combine interpersonal with mass mediated communication. Personal weblogs can contain diaristic or confessional material that traditionally would be understood as being meant only for the author alone or perhaps trusted intimates - but much of this writing is done on the web with a potential audience of millions. Temporal aspects of blogging can also appear to be contradictory. The individual postings from which weblogs are assembled are 
instantly updateable and often conversational in tone implying a focus on the here and now, but are archived within the blogs indefinitely. To make sense of these and other apparent puzzles and contradictions arising from this phenomenon, it is first and fundamentally necessary to analyse what it is that the people producing personal weblogs understand themselves to be doing. One can then examine the relevant contexts - both social and technical - within which this practice takes place and the manner in which these contexts may influence the form it takes. The core research questions in this study are: "how do personal webloggers understand this practice and how does the practice relate to its social and technical context?" The remainder of this chapter highlights the theoretical approach which is developed in this thesis and the methodology, together with an outline of the structure of the thesis.

\subsection{Theoretical Orientation AND Methodology}

The theoretical orientation that is developed in this thesis is a symbolic interactionist one, drawing largely on the work of Erving Goffman, with particular reference to his work on regions and region control. Goffman's insights are complemented by those who have directed their attention specifically to various forms of mediated interaction - John B Thompson and Joshua Meyrowitz. In No Sense of Place, Meyrowitz focuses on the way in which electronic media (in his example, television) can change the way what he terms 'social information' is shared through interaction, making region control more difficult to achieve. In The Media and Modernity, Thompson offers other ways to analyse the significance of mediation for interaction. Two of the lenses he provides are particular interest in this study. The first is the communicator's imagined social context which comprises the intended audience and the anticipated or desired direction of interaction - one way from communicator to receiver (monologic) or in both directions (dialogic). A third possibility, "telelogic" or many-to-many communication, drawing on the work of Ball-Rokeach and other scholars, is also introduced. The second lens drawn from Thompson's work is the anchor frame of space-time in mediated interactions - in particular, the way the persistence of mediated interactions through time is understood by media creators and audiences.

Neither Meyrowitz nor Thompson consider the potentially variable implications of specific mediating technologies for those who use them to interact. To take this aspect into account, I draw upon Andrew Feenberg's critical theory of technology in order to provide a theoretical framework for a more nuanced empirical examination of blogging technology as a context for mediated interaction. This enables an appreciation of the potential influences of technologies on the practices they mediate and an understanding that uses and perceptions of technology are often the product of selective perception and adoption of particular technical functions by social actors. These 
theoretical insights are developed to offer a conceptual framework which guides the empirical study in this thesis.

Personal weblogging practices are conceived as a distinctive form of interpersonal interaction. Because personal blogging involves the sharing of potentially sensitive social information, it would seem that bloggers may need a sense of control over the context of the release of information. Unlike most forms of mass media, weblogs provide multiple ways for weblog producers to interact with their readers, but it is unclear what relationship webloggers may be seeking or envisaging with those who read their blogs. In this study, I therefore examine the following empirical questions.

How are the readers of such sites imagined by the producers and how does this imagination shape the authors' practice? In particular, to what extent do they feel in control of their interactions, what do they feel might threaten their control over social information exchanged and how do they manage such threats?

Insofar as any technologically-mediated practice is subject to biases, as suggested by Feenberg, I also examine bloggers' experiences and a range of biases that may be invisible to bloggers themselves by asking:

What are the principal sources of constitutive and implementation bias in personal weblogging, and how are they perceived and encountered in practice by personal bloggers?

In the literature on blogging there is disagreement about the importance that bloggers accord to the fact that their blogs are archived. Little attention has been paid to the possibility that reading blog entries after their initial production could be as problematic for interactional control as the reading of blog entries by an unanticipated audience at the time of production. To investigate this aspect of blogging, I examine:

How do personal bloggers understand and negotiate the space-time interpolations inherent in their practice?

The subject of study is not well-understood and a qualitative method has been adopted to address the research questions in this study so that insight into bloggers' perceptions and the meanings they attach to blogging practices can be developed. In this study the bloggers themselves rather than their blog texts are the primary focus of the research. In-depth semi-structured, face to face interviews have been conducted with with 23 personal bloggers. The findings of earlier interview-based and ethnographic studies have been limited as a result of the tendency to use convenience sampling to identify interviewees. In this study, Google has been used to assemble a sample of personal weblogs whose owners were contacted and asked to fill in an online survey which provided demographic information and summary information about blogging practices. This provided the basis for the selection of an interview sample that was as diverse as possible in terms of educational background, gender and weblog popularity. Supplementary sources of data have been used to identify and analyse environmental factors that seem to influence blogging practices. The data have been analysed using a thematic coding procedure. 


\subsection{THESIS OUTLINE}

In Chapter 2, research on different aspects of mediated communication is examined focusing on studies of weblogging itself, but also home page-related studies and studies of the use of social networking services. In addition, social psychological studies of computer-mediated communication more broadly are reviewed, and (because the relationship between blogger and reader is one of the mysteries which prompted this study), studies of professional creators (artists and journalists) are examined to gain insight into the relationship between these communicators and their audiences. These studies help to establish the extent of scholarly work on aspects of my research questions, but these bodies of academic research work have not provided a pre-existing framework for research that would be responsive to the central research questions that guide this study.

Chapter 3, accordingly, sets out the theoretical perspective that informs this study. It concludes with a conceptual framework for this thesis which provides a basis for the development of the empirical research questions that are set in the preceding section of this chapter. In Chapter 4, the methodology for this study is discussed together with the way that concepts drawn from the conceptual framework have been operationalised.

The first empirical chapter, Chapter 5, focuses on bloggers and their relationship with their potential and actual readers. It outlines the variety of techniques potentially available to bloggers to count and to some extent to identify their audiences and reveals that they often appear to have little interest in using such tools, but that in the absence of detailed information they nonetheless tend to express a sense of their audience as being generally well-disposed and composed of the kind of people they would like to be reaching. Four main orientations toward the audience are identified. Some bloggers appeared to be largely monologic, wishing their posts to be read by friends but not seeking a response. Some were dialogic, using their blogs to engage with friends. Some were telelogic, using their blogs to engage with a broad range of unknown others. And lastly, (and unexpectedly) some appeared to be primarily self-directed in their blogging practice. For these bloggers the communicative and interactional aspects of their blogging appeared to be secondary to other goals, summarised as quasi-therapy (relief of emotion through its expression), quasi-sociality (a feeling of being heard by unknown others but without a strong desire to interact with them) or blogging as an end in itself (the pleasure of mastering a new tool or of expressing oneself through writing).

In Chapter 6, the focus shifts to the environmental influences on blogging practice. The bloggers in the sample were often insistent that they could do whatever they liked in their blogging practice, and this appeared to be part of the appeal of personal blogging. It is certainly possible that they are more free to express what they wish on their blogs than they are in other spheres of their 
lives, but the analysis suggests that their blogging practices are nonetheless potentially subject to various influences or biases to use Feenberg's term: i.e. constitutive bias, legal bias, market bias and societal bias. These biases are analysed in this chapter.

Two temporal aspects of blogging practice are discussed in Chapter 7. The tendency for blogging practices to change over time (because of changing motivations, personal circumstances or reader perceptions), while remaining in the same 'venue' is highlighted, as is the place of archiving in blogging practice, observing that bloggers themselves do not appear to see the archiving of their words as an important aspect of their overall practice.

In Chapter 8, the principal findings of the preceding three empirical chapters are considered in the light of the conceptual framework for this study. The concluding chapter, Chapter 9 suggests directions for future study building on this research with particular reference to the study of social network sites, discusses some potential policy implications, reflects on the theoretical and methodological choices made and limitations and provides an overview of the key empirical results and theoretical arguments of this thesis.

\subsection{Conclusion}

This study suggests that those who seek to understand why personal webloggers choose to share potentially sensitive information about themselves with a broad audience across the internet may be asking the wrong question. The focus of this study on how bloggers understand their practice suggests that some of them do not primarily see their practice as other-directed, instead seeing the activity itself as its own reward. This finding is consistent both with survey research and studies of other forms of information and communication technology (ICT) use. Several of those who were writing their blogs with the expectation that they would be read assumed that they would predominantly or solely be read by people they already knew rather than a wider audience on the internet. Many bloggers in the sample for this study appeared to be indifferent to the possibility that what they write could be read outside its intended context. In this study, three reasons for this are advanced. Firstly, they may enjoy their practice and avoid thinking about its possible consequences because that might encourage them to stop. Secondly, they may not regard what they reveal on their blogs as being potentially sensitive. Whether what they posted was in fact sensitive was not addressed in this study but reasons are advanced to explain why they might be willing to reveal material about themselves that others might deem sensitive. It is suggested that increased selfrevelation on blogs may be one symptom of greater pressure in modern society to share information about the self with others. It is also suggested that the bloggers were influenced by norms of selfrevelation specific to particular media practices - either weblogging norms or the norms influencing other media. Thirdly, because of the manner in which weblogging interaction is mediated, bloggers 
may be shielded from the reactions 'given off' by readers and only perceive certain reactions which, by convention, tend to be positive.

I have examined the possible origins of the norm of openness about the self that bloggers were found to perceive. These include the possibility that they perceive that blogging should be open because the media often characterise the internet as a space that is resistant to control of any kind. Bloggers may be influenced by explicit norms of openness articulated by early internet adopters and blogging pioneers who shared participation in Californian countercultural movements. They may also be influenced by the example of those whose blogs they read and whose blogging practices may in turn be influenced towards openness by the first two factors. 


\section{Chapter 2: Literature Review}

\subsection{INTRODUCTION}

This chapter locates the present study primarily within the broad canvas of studies of computer mediated communications and secondarily in relation to studies of the producer-audience relationship, focusing mainly on the empirical insights and on some of the explanations provided in this body of literature. It is divided into five sections. There are four main bodies of existing internet research that relate in some way to this research - studies of computer mediated communication (CMC), studies of personal home page production, weblog-related studies and studies of social network site (SNS) usage. Studies of the producer audience relationship in a mass media context have also been analysed to provide additional and contrasting insights into the relationship between bloggers and their readers.

Section 2.2 examines and critiques the social psychological literature on computer mediated communication which studied the relationship between authors of computer mediated communication and their recipients. Section 2.3 provides an overview of studies of personal home pages which may be considered to some extent as precursors to personal weblogs - these point to strategic self-presentation and self-exploration as important themes in personal publishing, and several studies address the potential influences of the technology used on the nature of home page practices. Section 2.4 on studies related directly to personal weblogging notes that most blogging studies are focused on 'non-personal' practices. It also points to a lack of interview-based or ethnographic work on blogging. Empirical evidence from existing research is then used to highlight some key issues which were suggested by studies of home page creation - notably the influence of social norms and of technological characteristics on blogging practices. Influences of particular interest include the temporal aspects of blogging (which are distinctly different from those of home page production and social network site use), the relationship between bloggers and their audiences and privacy issues. A discussion of definitions of weblogs and of the "ecosystem" of sites which offer blog-related features and services can be found in Appendix A. Section 2.5 draws on the emerging literature around social networking sites - in particular that which discusses privacy though it notes some key differences in the technological and social influences on practice between blogging and SNS use. Lastly, in Section 2.6 studies of professional producers and their relationship to the audience are outlined. The aim of this chapter is to demonstrate that certain facets of the experiential aspects of weblogging as understood by the webloggers themselves have yet to be fully conceptualised or adequately empirically investigated. As a result, the conceptual framework 
developed in Chapter 3 which follows is derived largely from literatures that are not specific to the study of computer mediated communications.

\subsection{CMC STUDIES}

While digital technologies enable forms of communication broadly analogous to both one-toone and broadcast communication (email at one end of the spectrum and professional web publishing on the other) they also enable a heterogeneous set of novel communication practices by individuals aimed at groups of others online, some of whose identities were not already known to them - sometimes referred to in popular accounts as 'many-to-many' communication but perhaps more usefully described as telelogic communication (Ball-Rokeach and Reardon 1988), since often the numbers reached in any given communication are small ${ }^{1}$. The main stream of CMC empirical research from the 1980s and 1990s relied on experiments that isolated online communication from offline communication and studied situations in which communicators had never met - often focusing on situations where both parties were anonymous. It focused primarily on the manner in which the other party to communication is perceived and the effect of such perceptions on what is communicated.

Early research has been categorised as the 'Cues Filtered Out' school (Culnan and Markus 1987), which suggested that the lack of visual and audible feedback available to communicators would make it difficult for CMC users to get a clear sense of the person they were communicating with and that this would therefore make it difficult to use CMC for anything but impersonal taskoriented communication. These researchers also noted that in their experiments CMC frequently resulted in anti-social behaviour ('flaming'). When it became evident subsequently that CMC was frequently used for personal, emotionally charged messages, and that flaming was less prevalent in workplaces than it had been in experimental conditions, subsequent research, culminating in what was called the SIDE model questioned the initial technologically-determinist interpretation of the likely effects of CMC in this context and took into account that CMC users would attempt to fill in missing social cues, relying on whatever information was available (and possibly exaggerating the few cues that were available) - particularly where communication took place over a sustained period (Postmes et al. 1998). Walther noted that CMC often resulted in 'idealized perception' of the other and explained this with his model of hyperpersonal interaction, which draws on Goffman's theories of self-presentation (Goffman 1959) and suggests that idealized perceptions frequently arise in asynchronous $\mathrm{CMC}$ because message senders take advantage of the time available to

\footnotetext{
${ }^{1}$ Although the novelty of such communicative situations can be exaggerated - 'party line' anonymous social (and sexual) phone conversations existed before $\mathrm{CMC}$, for example.
} 
"concentrate on message construction to satisfy multiple or single concerns at their own pace." (Walther 1996 p. 26).

What this research tends not to consider in detail is the imagined social context of communication. In most of the experimental studies, the social context is a completely artificial one. Naturalistic studies in this tradition have tended to study more-or-less bounded internet spaces - in studies of 'virtual communities', for example, researchers have looked at message boards on particular themes, mailing lists inside particular organisations, and multi-user dungeons among other spaces (Hiltz et al. 1986, Kiesler and Sproull 1992, Postmes et al. 1998, Sproull and Kiesler 1986). Participants in these spaces may not have met any of those they are communicating with and may not know their number or identities but they normally can assume that the context of the communication is mutually understood (or, importantly, they believe that they can) and in case of disagreement they may be able to appeal to other members of the group, including leaders (whether formal or self-appointed). Certainly the lack of visual cues to communication may have an impact in such cases, but perception of others is likely also to be shaped by the nature of the online space itself. Participants in an online disease discussion group, for example, might reasonably expect the other participants to be supportive and eager to hear about their experiences, while participants in an open political discussion group on a contentious issue may envisage a much more critical set of potential readers.

The unusual case of the personal weblogger brings the relatively neglected role of the imagined social context into sharp relief. The personal weblog unusually lacks the explicit subject or organizational boundaries that would provide a ready-made social context. In its place the writers in this case may be expected to construct an imagined social context that reinforces their activity. Related to this, the relevance of anonymity in interaction - often treated as an important influence on online behaviour - is difficult to gauge in relation to blogging. Even when bloggers do not use their real names or provide pictures of themselves they often reveal information which would allow others to identify them and, over time, they might reveal enough personal information such that they might come to expect readers to treat them as if their readers knew them. We will return to the importance of the imagined social context of online interaction in Section 2.3.1.

\subsection{STUDIES OF PERSONAL HOME PAGES}

Although personal home pages and weblogs differ in several respects, the personal home page can be viewed in many ways as a precursor technology to the weblog. Academic studies of home pages cannot be applied precisely to the personal weblog form because of differences in their technological characteristics but the approaches and findings have been influential to some extent in subsequent studies of weblogging and some of the themes they explore are similar. Given the 
relative paucity at present of theoretically-informed analysis of personal weblogs, personal home page studies provided a useful starting point for analysis in this study.

Not long after the creation of the World Wide Web in 1991, website creators began to put up websites about themselves and their interests. ${ }^{2}$ As the number of internet users increased, as the web became more well-known and as corporations began to provide tools to make web page creation easier (AOL 2006, Lycos 2004, Yahoo 2004), the number of web pages created by individuals rose. It appears to have reached a plateau with a sizeable minority of online users having created a personal site. According to the Oxford Internet Survey (OxIS), 16\% of UK internet users had tried to create a website by 2007 (Dutton and Helsper 2007) and according to an analysis of detailed OxIS data from 2003, half of these were 'personal' pages (as distinct from pages produced for work, school or other reasons) (Shepherd 2003). A US survey conducted by Pew in December 2007 found $14 \%$ of online Americans 'had ever' maintained their own websites (Pew Internet \& American Life Project 2007). Both of these figures almost certainly understate the proportion of people with some form of webpage about themselves. Many websites that require registration (webbased bulletin boards, social network sites and online dating sites for example) provide their users with the opportunity to produce a personal profile (or require one), though some of these may not be visible to all internet users. As a result, the number of pages on the web which display information about individuals and their interests within the context of a particular activity is likely rising rapidly, albeit at the expense of more free-standing sites by and about individuals (also see Appendix A for the difficulties of defining blogging and social network sites in a changing technological environment).

As Cheung outlines in a review of the literature on the subject (2004), three broad qualitative approaches have been taken in the academic study of the personal home page - it has been analysed as a tool for strategic self-presentation, as a means of self-exploration and as an artefact whose form is influenced by various social and technological forces.

\subsubsection{Strategic self-presentation}

Strategic self-presentation has been found to be the most straightforward use of the personal home page. Cheung suggests the home page enables individuals to raise their professional profiles, reach the 'right' audience for their individual interests and hobbies and helps those with stigmatized identities to reveal these "without risking rejection or harassment that may be experienced in

\footnotetext{
${ }^{2}$ In fact even before such sites existed a program called "finger" that worked across the internet provided simple information about users (whether or not they were online for example) and accessed ".plan" and ".project" files that could be edited by users - an early service analogous to a personal home page. (Indiana University Information Technology Services 2006)
} 
everyday life" (ibid p. 57). Here he draws on Goffman (1959) but he has not extended his approach to take into account the difference in circumstances between face to face and online communication. Chandler, the author of an early and influential short essay about home pages cited by Cheung, also has little to say about what interactions with the audience are expected by the authors of these pages. Chandler notes in passing that, "strangely", one respondent reported, "I hardly ever mention it [his home page] to my friends - it's almost 'my secret"' (Chandler 1998) but does not elaborate on the point. Cheung suggests that the personal home page (because of the authors' ability to draft and redraft the text) allows writers much more strategic self-presentation than everyday interaction despite the fact that the home page gives its owner no control over who might read it in what context and no way to interactively modify the impression given depending on the individual reader's reaction. For him "the global reachability of the personal home page enables the home page author to get validatory feedback from net browsers who empathize or share with the author's identity or narrative." (Cheung 2004 p. 61). He dismisses the potential for unsatisfactory interaction, saying "even if some people dislike our 'home page selves' and send us negative responses by email... these responses are not instantaneous, so we feel less pressure to respond to them - in fact, we can even ignore these comments." (Cheung 2004 p. 56). Similarly, Döring suggests home pages allow their owners to express themselves "without disturbance" and that they are thus "a medium of nearly unrestricted self-presentation" (Döring 2002).

Miller and Arnold's account (2001) includes a more nuanced exploration of some of the issues and difficulties that emerge when applying Goffman's (1959, 1986 [1974]) concept of framing to the interactions around the personal home page. It is worth quoting them at length on this point:

[In a face to face encounter] when we finally interact, we both know to some extent where we both are (geographically) and probably where the other is coming from (socially or organisationally). We also know what kind of interaction this is: whether it's a customer order, a chance encounter in the street, or a bedroom conversation. This enables us to 'frame' the interaction appropriately, so that we both know how to interpret what goes on in the context of what is really going on. When you call up our individual University home pages, by comparison, you may get there through an orderly route via our institution, department, speciality, and so on, but you might have found one of the pages because it is 'nerdy home page of the month' on the home page of someone in Mexico. If I knew that that was the way people were going to get to me, I might have arranged my public face differently.

Worse still, your communications (to the supposed audience of your pages) may be repeated by people you don't know to audiences you never intended. (Miller and Arnold 2001 p. 76)

In this way they begin to address the question of the imagined social context for interactions alluded to above in Section 2.2. Lacking an empirical component to their work in this paper, however, they do not speculate on how the resultant interactional difficulties inherent in home page creation are perceived or resolved. Moreover, despite this cautionary note they go on (as most other theorists have done - e.g. Chandler 1998, Chandler and Roberts-Young 1998, Cheung 2004, 
Kennedy 1999) to depict home page creation as a form of interaction without potential risks. Miller and Arnold maintain it enables authors to communicate with others without the felt risk of rebuff and they add, "Others may find your Web page ridiculous, but you probably won't be aware of it... So in two senses, it is easy to make a fool of yourself on the Web: there is little to stop you doing it, but doing it will cause you little pain." (Miller and Arnold 2001 p. 76). Rosenstein in her interviews with home page creators found by contrast that they appeared to be aware of the "coexisting, contradictory definitions of the social situation of the home page" and that these contradictions "often created interactional tensions for their authors, and frequently led to unanticipated social consequences" (Rosenstein 2000 p. 177).

While many personal home pages appear clearly to be spaces intended for strategic self presentation, some of the most personal sites are hard to see as 'strategic' in nature insofar as they can present their authors in an unfavourable light, possibly because (as Rosenstein suggests) the authors do not have an audience in mind when they are producing their pages. Rosenstein and Cheung among others (Cheung 2004, Rosenstein 2000) have therefore suggested that the practice of home page creation and maintenance may therefore sometimes be directed at the self, not others.

\subsubsection{Identity construction}

A number of leading sociologists (Bauman 2001, Beck and Beck-Gernsheim 2001, Giddens 1991, Lash and Friedman 1991, Rose 1999) have suggested that one of the principal characteristics of late modernity is the need for individuals to define their identities reflexively. It is this need that several authors have suggested the personal home page might help to meet. Chandler for example suggests that through self-reflexive writing home page authors can "change ourselves to who we really want to be" (Chandler 1998). Chandler usefully draws on Walter Ong's work on writing as consciousness-raising (Ong 1982 p. 179) and on Foucault's idea of writing about the self as a 'technology of the self' (Foucault 1988b) to place such activities in a theoretical context.

Through much of his life, Foucault concentrated on the ways in which, in certain historical contexts, particular kinds of subject (the mad, the ill, sexual deviants and criminals, for example) were produced through discursive and power relations. In his later work Foucault turned his attention to the ways in which the self could constitute itself in a positive fashion, using historical practices - particularly those of the Ancient Greeks and Romans - as illustrations.

The care of the self in Roman times consisted of care of the body, naturally, and private meditation but also "an entire activity of speaking and writing in which the work of oneself on oneself and communication with others were linked together." (Foucault 1986 p. 51) This included, "the talks that one has with a confidant... [and] the correspondence in which one reveals the state of one's soul, solicits advice, gives advice to anyone who needs it." (Foucault 1986 p. 51). By analogy, 
personal home pages in the present day have been construed by scholars like Chandler and Cheung as a form of correspondence about the self and thereby potentially as a new form of 'technology of the self'. Walter Ong reasons very similarly in Orality and Literacy:

"Like other artificial creations and indeed more than any other, it [writing] is utterly invaluable and indeed essential for the realization of fuller, interior, human potentials. Technologies are not mere exterior aids but also interior transformations of consciousness, and never more than when they affect the word." (Ong $1982 \mathrm{p}$. 82)

Sherry Turkle's work (1996a, 1996b) points in similar directions, and though it was based on identity play in multi-user dungeons (MUDs) rather than on home page production, it was influential in early thinking about the self online. Her research was influenced by postmodern thinkers and strong social constructionists like Gergen (1991). At one level much of her thinking resembles that of Foucault - for her, a MUD "can become a centre for discovering who one is and wishes to be" (Turkle 1996a p. 184) but she presents the liberatory potential of internet selfperformance differently. For her, "having literally written our online personae into existence, we are in a position to be more aware of what we project into everyday life." (Turkle 1996a p. 263) In other words, the author does not come to understand his or her (single) self, but may derive benefit from better understanding how $\mathrm{s} /$ he constructs his or her selves.

Where she appears to differ from Foucault in her approach to reflexive identity construction is that while Foucault in his later work on 'technologies of the self' (1988a, 1997a, 1997b) tends to stress the importance of interaction with trusted others to help with such analysis, the role of the audience for self-performance is not clearly defined in Turkle's work. Its existence is presumably necessary to justify the performance, but audience reaction to the performance does not appear very important - indeed Turkle (like Cheung) tends to stress that the internet enables self performance to an (implicitly necessary) audience but without the risks attendant on interaction with that audience particularly face to face.

Several home page authors Chandler interviewed clearly do see their site as a means to 'sort out who they are'. Nonetheless, the way in which his and similar research obtained a sample for interview and the small scale of some of this early work may tend to over-state the extent of the practice. Chandler's influential early piece for example is based on a reading of the texts of an unspecified number of websites and email interviews with an unspecified number of personal home page authors. Given its early date it also seems likely that those he interviewed would be a disproportionately 'keen' set of early adopters. A similar criticism can be levelled at Turkle's study of early MUD users and Hevern's work (2000) which suffers from similar limitations - his sample was small (eight people were interviewed by email) and deliberately selected as disadvantaged 'others' - five were gay men, three were disabled - who might be more inclined towards self- 
examination in the first place. Rosenstein's study was larger scale (she had 18 interviewees) but it was also done with a self-selecting sample from the San Francisco Bay area (where early adoption of internet practices would be common). This is not to say that self-understanding may not be aided through home page creation, but it is not clear how important or how prevalent a motivation or consequence this might be for home page creators as a whole.

\subsubsection{Technological and social influences on home page practices}

Harrison (2001) points out that those who provide storage space and associated services for home page creators may influence what is said or sayable using their services. This can happen most obviously through regulation. Many such services reserve the right to remove pages without notice or report such pages to the authorities if they have content the company deems 'inappropriate', for example - and this may include anti-government sentiments when the home page is created using services provided in authoritarian regimes (Kalathil and Boas 2002, Taubman 1998). More subtly, home page providers can influence what is written through the templates they provide into which the author's writings are placed -AOL in the UK for example provided a 'shortlist' of 'most popular' templates when it offered home pages to its users which included "My Newsletter, My Business, My Family, My Photo Gallery, My Car and My Pet” (AOL 2008). As Walker notes "Many servers that provide access to home page creation provide fundamental instruction to aid in their creation. Along with basic lessons on home page construction, these guides suggest information that should be included on the page, including the above-mentioned name, age, career, address, interests, and hobbies. Some pages never move past this initial formulation." (Walker 2000 p. 102). The manner in which such defaults may influence what is produced will be taken up in more detail in relation to weblogs in Section 6.3.1. Lastly Killoran suggests (2002b) that although in theory authors may be free to put what they like on their pages they often look to existing web pages as models and that they thereby "abandon the opportunity to explore their distinctive self-identities and represent themselves as 'domesticated, innocuous subjects and objects of a capitalist and bureaucratic order."' (Killoran 2002b p. 9)

\subsection{WEBLOG STUDIES}

As will be outlined below, a minority of blogging studies appear focused on personal weblogging practice although personal weblogs make up the majority of blogs produced. Among personal weblogging studies, many are quantitative rather than qualitative, and I will argue in Section 4.2.1 that the qualitative work that has been done to date has been based on samples which may have been unintentionally skewed towards particular kinds of personal bloggers. Most importantly, the qualitative work available tends to be more descriptive than theoretically focused, and no dominant theoretical approaches have been identified. Thus rather than grouping the studies 
theoretically, empirical findings from studies have been grouped according to themes which are developed theoretically in Chapter 3.

While there may be substantial overlap in the practices of personal home page production and maintenance and blogging, the weblog is a more constrained form than the personal home page. Weblogs are primarily defined as such by the technology and the accompanying visual designs used to produce them (but can contain a wide variety of content within that definition) - see Appendix A for more on definitions of blogging - while the personal home page is defined by its personal content (but could take any visual form, constrained only by what a web browser can display and by the technical skills of the author). As with home pages various categories of content (referred to by some authors as 'genres') within the weblog form have been identified. Because of the variety of different ways in which weblogs can be used, no one taxonomy has been agreed upon as yet.

Much of the scholarly literature on blogging has focused on the relationship between blogging and political opinion formation and on pedagogical uses of blogging - see for example (Bruns and Jacobs 2006, Gurak et al. 2004). There is a large body of scholarly research on weblogs produced for political goals or to express political opinions - particularly focused on those which are presumed to have a potential political influence because of their popularity among political elites mainly those in the US (Delwiche 2005, Farrell et al. 2008, Ferguson and Griffiths 2006, Su et al. 2005). Such discussion often focuses on their potential or actual contribution to a Habermasian public sphere through open debate of ideas (Froomkin 2003, Siapera 2008). Alongside this is a related focus in the press and academia on the weblog as a form of alternative to or critique of the mass media (Blood et al. 2003, Gillmor 2004, Graves 2007, Rosen 2004, Wall 2005).

As Herring et al. point out, however, this attention comes at the expense of research on the most popular form of weblog production (Herring 2004). Most webloggers appear to be maintaining their sites primarily for personal reflections in some form (Lenhart and Fox 2006), although as discussed in Appendix A there is no commonly accepted definition of "personal" except as a residual category after other categories have been excluded, and the manner in which weblogs can often mix personal and public-oriented postings can make rigid categorization difficult.

There may be political consequences to weblogging without a strong political motive which current research has not touched on, although these are not examined in the present study. Potentially, the public expression on weblogs of normally un-expressed identities by those whose voices are not often heard in the mass media (or whose lives are represented there in ways beyond their control) could improve public understanding of their lives and hence broaden the scope of public discourse, as Thorseth suggests (2008). Theorists like Young $(1990,1996)$ have called in 
other contexts for more 'storytelling' to enhance the quality of political debate but again, this study does not extend research in this area.

The literature search conducted for this study found no academic works on weblogs prior to 2002 and only eight before 2004. As with earlier internet technologies that have become popular, many of these early studies sought to describe weblogging or some aspect of it through ethnographic and auto-ethnographic research without providing a detailed description of their method, using quotations from weblogs to illustrate their claims. A large proportion of the qualitative work on personal weblogging then and since has been done based on interpretations of weblog texts, with little or no reference made to direct interrogation of other blog authors themselves about their purposes and the meanings of their work (except insofar as those writers are self-reflexive in their postings). There were also some potential problems with the way the samples for these studies were gathered (see Chapter 4.2.1 for more on both issues).

There appears to be little consensus about the most important issues and despite the similarities between personal home pages and blogs outlined above, there is not extensive reference in the blogging literature to home page-related literatures and some of the themes that emerged in home page literature have not been followed up in blog-related literature. The paucity of literature on the technological influences and social norms related to blogging practices is particularly striking, since as outlined above it is arguable that blogging technologies are more rigidly constraining in the forms they offer than the personal home page which had been the subject of earlier research. A discussion of the evidence for such constraints and of the studies which refer to them appears in the following section.

\subsubsection{Technological influences on Blogging practices}

A number of weblog studies have identified regularities in blogging practice. A common problem in these studies, however, is that they do not generally attempt to explain them - are they attributable to technological influences, social pressures or some combination? This problem may be in part attributable again to the predominance of textual analyses of blogging over interviews or ethnographic study of the bloggers themselves. Such studies can also fail to distinguish between the perceived expectations of blog readers and the norms of blog writers (though of course these are often the same).

There is a suggestion in some blogging literatures that weblogs are produced free from constraint or influence of any kind. For example:

Without the hurdle of editors, publishers, and corporations between writers and "publication" in some form or another, weblog authors are able to write exactly what they want to, in exactly the way they prefer. (Himmer 2004) 
This also appears to be internalised by some bloggers. For example, Reed says the bloggers he interviewed felt their blogs were, "a space in which persons can be themselves, free of constraints and able to say what they think and feel about everyone around them." (Reed 2005 p. 230) This framing of blogging practice as unconstrained may be partially explained by blog services' technological characteristics (see below) and will be elaborated upon in Section 6.2. When the relationship between blogging technology and practices is alluded to, often scholars make much of the technology's flexibility. Sorapure, for example, suggests:

\begin{abstract}
At a computer-and network-mediated writing interface, diarists must make decisions about page design and about the overall architecture of the work - considerations not so immediately present for print diarists. Online diarists must also consider the layout of text and image, and decide which, if any, multimedia and interactive elements to use... One might say that the interface is more flexible for online than for print diaries because the computer can perform certain organizational and even creative functions. While print diarists can fold or manipulate pages, and can include drawings, photos, and other visual elements, the computer provides a more diverse set of media and more interactive opportunities with which writers can work. (Sorapure 2003)
\end{abstract}

She does not take into account here both the ways in which default settings and existing practices influence such choices and the practical difficulties that less-digitally-literate individuals might have in taking advantage of the opportunities she recognises. Schmidt (2007b) recognises bloggers' ability to customise their blogging is limited both by their skills and in most cases by what features weblog hosting companies choose to offer but chooses to emphasise the underdetermined character of blogging software, noting that user communities can adopt different features in their own ways and can encourage blog developers to add features that they wish. In this it seems likely he is focusing on an elite group of "active", technically savvy users ${ }^{3}$ and does not draw the reader's attention to the importance of defaults in shaping practice (the role of defaults will be taken up in Chapter 6.3.1). Stern in her study of young personal home page users and bloggers is more critical of the technologies on offer:

By making expression easier through fill-in-the-blank templates and hosting clearing houses that promise wide exposure for personal expression, such companies nurture the idea that youths are autonomous producers at the same time as they place constraints on the types of creations that youths can produce (Stern 2008 p. 101)

Intriguingly, Vaisman points to a situation in Israel where adolescent girls attempted to take advantage of unforeseen features of a particular blogging platform to express themselves artistically (through posting self-made graphics to their blogs) but where this attempt to escape the constraints of code and of generic expectations gave rise to a second form of constraint via social norms "complaints on this practice and the stigmatization of these girls as illiterate and incompetent were one of the main posting subjects of the Israeli blogsphere in the following months" (Vaisman 2006).

\footnotetext{
${ }^{3}$ This is conjectural as there appear not to be any surveys as yet that would help to identify the extent to which different groups among users attempt to influence blog developers or the extent to which bloggers use blogs in ways that are consistent with or deviate from developers' expectations.
} 
Studies of blogging based on interviews and ethnographic research have unearthed a number of areas where the technical characteristics of blogging platforms appeared to influence bloggers' practice. One of the most frequently mentioned is a subjective feeling of control and ownership that bloggers appear to feel over their blogs and which has already been alluded to above. This is linked firstly to the asynchronous nature of the medium: "Bloggers don't have to deal with interruptions to their flow of storytelling. Jack compared a blog post to a 'monologue' in which 'other voices don't intrude'." (Gumbrecht 2004). Another interviewee of Gumbrecht's notes, "comments are allowed and encouraged, but they're also very clearly rhetorically subservient" (Gumbrecht 2004) which appears to refer to the typical visual layout of blogs, where comments are placed beneath the blogger's own post and may only be viewable if a reader clicks on a separate link. Fundamentally, bloggers appear to derive their sense of ownership and control from their ability to control various aspects of their technical function:

Bloggers discuss their blogs as though it is their home and others are invited to come over, provided that they abide by the norms devised by the blogger. The speaker controls the style, access, and whether or not listeners can comment. While anyone can access most blogs, it is this sense of ownership that makes the blog feel like a personal space (boyd 2006).

This is echoed by Hodkinson in his study of LiveJournal users - he says:

Readers were regarded not as equal participants in a communal forum but as guests or visitors and, as such, were expected to respect the sovereignty of their host. (Hodkinson 2007 p. 634)

And he goes on to note that one of his interviewees likened her journal to the physical space of her bedroom. There is evidence that this norm is recognised and generally respected by readers who if they comment, entering bloggers' virtual space, largely tend to be un-critical. Menchen Trevino writes of the bloggers she interviewed, "If they write about personal subjects they also get overwhelmingly positive comments from people who they do not know outside of the blogging context." (Menchen Trevino 2005 p. 15).

It also appears that the features of blogging software can encourage certain uses which then become understood as normal (and potentially normative). Kendall, who interviewed users of LiveJournal, observes that:

Many of my interviewees distinguish between blogs and LiveJournal. Their definition of a blog focuses on the technological difference... they also subscribed to the popular media model of blogs as essays or political commentary... LiveJournal participants primarily characterize LiveJournal as a site hosting online diaries. (Kendall 2007)

Compared to other blogging platforms in 2005, LiveJournal provided extensive tools for controlling access to postings, which makes it more technically suitable for the sharing of personal information.

In the following section, the technical characteristics that relate in some way to time and that the literature suggests have an influence on blogging practices are brought together. 


\section{Temporality}

One of the characteristics of blogging which appears central to its definition is its periodic character (see Appendix A for further discussion of the definition). Weblogs (as distinct from other forms like personal home pages) contain some fixed elements but the material of primary importance (and normally positioned centrally on the page) are "posts" which are placed in reverse chronological order. These posts are also automatically archived for later reference - generally by date but also potentially by keyword or category (depending on the software used). Despite this, the temporal aspects of blogging practice appear only to be examined in passing in the literature.

The significance of blog archives for the authors and readers is disputed. Killoran suggests:

Like newspapers, blog entries are normally dated and thereby highlight both their currency with the day's events and also their much shorter shelf life. Unlike the permanence posited by the personal homepage, which preserves the past in the form of old photos, genealogical trees, and résumés, the past in a blog, exemplified by older postings that get pushed down the page with each new update and that eventually get archived, quickly fades from view and from relevance (Killoran 2002a)

Sorapure appears to agree that earlier postings are viewed as of lesser importance, "past entries are relegated to the archives" (Sorapure 2003 p. 15). Hevern, on the other hand, implies weblog archives are central: "Bloggers travel along connected paths through their lives... they look back on what has happened to them and forward to what might occur" (Hevern 2004) and Van Dijck suggests that blogging is “about revising one's experience over time, allowing to adjust one's former observations and reflection — even the ones stored in the 'archive' — as time goes by and as personality evolves" (Van Dijck 2004). In a later piece, Van Dijck also stresses the importance of the archive for bloggers:

The fact that almost every software program contains an archive holding selected entries that go back to the very beginning of a person's blog signals a desire to build up a personal repository of memories. Although this hypothesis has bever been empirically tested, it would be no surprise to find that bloggers, like teenagers using SMS or cellphones, value their lifelog's archival function as much as its communicative function. (Van Dijck 2007 p. 72)

Another aspect of this format is that it makes apparent when and how frequently a weblog is updated. Schaap suggests:

The format of the weblog implies regular updates and this shapes the weblogger's everyday involvement and interaction with his or her weblog. Indeed, feeling the obligation to write yet another entry for the weblog is a regularly recurring topic on many weblogs. (Schaap 2004)

The divergence in the perceived importance of blogging archives is understandable since all three base their analyses almost entirely on textual and technical interpretation of blogs rather than on discussion with blog authors.

Little systematic discussion of the importance of archives can be found in interview or ethnographic studies of blogging. Hodkinson does note in passing that the conversations on the LiveJournals of those he interviewed had a "short overall time-span" because posts that were 
commented upon were "buried" by later posts (Hodkinson 2007 p. 638). Reed, on the other hand, suggests that the bloggers he studied, "view the weblog as a form of chronicle; they post entries with their own future reception in mind." (Reed 2005 p. 231)

One temporal aspect which does emerge in some studies relates to an intriguing ambiguity about the perceived rhythm of blogging practice - whether blogging interaction is perceived as oral (synchronous, un-archived) or as writing. To the extent that it resembles the former in the mind of the blogger, this would appear to contradict the emphasis put by some theorists on the importance of the archive.

In a study of Persian-language bloggers, Doostdar remarks that blogging draws on a "rich reservoir of speech genres, including many primary oral genres... blogging may be closer to an oral mode of communication than to a written one." (Doostdar 2004 pp 20-21). Mortensen in an autoethnographic piece reflects that for her the weblog is "a confusing medium" because of the manner in which it straddles oral and written communication:

"You have the speed, the immediacy, the two-way turntaking dialogue, you look away... and the message is still there... It appears to invite and promise oral immediacy, but it allows for written distance and delay." (Mortensen 2004, n.p.)

She notes that this contradiction not only causes difficulties for the writer, it can also result in differences between the writer and their readers if their framing of blogging practices conflict, citing public arguments about the blog postings of David Winer. He was accused of criticising others on his blog then removing the criticism from his blog's archives (Jogin 2003). "People expected communication and notifications from Winer with the long-term vision and the formality of the written language. Winer delivered it with the expediency and the informality of the spoken language." (Mortensen 2004)

A last potential theme of interest relating to time is the changing framing and purpose of blogging practices through time. This factor has only recently emerged in research because of the recency of the introduction of blogging. One study that raises the issue notes:

People have more than one motivation for blogging, and these change throughout the blogger's lifecycle... A primary motivation was always supplemented by additional and often different motivations for continuing to blog as knowledge is acquired. (Brady 2006 p. 10)

This is potentially important because the presence of archives in blogs means that this changing framing of one's blog is visible through time. Thus, unless personal bloggers elect to remove or edit their archives, any contradictions in the way they have presented themselves through time on their blog are available to readers, who may enter the blog's narrative at any point. Mortensen remarks that a blog "exists within a certain context, living in dialogue with a certain group of writers and readers, and to understand it reading one post is not enough." (Mortensen 2004) However, as Himmer notes: "multiple entry points are not only dynamic, but entirely beyond 
the constraint or control of the original author and the original text." (Himmer 2004) One of Reed's interviewees provides an example of what can occur when the framing of a blog changes:

"Peter... told me that when he started his weblog he didn't want anyone he knew to be aware of its existence. This was because he wished the text to be a full and complete account of his thoughts and feelings, including the day-to-day impressions he had of people around him. But one night, in a drunken state, Peter let his boyfriend know about the weblog. As a consequence of this indiscretion, he felt he needed to go back through the archives and edit large extracts from his old entries, anything that he didn't want his partner to read."

\subsubsection{Social Influences on Blogging Practices}

Social pressures might influence blogging practice in various ways. Lessig's work on influences on technologically-mediated practices, for example (Lessig 1999, Lessig 2006), highlights the importance of 'code' - the form of the technology itself (see Section 2.4.1 above) but also suggests that such practices take place in the context of particular legal, market and social norms. Schmidt's analytical framework for blogging practices (Schmidt 2007b) formally encompasses this breadth of potential norms in his discussion of "rules" but in practice says little about the legal and market influences.

Social norms bearing on blogging practice can be further divided into those which appear to be particular to the field of blogging itself - what I term "local norms" - and those which are broadly applicable across bloggers and non-bloggers alike. To the extent social norms governing blogging are discussed in the literature, scholars tend to focus on local norms.

\section{Blogger and audience}

In particular, the relationships between bloggers and their audiences appear to be the focus of most blog-related research into norms. The norm that early blogging studies appeared to stress the most is that of an interactive relationship between bloggers and their readers. Killoran, whose critical evaluation of personal home pages has already been mentioned, compared home pages and weblogs very early in blogging's development and concluded that weblogs offer a "creative alternative" to the "synthetic institutionalization" that he claims characterises personal home page creation practices (Killoran 2002b). He suggests they feature greater degrees of civic engagement because of a "collaborative ethos" in their production - weblogs "tend to be read zealously by other bloggers and interlinked with related blogs, thereby promoting responsive models of social relations" (Killoran 2002a). This early characterisation of blogs as interlinked and featuring many comments (shared by others including Mortensen and Walker 2002) was called into question by later quantitative studies, which suggested that most blogs are personal in nature and that most 
blogs (particularly personal ones) tended not to be interlinked or to contain comments ${ }^{4}$ (Herring et al. 2005, Mishne and Glance 2006). Nonetheless the characterisation of bloggers as "open to dialogue rather than engaging in one way communication" (Schmidt 2007b p. 1413) remains frequent in academic discourse. Even when scholars recognise that bloggers may not always be focused on their readers, they can be dismissive of such practices - Castells, for example, characterises blogging primarily for one's self as close to "electronic autism" (Castells $2007 \mathrm{p}$. 247). This suggestion that relationships with weblog readers both are and should be central to blogging practice will be further taken up in Section 3.3.2.

To the extent weblogs are expected to be collaborative enterprises there is a potential conflict with the framing of blogs as unconstrained spaces controlled by their owners which has already been described. Kendall, in her interviews with LiveJournal users noted this contradiction:

Many of my interviewees hold two diametrically opposed models of what they are doing on LiveJournal. On the one hand, based on the model of a private diary, their LiveJournals are their own private space in which to record thoughts, opinions, feelings, and events from their lives. On the other hand, these journals constitute a form of performance, complete with an expectation that a performance must give attention to audience desires. In return, the audience can be expected to respond.

She concludes by questioning the focus on interaction which had been noted in earlier studies, saying,'LiveJournal posts are essentially broadcasts. The audience might react, but is not expected to participate, per se.” (Kendall 2007)

A recent theoretical article contrasts blogging as a form of communication of "substantive information" through dialogue (Miller 2008 p. 389) with the use of social network sites (SNS) and "microblogging", suggesting use of the latter amounts to a form of "phatic communication" which is "content-less in any substantive sense" and non-dialogic (Miller 2008 p. 395). He identifies technological affordances and limitations which tend to encourage particular forms of use but the differences in use he asserts might also be because of the differing imagined audiences for users of each technology - specifically one of the factors differentiating earlier blogging practices and SNS and microblogging technologies is the control that the latter technologies allow over who might be receiving messages. The link between the imagined audience and phatic communication will be further discussed in Section 3.3.2.

A norm of authenticity is also apparent. Efimova notes for example that "weblogs are perceived as unedited personal voices" (Efimova and Grudin 2007) - though it is not certain to what extent bloggers themselves feel themselves to be bound to conform to these expectations. Reed said the bloggers he interviewed asserted "they put themselves forward unreservedly, as opposed for

\footnotetext{
${ }^{4}$ It is possible that bloggers did receive feedback via email and other private mechanisms but again since these studies relied on content analysis they would have no way to gauge this.
} 
instance to novelists, who, I was told, only let bits of themselves appear in their stories," (Reed 2005 p. 227) and Schmidt remarks "speaking in one's own personal voice" and being "personally authentic" are expected by blog readers (Schmidt 2007b p. 1413).

\section{$\underline{\text { Blogging as symbolic interaction }}$}

As noted earlier, several studies of home page creation used symbolic interactionism and in particular Goffman's presentation of the self (Goffman 1959) as a conceptual framework. Few blogging studies appear to have employed this framework, however, though it would appear that personal blogging and personal home page production have similar characteristics from a symbolic interactionist perspective. The principal study which employs symbolic interactionism and grounds its analysis using study of bloggers themselves is Lenhart (2006). Consistent with a Goffmanian approach Lenhart frames blogging as a reflexive practice of self-presentation. Her interviewees were aware of the possibility of unintended readers and as a result their blogging is marked by a tension in their blogging practice - as she puts it, "bloggers blog simultaneously for an audience and in apprehension of them" (Lenhart 2006 p. 102). She characterises the blogs produced by those she interviewed as "a constructed, idealized and public version of herself (even if it is idealized as "not constructed" or "true to my offline self") to her audience" (Lenhart 2006 p. 63). She notes that "bloggers sometimes forget exactly how public their blog really is" (Lenhart 2006 p. 138) but does not otherwise provide a thorough account of why it is that bloggers would choose to adopt this form despite the awareness she generally ascribes to them of the presentational difficulties inherent in the medium due to its exposure to multiple potential audiences.

\subsubsection{Privacy}

The problem of unintended readers identified by Lenhart is just one of the reasons why some scholars have focused on privacy issues in blogging. The work of boyd, particularly (2008a, 2008b) is useful in outlining the potential problems that those she spoke with could encounter because their interactions were taking place in what she characterises as "networked public spaces" and thus become "hyperpublic". She identifies four key properties of communications in such spaces: they persist through time, they are searchable, they are copyable to third parties and they are available to audiences which are not visible to the communicator (boyd 2008a p. 126, 2008b). In fact these characterisations of networked public space are more applicable to blogging practices than to the SNS practices she often them to. SNS offer more powerful controls over access than most blogging services and they limit (though they do not eliminate) the problem of searchability, since the text of a network profile is often not indexed by search engines. The availability of profiles over time is also of less concern for similar reasons - once removed an SNS profile (or an element from it) is 
not generally archived in a publicly-accessible form, and changes in a profile replace earlier versions, while weblogs generally automatically create an archive of earlier postings and their texts may be archived on third party sites even once they have been removed.

Although weblogs appear therefore to present greater privacy concerns than SNS, the latter have received more attention from those concerned about privacy - possibly because of the broader adoption of SNS. Little is known about attitudes towards privacy or degrees of revelation among bloggers. One survey (admittedly of a convenience sample of webloggers) found that $25 \%$ of them posted what they characterised as "highly personal" materials "fairly often" and only 19\% never did (Viegas 2005).

There are suggestions by some weblog scholars (echoed by later scholars studying the social impact of SNS) that these new forms of (more or less) public revelation of hitherto private behaviour are either reflective of or leading towards new conceptions of privacy. Kitzmann calls this connected privacy:

Connected privacy is the direct opposite of pure privacy, with the latter's conditions of defined isolation and secure boundaries. Yet at the same time, it is a privacy where private moments and places are possible and, in fact, desired. Connected privacy does not negate or eradicate moments of pure privacy, not does it subject everyone to constant surveillance. One can still be alone in conditions of connected privacy, yet the walls can be dropped at any moment without necessary leading to feelings of violation, exhibitionism, or disempowerment. As such, connected privacy can be characterized by a certain lack of paradox or contradiction inasmuch as the boundaries that separate the public from the private are recognized and respected but also ignored and transgressed. (Kitzmann 2004 p. 91).

This appears to presume however that those who indulge in these new boundary-crossing practices are aware of the implications of what they are doing as they do it and are happy with the consequences. There is some evidence, however that the privacy implications of bloggers' practices are not always present in their minds. Lenhart's reservations have already been noted. She also adds that bloggers who do not identify themselves intentionally on their blogs may feel themselves protected from privacy breaches by anonymity:

Many bloggers feel relatively confident in their online anonymity, reasoning that connecting their offline selves to their online selves would be a more difficult process than the average person would undertake, and that the large number of other weblogs and personal websites makes it unlikely that theirs will be found by people they hope do not see it. (Lenhart 2006)

Reed takes this further, asserting that some of the bloggers he encountered do not feel as if their blogs are really read: "Although it is known that other people visit the site, journal bloggers insist that they are its main recipient; the popular refrain among them is 'I blog for me'." (Reed 2005 p. 231). This is echoed by Lenhart who remarks weblogging "is not a private space, and yet it 'feels' like one" with blogs "generally created and consumed in a private setting, with one person at a computer composing the blog, and another person alone at a computer reading it, yielding a sense of blogs as private documents." (Lenhart 2006 p. 71). This impression is backed by one of the few 
representative surveys of bloggers in the US which revealed that $52 \%$ of bloggers say they blog mostly for themselves, not for an audience - only $32 \%$ say they blog mostly for their audience (Lenhart and Fox 2006). Likewise Bratteteig remarks in more general terms:

Even when I know that I publish my text on the internet, it is difficult for me as a non-journalist to imagine the potential number of readers that will have access to my text the minute I publish it. The text is still a text on my $\mathrm{PC}$ - the blurring of consumption, production and distribution tools into one tool (or tool box) makes it conceptually difficult to maintain these distinctions (Bratteteig 2008).

Others suggest that whatever the readers' actual reactions, they appear to provide largely positive feedback. Nardi suggests that "the diary-like format of a blog seems to induce a gentler, more reflective set of interactions" (Nardi et al. 2004b). As a result, it appears that a sympathetic readership may be assumed - Trevino notes, "although bloggers are well aware that others can read their blogs, sometimes the conception of "others" is limited to people like me, or other young people." (Menchen Trevino 2005 p. 15).

Although as we have seen various aspects of bloggers' relationships with their audience have been discussed in the literature, ymbolic interactionist approaches to blogging and privacy literatures around blogging and SNS have not hitherto included an empirically grounded focus on how audiences are perceived during the act of publishing itself, and the basis of such perceptions.

\subsection{STUdies OF Social NETWORK SITE (SNS) USE}

A fast-growing literature about the uses of SNS has begun to emerge, though most did not emerge until after I completed my fieldwork. A review of the literature (boyd and Ellison 2007) concluded much of it was centred around four themes - impression management and friendship performance, networks and network structure, bridging online and offline social networks and privacy. Very little work appears to have been done focused on the way in which the technical characteristics of SNS may influence SNS use practices except to some extent in relation to privacy issues, though I have briefly examined the technical shaping of MySpace usage (Brake 2008b). As with weblog research, most of the studies found in my own review for this thesis were based on analysis of the visible text and patterns of interlinking of profiles on SNS, on surveys of SNS users or on some combination of the two. Of 81 SNS-related academic studies examined, ten were based on interviews. A further eight were based on ethnographic research - all but one of which were by danah boyd. While interesting and informative the limited amount of methodological detail provided made it difficult to situate their claims and assess their broader applicability.

While SNS profiles and weblogs both involve online self-presentation, both the technical features and the framing of the practices around profile and blog creation and maintenance tend to be different. SNS (as confirmed by a recent study (Ellison et al. 2007)) are predominantly framed as a means to articulate and reinforce pre-existing social ties and appear to be used primarily for this 
purpose (though this research relies on users' accounts which might be influenced by perceived stigma attached to other forms of use). The framings of weblogging that have been found in studies appear to be more numerous and ambiguous. It is also relevant that while weblogs tend to have few or no controls over who can access what is posted on them, SNS tend to allow (and sometimes encourage) their users to limit both access to their profiles and contact more generally (via messages and comments exchanged within these sites) to groups and individuals who have been specified as "friends".

\subsubsection{Privacy}

The strand of SNS research relating to privacy is of particular interest and potential relevance to this study, notwithstanding the differences in context outlined above. This "hyperpublicity" presents potential dangers for the young people boyd has studied but while she mentions a few of the ways in which some young people tackle the problem - using SNS privacy settings or fabricating key identification data like their age and location - she does not substantially address two key questions which would appear to follow - how, and how effectively, do SNS users react to these potential dangers? In Livingstone (2008 p. 405), it is clear that the way in which SNS structure the mechanisms that tackle privacy cause young people difficulty, as in many cases they require a binary division of potential readers between "friend" and "not friend" which does not enable them to take into account the finer distinctions of face to face acquaintanceship. She also notes that users can have difficulty in understanding how to use privacy settings:

When asked, a fair proportion of those interviewed hesitated to show how to change their privacy settings, often clicking on the wrong options before managing this task, and showing some nervousness about the unintended consequences of changing settings. (Livingstone 2008 p. 406)

This might help to explain the results of two studies which contrasted students' expressed attitudes towards personal privacy and their activities on the Facebook SNS (Acquisti and Gross 2006, Tufekci 2008). Among other findings:

Almost $16 \%$ of respondents who expressed the highest concern ( 7 on the Likert scale) for the scenario in which a stranger knew their schedule of classes and where they lived, provide nevertheless both pieces of information [on Facebook] (in fact, almost 22\% provide at least their address, and almost $40 \%$ provide their schedule of classes). (Acquisti and Gross 2006)

This even though at the time of the study profiles could be read by anyone who could register using an email address from the same university. Tufekci similarly found that expressed concern about unintended audiences only correlated with revelation of religious status and of phone numbers. The Acquisti survey also revealed very common misunderstandings of or ignorance of Facebook's privacy policies and of its privacy protecting features. A second study by Acquisti (not involving SNS use) points to a related potential explanation for apparent contradictions between privacy related attitudes and behaviour: 
How is it possible that 34.5 percent of our respondents forget to think of their own bank or other financial intermediaries when asked to list which parties would see their credit-card transactions? When cued, obviously most people would include those parties too. Without such cues, however, many respondents did not consider obvious options. The information is somehow known to the respondents but not available to them during the survey - as it might not be at decision-making time in the real world. In other words, the respondents considered a simplified mental model of credit-card transactions. (We found similar results in questions related to email and browsing monitoring). (Acquisti and Grossklags 2005)

This points once again to an important gap in our understanding of online behaviour. As noted at the end of Section 3.2 we do not know, in Acquisti's terms (drawn originally from Simon (1982)) the "mental model" in operation when bloggers are posting. This is not to say that there is a lack of research that relates to media producers' conceptions of their audiences. Much of it, however, relates to the practices of mass media producers. In the section which follows, I briefly summarise these studies.

\subsection{STUDIES OF THE IMAGINED AUDIENCE FOR MASS MEDIA}

In The Media and Modernity, Thompson suggests that for producers of mass mediated products the audience is crucial. He notes they are "dependent on recipients for their continued existence as performers" and that their spectatorship "is the sine qua non of their own existence as producers" (Thompson 1995b p. 99) (see Section 3.3.2 for a more extended discussion of Thompson's view of the producer/audience relationship). One might therefore expect producers to attempt to reduce their uncertainty about the audience's reception of their work through ongoing dialogue with their viewers, listeners or readers. There are several ways in which producers in (notionally) monologic mass media can nonetheless gauge response to their work. Formal audience research conducted by or for large organizations falls into two categories - consumer quantification (ratings), which counts consumers and categorises them sociodemographically, and, more rarely, focus groups and other attempts to measure audience appreciation (e.g. the BBC's "appreciation indexes"). In addition to this, producers have some exposure to several sub-sections of their audiences from whose informal feedback they can assess their performance. These include feedback directly from those parts of the 'wider audience' motivated to comment through letters and phone calls (and now by email), and the testimony of friends and acquaintances - in particular fellow industry professionals - other journalists, competitors, customers and so on.

The ways in which producers envisage their audience - what it wants to hear and how it receives what it has heard - have received surprisingly little academic attention. What research exists tends to be done as a small part of wider producer studies. The evidence that does exist from ethnographic studies of news, film and television production, however, is remarkably consistent, and appears to contradict the supposed centrality of the audience for producers. It suggests instead 
that producers tend to rely most strongly on feedback from a small sub-set of the audience - their peers.

[from an interview with a BBC programme maker] we would say that we've been broadcasting to the people along the corridor [i.e., to editorial and managerial superiors] not to the people who are listening. You know one has followed their policy, done the sort of thing that we know will please them, and we haven't really thought about the listener, about what is the best way to tell the listener (Burns 1977 p. 200)

The television news producers Epstein studied tend to assume that their audiences are

largely inherited from the programmes that precede their own:

The general categories or even the content of news stories has little to do with audience viewing patterns so long as the presentation of the news is not offensive or "above the heads" of the general viewers ... On the other hand most producers showed a great deal of concern about the reaction of certain select audiences network executives, affiliate managers (who often spoke through network executives), peers in the news division and their own circle of friends. (Epstein 2000 [1973] pp 149-150)

Silverstone and Gitlin in production studies of a science programme and prime time US television production, respectively, echoed these findings (Gitlin 1994, Silverstone 1985).

To the extent producers pay attention to formal studies of audience reactions they are, as Ien Ang puts it:

particularly meaningful from the narcissistic perspective of the institutions themselves: in a sense, the subjective feelings of viewers about programmes are mobilized and quantified in the service of institutional self-confidence. (Ang 1990 p. 145)

In fact, repeatedly producers are depicted as being reluctant to engage with what their wider audiences think of what they have written - even to the point of shock and anxiety:

VARA researcher Dick Wensink [personal communication w Ang] observed at first hand how they are often appalled or surprised by what actual viewers have to say about and do with 'their' programmes. [...] In another instance, a British programme maker, watching a video of viewers watching his programme, was reportedly so shocked by what the viewers 'did' to his programme that he couldn't bear it any longer and decided to stop watching. (Ang 1990 p. 151)

There was, as one senior [BBC] official commented, I think rightly, 'no evidence to the people inside Television Centre, of people at the top of the Corporation knowing, or indeed caring, what the audience makes of the service it receives' (Burns 1977 pp 140-141)

This tendency toward reference to peers over other potential audiences for their work has also been noted among artists (literary and otherwise). Bourdieu suggests that particularly at the beginning of their careers artists are favoured who are "known and recognized by their peers and only by them... and owe their prestige, at least negatively, to the fact that they make no concessions to the demand of the 'general public"' (Bourdieu 1996 p. 217).

While alternative media often have as their expressed mission the desire to give their audiences a voice, and might therefore be expected to attempt to be close to them, there is often, it appears, a similar wilful blindness to the audience:

[Alternative media producers] often sustain illusions about the nature of their readership, imagining, for instance, that they communicate with the 'people' or the 'working class' or 'women' in some undifferentiated sense, while remaining wilfully ignorant of the fact that their actual readership is a particular, highly-educated, sub- section of any one of these categories. 
There is a real fear that information derived from readership questionnaires or from more detailed market research is somehow suspect, and that the producers themselves know best. Often they express this by saying they produce the publications for people like themselves. (Landry 1985 pp 17-18)

In recent years, the connection of mass media organizations to the internet and the dissemination of their work through this new medium has led to calls for the mass media to take advantage of the technical features of computer mediated communication and to enter into a deeper dialogue with the consumers of its products - and some claims that it is already doing so (Bowman and Willis 2004, Gillmor 2004). Hermida's study of the BBC's reaction to these technological changes suggests, however, that journalists and the institutions within which they operate continue to resist pressures to respond to their audience - at least insofar as it would jeopardise their 'gatekeeping' role:

Remarks by BBC staff indicate there are limits on how far the corporation is willing to let the public influence editorial decisions. In 2007, the TV news analysis program, Newsnight, started sending out its morning prospects not just to producers but also to anyone, inviting viewers to comment on the show's blog. But comments by the program editor Peter Barron showed the limits of this interaction with the audience. "First, that it's our job, not yours, to come up with programme ideas" (Hermida 2008a)

Similarly, after making a broader survey of UK news organizations, Hermida concluded:

There is little in the way of longer-form contributions or opportunities for readers to set the agenda. We could suggest then that the media is creating an architecture of publication for material from the audience, rather than an architecture of participation.

Where opportunities for readers to set the agenda do exist (for example in readers' blogs; or at message boards) they often seem to be part of what some have described as a "closed-off annex where readers can talk and discuss, as long as the media companies don't have to be involved". Attempts to create genuinely open spaces where readers can set the agenda are few and far between. (Hermida 2008b)

One logical conclusion of these findings is that despite the rhetorical and practical focus by producers on their audiences, their actual focus may (for example) be on their work as an end in itself. As Scannell noted, "there was in the past (and still is) more than a hint of the notion, among BBC producers (especially in the arts. drama and documentary departments) that they were making programmes for themselves as 'self' expression.” (Scannell 1996 pp 11-12).

These studies also provide little information about how media producers envisage the reception of their work by their readers/viewers, despite the assumed centrality of a positive response. It is possible, however, that as with the studies of bloggers mentioned in Section 2.4, producers tend to assume a positive response to their work, which could explain the degree of upset encountered when they are confronted by evidence that the audience's reaction is less favourable that they expected.

It is clear that in some important respects the contexts of personal webloggers may be different from those of the producers of mass media studied above, not least because although what they produce may reach a mass audience it is not generally likely to and it is not clear the extent to which this is an objective. 


\subsection{CONCLUSION}

There is clearly a need for a theoretically-grounded and methodologically sound qualitative study that privileges the views and experiences of webloggers themselves in order to address identifiable gaps in the literature. This chapter has demonstrated that a small but growing literature has emerged to examine personal weblogs and other forms of personal web page production, but in most of these studies those involved in the practice are seldom asked to provide their own accounts. It is possible to suggest motivations for weblogging practice and influences on it through examination of the technological structure that underlies weblogs or using textual analysis of selected weblogs. However, I suggest that the analysis of the accounts of those who practice weblogging can offer valuable additional insights into how technological structures are negotiated and the conditions under which texts come to be produced.

The key gaps in the literature that have been identified in this review are as follows. Studies of CMC, home pages, blogging and SNS use - in particular in relation to privacy - generally appear not to have focused on providing an empirically- model of the imagined social context of the communicative activity. As outlined in Section 3.1 we lack an analysis of the influences on personal weblogging practice that takes into account tacit or explicit influences embedded in the technical architecture of blogging services and the ways bloggers react to them alongside the technical features offered by such services. As outlined in Section 2.4.2, while there has been some attention given to 'local' social norms of blogging practice, the influences of wider social norms and of market and legal factors have also not been addressed. Lastly, the significance of temporal aspects of blogging technologies like the persistence of blog archives through time appears contested in the literature and empirical evidence is lacking to assess the merits of conflicting claims. The next chapter (Chapter 3) sets out a theoretical lens which is more responsive to these weaknesses and to the need to fill the gaps identified in the literature outlined above. 


\section{Chapter 3: Theoretical Framework}

\subsection{INTRODUCTION}

In the previous Chapter 2 which reviewed existing literature on personal weblogging and related research on other forms of mediated communications, it has been argued that notwithstanding the growing body of research there are significant gaps in our understanding of personal blogging relating to the imagined social context of a blogger's practice and the influences both technical and social on that practice. In response to the perceived gaps in research on blogging, a linked pair of central research questions for this study was developed: "how do personal webloggers understand this practice and how does the practice relate to its social and technical context?" In building a conceptual framework which relates this investigation to existing theory, this chapter begins with a principal theoretical focus - the study of personal weblogging as a form of symbolic interaction, drawing largely on Goffman's work. It goes on to argue that because of the important role that the weblogging technology plays in providing contexts for interactions it is necessary to incorporate key literatures related to mediation - particularly those which are grounded in an interactionist tradition, notably Meyrowitz (1985) and Thompson (1995b). It suggests that such literatures tend to lean towards technological determinism and therefore looks to Feenberg's work to provide a more flexible framework for the interpretation of the inter-relations between the technical and the social that shape how particular mediated technologies are developed and used. This culminates in the presentation of the conceptual framework for this thesis, which is followed by the theoretically informed research questions which set the boundary for the empirical investigation. Lastly, some alternative theoretical pathways that were explored before this one was chosen are briefly outlined.

\subsection{SYMBOLIC INTERACTIONISM}

As Chapter 2 outlined, there are several ways in which weblogging and related practices have been framed academically - as a means of political expression, a tool for learning, a forum for identity work and as a form of strategic self-presentation. Because of the relative novelty of blogging and the apparent ambiguities and contradictions inherent in it, and in the light of the relative paucity of research on the perceptions of and motivations for weblogging informed by study of those who produce these texts, it seems appropriate to locate this research centrally within a theoretical tradition that has sought to understand how meanings are jointly created through interactions among individuals. This suggests that this study is best principally located within symbolic interactionism, with particular reference to the work of Erving Goffman. 


\subsubsection{History}

Symbolic interactionism is a term coined by Herbert Blumer in 1937 (1937) and came to prominence at the University of Chicago from the 1930s to the 1960s (although the term itself seems not to have become popular among researchers associated with it until the 1970s (Plummer 1996 p. 225)). Differing strands of symbolic interactionist research have been identified by scholars. Fisher and Strauss (1979) and Denzin (1992) identify two principal early schools - one centred around the urban sociology of W. I. Thomas and Robert Park, the other stemming from Blumer's work. Starting in the late $60 \mathrm{~s}$, symbolic interactionism came under sustained attack. While scholarship that identifies itself as interactionist is less commonly found, several recent histories maintain that many of its core practitioners have forged links to postmodernist thought, and that its influence remains, unacknowledged, across much of contemporary sociology (Atkinson and Housley 2003, Dennis and Martin 2005, Maines 2001, Plummer 1996).

Symbolic interactionism had its intellectual roots principally in the work of the American pragmatist school. Its differing strands have been linked most centrally to Mead (of particular importance to Blumer and his followers) and to Cooley - also to James, Dewey, and Park.

Cooley coined the notion of the 'looking glass self' which pointed to the key role of others' reaction to one's own behavior in the development of the self (Cooley 1902). James posits a state of consciousness derived from a dialogue between the subject - "I" - and the self as object "me", with several selves resulting as each is called into being through different social relationships (James 1950 [1890]). While for Cooley and James there is a pre-existing self which examines itself in relation to others, Mead in the collected essays "Mind, Self and Society" describes the self as entirely constituted through language - talking to itself - and in relation to a "generalized other" constructed by the self as the imagined attitude of the whole community (Mead and Morris 1967 [1934]). Dewey's article on the "Reflex Arc" (Dewey 1896) was, according to Denzin (1992 p. 5), important to the development of Mead's theory as it "argued that the organism is not a passive receiver of stimuli but an active perceiver of the situations it confronts."

Blumer enlarges on the implications of this in Symbolic interactionism: perspective and method in which he asserts the following as fundamental premises of symbolic interactionism:

Human beings act toward things on the basis of the meanings that the things have for them.

The meaning of such things is derived from social interaction.

These meanings are handled in, and modified through, and interpretive process used by the person dealing with the things encountered. (Blumer 1969 p. 2)

This focus on meaning as constructed rather than inherent in any given situation is central to the approach taken in this study. 


\subsubsection{Goffman and symbolic interactionism}

The place of Erving Goffman in the field of symbolic interactionism is often described as problematic. He resisted labelling himself as a symbolic interactionist, saying he felt the term was too vague (Winkin 1988 pp 235-236), and the intellectual roots of his work appear to differ somewhat from those of other interactionists. He is chiefly associated with Durkheim through a shared interest in the place of ritual in everyday life, and with Simmel, though Goffman showed little interest in making explicit links to earlier theorists in his highly original but often unconventional publications. As Atkinson and Housley remark:

In many ways Goffman's sociology was sui generis. It did not derive from nor did it belong to any specific sociological school or tradition. His proper place and the categorization of his work remain contested... No doubt Goffman assimilated a variety of inspirations, and created his own unique approach. It must, however, be counted among the general family of interactionist work. (Atkinson and Housley 2003 p. 12)

The relevance of Goffman's work to the field of symbolic interactionism can best be demonstrated by noting how it is consistent with the approaches to research held to be common to symbolic interactionists. His approach to his work is clearly consistent with the summary of symbolic interactionist method briefly outlined by Blumer above. In addition there have been a number of other attempts to outline the central tenets of symbolic interactionism (Denzin $1992 \mathrm{p}$. 20, Plummer 1996 pp 223-4, Stone and Farberman 1970). Maines, himself a symbolic interactionist scholar for many years, provides a lengthy list of these attempts (Maines 2001 p. 2) and from it derives four central "facts" which "all interactionists and some noninteractionists tend to take seriously":

1) People can think and they possess self-awareness. Despite the variation in cognitive abilities among people and the various conditions under which people may be more or less aware of themselves, $[\ldots]$ interactionists study and write theories about cognition, selves and identities.

2) Communication is central to all human social activity. [...]

3) All forms of human activity occur in situations. Human behaviour must occur somewhere, and if that behaviour is overtly social then it occurs with someone in a cultural, institutional, gendered, national, racial, economic and/or historical context. [...]

4) Human relationships and collectivities are forms of activity. These forms can range from interpersonal relations to social structures to global economies, but in each case the interactionist will regard them as action and agency-endowed. (ibid. p. 3)

This list is similar to that provided by Blumer but in with items 3 and 4 it attempts to counter a common criticism of symbolic interactionism - that in concentrating on individual meaning making it has little to say about the influence of broader social structures. In his work, Goffman focused on the 'co-mingling' of persons and on the interactions and dynamics between them as indicated in the following quotation:

"A sociology of occasions is here advocated. Social organization is the central theme, but what is organized is the co-mingling of persons and the temporary interactional enterprises that can arise therefrom... the proper study of interaction is not the individual and his psychology but rather the syntactical relations among the acts 
of different persons mutually present to one another... Not then, men and their moments. Rather moments and

their men." (Goffman 1967 pp 2-3)

The overlap between this outline and the list above is striking. In his stress on the centrality of communication ("interaction") (2) and the manner in which society is organized through activity ("interactional enterprises") (4), Goffman showed in his work closely examining everyday interactions that there are complexities hidden within individuals' relational practices whose nature is normally taken for granted. Crucially, without a deep understanding of the nature of a practice, attempts to understand the motivations for such interactions as well as their consequences may be led astray.

\subsubsection{Key aspects of Goffman's research}

Branaman (1997) divides Goffman's work into four themes which correspond roughly to periods in his working life. The first theme is the production of self. Goffman's view of the self is essentially dualistic, resembling James' conception, with a self-as-performer reacting to different situations to produce the self-as-character. Famously, however, he gives the latter self the central role:

A correctly staged and performed scene leads the audience to impute a self to a performed character, but this imputation - this self-is a product of a scene that comes off, and is not a cause of it. The self, then, as a performed character, is not an organic thing that has a specific location, whose fundamental fate is to be born, to mature, and to die; it is a dramatic effect arising diffusely from a scene that is presented. (Goffman $1959 \mathrm{pp}$ 252-253)

In Frame Analysis he clarifies this point, countering those who criticised him for failing to consider the persistence of identity through time. He asserts the existence of a continuous and consistent self-as-performer (Goffman 1986 [1974] pp 286-288) but suggests that both sides of the self are "equally open to a possible social accounting." (Goffman 1986 [1974] p. 270).

The second theme, of less relevance to the present research, is his concern with the confined self, which he developed through study of "total institutions" like asylums (Goffman 1961, Goffman 1968). In Relations in Public, Goffman speaks of the necessity of "territories of the self" (Goffman 1971a p 29) - spaces or situations of (relative) autonomy needed to sustain a viable self. The examination of extreme situations where such territories are denied to inmates helps to illustrate their necessity, and reveals some of the tactics that are used by those whose sense of self is threatened by them. These works also exhibit a focus on the broader social and institutional contexts of interaction which some scholars assert is lacking in symbolic interactionism and in Goffman's work in particular (Gouldner 1971, Reynolds 1990).

The third theme, frames and the organization of experience, groups Goffman's last works in which he moves from close analysis of specific interaction situations to linguistic analysis (Goffman 1981), the construction of gender (Goffman 1979), and the relationship between the 
interpersonal interactions he has studied - what he terms the "Interaction Order" and wider social structures (Goffman 1983, Goffman 1986 [1974]). Of particular importance to this study is Frame Analysis (Goffman 1986 [1974]) wherein he attempts to provide a systematic overview of the way in which interpersonal interactions are 'framed'. By this he means how "definitions of a situation are built up in accordance with principles of organization which govern events - at least social ones - and our subjective involvement in them" (Goffman 1986 [1974] p. 10). Of particular relevance to this study is the vulnerability of framings to misconstruction. Goffman maintains that in general “our interpretive frameworks are more or less adequate" (p. 440) and while he catalogues a number of ways in which frames may be temporarily misunderstood, he notes that in the face to face interactions he analyses:

ambiguities have to be resolved, lest the individual remain in doubt about the entire nature of the happenings around him. Ambiguities in regard to primary frameworks typically seem very short-lived and for a good reason: because these frameworks are fundamental to the organization of activity. (p. 304)

Likewise errors in interpretation are short-lived because "the action the individual introduces on false assumptions is likely in itself to create contradictions and add to the likelihood of his detecting that (and how) he has gone wrong." (p. 321).

Also of importance is the way in which a 'strip' of experience ("any arbitrary slice or cut from the stream of ingoing activity"(p. 10)) is spatially and temporally organized into frames using various forms of 'bracketing' devices (pp. 251-269) and co-participants thereby separate this bracketed activity from may be going on at the same time and in the same space - often by deliberately 'disattending' distractions (pp. 202-210) or onlookers (p. 225).

The last theme (third in Branaman's division and in chronology) is also very relevant for this study. In it Goffman examines the nature of social life variously as a series of games, rituals and dramatic performances. Of particular importance to the present study is his close study of the importance of the physical context of interaction - what he terms "regions" of interaction - which is outlined in the section which follows.

\section{$\underline{\text { Regions and region control }}$}

In the analysis of the practice of personal weblogging, one of the most striking problems is to understand the relationship between bloggers and those who may read their work. Goffman's dramaturgical reading of social interaction provides a useful set of orienting concepts. The best known exegesis of his view of social life as drama can be found in The Presentation of Self in Everyday Life (Goffman 1959). Of particular importance to this study is his Chapter 4 on Regions and Region Behavior (1959 pp 106-140). Here Goffman describes three principal spaces of interaction - 'front stage' areas where social actors are engaged in formal interactions with their 
intended audiences, suppressing all facts about themselves that might contradict the performance, 'back stage' areas where individuals and, particularly, teams, can 'let down their guard' to themselves or each other and lastly 'outside' where individuals not presumed to be involved in the performance are expected to remain. As Giddens points out in his discussion of Goffman's work, divisions between these areas may be 'real' (in the sense that a physical barrier may completely prevent interaction) but may also be co-constructed by social convention: "Walls are socially respected communication barriers as much as they are purely material divisions.” (Giddens 1987 p. $125)$.

Goffman points out that people who are co-present will generally collude to maintain normal relations and avoid potential loss of face.

Just as the member of any group is expected to have self-respect, so also he is expected to sustain a standard of considerateness; he is expected to go to certain lengths to save the feelings and the face of others present, and he is expected to do this willingly and spontaneously because of emotional identification with the others and with their feelings. In consequence he is disinclined to witness the defacement of others. (Goffman 1967 p. 10)

For example, individuals show tact by staying away from regions to which they have not been invited (ibid. p. 229-237). The concept of 'civil inattention' (Goffman 1963 pp 83-88) is a useful illustration of the complexity of tact in action. As he describes it:

One gives to another enough visual notice to demonstrate that one appreciates that the other is present (and that one admits openly to having seen him), while at the next moment withdrawing one's attention from him so as to express that he does not constitute a target of special curiosity or design. (Goffman 1963 p. 84)

With a momentary movement of the eyes, co-present individuals imply to one another,

that he has no reason to suspect the intentions of the others present and no reason to fear the others, be hostile to them, or wish to avoid them (at the same time, in extending this courtesy he automatically opens himself up to a like treatment from others present.) This demonstrates that he has nothing to fear or avoid in being seen and being seen seeing, and that he is not ashamed of himself or of the place and company in which he finds himself. (Goffman 1963 p. 84)

Thus even a momentary glance is not just about the practical business of seeing or being seen but is freighted with social meanings which each party assumes the other will understand.

The tact exercised by others is one of the ways that what Goffman calls the Umwelt ${ }^{5}$ is preserved. The Umwelt is "the sphere around the individual within which potential sources of alarm are found" (Goffman 1971a p. 252). Of particular interest in Goffman's discussion of the Umwelt is one of his few references to media technologies - in this case as a potential threat:

\begin{abstract}
“A working assumption in everyday life is that one's surround will be 'dead' - that is, contain no recording and transmission devices. The subject therefore assumes that he can scan his Umwelt and correctly determine how he is being witnessed and by whom, for at worst there will only be a hearsay link between what happens inside the frame and allegations made about this outside the frame. Orientation segregation is thus taken for granted and otherwise vulnerable activity predicated on it. (Goffman 1971a p. 286)
\end{abstract}

Separately, Goffman developed a related pair of concepts - the informational and conversational preserve (Goffman 1971b). The former describes "the set of facts about himself to

\footnotetext{
${ }^{5}$ A term he borrows from from Jacob von Uexküll (1957 [1934])
} 
which an individual expects to control access while in the presence of others" (1971b pp 38-39) and the latter "the right of an individual to exert some control over who can summon him into talk and when he can be summoned; and the right of a set of individuals once engaged in talk to have their circle protected from entrance and overhearing by others" (Goffman 1971b p. 40).

Since a blog is itself a transmission device, and one that may not provide much indication of who might be reading, bloggers might be expected to write them with due attention to the threat that might be posed to themselves in doing so, but this would depend on a continual mindfulness of undesired witnesses in the face of habits of interpersonal speech that assume and take for granted the segregation of their everyday interactions from others.

Goffman observes, however, that strangers who are not the focus of an interaction tend not to be perceived as a threat in everyday interactions:

Just as the individual assumes that the apparently incidental contacts he is now having with others in his Umwelt have not come about because of nefarious design, so he also assumes that the minor dealings that he is now having with persons passing on their separate ways will not be used by them to provide the bases for unanticipated costs to him later. In brief, he assumes that many of the involvements he sustains with those in his Umwelt will give way shortly to no connectedness at all. (Goffman 1971a p. 320)

The core concepts drawn from Goffman - framing, regions and maintenance of face, and the Umwelt and conversation and informational preserves - can be used to examine the frameworks understood by the authors to apply to weblogging practices. His approach suggests that it is important to examine how the authors form and maintain their conceptions of the frame they are operating in. We can also note, where applicable, how authors may be unaware of different framings of their activity that may exist, though without having studied in detail the orientation of weblog readers towards the activity this analysis is necessarily incomplete on this point.

\subsection{ASPECTS OF MEDIATION}

Goffman's research is rooted in an analysis of face to face interaction - indeed one of his key works, Interaction Ritual, is subtitled "essays in face to face behaviour". As noted earlier one of the key tenets of symbolic interactionism is an attention to the context within which interaction takes place, and Goffman's work is attentive to the way different contexts constrain interaction and the way those involved choose to interpret and sometimes subvert such constraints - particularly in his work on "total institutions" (Goffman 1961, Goffman 1968), but unfortunately he devoted almost no attention to the implications of mediation for communication ${ }^{6}$. However his orientation towards a micro-level understanding of interpersonal communication as situated in "temporary interactional enterprises" (Goffman 1967 p. 2) has been adapted to other, technologically mediated interactional

\footnotetext{
${ }^{6}$ He did talk about radio in a chapter in Forms of Talk (Goffman 1981) but did not really address in depth the issues raised by the mediated nature of the communication.
} 
settings. For example, Meyrowitz (1985) applied and extended Goffman's concept of regions of interaction in his study of the way television plays a mediating role in society and Thompson (1995b) used aspects of his approach to analyse mediation more generally.

\subsubsection{Meyrowitz: the importance of control over social information}

In No Sense of Place (1985), Meyrowitz links medium theory (primarily as espoused by Innis (1950, 1951), McLuhan (1962, 2001) and Ong (1982)) to a ‘Goffmanian' analysis of interaction. He brings them together by saying that both:

reject the significance of studying only lower-level variations within a system (such as variations in content within a medium or variations among individuals behaviors within a situation). Instead they both focus on the overall effects of the larger structure of the environment... and deal with a similar theme: patterns of access to each other. The situationists suggest how our particular actions and words are shaped by our knowledge of who has access to them, and the medium theorists suggest that new media change such patterns of access. (1985 p. 33)

He develops this argument suggesting that the importance Goffman gives to physical place in face to face situations through his discussion of interaction regions is in large part effectively a recognition of the importance of control over the flow of "social information" which he defines as “that nebulous 'stuff' we learn about each other in acts of communication” (1985 p. 37). He argues that "physical settings and media 'settings' are part of a continuum rather than a dichotomy. Places and media both foster set patterns of interaction among people, set patterns of social information flow." (1985 p. 38)

Meyrowitz in Chapter 4 of No Sense of Place (1985 p. 38) spells out some of the ways such information is important - notably in the establishment and maintenance of social roles through privileged access to social information by particular groups. Much social information exchanged in everyday contexts is clearly of little or transitory significance (for example my feelings about the weather, your discomfort with your commute) and therefore its control may not be important, but Meyrowitz does not probe the distinction between sensitive and non-sensitive social information, and indeed such distinctions would be problematic to maintain in practice, since the degree of sensitivity of many social facts can vary depending on the social context of their reception.

Crucially Meyrowitz suggests a focus on mediation in communication primarily as a means of enabling new communicative situations which, in turn, he asserts, foster new behaviours. In particular, he suggests that through television viewers increasingly gain access to areas once thought of as backstage, bringing into existence a new communicative region he terms "sidestage" or "middle region" (1985 p. 47). He notes that "the competent performer adjusts his or her social role so that it is consistent with the new information available to the audience" (1985 p. 47) but maintains that while "in once sense middle region behaviors are simply new front region 
behaviors... if we think of them merely as front region behaviors we lose the ability to see the nature and direction of the behavioural change." (1985 p. 48).

He argues that while people can adjust in the short term to the ways in which television reveals the backstage behaviour of themselves and others, over the longer term it becomes impossible to maintain one's "front stage" in the same fashion:

For a brief period, a revealed back region can be converted into a relatively traditional front region performance. The less performers can control and restrict others' access to themselves, however, the more back region behavior must come to light. A normally sloppy teenager, for example, may clean his room when his aunt comes to dinner on Easter Sunday. But if Aunt Mary stays for six months, she will undoubtedly witness a different drama... The longer and more closely people are observed, either in person or by camera and microphone, the more their behavior is stripped of its social symbols and posturing (1985 p. 48)

This shift in behaviour takes place in a "largely invisible" way because "people very quickly adapt to the new definitions of situations" (1985 p. 48).

He goes on in the remainder of the book to suggest a number of particular new communicative situations enabled by television and new behaviours he links to them. For example, he suggests that television makes information previously distributed in books and circulated among experts more freely available and presents it in a way that is more accessible, undermining traditional hierarchies and authority. He also suggests that by exposing young people to subject matter previously only discussed among adults, television is blurring the division between childhood and adulthood, and that by exposing politicians to increased scrutiny television is both undermining the mystique of politics and encouraging a shift in voter preferences towards politicians whose personal styles are compatible with increased exposure of their middle region behaviour.

No Sense of Place is subtitled "the impact of electronic media on social behaviour", but Meyrowitz' discussion of media is centred largely on the role of television. He does mention computers in passing, but only as an alternative form of information retrieval tool that may be more effective than television but which is also less accessible (1985 pp 324-328). Because of the state of development of computers at this time he does not envisage them as interpersonal communication tools, nor does he examine the ways in which computer mediated communication (CMC) may differ fundamentally in kind from televisual communication. Indeed he does not focus his attention on the nature of the interactions that are mediated through television at all - his focus is on the presumed cumulative effect of the exposure to new social information that is enabled via this new communicative situation. As a result he does not fully take into consideration the way in which individuals and organizations can reflexively adapt to such situations. To provide a framework for a focus on the way specific characteristics of particular media forms can shape interactions and on the ways in which individuals can adapt to these pressures let us to turn to John B Thompson. 


\subsubsection{Thompson: New forms of interaction and the role of the imagination}

In The Media and Modernity (Thompson 1995b) Thompson outlines a typology of interaction. In it he contrasts face to face interaction with a variety of forms of mediated interaction. His definition of mediated interaction is broad. "Mediated interaction involves the use of a technical medium (paper, electrical wires, electromagnetic waves etc) which enables information or symbolic content to be transmitted to individuals who are remote in space, in time, or in both." (1995b p. 83). Thompson then splits the communication enabled by media into two types. Communication aimed at "specific others" and "dialogical" in character he terms "mediated interaction" (which for clarity's sake I will style as mediated interpersonal interaction) while those aimed at "an indefinite range of potential recipients" and which are predominantly monological in character, being disseminated via the mass media he terms "mediated quasi-interaction" (1995b p. 85).

Thompson here differentiates mediated quasi-interaction from mediated interpersonal interaction using three distinct criteria I have labelled the intended audience (specific or indefinite), the imagined or desired direction of flow of interaction (whether the communication is monological or dialogical) and the nature of the medium (mass media or interpersonal media) used for communication. (Thompson 1995b pp 84-85) ${ }^{7}$ All three criteria are implicitly linked. Although Thompson does not spell this out, his argument might be that because they reach a large audience, mass mediated messages cannot be intended solely for specific others, that the consumers of such messages recognise that they are not specifically targeted and, therefore, do not generally attempt to enter into a dialogue with the creator of such messages, and that both sides of the communicative process understand and anticipate the others' expectations. While Thompson characterises the intended audience of mass mediated communication as "indefinite", this is only true in the sense that specific individuals are not addressed - in general, whether in the interests of advertisers, for technical reasons of distribution or to simplify the creation of content, specific categories (geographic and sociodemographic) of reader, listener or viewer are generally envisaged. Such communication generally has a significant cost to create and distribute and, therefore, an intended audience can be assumed in order to justify incurring such costs: "producers in turn depend on recipients for their willingness to watch and for the support afforded by their spectatorship" (Thompson 1995b p. 99).

Thompson goes on to problematise his division of media into dialogic and monologic. He points out that, "many of the interactions which develop in the flow of day-to-day life may involve

\footnotetext{
${ }^{7}$ This is a re-interpretation of his Table 3.1 and discussion, which also contrasts mediated and non-mediated interaction in the first two elements of that table.
} 
a mixture of different forms of interaction - they have, in other words, a hybrid character." (ibid. p. 85). Individuals can adjust to and compensate for technical limitations of communication flows in one medium by supplementing it with another. For example a television show (normally monological - those broadcasting cannot directly hear or see their viewers) may encourage viewers to engage in a dialogue using mediated interaction via telephone (e.g. a "call-in" talk show). Of more direct relevance to this research, he also cautions, "new forms of interaction might be created by, for example, the development of new communication technologies which allow for a greater degree of input from recipients.” (ibid. p. 86). Unfortunately, because the technologies he refers to were only just beginning to attain widespread adoption he did not develop this theme further.

With the advent of computer mediated communication (CMC), scholars identified a third "ideal type" of communication which follows the "logic" of this new medium and which they call "telelogic" (Ball-Rokeach and Reardon 1988, Voiskounsky 1997). This form reflects the ease with which individuals using computers can reach and be reached by many others at low cost. To the extent CMC can reach a large audience it resembles (monologic) mass media, but because it enables those reached to respond it is in some respects dialogic. Ball-Rokeach and Reardon argue "the telelogic communication form exhibits some characteristics of the interpersonal form and some of the characteristics of the mass form; but the idea that telelogic communication is simply a blend of interpersonal and mass forms cannot account for the total pattern of differences." (Ball-Rokeach and Reardon 1988 p. 147). One of the key novel characteristics of telelogic communication and the one that sets it apart from the other forms for the purposes of this study is its ability to enable an interactive communication with an audience consisting partially or wholly of people previously unknown to the communicator - what is sometimes called a "multilogue" (Kitzmann 2004, Serfaty 2004, Shank 1993).

The internet enables many kinds of communication, not all of it telelogic. A web page which does not provide contact information for its author is monologic, and email (with the exception of mailing lists) is predominantly dialogic, since it generally involves communication with known and specified others. The technical features of weblogs appear to favour telelogic communication, as by default a weblog posting is available to an un-specified and unlimited audience, and (again by default) they invite a response from readers - either through the "comments" section to each posting or through email and other contact details that may be provided on a blog's "profile" page.

\footnotetext{
${ }^{8}$ Also popularly termed "many to many" communication because unlike the mass media it is accessible to "many" users and can nonetheless reach a large audience.
} 
As alluded to earlier in Section.2.4, those attempting to define weblogs and weblogging frequently stress the importance of interaction with bloggers' audiences in those definitions, positioning weblogging as an essentially telelogic practice (Conniff 2005, Halavais 2005, Nardi et al. 2004a, Rettberg 2008, Walker 2005). Nardi for example, asserts, "Blogs then, are a studied minuet between blogger and audience. Bloggers consider audience attention, feedback, and feelings as they write". While Halavais acknowledges, "a large number of bloggers might be classified as "mumblers"... who seem to post weblogs to a void, without obvious comments or reader", he goes on to say, "Even in this case, though, it is clear that one of the motivations for blogging is feedback through comments, links, and other channels." As Halavais' choice of term reveals, there is some stigma attached in both media and academic accounts to people who do not appear to use blogs in a telelogic fashion.

This is consistent with a tendency among media scholars to associate particular media forms exclusively with whatever relationship between communicator and audience appears best suited to that medium. Thus face to face interaction is predominantly framed as a dialogical situation, radio and television mediated practices tend to be framed as broadcast or monological situations. In practice, as many scholars in the social constructivism school have pointed out in other contexts, technologies can be adopted in a variety of ways which do not necessarily follow what later appear to be its 'natural' potentials. Radio was once seen as a 'one-to-one' medium while telephones were initially seen by some as a broadcasting medium (Pool 1977 p. 19), - precisely reversing the way in which they are used now which seems inevitable or technologically determined (Marvin 1988, Winston 1998) and the ARPANET, the precursor to the internet, was designed to give remote users access to data and processing power, not to facilitate inter-personal communication (Hafner and Lyon 1996 p. 189) (see Section 3.4 below for more on the role of constructivism in this study). Moreover, as interactive digital technologies are increasingly incorporated into existing practices (as with interactive television), the boundaries which seemed to be distinct between broadcast and interpersonal communication, have begun to blur.

As noted in Section 2.4 in the discussion of the blogger-audience relationship and in particular the discussion of Miller's article on phatic online communication a link appears to be implied between the imagined audience for communication and its phatic/monologic or dialogic nature. Phatic communication as described by Malinowski "serves to establish bonds of personal union between people brought together by the mere need of companionship" (Malinowski 1923 p. 315 ) and he ties it to the notion of co-presence, speech being necessary because "to a natural man, another man's silence is not a reassuring factor, but on the contrary, something alarming and dangerous". Laver suggests, "the process of phatic communion allows them the opportunity to 
explore, in a tentative way, the social identity and momentary state of mind of the other participant." (Laver 1975 pp 218-219) The extension of phatic communication to the online context seems to makes sense when used to communicate to a group of people already known to the writer (as with "microblogging") but is less obviously explicable when it appears to be directed towards an audience of indefinite others with whom one may not have an expectation of further interaction.

While Thompson's typology of mediation may be useful in itself when extended, it is also useful insofar as it focuses our attention not on how the technical properties of particular communicative tools influence interactions, but on how important the imagination is in visualising the context of mediated interactions. As Thompson puts it,

In face-to-face situations, the interlocutors are able (and are generally obliged) to take account of the ways in which others respond to what they say, and to modify their subsequent actions and utterances in the light of these responses... In so far as mediated interaction (such as a telephone conversation) is dialogical, it too involves the reflexive monitoring of others' responses, although the symbolic mechanisms and cues which are available to participants for this purposes are generally more restricted. (Thompson 1995b p. 96).

By contrast, producers in situations of mediated quasi-interaction are "deprived of the kinds of continuous and immediate feedback which would enable them to determine whether and how their messages are being received and understood." This, he claims, "enables them to determine the course and content of the quasi-interaction without having to take account of recipient response" but “is also a potential source of uncertainty and trouble" (Thompson 1995b p. 97). The producer's message is not the only relevant element in a mediated quasi-interaction. To use Meyrowitz' terminology, knowledge of a recipient's response (whether "given" or "given off”, in Goffman's terms (1959)) is itself an important piece of relevant "social information".

Thompson's focus is primarily on the receiver of mass mediated communications rather than the producer, so he does not develop an in-depth analysis of how producers respond to this situation of uncertainty. However, if audience reactions are not directly perceived, yet must be taken into account, this clearly provides a role for the producer's imagination. Two of the three principal differentiating criteria I identified above with which Thompson divides mediated interpersonal interaction from mediated quasi-interaction are, in some fashion, activities of the imagination - that is, it is the intended not the actual audience and the anticipated level of interactivity that are important in the framing of mediated interaction. While the particular communication medium chosen can affect the likelihood of interaction or the actual size and composition of the audience and in that way affect producer's expectations, there is always an element of uncertainty about the audience in mediated communications which must be taken into account. In particular, a personal weblog posting may have many readers or none, many responses or none. As has been shown in Section 2.6, however, studies of producers using various media reveal a variety of attitudes and expectations towards those who might be reading or listening. Also as noted in Section 2.2, one of 
the weaknesses of studies of computer mediated communications, in particular, is that while they provide a model for how communicators make the most of (or make too much of) the information they have about the recipients of their communications, they do not discuss very much how these communicators deal with the resulting uncertainty.

\subsubsection{THOMPSON: MEDIATION AND SPACE-TIME}

Thompson's work on mediation touches on the re-ordering of time and space that mediation can entail. In The Media and Modernity he outlines some of the implications. While face to face exchange of symbolic content requires both parties to be in the same place at the same time, mediation uncouples communication. With electronic communication, symbolic content can cross great distances in almost no time, and with this "the experience of simultaneity was detached from the spatial condition of common locality. It became possible to experience events as simultaneous despite the face that they occurred in locales that were spatially remote." (Thompson 1995a p. 32). As a result, "the spatial horizons of our understanding are no longer restricted by the need to be physically present at the places where the observed events etc. occur." (Thompson 1995a p. 34)

His analysis of the implications of the uncoupling of time and space in television production and consumption is of particular interest. As he notes, the space-time coordinates of the contexts of production, the message itself and of reception are separate and are spliced together by the viewer in a process he calls 'space-time interpolation'.

In receiving televisual messages, individuals routinely orient themselves towards space-time coordinates which differ from those characteristic of their contexts of reception, and interpolate mediated space-time coordinates into the spatial-temporal frameworks of their everyday lives." (Thompson 1995b p. 93).

He adds that television requires recipients to "negotiate effectively the different space-time frameworks which are in play" (Thompson 1995b p. 94) and if they are unsure about these they can be bewildered or disoriented.

[“Competent" viewers'] experience of space and time becomes increasingly discontinuous, as they are able to move between worlds, both real and imaginary, at the flick of a switch. And yet, despite this increased mobility, the space-time framework of the context of reception remains the 'anchor frame' for most viewers, since their life projects are rooted primarily in the practical contexts of their day-to-day lives. (Thompson 1995 b p. 95)

Thompson mentions but does not analyse the fact that mediated communication generally results in "extended availability [of the communication] in time and space" (Thompson 1995b pp 84-85). Goffman also touches obliquely on the importance of this aspect of time in Frame Analysis, with particular reference to the potential risks of loss of face which may occur when an interaction occurs outside of its original temporal context:

Howsoever the individual presents himself on any occasion before any audience, there will be other places, times and audiences when he quite properly conducts himself in a manner that would discredit this first performance were his other conduct to be vividly brought to light. Barriers to communications such as walls and distance, along with audience segregation, ensure that such discrediting will not occur. Any monitoring of any individual's behavior that he does not know about will then have a discrediting power; all forms of secret 
surveillance function to undermine later activity, transforming it into a discreditable performance. (Goffman 1986 [1974] pp 168-169)

In the mediated context of blogging the main products of the mediated interaction - the weblog postings and associated comments - are generally archived and linger online through time. In fact when examining weblogging it would be useful to distinguish between two different potential "space-time coordinates" of reception - primary reception, which takes place at something approximating the time that a posting is first made, and secondary reception, which takes place at a greater temporal distance. Among other issues, secondary reception may be more likely to discredit current performances. As the discussion of temporality in Section 2.4.1 suggests, while much blogging research hints at the importance of time in blogging practices, there are conflicting claims about many aspects - particularly about the perceived importance of weblog archives - and some significant gaps in the literature. Also, little has been said about the 'anchor frame' used by bloggers - which of the forms of reception outlined above that bloggers may have in mind, either when they post or subsequently.

\subsection{BLOGGING AS A TECHNOLOGICALLY MEDIATED PRACTICE}

This section briefly outlines rival theories about the relationship between technologies and society and suggests a framework for analysis primarily centred on the work of Feenberg (1991, 1999, 2008).

\subsubsection{Technology and Society}

As we have seen Goffman draws attention to time and most particularly space as critical contexts for interaction. Meyrowitz draws our attention to the importance of mediated communication as a pervasive enabler of new spaces, which he suggests lead to new potential interactional spaces and thence to new behaviours. Thompson draws our attention to specific characteristics of mediated interaction - its directionality (monologic or dialogic) and (in the case of mass mediated communication) the imagined character of its audience. They draw extensively on interactionism, which - particularly in the form defined by Blumer (1969) - tends to question structuralist analyses ${ }^{9}$. It is surprising, then, that both largely treat mediating technologies themselves as autonomous, with fixed effects on those who produce for it and consume its products. According to Winner (1977), most early social studies of technology - notably Ellul (1965) and the scholars of the Frankfurt School - share this technological determinism, and it is still common in lay discourses. But in recent decades there has been a reaction, with a number of competing approaches to the analysis of technology which can be loosely grouped as "social constructivism". Some

\footnotetext{
${ }^{9}$ Although they draw primarily on Goffman, who, as we have seen above, was less inclined than other interactionists to take issue with structuralism, arguing that social structures are outside the focus of the interaction order. (Goffman 1983)
} 
concentrate primarily on the process of invention and diffusion of technologies, emphasising the contingency of particular forms of development (Bijker et al. 1990) (Bijker and Law 1992, Latour 1987, Latour 1996, Williams and Edge 1996). Other scholars, notably those studying what they term the 'domestication of technology', focus on the manner in which those who use technologies appropriate them in differing ways (Bakardjieva 2005, Lally 2002, Lie and Sørensen 1996, Silverstone and Haddon 1996) ${ }^{10}$.

One cluster of cultural theory scholars (Du Gay et al. 1997) has produced an ambitious framework - the "circuit of culture" - defining five major processes encompassing both the production and consumption of cultural artefacts. In essence, they argue that the cultural meaning of an artefact is established through the manner in which it is represented (predominantly a semiotic analysis), through the identities that are constructed around and using the artefact, through the (invention and) production of the artefact (which takes place in particular cultural and economic contexts), through the differing ways in which individuals consume the artefact - acquiring it and selectively appropriating its functions, and through the ways in which society adjusts to the artefact in use by attempting to regulate it and its uses.

The 'circuit of culture' framework is somewhat unhelpfully centred on physical artefacts themselves, when the authors' own epistemological position would seem to suggest that the object of study should be the cultural meanings associated with the artefact - which "do not arise directly from an object - 'the thing in itself' (Du Gay et al. 1997 p. 4). Thus there are multiple possible "circuits" because of the multiple potential forms of representation, identification, regulation and consumption of a given artefact. The authors themselves implicitly take this into account in their critique of Chambers' interpretation of the social significance of the Walkman (Chambers 1990) when they note that "Walkman use is a highly differentiated phenomenon... different people in different contexts use it for different purposes and to differing effect." (Chambers 1990 p. 108)

A shift of focus from the object to its use is vital in the application of this framework to the present case. The weblog may be defined in such a way that it appears to be a single artefact, as outlined in Appendix A, but it has (to use the terminology of the circuit of culture) been produced in multiple forms with significantly different characteristics, and has been represented in different ways (as a tool for political influence, for more effective public relations or for sharing interests as well as for personal expression) leading to the adoption of different forms of use (consumption). For clarity's sake, therefore, this study focuses on a single form of consumption ${ }^{11}$ (the personal or

\footnotetext{
${ }^{10}$ For more on domestication theory see section 7.2

${ }^{11}$ Confusingly, this "consumption" or use of blogging takes the form of "production" of text and images.
} 
diaristic weblog) and two particular contrasting produced forms (the Blogger blog and the LiveJournal) in order to illustrate the inter-relations between form and use.

Social constructionism is a necessary corrective to strongly determinist arguments but arguably neither extreme can give a complete picture of the inter-relation between technological artefacts and social practices. Compare, for example, interaction via email and via the telegraph. Thompson's framework does not adequately equip us to describe the differences between interactions thus mediated as they are largely equivalent on the axes he identifies as important both are principally dialogic media which transmit messages instantaneously and thus both are tools for mediated interpersonal interaction ${ }^{12}$. The "circuit of culture" gives us tools to compare, for example, the representation of telegrams as tools for formal communication (e.g. for weddings) with the relative informality of email, which in turn influence how the same messages sent using either medium would be consumed differently.

But constructionist approaches in turn do not capture the broader reality of the role of a particular medium in an interaction. For example, one of the most recognised characteristics of the telegram is the concision of the messages sent through it. Indeed one of the accepted meanings of "telegraphese" is a "concise and elliptical style" (Simpson and Weiner 1989). Though the style is now part of the representation and cultural regulation of the telegram its origins stem originally from the physical characteristics of the telegraphic medium itself - the necessity for an operator to convert any message into Morse code in order to send it, which (under ordinary circumstances) allowed only a few tens of words a minute to be sent. Even a poor typist can compose an email faster than a competent Morse telegraphist.

\subsubsection{Feenberg: Between determinism and social constructionism}

Feenberg's critical theory of technology provides a sociologically-informed framework that recognises the reciprocal interplay between a technology's development, its eventual technical features and its social adoption. He recognises that "technology is thus not merely a means to an end; technical design standards define major portions of the social environment" (Feenberg $1999 \mathrm{p}$. 78) but adds that "differences in the way social groups interpret and use technical objects are not merely extrinsic but make a difference in the nature of the objects themselves" (Feenberg 2002a).

He describes the process of the design of an artefact as involving two analytically separate but intertwined processes - primary and secondary instrumentalization. In primary instrumentalization, a set of "primitive decontextualized and simplified elements" (Feenberg 2008 p. 15) with certain

\footnotetext{
${ }^{12}$ Because email sent and received is often stored in searchable databases at each end, it does have a different relationship to time, but despite Thompson's concern with space-time, he does not sub-divide communications by their durability.
} 
technical features are assembled to achieve a particular goal. These have to be "systematizable" that is, the artefact as designed has to be linked to its technical and natural environment - there is no point in designing an electrically-powered device for a society without access to electricity, for example. There are, however, inevitably a number of different ways in which elements can be combined to accomplish such goals. The process he calls secondary instrumentalization describes the ways in which a variety of social pressures work to define the goal of an artefact in a particular way and to favour some potential implementations while excluding others. These "valuative enactions" include

Legal, moral, and aesthetic constraints [which] intervene in the design and production process, determining an artefact capable of entering a specific social world." (Feenberg 2008 p. 17)

As the above implies, a variety of social actors is involved in this process. Feenberg mentions "businessmen, technicians, customers, politicians and bureaucrats" (Feenberg 1999 p. 11) but he does not attempt a comprehensive outline of relevant actors - he focuses on the roles of the market, legislators and designers on one side - the "technical context of development and production" and the user's "lifeworld context of disclosure and use" on the other (Feenberg 2008 p. 23).

Lessig approaches the regulatory power of software from a legal rather than a sociological perspective $(1999,2006)$ but in doing so provides a convenient outline of the potential categories into which these forces can be grouped - legal, market, social and what he terms "code" which is analogous to what Feenberg terms constitutive bias (see below) which aided in the operationalization of this study (see Section 4.3.1). One additional significant potential set of actors Feenberg and Lessig do not explicitly single out are the media themselves, whose power to frame reality has been widely discussed - for example by Gitlin (2003) and Couldry (2000).

An example of the secondary instrumentalization process Feenberg uses is the widening of the definition of the internet from a data transmission mechanism to include interpersonal communication, spurred, he says, by "a cultural shift that occurred unexpectedly among the user community" (Feenberg 1999 p. 126). Although during the invention, design and initial adoption processes, the nature of the emerging artefact is somewhat malleable (at least given the limitations of technical implementation inherent in primary instrumentalization), Feenberg suggests that artefacts over time acquire "technical codes":

Standard ways of understanding individual devices and classes of devices emerge, called "black boxing" in constructivist studies of technology. Many of these standards reflect specific social demands shaping design. These social standards impose the technical code. Technical codes are durable, but they can be revised in response to changes in public opinion. (Feenberg 2008 p. 23)

In influencing how artefacts are perceived these codes, he implies, also influence (to a greater or lesser extent) the ways in which a given artefact is used. They emerge through iterations of design and in response to the generation of further secondary instrumentalizations by the lifeworlds 
of those who adopt them. Such codes, says Feenberg, are "similar to law in a democratic state" and "establish stable regularities in social life." (Feenberg 2008 p. 24). Unlike such laws, however, he argues that "these codes are usually invisible because, like culture itself, they appear self-evident" (Feenberg 1999 p. 88).

Feenberg is particularly interested in these codes when they result in what he calls "formal bias" - systems or artefacts which favour a particular social group (Feenberg 2008 p. 10) - because his approach is rooted in the political economy tradition. One can nonetheless usefully employ his framework in a more interactionist mode and extend the notion of bias to encompass systems and artefacts which favour particular forms of interaction, without attempting to assess the extent to which any changes to the patterns of interaction that result might favour particular groups.

He identifies two forms of bias, depending on the source of such bias ${ }^{13}$. Biases which emerge because of the nature or design of the artefact itself he terms "constitutive bias". These include the bias against disabled people inherent in a sidewalk designed without ramps . The second form of bias he calls "implementation bias" - biases which stem from the way in which a particular artefact has been adopted and integrated into society. An example of the latter he suggests is the digital divide - "it strengthens the rich at the expense of the poor, but only because the artefacts are distributed in a specific context of wealth and poverty, not because computers are inherently hostile to the poor." (Feenberg 2008 p. 11).

This second form of bias, and the example chosen to illustrate it, help to expose an underlying ambiguity in Feenberg's work - is the object of his analysis particular artefacts as designed objects or is it a set of practices centred around such artefacts? He often appears to be discussing the former but it is apparent in his introduction of the notion of "implementation bias" that his primary focus is on the latter, since he suggests that artefacts that are problematically biased in one implementation (ie biased when made part of particular practices) may be blameless or even beneficial when in a different context.

The focus of Feenberg's work is on the necessity to tackle harmful biases through more democratic forms of technological design. He argues (counter to what he describes as the technological essentialism of Heidigger (1977) and Habermas (1970)) that while under capitalism the biases of technology tend to buttress the interests of the powerful in society, this is not an inherent weakness of technology itself. He concludes:

\footnotetext{
${ }^{13}$ He discusses bias in earlier works (Feenberg 2002b pp 80-82) (Feenberg 1999 pp 178-183) using slightly different terminology (what is here termed "constitutive bias" he dubbed "substantive" bias, while "implementation bias" is earlier styled "formal" bias). The thrust of his argument is the same, however.
} 
A socialist technical code would be oriented toward the reintegration of the contexts and secondary qualities of both the subjects and objects of capitalist technique. These include ecological, medical, aesthetic, urbanistic, and work-democratic considerations that capitalist and communist societies encounter as "problems,"

"externalities" and "crises." (Feenberg 2002b p. 184)

Although in the concluding chapter some suggestions about the design of weblogging software can be found, the focus of this study is on a particular use of weblogging technology, not on the design of the technology itself, and is primarily analytical not normative, because of the asyet-poorly-understood nature of weblogging practice itself. Until one understands more about the origins and nature of the biases which exist in this artefact, one cannot begin to gauge its social consequences, suggest whose interests are served by such biases or suggest remedies, insofar as they may be needed.

\subsection{CONCEPTUAL FRAMEWORK - PERSONAL WEblogging AND THE ROLE OF TECHNOLOGICAL MEDIATION IN INTERPERSONAL INTERACTION}

As indicated in the foregoing, the core research question for this thesis is: "what kind of interaction does personal weblogging represent and what role does the mediated nature of the interaction have in shaping it?" Central to the conceptual framework for this thesis is personal weblogging conceived as a distinctive form of interpersonal interaction. This particular way of understanding personal weblogging draws initially upon Goffman's insights into (predominantly) face to face interaction and, in particular, on his focus on the contextual threats which may mean that interpersonal interactions are perceived by one or more parties as being unsuccessful. He draws attention to the necessity for all parties to an interaction to arrive at a consistent frame in order for it to be mutually intelligible and suggests that under normal circumstances all parties to an interaction seek to prevent loss of face - whether theirs or another's. He also observes that individuals seek a sense of control over their surroundings ("Umwelt") as a key part of the context of their interactions. This sense of control can be maintained physically through spatial segregation from unwanted others (as when 'backstage' interactions take place in a room separated from the public) but can also be maintained socially through the use of tact and 'civil inattention'. In the context of personal weblogging it was unclear at the outset of this study what the 'frames' of the interactions mediated therein might be (are they akin to everyday chat? Serialised autobiography?) or on what basis they might be constructed (given the uncertainty over who the audiences for such blogs are or what they seek). My review of the literature has also suggested that this issue has received very little scholarly attention. Given the considerable uncertainty over how personal blogs are received by their readers it is not clear to what extent personal bloggers may in fact be harmed through others' reception of their blog postings outside their intended context. However, it is feasible to 
examine the extent to which bloggers perceive saving their face and protecting their Umwelt being as important, the extent to which they perceive that their blogging practice might threaten their Umwelt, the extent to which they believe themselves to have been successful in protecting themselves from potential harm, and the evidence they call upon to gauge their success or lack thereof in achieving this.

This thesis examines the role of the mediated nature of personal weblogging as an important contextual factor for the interactions that take place. The works of Meyrowitz and Thompson in particular draw attention to some of the relevant ways in which particular media technologies and interactions inter-relate.

Meyrowitz (1985) provides a conceptual bridge between face to face and mediated interaction by re-interpreting Goffman's interest in physical region control in terms of control over social information. One of the principal reasons personal weblogging was selected as a pertinent subject was that the 'personal' aspect of personal weblogging involves precisely the communication of social information (as opposed to, for example, blogs which are characterised by the anonymous dissemination of news on a given subject of general interest) and, as noted in Section 1.1, the lack of control over such information that characterises most weblogging is one of the most striking features of this communicative form.

He also asserts the importance of the study of mediating technologies as cultural environments (derived from medium theory) rather than merely as conduits for content because of the changes in behaviour that stem from new communicative situations. This study's scope is limited to the analysis of personal blogging as one such new communicative situation and seeks only to be suggestive of some of the possible changes in behaviour that might arise as a result of the spread of this phenomenon. One key objective of this research is that by providing a better understanding of the new communicative situation under study, future researchers will be better able to identify and analyse such potential behavioural changes and the circumstances under which they might occur.

Thompson's work on mediated interaction - in particular, when used from a producer perspective - focuses our attention on three aspects of such interactions, which are in turned linked to the technical characteristics of the media themselves.

The producer's imagined social context can be understood to have two relevant aspects. The first is the imagined or desired direction of flow of interactions. This comprises not merely the delivery of messages but the flow of relevant social information 'given off' like the nature of the audience and, crucially, its reaction. Thompson divides media into monologic and dialogic, to which other scholars considered in Section 3.3.2 of this chapter have added a third category - 
telelogic media - to take into account what they see as the differing technical features of computer mediated communications. He recognises, however, that while the technical characteristics of a medium may preclude interaction in one direction (e.g. conventional TV or radio broadcasters cannot directly perceive their viewers or listeners), other communication media may be used to circumvent these technical limitations.

In the case of the personal weblog, as will be discussed in Section 5.2.1, there are several means available for blog producers to count or even identify readers, and (at least in the cases under study) there are numerous ways that readers can reach the producers - principally via comments on their sites and via email - but the extent to which they are used and the importance assigned to them in the process of interaction is not pre-determined and is the subject of empirical investigation in this study.

The second relevant aspect is the intended audience. While in mediated interpersonal interaction, the intended recipients are often specified explicitly (as in a list of email recipients) or implicitly assumed to be known and limited (as in a phone conversation), Thompson characterises mediated quasi-interaction as being addressed to an "indefinite range of potential recipients".

What we now see in communicative situations like the personal weblog, is that Thompson's implicit grouping together of medium chosen, envisaged response and audience orientation is increasingly problematic. Specifically, it is not clear whether postings on personal weblogs are being transmitted using a "mass medium". They are potentially readable by millions but are in practice likely to be read by only a handful of people. It is not always clear a priori whether a weblog posting has been written for specific others, for Thompson's "indefinite range" of participants or indeed for any readers at all, although the content and style of such messages often provide clues to the readership envisaged. Lastly (and for similar reasons) it is not obvious that weblogs are predominantly monological, dialogical or even telelogic in their orientation. Insofar as they normally allow interaction between the weblog producer and specific intended readers, they may be considered dialogic, and insofar as they allow interaction between the blogger and an indefinite range of respondents, they may be telelogic. But while many early weblogging evangelists stress the importance of interaction with readers, monologic weblogs without commenters or blogs without intended readers at all are still recognisably weblogs and most definitions of weblogging reflect this (see Appendix A). This study therefore examines a crosssection of blogging practices to establish the variety of communicative contexts available and analyse how these contexts are perceived by blog producers.

Lastly, Thompson's discussion of space-time in mediation concentrates primarily on the context of reception - this study focuses on the personal blogger's view of the 'space-time 
interpolation' involved in what they post. In particular it examines the anchor frame of space-time used by bloggers as they blog. Several distinct time frames for production and consumption of blog postings can be identified - the time of conception of a posting, the time of its initial production and distribution (normally the same time, unless a posting is written and 'shelved'), the time of its initial reception (primary reception), the time in which it remains in the archives of an active blog, the time over which any postings may remain archived when once a weblog has been abandoned or deleted, and the time of subsequent reception. This study will examine how and to what extent these different times are incorporated into personal webloggers' accounts of their interactions. In other words, alongside the imagined audience this study considers the imagined time of blogging.

So far the technical artefact of weblogging software itself has been treated as a context for interaction. Feenberg's work discussed in Section 3.4.2 provides a framework within which the scope of this study can be broadened to encompass some aspects of the social and economic contexts relevant to the uses of this particular artefact.

He discusses the ways technical artefacts may influence behaviour in terms of "bias". Those aspects of bias which derive from technical characteristics of an artefact itself (primary instrumentalization) he terms constitutive bias. Those aspects which emerge through social influences on design and use of the artefact (secondary instrumentalization) he terms implementation bias.

While there is a core of functions which weblogs have in common and which make definitions of the technology possible, there is considerable variety in implementation of other functions, and these services are undergoing continuous development. Of particular relevance to this research, some weblogging services (e.g. LiveJournal) enable bloggers to control who reads their work while other services do not (e.g. Blogger - at least at the time of my initial fieldwork in 2005), but other forms of potential constitutive bias will also be analysed.

While there is already considerable variation in the primary instrumentalizations of blogging, there is even more variation in the uses of blogging technologies. These may be governed in part by these primary instrumentalizations but since one can generally find examples of a wide variety of uses even within a single weblog service, it appears that secondary instrumentalizations play a major role in influencing use. This study concentrates on one particular set of practices mediated by blog technologies as identified in the literature - "journal" or "personal weblogging" (see Appendix A for definitions of blogging). Defining the relevant social actors which may cause implementation bias in this particular form of blogging is a methodological challenge, as a daunting array of direct and indirect influences can be found or suggested. In this instance, the methodology was devised as a complement to this aspect of the conceptual framework by drawing on a range of potential 
influences suggested by Feenberg's examples and an assessment of similar influences drawn from the work of Lessig (2006). The choice of relevant influences was also informed by my own nine years of experience as a blogger and relevant factors that emerged during the fieldwork (see also Section 4.4.3). Potential implementation biases were grouped under the headings of legal, market, and social influence (see Chapter 6). Empirical observation also helped to assess the actual salience of the various potential sources of bias.

The key components of the conceptual framework for this study are therefore an understanding of:

1) The personal blogger's conception of an imagined audience, particularly the perceived and desired direction of information flow and an analysis of webloggers perceptions of control over information flow,

2) The mediation process as constituted through personal weblogging between bloggers and their readers, taking into consideration both constitutive and implementation biases, and in particular

3) The relevant temporal aspects of this form of mediated 'interpersonal' communication particularly the perceived relationships with readers not reading at the time of posting.

\subsection{RESEARCH QUESTIONS}

In the light of this conceptual framework, the core research questions, "how do personal webloggers understand this practice and how does the practice relate to its social and technical context?" are further specified as indicated below.

SubRQ1: How are the readers of such sites imagined by the producers and how does this imagination shape the authors' practice? In particular, to what extent do they feel in control of their interactions, what do they feel might threaten their control over social information exchanged and how do they manage such threats?

Initially it was expected, based on the conceptual framework - particularly based on Meyrowitz's application of Goffman to mediated interaction, that personal bloggers would seek as clear an idea as possible both of who is receiving the social information that they are sharing and what their reaction is, both by using technical tools (web traffic logs) and through careful consideration of the direct feedback that they receive. To the extent that they are unable to get such information, they might be expected to attempt to more closely control access to what they have written, to alter or cease those aspects of their blogging practice that reveal sensitive social information, and potentially to edit their existing texts to remove any sensitive social information they may already have revealed. 
SubRQ2: What are the principal sources of constitutive and implementation bias in personal weblogging, and how are they perceived and encountered in practice by personal bloggers?

Although Feenberg provides a framework for the identification of technical codes and the biases that are associated with them, little empirical work has been done to determine what those biases might be in the context of personal weblogging. Indeed, as Section 2.4 makes clear, most academic literature on blogging suggests it is a practice marked by considerable freedom from commercial, legal and social constraints.

SubRQ3: How do personal bloggers understand and negotiate the space-time interpolations inherent in their practice?

Initially it was expected that bloggers might be encouraged to blog regularly in order to satisfy the 'requirement' for up-to-date content implied both in the discourse surrounding blogging and in the way that blogging software and its 'ecosystem' operates. Bloggers were expected to value the archives that would gradually emerge from their practice over time, as a record of their work both for themselves and for others, though they might seek to edit those archives over time to ensure that they presented a view of the author consistent with their current self-presentation.

\subsection{PAThS not TAKen}

The conceptual framework outlined above was not the only analytical approach considered as a starting point for the conduct of a study aimed at filling some of the gaps in existing research. Four other frameworks were considered before the present study was embarked upon. While these proved impracticable, they had some influence on the course of the research and are, therefore, briefly outlined below. These influences will be noted as appropriate in the analytical chapters which follow.

A (predominantly) macro-level sociological study of weblogging practice drawing predominantly on the work of Pierre Bourdieu was initially considered. This would have attempted to discover and chart the range of different fields of practice of weblogging as found in the UK and the perceived 'rules' of participation in these fields through examination of sites and practitioner interviews (Bourdieu 1993a). A survey of webloggers might have been conducted in order to outline the ways in which participation in the fields may be influenced by participants sociodemographic backgrounds - the combination of gender, education and social class that together form what Bourdieu calls the habitus (1977) - a way of understanding and acting in the world largely derived from early childhood upbringing and education which shapes what courses of action can be considered. 
This research approach proved un-workable in practice for a number of reasons. It would not have been practical to do sufficient interviews to be confident both of finding all of the fields emerging through this medium and understanding the way in which participation in each field is structured. Moreover, while in some cases weblogging fields (in Bourdieu's sense) appear to be emerging - weblogging of political commentary for example - in others - personal weblogging in particular - the boundaries of the field, if any, are hard to discern. Moreover the competitiveness between participants in a field which is arguably central to Bourdieu's field theory (Bourdieu 1993b p. 72, Swartz 1997 pp 121-3) is often hard to detect among personal webloggers, in particular, as is the precise nature of the 'capital' or 'interests' which Bourdieu suggests participants in fields strive to maximise (Bourdieu and Wacquant 1992 p. 117). Lastly, the practice of weblogging is still unusual enough that fine-grained analysis of different forms based on a conventional (phone or postal) survey would have been impossible (too large a sample size would have been needed), and no way could be found to construct a truly random sample of UK webloggers via the internet ${ }^{14}$. Although a full-blown study of this kind proved impractical at this stage of the development of weblogging and with the available resources, it was Bourdieu's concept of the habitus - outlined in Bourdieu and Wacquant (1992) and elsewhere - which encouraged me to seek in my research to interview webloggers from as wide as possible a range of sociodemographic backgrounds in an attempt to examine the extent to which blogging practice might be influenced by the habitus of individual bloggers, and attempts during the pilot research to identify relevant sub-fields for analysis both sensitised me to the large variety of practices that could be found among weblog software users and drew my attention to personal weblogging as a particularly noteworthy practice.

As briefly noted in section 3.4, scholars studying what they term the domestication of technology have focused on the manner in which particular technological artefacts are adopted and used - chiefly (though not exclusively) in the home ${ }^{15}$. This approach typically divides the domestication process into a number of stages from the decision to adopt through to manner in which the 'domesticated' technology is represented to others - particularly those outside the group or family unit. The focus of these scholars on the meaning of a given technological artefact for those using it was appealing, since this is a gap in the research on blogging which I had identified, but it became apparent that the practice of weblogging did not lend itself well to examination using this framework. Domestication studies have tended to focus on technological artefacts like personal

\footnotetext{
${ }^{14}$ See Li and Walejko (2008) for a discussion of some of the methodological difficulties in constructing samples of blogs.

${ }^{15}$ See (Haddon 2007) and (Silverstone 2006) for brief discussions of the history of this concept and a review of some key texts.
} 
computers or televisions whose use is recurrent and often shared. A key part of the analysis of domestication is the examination of how such use is negotiated within households and represented by users outside of the home. By contrast, blog construction and maintenance tends to be intermittent and individual and is not infrequently secret (or at least not often spoken of in everyday life). Domestication research frequently employs ethnographic techniques involving spending extended periods in the setting of use (Bakardjieva 2005, Lally 2002, Murdock et al. 1992). Here too both the intermittent nature of blogging practice and its often unpredictable timing would have made it difficult to observe bloggers in person without requesting them to schedule their blogging (which would have disturbed the spontaneity which appears to characterise much blogging practice).

Despite the anticipated difficulties, the domestication framework did encourage me to ask interviewees for this study if they would be willing to be interviewed at home or in the location where they typically blogged. As will be discussed in Chapter 4, however, all of those approached wished to be interviewed either in a private room at the LSE or at my home rather than in their own local contexts.

As was outlined in the review of the literature in Chapter 2, several of the studies of personal home pages, personal weblogs and social network sites have focused on their role in creating, maintaining and sharing identities. The study of identity is also one of the key themes of symbolic interactionist research (as noted in Section 3.2.1 above). It is not, however, a necessary subject of study using a symbolic interactionist approach. The connection between weblogging practice and identity did feature as a potential subject of inquiry in the early stages of the fieldwork, but the results of early interviews suggested that the accounts of the personal webloggers themselves were not providing data that would be useful in exploring questions of identity because they were not accustomed to thinking of their weblogging in those terms, and rather than focusing further on this issue, it was decided the time allotted to those questions would be better used in probing the issues which have been outlined in the conceptual framework above.

This study therefore does not attempt to address questions of the relationship between weblog use and identity directly. Instead its objective is to equip scholars who have an interest in exploring the connection between identity and weblog use (or other blogging issues) with a grounded understanding of weblogging practice as it is experienced by blog writers.

A number of studies of personal weblogging and of personal home page creation analyse these practices as forms of autobiography or diary writing (Kitzmann 2003, Sorapure 2003, Van Dijck 2004). Such studies tend to be based on an analysis of the texts produced when blogging and, secondarily, of the technical characteristics of blogging software. It appeared, however, that 
scholars' interpretations of the meaning of blogging practice might miss aspects of the meaning of blogging for bloggers themselves which were not visible to or concealed from readers. In particular, while as a form of written communication containing authors' reflections on their everyday lives, personal weblogs appear to be autobiographical, qualitative studies of blogging practice which did involve interviews with bloggers suggested that personal blogging could be seen in a variety of ways by its participants and that its diaristic function was only one framing among many. It seemed therefore that choosing to view blogging as a form of autobiography might prematurely narrow the scope of research (see Section 4.2 for a more extended discussion of the weaknesses of analysis centred on the text of blogs themselves).

\subsection{CONCLUSION}

In this chapter, a conceptual framework has been outlined that informs the development of three inter-linked research sub-questions. The next chapter lays out how these questions were operationalised and the ethical and methodological problems that were encountered and addressed during the research. The three chapters that follow (Chs. 5 to 7) each predominantly focus on one of these sub-questions in the order listed in Section 3.6. Chapter 8 brings together the findings of those three chapters and relates them to the conceptual framework outlined here and to the theories underlying it. 


\section{Chapter 4: Methodology}

\subsection{INTRODUCTION}

As indicated in Chapter 3, the principal research questions for this thesis are: "how do personal webloggers understand this practice?" and "how does the practice relate to its social and technical context?". In order to examine these questions, this chapter outlines some methodological weaknesses of earlier research into weblogging and explains how the conceptual components of this question have been operationalised for the empirical component of the study. Section 4.2 provides an overview of the methods employed by prior empirical research on personal weblogging, indicating how the design of the present study provides a fresh methodological approach to examination of weblogging practices. Section 4.3 provides an overview of the project, followed by a discussion of the ethical concerns that arose and my approach to addressing them. A detailed explanation of the methods employed in each phase of the research follows in Section 4.4, and Section 4.5 provides reflections on what was learned in the process of the fieldwork.

Methodological recommendations for future research will be outlined in the concluding chapter (Chapter 9).

\subsection{DEPARTING FROM EXISTING EMPIRICAL RESEARCH}

This section reviews existing empirical research in order to demonstrate why a departure from the predominant approaches in the literature is required to address the specific research questions in this thesis. As discussed in greater detail in Section 2.4, the study of weblogging remains underdeveloped - in particular, while the few surveys available suggest most weblogs are personal or 'journal' weblogs (Herring et al. 2004, Lenhart and Fox 2006), academic attention has tended to focus on the use of weblogs for political communication or knowledge sharing. Comparatively little research has so far been produced to reach an understanding of personal weblogging as a practice.

Where this has been attempted, researchers have tended to concentrate on the products of the practice - the weblogs - rather than on the practitioners; for example by attempting to group them into genres (Herring et al. 2005, Scheidt 2008, Schmidt 2006). Several such authors have sought to explain the purpose and meaning of personal weblogs for their creators through a combination of textual analysis and autoethography (Amir-Ebrahimi 2004, Hevern 2004, Killoran 2003, Rettberg 2008, Serfaty 2004, Sorapure 2003). The analyses offered are often evocative but sometimes make claims about bloggers' motivations and how bloggers understand their practices that would seem to require further evidence to substantiate. Take for example Hevern's characterisation of personal bloggers' writings about their lives:

"Bloggers travel along connected paths through their lives... they look back on what has happened to them and forward to what might occur... Identity is conceived here as an ongoing process of construction across both 
time and space, one in which an author draws out and twists together a multi-layered overlapping set of concerns, beliefs and engagements among the postings." (Hevern 2004 p. 332).

This characterisation of weblogging as a deliberate identity project which relies in part on communication with others, inspired by Foucault's "technologies of the self" (as applied to home pages, in Section 2.3.2) is echoed by Germann-Molz (2006). It is certainly arguable that a reader seeking to engage with the identity/ies written on a personal weblog would have to assemble an impression of the author through examining overlapping sets of concerns, beliefs and engagements, but whether, to what extent and under what conditions personal bloggers themselves actually do "look back on what has happened to them" via their weblog postings or to what extent they incorporate the comments of others in the process of establishing or evolving their identities is not clear. Interviewing other personal webloggers would provide one way to flesh out and substantiate claims made about webloggers' understandings of their practices.

Many of the studies that have contacted weblog authors themselves have done so using surveys (Li 2005, Miura and Yamashita 2004, Schmidt 2007a, Viegas 2005) ${ }^{16}$. Surveys can be valuable, particularly when the field of study is well understood and there is a limited range of answers possible to the research questions. In this case, however, the field had not been extensively studied at the time these studies were done, making it difficult to ensure that the questions asked were meaningful within the context of blogging practices. Moreover, qualitative studies of blogging practice (see Section 2.4) suggest that bloggers' own understandings of their practices and motivations can be unclear or mixed. As others have argued, (Bourdieu 1979, Miller and Glassner 1997 p. 100), where the answers to such questions are not particularly clear to those being asked, respondents may answer with whatever 'comes to hand'. There are also considerable difficulties in constructing a representative sample of bloggers (Li and Walejko 2008). Particularly when they are conducted online and survey entry is open to all, the validity of such survey results may be questionable.

Two recent academic surveys on internet use have touched on weblog use employing a random digit dialling sampling strategy in an attempt to tackle problems of generalisability. The first of these - the OxIS survey (Dutton and Helsper 2007) in the UK - was a broad-based Internet use survey with few detailed questions on blogging practices. The Pew survey (Lenhart and Fox 2006) is useful insofar as it was focused only on blogging, but since there were only 233 respondents, this limits the generalisability of the results. Since it only covered US bloggers, the relevance of its results to blogging practices in other countries is open to question.

\footnotetext{
${ }^{16}$ A number of market research driven commercial surveys also have been done (Digital Marketing Services 2005, MSN 2006, Nielson/NetRatings 2006) but they generally do not describe their methods sufficiently clearly.
} 
A third survey (with a much larger sample $-\mathrm{N}=5,246$ ) was conducted in Germany in 2005 using an online questionnaire to which blog users were invited mainly by email. Since it was open to anyone to complete, its results cannot be considered statistically representative of the Germanspeaking blogosphere (Schmidt 2007a).

In summary, the claims made about the meaning of blogging practices by those who rely heavily on analysis of blogging texts may be insufficient to thoroughly understand these practices, and the limited number of surveys of blogging behaviour conducted so far are also problematic, particularly because of difficulties with the sampling frame.

Semi-structured interviews - the primary data gathering technique of this thesis - have been employed as they are frequently favoured as one of the most suitable methods to understand discourses and practices that are not yet well charted (Flick 2000, Flick 2006b, Gubrium and Holstein 2002, Kvale 1996, Robson 2002). The research design is in line with this observation and the selection of the principal method aims to elicit new insight into bloggers' own reflections on their practice.

\subsubsection{Limitations of prior interview-based and ethnographic research}

I have identified several studies where personal webloggers have been interviewed, but because the sampling methods for finding authors and/or their weblogs have been mainly opportunistic (or undocumented) it may be the results of these studies of webloggers and their practices are skewed towards webloggers of a similar socio-economic status to the researcher. In Section 4.2.2 the means chosen to tackle this problem in this study are discussed.

Menchen Trevino (2005) interviewed college student bloggers, Lenhart interviewed "generally well-educated professionals and business owners; people involved in higher education or actively pursuing new educational opportunities" (2006 p. 29); Brady targeted experienced bloggers and those interviewed were "almost entirely 'information professionals' in some form" (2006 p. 4); and the interviews by Nardi et al. were all with "well-educated, middle-class people either in school or employed in knowledge work or artistic pursuits." (Gumbrecht 2004, Nardi et al. 2004a, Nardi et al. 2004 b p. 2, Schiano et al. 2004) ${ }^{17}$. Of the group on which Reed's ethnographic study was based, the "vast majority were middle class... nearly all university educated" (2005 p. 225), and half of Kendall's snowball sample worked in the technology industry, most being in their late 20s to late 30s (2003, 2007). Two studies concentrate on young people alone - Stern's “hundreds" of interviewees (Stern 2008) were all between 12 and 21 years old and Cadle (2005) used interviews with four self-selected teenagers, all known to her teenaged daughter. Two further studies mention

\footnotetext{
${ }^{17}$ All of these papers were based on the same interviews.
} 
interviews with webloggers but do not give any detailed socio-demographic information or indicate how the bloggers were found, making it difficult to assess the diversity of their samples (boyd 2004, Schaap 2004). While Senft (2008) interviewed LiveJournal users and discussed LiveJournal practices in passing she did so in the context of a study primarily focused on 'camgirls' (women using webcams). Her sample of ten camgirls was gathered using snowball methods and the interviewees' socio-demographic characteristics were not systematically discussed in her study.

The class and education similarities of the interviewees in the samples discussed above (to the extent that the socio-demographic characteristics of the samples are known) would be less problematic if they reflected a known systematic bias among those using blogging tools, but surveys suggest that blogging of all kinds is practiced by a much broader range of ages and social classes than are encompassed by these interview-based results (Dutton and Helsper 2007, Lenhart and Fox 2006).

Moreover, the high levels of education and the prevalence of knowledge workers among those studied may have some implications for the themes of interest in this study - in particular, for the sophistication of their use of blogging tools and the level of reflexivity with which they approached their potential readers (see Section 3.5).

Additionally, it should be noted that of the interview and ethnographically based blogger studies referenced here, only two were UK-based (Hodkinson 2007, Reed 2005), almost all of the remainder being US-based, suggesting that the results of research on blogging by people from a single country is resulting in limited insight into the array of possible practices. Lastly, it should be noted that none of the qualitative research on weblogging encountered included a longitudinal analysis of blogging practices over time, although some of those interviewed in some studies did reflect on changes in their practice.

\subsubsection{Towards a methodological reorientation}

Having evaluated the methodologies used in the relevant literature, this study was crafted to produce data from new and complementary sources in a manner that has the potential to avoid some of the earlier methodological weaknesses. Accordingly, in this study data are gathered to generate rich qualitative insight into weblogging practices through semi-structured face to face interviews. Using demographic information about potential respondents gathered in a survey, the sample was structured to provide as broad a socio-demographic range of interviewees as possible. This is also (as noted above) one of very few non-US-based qualitative studies of bloggers, thus adding to the diversity of research participants.

This study uses the text produced in these interviews as a resource for analysis but it is recognised that this cannot serve as the sole basis for understanding weblogging practice. Self 
reports generated in face to face interviews may have encouraged the interviewees to seek to please the interviewer or to conform to perceived expectations. To the extent they referred to past behaviour they might also have mis-remembered facts and attitudes. The results are treated therefore as representations of currently-held (reported) attitudes and beliefs about blogging practice.

As is discussed later, an effort was made to triangulate and to interrogate interviewees' testimony during interviews and during subsequent analysis using an examination of the texts produced through their blogging, through comparisons with their answers to a survey, and by using a conversational style of interviewing, and by returning to key questions which enabled some reflection on the part of interviewees.

In this study the conceptual framework embraces some of the wider social and technical biases that may influence blogging practice. This study therefore includes an analysis of a number of identifiable biases emerging from a thematic analysis of what interviewees said, from an analysis of earlier research, and from the author's own experience as a blogger.

Lastly, although this research was not designed as a longitudinal study, the monitoring of blogging practices post-interview over four years, and email contact with interviewees whose practices changed during that period, provides additional insights.

\subsection{OPERATIONALISING THE CONCEPTUAL FRAMEWORK}

As set out in Chapter 3, the core components of the conceptual framework are:

1) The personal blogger's conception of an imagined audience, particularly the perceived and desired direction of information flow and an analysis of webloggers perceptions of control over information flow,

2) The mediation process as constituted through personal weblogging between bloggers and their readers, taking into consideration both constitutive and implementation biases, and, in particular,

3) An analysis of temporal aspects of this form of mediated 'interpersonal' communication particularly the perceived relationships with readers not reading at the time of posting.

The dynamics of the relations between these were examined empirically through the following three research questions:

subRQ1: How are the readers of such sites imagined by the producers and how does this imagination shape the authors' practice? In particular, to what extent do they feel in control of their interactions, what do they feel might threaten their control over social information exchanged and how do they manage such threats?

subRQ2: What are the principal sources of constitutive and implementation bias in personal weblogging, and how are they perceived and encountered in practice by personal bloggers?

subRQ3: How do personal bloggers understand and negotiate the space-time interpolations inherent in their practice? 
SubRQ 1 was operationalised primarily through the interviews. For example, interviewees were asked, "Do you have a mental picture of the people who read you? What kind of people are they?" and "Have you been surprised by finding that a particular person or kind of person reads your site?" to establish their perceived readership and their reaction to it. To establish the basis on which they constructed their view of the audience they were also asked, "Do you keep track of the number and kind of visitors you get?" and "How much do you know about your readership?"

The operationalization of subRQ2 relied on a broader range of methods. The interviews were valuable in establishing the nature and strength of the biases that the sample interviewees were aware of. Questions relevant to this included, "Is there a sort of content and/or practice that people expect from journal writers?", "How do you decide what to write about? What counts as 'blogable'?" and "Are there features on your site you would prefer not to have?"

However, Feenberg suggests many biases may be invisible (see Section 3.4.2). This was partially borne out in the manner in which the blogging practices as manifested by the blogs of those sampled sometimes appeared to contrast with the interviewees' claimed objectives and selfreported attitudes. It was therefore important to analyse additional factors that might bias the blogging practices of the interviewees to discover reasons for apparent contradictions between between the reported attitudes and observed practices. The manner in which potential biases were identified and analysed will be elaborated in Section 4.4.3.

The analysis of subRQ3 was conducted in a similar manner to that of subRQ2. Although bloggers' imagined relationships with readers of archived postings were the subject of a single question in the interview schedule - "Do you think people expect you not to remove past postings?" - the theme emerged in several interviews and was coded and analysed.

\subsubsection{Research design}

As discussed in greater detail in Chapter 2, several of the issues examined in this study of weblogs have also been studied in relation to personal home pages and to $\mathrm{SNS}^{18}$. Although personal home pages and personal weblogs or journals are often used for broadly similar purposes (indeed home pages were sometimes done by hand in the form of a weblog before specialist weblog services became available), this research focuses solely on webloggers for four main reasons. Firstly, home pages are more heterogenous in form and content than weblogs and are hosted on a variety of services, making sampling difficult. Secondly, while home pages can, in principle, be continuously updated, in practice, they are often left unchanged for long periods, while the weblog

\footnotetext{
${ }^{18}$ SNS were very infrequently used in the UK at the time of this study's fieldwork so they were not considered, though as will be discussed in the concluding chapter much of this research might be applicable to future study of SNS.
} 
form (built around a sequence of dated postings with the latest at the top) tends to encourage users to update regularly ${ }^{19}$. As a result, weblogs arguably require more of a commitment from their owners and this may, therefore, enable those owners to provide a more detailed account of their practice. Thirdly, the weblog form by default archives all previous content posted while previous sites are not preserved when a home page is updated (except through third party sites), which potentially presents different concerns over self-presentation and, therefore, provides an additional lens through which to examine the producer audience relationship. Lastly, while personal home pages vary widely in the degree of direct contact with readers allowed or encouraged, weblogs (by default) appear to invite interaction with readers in a multitude of ways - not just through a guest book or email address as with many personal home page sites but through invitations to comment on individual postings and automated links to postings on others' weblogs. The relationship between personal webloggers and their imagined and actual audiences is one of the key issues examined in this thesis.

This is not a comparative study either between personal weblogs and home pages or between personal weblogs and SNS. However, two contrasting weblog technology platforms were chosen from which to sample users both because they appeared to be at the time the services with the largest number of users (Henning 2005) and because they had feature sets that differed in potentially theoretically illuminating ways - LiveJournal allows its users to control access to individual postings on a post-by-post basis and encourages 'virtual communities' around expressed interests while Blogger emphasises ease of use and did not provide such features ${ }^{20}$. This, it was thought, might shed some light on the relationship between technological codes and personal weblogging practices.

This research focused on 'personal' weblogs, in particular, because it was hoped that authors of such sites would be more able and prepared to reflect on the relationship with their audiences because of the tensions and contradictions that would appear to be present given the potentially sensitive nature of the social information such bloggers reveal. As noted in Appendix A there is no widely-accepted definition of what constitutes a 'personal' weblog. Only authors of sites that provided a significant amount of social information which appeared to be of a potentially sensitive nature were included, thereby seeking to exclude purely instrumental or professional sites designed solely to share information of a less sensitive character. Some sites mix professional/impersonal and

\footnotetext{
${ }^{19}$ Both because the date at the top of the page reveals prominently how recently updated the weblog is (implicitly suggesting the degree of commitment the blogger is to the practice) and because automated tools exist that alert wouldbe visitors when new entries are posted and thus without new entries visitors may never return.

${ }^{20}$ In August 2006 - after the interviews for this study were complete - Blogger introduced some more limited privacy controls.
} 
personal reflections and, where this occurred, they were included in the sample as long as some social information was found on the front page of the blog.

Because face to face interviews were the primary data gathering method, initially recruitment of interviewees from across the UK was considered. However, it was thought (based on data on the diffusion of internet and of broadband) that the bulk of webloggers at the time of the sampling would be based in London and the South East (Point Topic n.d.). The personal circumstances of rural users and users from different regions of the UK could be different to those from London in ways relevant to their weblogging practice, but choosing regions or particular communities which could represent the diversity of regional practice and interviewing a sufficiently large number of respondents in each selected region in order to draw reliable conclusions about the interaction between location and practice appeared impractical given the overall scale of the research.

Accordingly, weblog selection was narrowed to those that purported to be London-based, using the appropriate keywords in the Google search ${ }^{21}$. This facilitated later face to face interviewing while providing a large enough sample such that interviewees from a range of gender and sociodemographic backgrounds could be included.

\subsubsection{Ethical considerations}

This research followed the requirements for ethical conduct as outlined in the guidelines of the London School of Economics and Political Science and of the Economic and Social Research Council (LSE 2003, ESRC 2005). Those interviewed were informed about the general purpose of the research (the study of personal webloggers and the people who read them), were all able to give their consent (were 16 or over) and did so freely, signing a consent form (see Appendix B) after a verbal explanation of the nature of the questions and possible risks. The identities of those who were interviewed have been concealed with pseudonyms. However, as Murphy and Dingwall suggest, "the ritualistic observation of [rule-based ethical] codes may not give real protection to research participants but actually increase the harm by blunting ethnographers' sensitivity to the method-specific issues that arise" (Murphy and Dingwall 2001). The complex relationship between publicness and privacy of those interviewed and what they wrote in their blogs was evident even before the research began. This called for a careful examination of what would constitute ethical conduct in this case.

\footnotetext{
${ }^{21}$ The search string used for Blogger users was "site:http://www.blogger.com/profile/ "location: London" -Ontario"the one for LiveJournal users was, "site:livejournal.com "User Information" London e-mail -Ontario". In both cases this essentially searches for blog sites whose authors have provided email addresses and say they live in London (but not London, Ontario, Canada).
} 
Social science researchers routinely anonymise respondent data - particularly if, as in this case, interviews might touch on sensitive issues. It has been argued, however, that in the case of public online performances, performers may "wish to enjoy the benefits of pseudonymity but have no wish to be truly anonymous", and that they may be "putting on a show, and craving an audience and credit for their accomplishments." (Danet 2001). The personal weblog has been construed as just such a public performance (Serfaty 2004) so the form used to request consent to interview was modified in order to accommodate any desire to waive anonymity.

Respondents were offered the option to request that their name and/or their weblog address should be published and were asked whether they would be happy to have excerpts from public and from 'private' parts of their weblogs published. Despite cautions both on the form itself and verbal cautioning about the potential consequences of disclosure, most respondents stated a desire to reveal their identities and many were even willing to indicate that extracts from parts of their website not visible to browsers without permission ('friends only' posts) should be published. Of course to some extent this may simply be a measure of the fact that non-academics have not internalised the strong sense of caution about identifiable data in research, and they may have felt that friends, family and colleagues were unlikely to read an academic text, but this openness may also reflect both emergent norms among webloggers and greater openness and desire for self-exposure in contemporary British society (see Section 8.3). Notwithstanding the expressed willingness - even desire - of many interviewees to be identified, I have elected to anonymise them as much as possible, for reasons outlined below. Not only are all respondents identified only by their pseudonyms, but details which could help to identify them that feature in interview extracts have been concealed.

The ethical stance of Viviane Serfaty, another weblog researcher, is instructive as it is to some extent a mirror image of my own stance. She argued she should not have contact with the authors of weblogs because, "scrutinizing the diary of a person the researcher is acquainted with and eventually publishing the results might be assimilated to a breach of trust" and she suggested that intimacy with diarists could "induce reluctance to expose certain, sometimes unflattering, perhaps even sordid aspects of the diarist's life" (Serfaty 2004 p. 11). On the other hand, she chose to assume that the texts themselves are, in Paccagnella's words, "public acts deliberately intended for public consumption" (Paccagnella 1997). Yet a few sentences earlier Serfaty admits that in many cases this would not be so:

Others, however, even while putting forth their writings on as public a medium as the Net, may strenuously object to academic scrutiny, not so much because of rather improbable possibilities of publicity, but for deeper, unconscious reasons, having to do with the very reasons why they undertook a diary. Bowing to the reluctance 
of such diarists would make the remaining ones a virtually self-selected sample, with the attendant distortions this would imply. (Serfaty 2004 p. 12)

By contrast, I chose not to interview two people I knew whose weblogs came up in the sampling frame and, in the case of others whom I interviewed, I did not presume to believe and did not encourage interviewees to believe our relationship would be anything other than that of a curious but disinterested researcher encountering a fellow weblogging practitioner. Thus the issue of 'breach of trust' did not, in my view, arise. I also do not suggest as Serfaty appears to that the dangers of publicity to individuals interviewed for academic research are entirely 'improbable' and this would in any case not excuse potentially harmful disclosures within the norms of social science publication.

Text from the webloggers' sites has not been reproduced here despite the consent interviewees gave to do so because several of those who make their weblogs available freely online (and would be prepared to have them publicised in an academic study) may come to regret that choice later in life. To give but two examples, one of the interviewees refers in her weblog to a suicide attempt and repeated self-harming, and another discusses details of her sexual history on several occasions.

It might be argued that as long as the names of webloggers themselves were protected by pseudonyms and no clearly identifiable details were included in excerpts from their weblogs, their identities would be protected, but this could not be guaranteed. As Hine noted in the context of usenet postings (2000 p. 24), a reader of this research could put a vivid or original turn of phrase from a weblog that was quoted into a search engine and be led directly to the weblog of the author. Even if that weblog was itself pseudonymous, many of these weblogs retain a great deal of material in their archives with references to material that could help a reader - particularly one with prior knowledge - to identify the author. Rosenstein, an early researcher who interviewed personal home page creators elected not to provide quotations from their pages in her analysis for precisely this reason (Rosenstein 2000 p. 51).

Associating anonymised interviewees with the texts of their weblogs would significantly increase the likelihood that their anonymity would be breached - in fact it would pose a double threat to their privacy. Even if it did not enable readers to identify the authors, it might enable those who only know their 'front stage' weblog identity to learn details of authors' 'back stage' lives via the interviews - not least their attitudes towards their readers.

\subsection{OVERVIEW OF EMPIRICAL RESEARCH METHODS AND PROCESS}

Table 4.1 below sets out the main phases of the fieldwork for this thesis.

Stage of fieldwork 


\begin{tabular}{|l|l|}
\hline I & Used search engines to find personal weblogs \\
\hline II & Selected webloggers for initial contact from search results \\
\hline III & Sent survey and selected interviewees based on survey results \\
\hline IV & Interviewed respondents face to face \\
\hline V & Conducted structural analysis of weblogging biases \\
\hline VI & $\begin{array}{l}\text { Re-contacted interviewees via email when their blogging practices } \\
\text { appeared to change }\end{array}$ \\
\hline
\end{tabular}

Table 4.1: Phases of Research

The empirical research was conducted as follows. Initially, search engine queries were used to attempt to identify webloggers in London who had provided email contact details on their weblogs and were using one of two weblog hosting services (Phase I). 510 sites were examined and from that list of sites 237 were found which fulfilled the sampling criteria (see Section 4.1), were classified as 'personal' and had been updated in the last month (Phase II). A short survey was sent to the owners of these weblogs and based on the results from those who responded (Phase III) 23 interviewees were purposively selected to provide a range of sociodemographic and weblogging characteristics (Phase IV). The primary method of data collection was a series of semi-structured face to face interviews, one to two hours in length. Interviews were transcribed and the transcripts were then coded and analysed thematically. (see Section 4.4.2). In Phase V, technical features of blog software which might influence the personal weblogging were identified alongside other contextual factors (see Section 4.4.3). The weblogs of interviewees were monitored via their RSS feeds in the period after the initial fieldwork and in Phase VI emails were sent to six whose weblogging practice appeared to have changed significantly.

The texts of the weblogs themselves have not been analysed because of the ethical concerns outlined above, although a reading of them did inform the analysis in various ways (see 'data processing and analysis' below).

\subsubsection{The Research sample}

The intention of this research was not to generalise the results to make representative claims about the population of webloggers in the UK or globally - it was to provide an in-depth examination of a particular practice as it is performed by actors from a variety of backgrounds in order to gain insight into their perceptions of their practices. The empirical analysis is therefore based on a purposive sample of webloggers - thus avoiding many of the difficulties outlined elsewhere in producing a random sample of web pages or blogs (Li and Walejko 2008, Schütz and Machilek 2003). The number of webloggers interviewed (23) was limited in part by the sense during the field work that a point of saturation (Bauer and Aarts 2000 pp 32-34) had been reached 
and by the assertion by Bauer and Gaskell (2000 p. 43) that somewhere between 15 and 25 interviews is the upper limit for a single researcher to be able to sensitively analyse.

As noted in Section 4.2.1 qualitative studies of webloggers have largely relied on convenience or snowball samples. These would seem likely to favour bloggers similar to the authors of these studies, although available statistical evidence suggests that blogging takes place across a broad range of socio-economic backgrounds. To maximise the diversity of my sample as much as was practicable, Google was used to find a broad selection of webloggers whose blogs were hosted by Blogger and LiveJournal.

There are many different weblogging tools available, each with different sets of features and each therefore potentially influencing the manner in which the authors express themselves (an interaction which will be examined in detail in Chapter 5). The process of constructing a sampling frame of weblogs and their authors would also be different for each weblog host - it was therefore decided to concentrate on the creators of weblogs hosted by Blogger and by LiveJournal (see also Section 4.3.1 above).

Both Blogger and LiveJournal require weblog authors to produce profile pages about themselves (possibly including email addresses and author location) that can then be searched. Not all users have registered all of this information or have elected to make it public, however, the prompt to provide the information is now a standard part of registration. This profile was used as the basis of the search in order to find potential interviewees whose blogs provided email addresses enabling their authors to be contacted and whose authors would be located in London, UK, facilitating face to face interviews.

Search engines try to prioritise their results using 'relevance' measures that tend to bring the most popular sites matched to the top of the page, so the first 200 results were disregarded. Nonetheless, only a small fraction of the search engine's overall number of indexed pages is presented - the "top" 1000 out of 11,000 (in the case of Blogger) or 117,000 (in the case of LiveJournal) at the time the research was conducted in 2005 - so it is likely that the sampling frame tended to favour the more popular weblogs and weblogs that had been recently updated ${ }^{22}$.

From the list of web addresses provided by the search engine, a number of administrative exclusions were made. Links to pages where a weblog no longer existed were excluded but weblogs were also excluded from the sample if they either had fewer than five posts in total or had not been updated in the previous month. This was done in order to ensure that those who were subsequently

\footnotetext{
${ }^{22}$ While studies suggest many weblogs are abandoned shortly after they are created, few of the weblogs found using search had not been updated recently, though as will be noted in Chapter 7 a number were abandoned after their owners were interviewed.
} 
interviewed both had sufficient experience of the practice to be able to provide a detailed account of it and to ensure that their active participation was recent enough for them to remember and describe. Weblogs were excluded if they were not in English, because of the need to interview their authors in that language. They were not included where the weblog author was already an acquaintance as it was felt this could create awkwardness and make it difficult to get full and open responses to some of the questions. Four of the weblogs found were created by more than one author - these were excluded because the dynamics of group weblogging were thought likely to be different from those of individual weblogging and not enough potential interviewees were available to enable a thorough examination of that particular form.

Since, as discussed in Chapter 3, the object of study is the practice of weblogging not the weblog itself, only weblogs which provided an email contact address for their authors were selected because contacting and interviewing the authors was the primary research method. Some of the weblogs examined that lacked email addresses offered other means of contacting their authors occasionally instant messaging addresses and very often comments. Comments fields were not used to attempt to recruit because the public nature of the contact might cause un-wanted 'pass along' responses and because the knowledge or suspicion among their readers that the weblogger might be interviewed might cause embarrassment. If a sufficient number of email addresses had not been available, instant messaging might have been used to recruit but this was not regarded as being ideal because interviewees approached in that way might attempt to bypass face to face interviewing in favour of online interviews. Indeed, some contacted by email also suggested interviewing by email or instant messaging. Online interviewing was considered but rejected for reasons outlined in the "data collection" section below.

Only sites that could broadly be termed 'personal' were chosen since as indicated in Chapter 3, this research seeks to analyse how intended and unintended audiences are understood and negotiated, and bloggers who include information about themselves that might be considered private on public weblogs present a particularly striking potential conflict which could be used to stimulate discussion. It is also widely accepted that personal weblogs are the most common blogging form (Lenhart and Fox 2006). While any site which is identifiably by an individual says something about that individual (and tacitly excludes other aspects of that person's self), this research sought to exclude purely instrumental or professional sites designed solely to share information. No commonly accepted definition has been proposed for identifying personal weblogs in the studies that have been conducted to date - consistent with the definition proposed in Scheidt's literature review (see Appendix A), the sample excluded any site which did not contain at least one reference to the author's own views or experiences of everyday life. To minimise the amount of 
reading required, only postings from bloggers' front pages were included ${ }^{23}$. In doing this, by necessity this sample excluded any users of LiveJournal who used its privacy features to block public access to "personal" postings. This may mean this sample was of people whose use of LiveJournal was uncharacteristically 'open' but no studies are available that indicate how often the privacy controls are used or in what contexts.

An introductory communication was sent to the list of the email addresses collected from the sample thus derived (see Appendix C). It outlined the general nature of the research and linked to a brief online survey (see Appendix D). Weblog authors were told in the survey that they might be interviewed and were given the option to opt out of further contact at that point or to provide the preferred means of contact for follow-up. The results of this survey have not been extensively analysed for two reasons. Firstly, while the sample was constructed to maximise variety it could not be representative because of the difficulty in establishing the size of the sampling frame and in sampling randomly from it (see Li and Walejko 2008, Schütz and Machilek 2003) and in any case despite a good response rate the overall number of respondents was small $(\mathrm{N}=150)$. Secondly, the conceptual framework of this research implies a qualitative approach, as it is seeking to develop an understanding of personal weblogging practice as it is understood by its practitioners rather than seeking to quantify the proportions of webloggers acting in a particular way.

Examination of the responses helped in the construction of the interview schedule and the individual responses of those chosen to be interviewed were used (alongside a reading of the authors' weblogs themselves) to direct some of the questioning (see Section 4.4.2). The main purpose of the survey, however, was firstly to enable purposive sampling of the interviewees by gathering basic socio-demographic data and information about relevant blogging characteristics like the size of the bloggers' audiences and secondly to exclude ineligible interviewees (e.g. people unwilling or unable to be interviewed and young people who could not be interviewed without the consent of a guardian).

A purposive sample (Chadwick et al. 1984 pp 65-66) was drawn from those who responded to the survey ( 23 were chosen out of 150 who completed the survey - see table 4.2), attempting to ensure those interviewed spanned as wide a socio-demographic range as possible. In addition, the survey enabled selection of respondents from a range of levels of perceived weblog "popularity" (as

\footnotetext{
${ }^{23}$ As will be apparent in subsequent chapters, a small number of the weblogs that appeared to be personal were, according to their authors, primarily used for instrumental or professional purposes, and several of the others did feature some postings that were more consistent with the other genres of weblogging identified by earlier studies, for example comments about and links to third party sites (Herring et al. 2004). This points both to the difficulty of classifying weblogs using their textual content alone and to a fluidity of genre boundaries among bloggers, whose framing of their blogging practices can be mixed and can change over time (see Section 7.2).
} 
measured by the number of readers they believed they had and the number of comments they received).

Detailed demographic data about UK weblog authors was not available at the time fieldwork began. Data that was available about US weblogging and UK home page creation (Rainie 2005, Shepherd 2003) suggested that finding interviewees with lower social status or education might be more difficult than finding middle class ones, and this proved to be the case. Of all those who indicated their education level, $45 \%$ were graduates and a further $21 \%$ were postgraduates. Likewise, $60 \%$ of respondents identified themselves as middle class and $13 \%$ as upper middle class - only $15 \%$ self-identified as working class. All of those who said they had no higher education degree qualification and all who said they were 'working class' were invited to interview. There was nonetheless an apparent shortage of 'genuinely' disadvantaged interviewees. Many selfidentified 'working class' people had middle class jobs and those without degrees had training that gave them access to middle-class careers (like accounting or IT). This is consistent with surveys that suggest a significant number of Britons who would be considered middle class because of their income or profession identify themselves as working class (BBC News Online 2006a).

This difficulty in finding 'truly' working class users might have simply reflected the class background of UK bloggers in 2005 but it might also have been exacerbated by two factors - a bias towards more popular or more frequently updated blogs potentially encountered because of the search engine-based sampling technique and secondly a possible reluctance by less educated or lower-class people to participate in social research.

Those who identified themselves in the survey as being below the age of 16 were not interviewed in order to avoid the necessity of seeking parental consent ${ }^{24}$. The initial response rate to the survey was good - with an initial invitation and one email reminder, 63\% completed it online. Based on the answers provided in the survey, interviewees were selected, evenly split by gender, $74 \%$ white, ranging in education level from vocational to postgraduate degree $(73.9 \%$ were degree educated), and self-identified from working class to upper-middle class (56\% said they were 'middle class', 13\% (3) self-identified as 'working class'). Ages were collected as ranges and participants were chosen from all of the age brackets represented, ranging from 16-24 to 50-64 (though there were only two interviewees in the latter age bracket and no survey respondents over the age of 65). Interviewees were also chosen from across the scales provided in the survey for

\footnotetext{
${ }^{24}$ This choice did not turn out to be as much of a distortion as was feared. Early data suggested people who stated they were under 16 made up $14.3 \%$ of active LiveJournal users (LiveJournal 2004). In my sample, however, only two questionnaire respondents (1.3\%) said they were younger than 16 and six (4\%) (who were not interviewed) gave no age.
} 
degree of self-revelation and number of anticipated readers (ranging from "none" to "more than a thousand a week"). See the overview of interviewees in Appendix G for more details.

Number of webloggers contacted

Valid responses to survey

Invited to interview

Agreed to interview
237

150

75

23

Table 4.2: Response Rates

\subsubsection{Interview Data collection}

The results of the interviews that form the core of this analysis in subsequent chapters were elicited by semi-structured face to face interviews (see interview protocol Appendix E). While internet-mediated interviewing would have been possible, this option was rejected. This was not because of any conception that the quality online interviewing is necessarily inferior to face to face or less trustworthy - as Markham puts it, "authenticity is questionable in any setting, online or offline, and the search for authenticity presumes not only that people have real selves to be revealed, but also that the authentic reality of a person is revealed by one's physical presence" (2004 p. 103). Seeing respondents face to face did mean that their age and gender could be verified to a greater extent - particularly to better establish that they were over 16 - but the main reason face to face interviewing was chosen was that it was expected to produce a greater volume of material. Firstly, in a face to face meeting informal social regulation tends to ensure that participants remain until the researcher's questions have been answered. Secondly, because speaking is a faster medium of communication than typing, it was expected that interviewees might provide a more extensive account of their practice than they might in an exchange of email or instant messaging. One scholar who mixed instant message and face to face interviews found the length of her face to face interview transcripts was three times that of the instant message transcripts (Lüders 2005). The median length of the face to face interview transcripts produced in this study was 11,400 words - at a typing speed of 40 words per minute this would have necessitated an average of nearly five hours of continuous typing time in an online interview.

An initial interview schedule was constructed based on the research questions, the literature available, the responses to the survey, and on my own nine year experience as a weblogger. It was revised after two pilot interviews and revised again midway through the interview process to examine additional aspects of weblogging practice of interest as they emerged ${ }^{25}$.

\footnotetext{
${ }^{25}$ For example to get further information about how and why the webloggers read others' personal weblogs (because it appeared in the open questions this was linked to their writing practice).
} 
A considerable amount of contextual information was available about each blogger's practices and was drawn upon in the preparation for each interview. Although as noted earlier the text of the blogs of each interviewee was not formally analysed, I read current and archived postings on their blogs to familiarise myself with the lives of the interviewees to the extent they were revealed and with the style and the content of their blogs. I was also able to refer to the answers they gave to the questions on the survey that they had responded to earlier. As a result, interview time did not have to be allotted to the collection of basic social and demographic information, and only those questions from the interview schedule that appeared likely to be relevant to an individual blogger's experiences were asked.

In the course of the interview itself, the phrasing and order of the questions varied in order to maintain a conversational flow, and my blogging experience also helped to build a rapport with the interviewees (especially since at the time the interviews were conducted blogging was still a fairly unusual practice and many of these bloggers would rarely if ever have had the chance to discuss blogging face to face). I provided the address of my 'personal' weblog (http://blog.org/) in my first email contact, in part to assure interviewees that I was 'one of them'. I was able in most cases to draw on this experience to understand and, where appropriate, to use the weblogging-specific argot of interviewees (see Appendix A for a glossary of some key terms) which may also have put them at their ease.

The questions were designed to be open-ended and the interviewing approach was primarily episodic (Flick 2000, Flick 2006c). Narrative interviewing (Bauer and Gaskell 2000 pp 57-74) was considered as an alternative but it was apparent from earlier studies that, while weblogging may be continued through time, it is generally conducted in as a series of short and (individually) inconsequential activities making it potentially difficult for interviewees to provide a single sustained narrative about their practice. Instead, they were prompted to tell a series of micronarratives about particular aspects of interest, using concrete examples wherever possible.

Interviews were conducted face to face (recorded onto a computer hard disk and onto minidisk simultaneously as a backup). It was originally hoped the interviews could take place in the location from which the authors normally create their online journals both in order to facilitate reference to email, past pages and other information stored on their computers and because the physical environment could provide additional information on the way in which journal-writing is integrated into the authors' everyday lives. Meeting people for the first time in one's home is not customary in London, however, and additionally several respondents made reference to concerns about the potential hazards of meeting people face to face who they had only met online. Therefore most interviews took place at the London School of Economics and the remainder took place at my 
home. All interviewees were given (and talked through) a consent form to sign before beginning and all were told they might be called upon to be re-interviewed or re-contacted via the internet for clarification.

Post interview, some interviewees were re-contacted by email or instant message and asked about changes in their blogging practice, but these exchanges were brief. While these responses contributed to analysis they were not systematically coded.

\subsubsection{Analysis of technical and social contexts of blogging}

The theoretical framework used for this study - in particular the application of theories of mediation within symbolic interactionism in Section 3.3 and the critical theory of technology outlined in Section 3.4.3 -implies a need to attend to a broad range of technical and social contexts when analysing the meanings of potential interactions between bloggers and their readers. Feenberg's work implies that much of the context that may influence blogging interactions may be invisible to those involved - in particular what he terms "constitutive bias" - that is, the elements of the technologies themselves which enable certain uses and discourage others. This suggests that analysis of biases must rely on more than the evidence provided by participants in potentially biased practices. He does not, however, provide tools for the researcher to identify relevant potential biases. The work of Lessig $(1999,2006)$ was therefore used to suggest the broad categories into which such biases could be grouped - "architectural” (in Feenberg's terms, constitutive biases), legal, market and social biases (see Section 3.4.2). It was beyond the scope of this thesis to investigate in detail all of the relevant factors which fall into these groupings and which could potentially bias personal weblogging practice but some indicative evidence in each of the groupings was assembled (see Chapter 6). Some of these biases were explored by the interviewees themselves - for example the bias against bloggers discussing what transpires at work. Some were alluded to briefly by the interviewees and were investigated in more detail after the interviews using media reports and related academic studies - for example the bias towards keeping one's postings short. Lastly some - in particular the examination of the constitutive biases of blogging software, like the pressure to update one's weblog frequently - were largely my own interpretation of the potential biases of particular technical characteristics, drawing on my blogging experience. These analyses are indicative and I acknowledge that a different set of interviewees might have focused attention on different biases. Analysts might have different views of the biases embedded in the technology of blogging. The primary purpose of this portion of the study is to provide examples of the kinds of bias that may exist, offering suggestions for further study. 


\subsubsection{Data processing and analysis}

The interviews were fully transcribed and coded using NVivo software. The interview transcripts have been examined using thematic analysis (Flick 2006a), developing themes through an interactive process of open and selective coding. This approach is designed to develop a thematic structure that is grounded in the data but comparable across the interviews. Analytic induction was applied to the results first to enhance and reshape the conceptual framework and then to iteratively refine the initial propositions derived from it.

Before coding began, three broad themes were identified, based on earlier findings motivations to start and continue blogging, relations between the blogger and their readers and the manner in which the technology platform or understood social conventions biased their blogging practices. In the course of further development of the conceptual framework, the focus was shifted away from bloggers' motivations. Instead, selected results from that code were used in the analysis of bloggers' framings of their blogging practice. This formed part of the analysis of the bloggers' relationships with their audiences which is in Chapter 5. Chapter 6 brings together most of the coded material on the technological and social bias. The first three interviews were coded first in relation to these three 'root' codes (plus a fourth 'other' code for issues that arose which appeared interesting). This broad coding helped to provide an overview of the overall content at that point. With subsequent interviews, sub-codes were produced for each root code and a number of additional root codes were added - one for accounts of positive and negative consequences of weblogging practice, for example, which are touched on in Chapter 9, and one for cross-cutting issues relating to temporality which had not been anticipated but which were developed in Chapter 7. This focuses on the temporal aspect of blogging - bloggers' attitudes towards their archives in particular - bringing together relevant interview material dealing with bloggers' imagined relationships with future audiences and with audiences focused on what they had written in the past, and the technological and social biases that might shape that relationship.

The accounts given were critically interrogated and the data triangulated firstly through comparison with the evidence provided by the weblogs they produced, secondly, by noting inconsistencies and contradictions within the interviews themselves and, thirdly, by comparing assertions made in the interview and answers each interviewee provided to the survey about their blogging they completed as part of the sample selection process. I returned to some of the interviewees to clarify points and offered to send them a summary of the findings when possible, but they were not given the final say in the interpretative process. As Gellner suggests, the analyst has a responsibility to interpret the evidence to the best of his or her ability even when that may lead to conclusions that the subjects might disagree with (Gellner 1970). 


\subsection{Methodological Reflections}

Over the course of the fieldwork, a number of unanticipated problems and issues arose which are discussed here, and analysis of the data that resulted has suggested a number of areas which merit further examination but are beyond the scope of the present thesis (future research directions are discussed in Chapter 9).

As alluded to earlier it was a source of some disappointment that I was unable to interview a sufficient number of working class people to be able to suggest how their practice might be different from that of other social groups. When the fieldwork was conducted (summer 2005), weblogging was still at an early stage in its social diffusion - statistics were not available at the time to indicate how widespread it was, but it later emerged no more than 5\% of UK internet users had a blog at that time (Dutton et al. 2005). By 2008, however, the picture has changed. Not just because the proportion of UK internet users who maintained a blog in 2007 rose to 9\% (Dutton and Helsper 2007), but because of an explosive growth, particularly among the young, in the use of so-called 'social networking sites' (SNS) like MySpace and Bebo. These new sites and practices appear to provide both a promising avenue to reach different sociodemographic groups and a potentially interesting contrast to weblogs in terms of the interplay between technological form, emergent genre norms and motivation - see Section 2.5 for a comparison of blogs and SNS and a brief review of the literature about the latter.

It is hard to assess to what extent the purposive sampling method used helped to provide a better picture of the breadth of personal blogging practices. A link between bloggers' gender and their willingness to express political views was tentatively raised in Section 6.4.4, and some connections were suggested between bloggers' professions and their framing of blogging practices in Section 5.4.3 and in Section 6.4.4 insofar as bloggers whose professions involved writing appeared to frame their blogging practice either as a contrast to their professional practices or as an extension to them. Overall, however, differences between bloggers' practices attributable to individual attitudes seem to be more important than any that this study could link to bloggers' sociodemographic characteristics. It is possible, however, that the sample size was too small to pick up such differences, and the thrust of this research was in any case not comparative.

It should also be understood that there are a number of ways in which the sample constructed for this research is not and was not designed to be representative of personal webloggers in the UK. Firstly, the sample was chosen via search engines and from among weblogs that had been recently updated, which in both cases would tend to favour bloggers with a greater commitment to the practice than average. Secondly, bloggers whose blogs were not visible to search engines at all could not have been found, and those whose LiveJournals contained little or no personal material 
were excluded from this research. This sample therefore excludes by its nature the large population of LiveJournal creators using the service in private networks.

The passage of time has turned up noteworthy changes of practice even among my small sample, as noted in Chapter 7. Four of the 23 webloggers have announced a halt to their weblogging, and a further three changed the location and technological platform of their weblogs (with a fourth moving her weblog elsewhere in order to escape the attention of her ex-partner). As has already been noted, in the year following the interviews, a number of alternative personal site 'platforms' have arisen - notably social networking sites like Bebo, MySpace and Facebook and some of the respondents have started using these sites as well. With a view to completion of this study, re-interviewing to examine how blogging practices might have changed in the light of the widespread adoption of these new SNS was not undertaken.

As noted in Chapter 2 a number of researchers of weblogging have termed their research 'ethnographic' and/or based on participant observation (boyd 2004, Gumbrecht 2004, Hodkinson 2007, Reed 2005). I do not claim this is an ethnographic or participant observer study.

I considered attempting an ethnography of personal blogging practices. This would have enabled a stronger triangulation of the data because it would have provided direct observation and engagement with the practice as well as interpretation of the accounts given of it (interviews with bloggers) and the products of it (the weblogs themselves). I determined, however, that doing an acceptably thorough virtual ethnography would present considerable ethical and practical difficulties because of the personal nature of the weblogs under study. It seemed likely from previous weblog studies that some of the authors whose weblogs I encountered only expected friends and prior acquaintances to comment on their writings (this suspicion was confirmed both by the survey and by my subsequent interviews). In neither case could interaction take place 'naturally'. I could have used my own connections to existing individuals and groups with weblogs as a starting point but apart from the ethical problems of retaining their anonymity in such a case, as discussed previously I wished to extend the study of weblogging practice beyond the well-educated middle class bloggers who have already received some attention. It also seemed that I might be able to obtain more frank and open responses from my interviewees precisely because there would be no expectation of ongoing acquaintance (though I told them I might return to them for follow-up research).

An ethnography that combined both online and offline contexts would have provided different insights but it would have presented its own difficulties. It would be necessarily multi-sited (Hannerz 2003, Marcus 1995). It would at least have to include the weblogger's 'virtual space' and the physical place and time at which they normally blog but as weblogging can be done from 
anywhere with an internet connection and at any time this might involve a number of locations for each participant (one had begun to blog using his phone). It could also include involvement in face to face gatherings which included substantial numbers of others known to the blogger and could even be extended to encompass the experience of those who read the 'central' author's blog. The only examples I have found of this are Reed's ambitious study of a group of UK bloggers (Reed 2005) and Hodkinson's study of Goth users of LiveJournal (Hodkinson 2007) - in both cases their research would have been significantly aided by the fact that the bloggers studied were more committed to the practice than most and they belonged to an explicit 'community' of bloggers which met offline regularly. This meant they were accustomed to discussing their weblogging practice with people they did not previously know and that there was a 'natural' means of joining the group. The bloggers researched in this study are more typical in that, while they might be connected to other individual bloggers and internet users, their blogging itself is not part of a formalised community structure.

The research has demonstrated considerable variation in approaches to personal weblogging among interviewees which is itself an important finding. Unfortunately, this has also been problematic in that, for most of the facets of weblogging practice under study, only a limited number of interviewees have spoken about this in their interviews. The semi-structured nature of the interviewing meant there was flexibility in the directions that the interviews could follow. This broadened the scope for new insights but also reduced the amount of triangulation possible between interviews because the interviewees were not all asked an identical set of questions.

\subsection{CONCLUSION}

Any research project is necessarily imperfect in practice because of limitations on resources, human fallibility and unforeseen occurrences. In the reflections above I have outlined a number of respects in which the methodology for this research has some weaknesses. Nonetheless, the methodology for this research was successful in enabling me to achieve most of the aims. A sufficient number of people agreed to be interviewed to provide a rich set of data resulting in many interesting insights and, while they were not as varied a group as I had hoped, there was greater variety than in most previous qualitative studies of personal weblogging practice. The interviewees were generous with their time and all were willing and able to be reflexive about their practice.

To recapitulate, the research design for this project can best be characterised as a qualitative study of personal weblogging practices. The unit of analysis was individual personal weblog authors, and the main research method was the semi-structured interview, supplemented by a preliminary analysis of technical and social factors influencing blogging practices. The main analytic technique applied for the processing of the interview texts was thematic analysis. The 
structure of the remaining components of the thesis was outlined in Chapter 1. The next chapter, Chapter 5, is the first of three chapters containing the empirical findings. 


\section{Chapter 5: Imagined audiences}

\subsection{INTRODUCTION}

The relationship between bloggers and those who read their blogs is often a complex and even contradictory one. While there has been some academic research in this area (see Section 2.4), scholars have tended to ascribe attitudes about their audiences to the authors of weblogs based on readings of their texts or have assumed that the 'public' nature of personal disclosures on weblogs which are, in principle, readable by millions, necessarily indicates a desire by the authors for a broad public to read what they have written.

This chapter draws upon the interview data as indicated in Chapter 4. The first half of this chapter examines in detail the technical facilities that exist in weblogging to give bloggers information about their readers and the manner in which these tools are used by the bloggers interviewed. The evidence of this study suggests firstly that (contrary to assumptions underlying the CMC literature described in Chapter 2.2 and to the blog-related studies discussed in 2.4.2), bloggers often do not focus their attention on those who may be reading their postings. Secondly, even when bloggers can construct a mental picture of their readers a divide can emerge between what webloggers know or believe about readers and the way they think about their readership as they write. In practice this suggests that their perception of the communicative space - at least in the moment of production - often tends to be what they would like it to be rather than what (on reflection) they believe it to be. As Section 2.6 makes clear these discoveries are consistent with studies of mass media producers though they have not been the focus of CMC studies. This is discussed in more detail in Chapter 8.

The second half outlines four possible broad orientations of bloggers towards the readers as they perceive them - three based on previous communications literature and the fourth suggested by this research. Specifically these are narrowcast, dialogic, telelogic and 'self-directed' orientations. The overall argument is that while the enabling of communication with unlimited global audiences is a novel and much discussed feature of blogging tools, those personal bloggers interviewed may not be continuously mindful of this aspect of their practice, and may vary widely in their attitude towards it. This is also taken further in the analytical chapter (Chapter 8).

\subsection{WHO DO PERSONAL WEBLOGGERS THINK THEY ARE TALKING TO?}

\subsubsection{How much do bloggers know about their readers?}

"Some of them I don't even know what they look like. I don't even know that the gender they are is the gender they actually are." - Donald ${ }^{26}$

\footnotetext{
${ }^{26}$ This (and all other names of interviewees given in this study) is a pseudonym.
} 
The internet offers communicators the possibility to gather substantial amounts of information about those who receive their communications - if they have the motivation and the necessary skills and resources to track them (Froomkin 2000, Garfinkel 2000). Despite this, however, this study suggests, as Donald indicated above, most weblog owners experience the internet as a space of potential anonymity rather than a panopticon and therefore envisage it as $\operatorname{such}^{27}$.

Free web log analysis tools ${ }^{28}$ can indicate roughly how many people have accessed a given page and often the country they are accessing from - precisely who accesses a page is not normally knowable, however ${ }^{29}$. Though web log analysis tools are available free of charge through a number of websites, there is only limited evidence that those engaged in these activities use such tools to track the number of visitors who read their pages. Of those who do use these tools it appears few check their results regularly ${ }^{30}$. It is possible that some of those without tracking tools would want them but are not aware that such tools exists or do not know how to make them work. In the case of the 23 interviewees for this study, however, there was little evidence that they were interested in tracking tools. Most interviewees were asked if there were things they would like to be able to do with their weblogs that they had not done, but only two (Betty and Renia) evinced a desire to be able to better identify or track their readers.

Three of the six people interviewed who said they had used tracking tools were unenthusiastic about using them. Charles said at interview that he had stopped looking at his, "I did actually sort of have a hit counter because I was intrigued to see whether anyone was reading and I was you know horrified to find that pretty much nobody was". Nancy, similarly, said, "I think I used to have one but... I don't know... it's not that interesting. It's just numbers." And Frances was hard pressed during her interview to guess how many people viewed the site:

Um... I don't know. I know there are a lot of bloggers who are really crazy about traffic and who really go by what their stats say. It's not something I check all the time but I think that's about... and it goes... looking at it weekly I think maybe there are about... I don't know there must be... I don't know there's about maybe 30.

Harriet, by contrast, said she was "always checking my stats" but said she was doing it less often now because "I don't quite have the same time to doss at work", and Annie was also a regular

\footnotetext{
${ }^{27}$ This finding is also echoed by a number of researchers focused on the ethics of online research - see (Ess and AoIR ethics working committee 2002 p. 7, Waskul 1996).

${ }^{28}$ This use of the term 'web log' is separate from 'weblog' as used elsewhere in this thesis and refers to the files all web servers generate tracking the number of visitors to a site, which pages are viewed and other data.

${ }^{29}$ Greater precision is achieved on many commercial websites with the use of registration and 'cookies' but these techniques would be beyond the capabilities of typical weblog producers. As outlined below one interviewee - Donald did identify an "anonymous" commenter but he was unusually knowledgeable, having experience in Internet marketing, and he already had some idea of who the commenter might be, which their IP address confirmed.

${ }^{30}$ A US survey found that nearly half of webloggers surveyed have no idea how many people read their sites(Lenhart and Fox 2006 p. 18). The survey of personal webloggers based in London done prior to interviewing $(\mathrm{N}=150)$ by the author found only a third of them said they used traffic analysis tools and a third of these said they checked their traffic monthly or less often.
} 
user of such tools. Betty's web logging software is basic but she said, "I'd love to have a tracker that told me everything about everybody. Because I'm really nosey. It just fascinates me”. She said she would not be willing to pay $\$ 6$ a month to the web logging software company to have more detailed information though, and for most of those interviewed the audience data when it is sought at all remains, in Nancy's words, "just numbers".

This is not to say that the other sampled bloggers were entirely unaware of how many people were reading their weblogs or who they might have been. They were aware of many real and potential readers - those who they had spoken to about their weblogs and those who commented about what they had written (either using the weblog's comment facility or directly). But they generally did not and could not know when or if specific people read the site without commenting, and without using tracking tools they would not know how many people read it either. Needless to say they also had no idea how what they had written had been received unless the readers chose to tell them.

A few of the bloggers that were interviewed - Annie, Donald and Harriet - did use or contemplate using their internet skills and available tools to track individual readers as well as aggregate numbers. Of these only Annie (who has now ceased blogging) could have been described as a committed user, even though she does not have a technical background. She did not just count the number of visitors she gets, daily, she also looked at "where they are coming from and I can break it down and see how much time they are spending and what keywords they use to find my site and stuff." 31 She used the information available in an attempt to find whether the people who visit her site have weblogs themselves, "just because it's interesting".

While Donald did not track his user numbers - "I wouldn't ever bother with that" - he did use his understanding of internet tracking once because a friend posted a comment anonymously that angered him and he traced the anonymous comment back to its source. In this case it seems to have been done as much as a display of expertise as anything, however. "He seriously didn't realise that he could be traced through the internet which is quite funny. I just sat at work and traced his IP." In Harriet's case she said she tracks the number of readers she has daily, but she worked in technology-related advertising and might therefore have come to see the use of reader monitoring tools as normal, even though she was not exploiting this information for commercial gain. She did threaten to track down specific readers but only after they had written a number of offensive and abusive comments on her site.

\footnotetext{
${ }^{31}$ Though she estimated she had 250-1000 weekly readers while her public site statistics indicate a number closer to 100 .
} 
I said 'you know what - I have IP addresses for you guys. If you guys keep on continuing I can get it traced and you people will be... He said 'oh you can't take threats from us..' funny enough this guy who I know as well from the blog he said 'I'm going to speak to a friend of mine'. And it all stopped.

The lack of 'hard' information about their readers did not appear to worry most of the bloggers, even those who acknowledged that they could face embarrassment or worse if some of what they wrote was read by the "wrong" people. While some of the bloggers expressed concern about this potential harm - and those who did normally said they took care not to reveal material that could harm them - there is a strong tendency (as will be discussed further below) for bloggers to concentrate attention on the readers they do know about (the ones who comment, for example who tend to comment sympathetically) and to ignore the rest. Frances, for example, was asked about those readers who found her by accident:

Whether there's 50 of them or 500 of them is neither here nor there for you?

No I'm pretty nonplussed. There could be 500 people reading for all I know but they don't comment. Lurkers that's what we call them.

There was little evidence in their blogs or interview testimony of direct appeals to the readers to identify themselves or state why they were reading or what they felt about the blogger him or herself, though some bloggers asked their readers for help on a factual matter, for advice on what they should do in a given situation, or for feedback on the quality of their writing itself (see Section 5.3.3).

This apparent absence of concern about the audience is to some extent an artefact of the sampling method used to find interviewees - those who were seriously concerned about their potential audience and took care to control who might read them by managing the privacy settings for their weblog to exclude the uninvited would have been excluded from the sample for this research. However, there is evidence from media reports and from bloggers' own testimony that this lack of interest in readers who are not intended is commonplace - and can result in harm to some bloggers. The examples most often cited in the media appear to centre around bloggers who lost their jobs because what they said on their blogs was of concern to their employers (Armstrong 2002, BBC News Online 2004, Hanscom 2003, Leiby 2004, Pollitt 2005). The potential consequences of a failure to consider who the audience may be will be examined in more detail in Chapter 9. The bloggers' perceptions of their practices with respect to intended and unintended audiences serve to focus our attention on the imagined space of interaction and provide a rationale for further examination of how bloggers experience that space and the extent to which they might perceive themselves as being protected by anonymity.

The mixed picture of concern and lack of concern about unknown readers accessing the interviewees' weblogs could be attributable to a perception by the authors that their identities would 
not be discernable, thus insulating them from any non-virtual repercussions of what they wrote. However, the interviews suggest this was not always the case. Although 14 of the 23 interviewees used some form of pseudonym instead of their names on their weblogs, of these eight were more or less easily associable with their owners by the reader without any further contextual information ${ }^{32}$. In addition, the degree of self-revelation evinced in the weblogs of the interviewees for this study themselves did not appear to bear any strong relation to the degree of perceived or desired anonymity. Two of the bloggers most open about their personal lives in their weblogs were also open about their identities - Annie gave her name and profession in order to promote her business, and Frances gave her (unusual) first name and (small) country of origin on her weblog.

\subsubsection{How do bloggers picture their readers?}

The ways in which bloggers report their perception of their readers suggests a departure from the assertions of many of those who have studied home page, weblog and SNS profile authors, though it is consistent with some of the research on "conventional" communicators like authors, journalists and television producers as discussed in Section 2.6.

One of the interviewees referred to a 'slight form of insanity'.

I put things on my blog but I don't think of anybody reading it. Someone will say, "what the hell did you write that for?" and I'll say "oh yeah - sorry". I just don't put two and two together - it's a slight form of insanity I suppose. - Elaine (who had hundreds of readers a week)

However much or little the bloggers interviewed actually reported that they know about their readers, it appeared that when they are writing their imagined communicative space is seldom primarily constructed based on that knowledge. Most often they imagine themselves to be writing in a safe space occupied by well-disposed readers (whether strangers or close friends or a mixture). As Lenhart remarked in her blogger study, "Even with all the other sources of information, there are still audience members not captured or unknown, and the blogger fills in these 'real' or 'hoped for' readers through his or her imagination." (Lenhart 2006 p. 83) (see Section 2.4 and 2.6 for more on the presumed reactions of readers in other studies).

The presumption of sympathy is clear in Colin's reflections on why he moved from writing a private diary to writing a weblog:

mainly because there was nobody to read it [the diary]. There was no one to say, "hey that's really good." Um, just very difficult question to answer. It suddenly became an attractive proposition. "Wow, I'm writing my diary. People are reading the bits I want them to read..." And I think in some cases they know what I feel. This is very nice.

Donald likewise referred to his readers as "like-minded people".

\footnotetext{
${ }^{32}$ It is difficult to be clear about how identifiable a weblogger might be from their weblog postings without knowing about what others might already know about them in other contexts - a mention of a seemingly commonplace detail could reveal a blogger's identity to a person familiar with that detail.
} 
In order to be able to write about things and not get into pointless arguments about them ... Having the journal I thought 'I'll be linked to people I know - friends - and it'll be a much easier space to have discussions'.

A few echoed Elaine (above) in saying they felt initially as if they had no readers at all, though unlike her they said this perception changed as they began to receive comments:

"It started as a diary. [...] it very quickly became, "I'm writing a diary but people are reading it." The moment you start to have comments on it, it actually shifts - or for me it shifted the way that I approached it. Suddenly I'm not writing something for me to read." - Colin

"When I first started I think I was writing it to myself" - Isobel

Others recognized that they must have readers but appeared to find it difficult to admit to themselves:

There was the idea that one day it might be found... with blogs you seem to get... you seem to be online on a different format and there's always the possibility that someone was reading it. - George (emphasis mine)

I won't permit myself to think 'oh yeah there will be thousands of people reading my blog' it just seems a bit self-important to think that really. Why would they read my blog when they can go and read the BBC News website instead? - Elaine

This is in marked contrast to the results from Kendall's interviews with LiveJournal users, who, "were conscious of their use of the filtering feature of LiveJournal to manage their appearance to different elements of their blended audiences. For instance, many were careful to keep their personal and work lives separate." (Kendall 2007). To some extent this may be a sampling issue those who maintained highly-filtered LiveJournals would not have been included in the sample for this research - but may also reflect the nature of Kendall's snowball sample of mostly "savvy computer users" which as she acknowledged "do not represent typical LiveJournal users" and which she interviewed in 2003, early in blogging's development. More experienced weblog users or more experienced internet users in general may be more aware of the likely readership of what they post. Linda, for example, remarked:

They [her more experienced friends] were more aware than I was that other people can just click on [her journal] and see it. I still don't understand how the internet works so I have the idea that 'oh I'm just writing this to you guys so only you guys will get that'.

LiveJournal in its description of what their service is for reinforces the notion that LiveJournal readers are people like the author. It says you can "easily connect with others like you" and "share with friends" (LiveJournal n.d.-b). It is true that because of its sophisticated filtering tools, LiveJournal users may be more able than most to restrict their audiences to people like themselves, but by default these filtering tools are switched off, and it is not clear how many people use them, or to what extent.

The perceived safe space that enables those interviewed in this study to write freely is often maintained in the face of experiences that one might expect to challenge that perception. For example, Annie, Elaine and George, in particular, were all aware that what they wrote may be read by a large audience but when interviewed they reported that they acted as if their audience is small 
- or even non-existent. Annie, as remarked earlier, claimed to check her site statistics daily and according to these she was getting around 100 visitors a week - at least a third of them new. Yet when asked whom she visualised when writing she said, "I usually write it for my friends, and I write it for myself." Elaine created a weblog initially just to show how to do one for an article she wrote (in a magazine aimed at tens of thousands of internet users), but said, "I didn't expect anyone to read it you see - it was just a means to an end" - an attitude that persisted even though she used site tracking tools and indicated that she gets 250-1000 readers a week. George was fired from his job because of his weblog, but did not appear to believe his employers could really have found it:

"My social life was very fortunately separate from my working life. There was not much chance of work discovering it really I think. The official line is that a client typed their name into Google and my thing popped up. I don't know."

These are just a few of the most extreme examples of what appears to be a consistency in the interview data, however. One of the most consistent results from the interviews is that whether bloggers wanted to be read only by strangers, only by their friends and family or by a mixture, they perceived their readership as being generally supportive and made up of the kind of people for whom they were intending to write, consistent with some early qualitative blogging research (see Section 2.4). George, whose blog contained remarks which subsequently led to his dismissal, remarked that in his previous writing (for a music zine) "people used to always really like it and they used to compliment my writing" and said "most people seemed to like" his blog as well. Harriet suggested that her audience were "people who buy into my ethos and values", and Donald spoke of his internet use as a way to find "like minded people". Conversely, they appeared to assume that people who did not like them or their blog would not find it or bother to read it. As Annie put it, "I wouldn't go and spend time on blogs I don't like - so if they don't like my blog they don't have to spend time there", though in fact she subsequently closed her blog after being "stalked" through it.

Moreover, there is some evidence that if the desired audience changed, the perception of the audience would change to match it. At first Charles reported that he used his weblog for political postings, then he used it to allow friends and acquaintances to keep up with his life and feelings while abroad. When he returned, the purpose of the blog changed again, becoming less personal. As he puts it,

I felt like what I was doing in America was pretty much honesty about my emotional states without any particular sort of editing - except the general that you do when you're emailing a bunch of friends some of whom you haven't seen for a long time. It wasn't pouring my heart out but I was fairly sort of honest. Whereas I think when I am doing the political stuff and more generally when I am just doing 'here is a [post?], here's a this here's a that' it's a bit more of sort of a public face if you know what I mean. 
He refers here to the need for levels of disclosure to be appropriate to the intended communication recipients but the changing context in this case appears to be subjective - as his motivations for writing changed so too did his reported imagined readership.

Justifications were frequently given by the interviewees for their differing views of their likely readers and, since the desired audiences for these sites are different, the accounts of who would be likely to read the blogs and why also differ, often being diametrically opposite. For example, George, whose personal revelations led to the loss of his job said, “blogs don't register much on Google do they? ... on the whole it's proper websites". Harriet similarly had problems in the past with personal revelations on her blog and said at one point in the interview that she felt nobody read it. However, towards the end of the interview when she was explaining that she saw her blog as a potential tool for self-promotion, "because Google now owns Blogger all the blogspot.com domains Google likes them so they get... so it's easy for people to find you." In other words, it is possible Harriet thought Google helped one to be found because she wanted to be found while George, who wanted not to be found, assumed that Google tended to avoid weblogs.

What is important to note here is not whether these interviewees were right or wrong about Google's interest in weblogs - in fact Google's search preferences are a closely-guarded trade secret - but that each blogger appeared to interpret whether he or she would be found in the way that was most convenient to their prevailing vision of their communicative space.

The apparent range of interpretive flexibility indicated by these self-reports may be related to the very novelty of weblog writing and reading. At the time of writing in 2009 little is known about what kind of people read weblogs or how they find them and the numbers and proportions are in any case changing rapidly as the technology diffuses. Moreover, weblogging itself may not be a common topic of conversation among participants and their peers - several of the interviewees appeared to see the practice as embarrassing and therefore conceal it from their friends (Section 6.4.4). On balance, most of the interviewees for this study appeared to assume that nobody they did not know would be likely to read their blogs unless they had set up their blogs expressly to reach unknown others.

It appears that in overlooking or purposely ignoring the possibility that what they write will be read by those they are not addressing, they may be attempting to maintain an imagined informational or conversational preserve, in Goffman's terms (see Section 3.2.3).

As I will argue in Section 6.3.1, the experience of blogging itself may obscure what is 'actually occurring' in terms of communication for the blogger - at least during the blogging process itself. This obscurity or ambiguity may enable bloggers to characterise their experience in 
their own minds in the way that is most comfortable for them. The next section turns to a consideration of what bloggers may be seeking in terms of a relational communicative space.

\subsection{WHAT RELATIONSHIP TO THEIR READERS DO BLOGGERS SEEK?}

Studies of the relationship between communicators and the recipients of their messages have focused on three broad contexts - 'one-to-one' (dialogic), 'one-to-many' (broadcast) and, most recently, 'many-to-many', which has also been dubbed telelogic communication (see Chapter 3 for a discussion). The case of personal weblogging is particularly illustrative of the manner in which drawing boundaries between different communicative modes has become increasingly difficult. This study reveals that the personal weblog can be used in all three of these modes - and sometimes (as elaborated in Chapter 7) the same author uses or envisages their weblog in different ways at different times. In this section, I argue that the use of personal weblogs varies and is therefore not easily reducible to just one of the three modes of inter-subjective communication envisaged in the literature. In addition there is a significant number of interviewees whose practice appeared to be primarily intra-subjective or, as I have termed it, 'self-directed'.

Although on the internet the pure "broadcast" of messages is possible (from a website that does not provide an email address for its creators for example), in practice, the opportunity for the web page reader to respond is very often available ${ }^{33}$. As discussed in Chapter 3, weblog studies frequently see dialogue or telelogic communication as an essential characteristic of blogging practice. However, the results of the present study call this assumption into question. The analysis of the interview data in this section suggests the need to give greater emphasis to the importance of individual and social expectations as well as to the technological features that shape actual use.

The analysis of the interviews conducted for this study suggests firstly that a range of orientations of personal bloggers towards their readers exists, and secondly that the individual bloggers interviewed did not always have a single orientation to their readers which remained consistent over time.

The bloggers interviewed for this study sometimes reported that they used the technology as if it were a dialogic technology through which they addressed specific others and expected a response, sometimes that they used it as if it were a narrowcast ${ }^{34}$ technology - normally also addressing a

\footnotetext{
${ }^{33}$ Certainly this is the case with weblogs now which almost universally have comment facilities, activated by default though it was only in May 2004 that Blogger - one of the largest services - provided its users with this facility on their blogs (Google 2004). With most weblog software (including all Blogger and LiveJournal sites) it is possible to 'turn off' comments - and several of the most popular weblogs do not permit comments due to the size of their readership but according to one survey $80 \%$ of weblogs allow public comments to be posted to them (Mishne and Glance 2006). All of those interviewed allowed comments on their sites.

${ }^{34}$ While the term "monologue" suggests itself for unidirectional communication and would be consistent with the framework used by Thompson which is being adopted and extended here, it can have the implication (as in theatrical
} 
specific imagined audience but not expecting a response, and sometimes (though more rarely) that they used it in a 'telelogic' way as a means of reaching others not previously known to them. In addition, sometimes the bloggers I have termed 'self-directed' indicated or revealed that they used their weblogs with no clear communicative intent at all.

As indicated in Section 5.2 the way in which the bloggers interviewed regarded their relationship with their readers frequently bore little relation to what the technology they were using in each case enabled. In particular, in many cases, webloggers reported that they wrote either for a group of known individuals or for a specific kind of reader and in some cases reported that they were indifferent to or even hostile to other readers. They appeared to be writing in this case as if the unwanted readers did not exist even though they either had no way of restricting access or did not use the tools available to restrict access to those audiences ${ }^{35}$.

The four main orientations towards the audience that were revealed as a result of the analysis of the interview data are outlined in Table 5.1 below $^{36}$.

\begin{tabular}{|l|l|l|}
\hline $\begin{array}{l}\text { Character of intended audiencel } \\
\text { Anticipated direction of interaction } \\
\text { flow }\end{array}$ & One way & Two way \\
\hline Friends (specific) & Narrowcast & Dialogic \\
\hline Strangers (indefinite) & Self-directed & Telelogic \\
\hline
\end{tabular}

\section{Table 5.1 Forms of intended weblog interaction}

These orientations help to visualise the variety of framings of blogging practice. However, it is important to note that the webloggers interviewed sometimes expressed motivations to write and attitudes towards their readers that varied throughout the interview and at different points in the evolution of their practice. The importance of change over time in the analysis of blogging practice is discussed in Chapter 7 and Section 8.5. In the most extreme example of this, one weblogger, Elaine, said she started her weblog with no desire to reach an audience at all and apparently with no conception that she was reaching one. When she could no longer ignore that she was reaching an audience she described her attitude changing - she revealed her real name on the blog for example

use) that the speaker has no intention of being heard by others. This could cause confusion with the 'self-directed' blogging uses that are analysed separately. For predominantly one way communication I use the term 'narrowcast' rather than 'broadcast' to suggest the intended scale of communication, as none of those interviewed had or believed themselves to have an audience large enough to be in contention with conventional media broadcasters, though some suggest that the most popular weblogs are beginning to approach that scale. The weblog of Chinese actress Xu Jinglei, for example, appeared at one point to be linked to by bloggers more often than the LA Times or Reuters were. (Sifry 2006)

${ }^{35}$ As noted in Chapter 4, the sampling method excluded LiveJournal users who employed the privacy-protecting tools available to control access to personal postings. This behaviour may not be typical of LiveJournal users more broadly.

${ }^{36}$ An extension of Thompson's typology of mediated interaction that was discussed in Section 3.3.2 
so she could capitalise on her newfound popularity. Yet despite this shift she confessed elsewhere in the interview that she often had difficulty remembering that she is not writing the blog just for herself.

\subsection{1 'Narrowcast' weblogging}

I listen to what people have to say and I welcome it and draw it in but I kind of filter it back out to suit my own thing because I think if you've got - at the moment on average - about 15 or 20 comments on a post if I take in every single thing and take every single comment to heart I wouldn't know my arse from my elbow. - Harriet

For the largest proportion of those interviewed, their weblogs were primarily a way in which they could stay in touch with friends and acquaintances, but this does not itself make their weblog practice dialogic. For five of 23 interviewees it appears the key benefit of the weblog was to let others know how they were and what they were doing or even to impress others, rather than to maintain relationships through a reciprocal exchange of everyday information and opinion.

Many respondents maintain - in interviews (nine of 23) and in the survey of personal bloggers conducted at the outset of this study - that the comments they received (whether through email or on the sites themselves) were important to them ${ }^{37}$. This result may be a reflection of the fact that the importance of interactivity on the internet and on weblogs in particular, has been stressed in many media depictions of weblogging in the UK press and by leading webloggers such as Rebecca Blood and Meg Hourihan (Blood 2000, Hourihan 2002) ${ }^{38}$. On closer examination, however, there is a division between those for whom comments are reported to be a necessary part of their practice and those for whom they may be welcome, but are of peripheral interest.

When those characterised here as 'narrowcasting' bloggers wrote about their personal lives they often appeared to be doing so not in order to convey useful or even interesting information but as a form of phatic communication concerned with keeping friends up to date. It was clear from the interviews that this could be rewarding even when there is little or no actual response as long as a favourable reaction can be imagined. For example as Charles said, "I was quite happy if someone who just met me very briefly in the pub typed me into Google to find out more about me".

Charles provides the clearest example of the importance of this imagined interaction. His weblog (in its earlier stages) began as a space for political discussion but the use he stressed in the interview was as a replacement for an emailed bulletin to friends about an extended stay in the United States. In discussing the motivation to move from an email to a weblog form, Charles explains, "I knew I was going to be sending long, complicated emails home explaining what fun I

\footnotetext{
${ }^{37}$ I stress online comments because interviewees seldom mentioned speaking on the phone or face to face with their peers about particular blog entries.

${ }^{38}$ This also appears to be considered central to blogging practice or even normative by several blog scholars - see Section 3.3.2.
} 
was having, and I was going to send these to a fairly broad list of people but people's email addresses change, people you know don't check them, delete them, blah blah blah." In other words by adopting the weblog form he seemed to believe that he could address a broad imagined circle of friends, acquaintances and people he had met - even if he did not have their email addresses. And, crucially, while email is 'pushed' to people, some of whom may be indifferent to it or ignore it, he appeared to be able to envisage an audience for his activities, all of whom he presumed would be interested because they had elected to read it. Instead of a circumscribed imagined readership of specified individuals some of whom he could imagine rejecting his messages, the weblog appeared to provide Charles with a much broader audience of interested people (including people he did not know would be interested and therefore who he would not bother by sending them an email). He said he saw the weblog as something for "the people on the very sort of edges of your life who drift in and out. I thought it would be useful for them because I wasn't emailing them."

Given the marginal nature of acquaintance he appeared to be assuming, it is not surprising that he reported that he found it "quite a one-sided process. My readers just tend to read and apart from an email saying 'oh that's interesting - how are you?'... it might just start a personal conversation but even then it won't be particularly about what I've said." He said in any case "the idea of a long conversation [on the weblog] doesn't interest me" - at least in part because he said that he found computer mediated communication "very time consuming."

Four of the 23 interviewees suggested their weblogs were, to a significant extent, spaces for boasting. Here, too, an imagined audience appears to be necessary but dialogue is not, as long as the writer can assume a favourable or impressed reaction. Nancy for example, who was just leaving school (sixth form college), was forthcoming about her intent to impress. She remarked about her blog, "I think it's mostly to get people to think that I have an interesting life but - not feel jealousy obviously - but to think 'wow that's cool' and 'she's doing fun things'." As well as wanting to impress her friends she reported that she would like to impress some of her readers who live in "tiny little towns" in the Midwest - "I do play up the way that I am lucky like 'oh my God I live in London and it's so cool!'” In her case and that of Charles above their 'narrowcast' sociality also appeared to shade into what will be discussed in Section 5.3.4 as 'quasi-sociality' - a pseudoconversation - often merely phatic in character - with a group of others who are largely unknown.

Even among those who seemed to be trying to impress, however, contradictory motivations for blogging seemed to undercut their impression management as when boasting seemed to yield to 
a form of confession ${ }^{39}$. Annie, for example, spoke of how what she wrote is intended in part for both her (then-estranged) husband, his girlfriend and ex-boyfriends, "I have a good life so... I just want them to know that I've moved on, that I'm keeping on, that I'm not in the gutter somewhere". On the other hand, she reported that she had posted when depressed and though she noted her family has expressed some concern about her drinking as described on the weblog, she continues to talk about it and said "I kind of play towards it." In her case, the desire to tell a good story and to vent her feelings frequently seemed to overcome the impulse to present herself as successful and happy. George's case was similar - "I really took as much enjoyment out of anything as putting my flaws down onto the page - writing them out".

Another form of narrowcast weblogging appeared to be more concerned with expressing views. The sample excluded interviewees whose weblogs were solely or primarily about politics because of the emphasis in this research on those writing weblogs containing personal content (Section 4.4.1). However, three of the men interviewed produced personal weblogs with some political content. For the most part, however, they did not correspond to the ideal 'telelogic' form of the political weblog - one that is intended to spur and react to political debate in an open, unbounded public arena (Section 2.4). Instead, these three interviewees used their sites to state their views - reader response appeared to be important only when it served to clarify or reinforce those views. Charles, for example, admitted that his weblog was to an extent a substitute for political discussion:

"I did have more of a political network and I shed it because it was hard work because they kept expecting me to go to protests and demonstrations and running meetings and blah blah blah. And I think partly it does function as a substitute. It gives me a way to feel that I am promoting these causes that I believe in without the responsibility of entering into dialogue with people."

He said that rather than a political weblog, his was, in part, a campaigning weblog - "urging this imaginary audience - or not so imaginary - to do these things" and he reported that he was “restricting it to issues where there doesn't seem to be much of a question, like I don't know anyone who really actively opposes the 'Make Poverty History' campaign.” Charles had a history of political activism in his student days but he did not produce a political weblog in a committed way because, "I didn't think anyone was reading it and someone was always doing it better somewhere else... setting up something that was dedicated to my political opinion would always seem a bit geeky and a bit sort of arrogant." (see Section 6.4.4).

Bruce reported that he deliberately started his blog in part in order to have political discussions in a controlled environment (Section 6.2). Initially, he justified this as a desire to avoid

\footnotetext{
${ }^{39}$ Not in this case performed in order to help self-understanding or to yield absolution but as a form of inverted boasting or attention getting - 'look how messed up I am'.
} 
“people coming on and 'trolling' or deliberately trying to start arguments - making personal comments all the time" but as he admitted later, "my political stuff tends to be fairly declamatory". He went on to say that he finds satisfaction in finding people who are "of a similar mindset... who can see what you mean and you don't feel so alone in your views." In other words, consistent with the observations of those sceptical about the internet's place as a forum for public debate (Chin 1997, Gitlin 1998, Sunstein 2007), both these interviewees seem to be seeking to addressing only those who already agree with them on the issues at hand.

Of those interviewed, three of 23 - Adam, Elaine and Quentin - saw their weblogs as acting as a conventional media outlet like newspaper or magazine columns. Elaine and Quentin are both media professionals, which may have influenced their framing. Despite alluding to the interactive possibilities the technology offers, they appeared to have a distanced, indifferent attitude towards their readers. Readers were, of course, necessary according to these interviewees. Interactions with them were often characterised early in the interviews as being important but as the discussion progressed it seemed more apparent that they viewed the readers in an instrumental way and saw their response as essentially secondary to (and sometimes potentially a threat to) their own artistic or professional objectives. These views are strikingly similar to the attitudes of those reported in studies of mass media journalistic production (Section 2.6).

Phillippa, an artist, expresses a tension between an openness to feedback and a desire for artistic autonomy. Early in her interview she said:

it's good to have other people's opinions. I mean in the end you have to sit down and think what you want to do as with anything. But working solitarily in the studio having somebody else look at something - even if it's online - and just go 'oh have you thought of this?' or 'have you seen such and such' - that can be good - that can be a really good thing.

Nonetheless she strongly stresses that she accepts this feedback on her own terms:

If you are struggling with a piece of work and you want to know which way to go with it would you ask your audience?

Um.... I haven't really thought about it in that sense ... if somebody responds then that's great - if they don't it's really up to me to sort it out anyway so I'm not really looking for an answer if you see what I mean.

So there's more of an expression of the question rather than really "tell me what to do".

Yeah exactly - I mean I think I have to tell myself what to do and it has to come from me really. Obviously you get input from all kinds of different things - from the media or from walking around seeing things or talking to people or just any experience in your daily life but in the end the work has to be generated from me otherwise what's the point?

Likewise for Kevin, a writer, his weblog was strictly promotional:

I guess I went to LiveJournal because it was actually an easier tool for me to do the regular updates and to keep track of things rather than fiddling with my own web pages and adding to it and it's all there and the tools are easy and it's presentable and it's a nice easy way to do it. Because it has a far more public presence than actually going into and searching a website I think it's more useful to me in terms of public presence. Is that against the grain of how it's intended to be used? I don't know. It's a networking tool... 
It contains fairly frequent discussion of 'personal' issues and in many ways resembles weblogs used to connect people to their friends but, in this case, the implied invitation to interaction was actually seen by Kevin as a burden:

I don't actually expect responses on LiveJournal. If I do get responses it's often a chore. Because then I feel the need to - I have to actually acknowledge that somebody has actually responded to the post and make the appropriate comment which is again another time sink.

Similarly, he "scans" the people he has "friended" and while he reported that he sometimes posts on other people's journals (consistent with the interactive expectations of the LiveJournal 'community'), he saw this activity as a "combination" of supportiveness and the need to be seen as a member of an online community around his literary genre, suggesting that he sometimes posted when he felt "it would be a good thing to have my presence in this particular discussion". As he put it, "I'm here, I'm still around, and don't forget me." In some respects this use resembles the 'narrowcasting' mode of weblogging for keeping friends in touch because the readers are perceived to feel themselves to be interacting socially, but in this instance, Kevin saw his audience purely instrumentally. In this sense his weblog can be characterised as a kind of ongoing public relations campaign.

Another instance of the use of a blog in a form akin to a media outlet is provided by Elaine's account. Her relationship with her readership was complex and had changed over time. As noted in the first part of this chapter, early in her blog's existence, she tended to deny that she had a readership altogether. A few weeks before her interview, she was approached by a professional blogger who invited her to write as part of a larger, commercial group weblog. While she says that it was her move from full-time to freelance journalism several months previously that made her see her weblog as "something that I feel I should market... because it's a way of hopefully getting myself some work", she appeared not to have framed the weblog in this way prior to meeting the professional blogger. She reported that she was completely ignorant of how to market a weblog prior to the meeting. In the months since the meeting and since the interview, however, first person references in her weblog gradually ceased and she added her own name to the site for the first time. Postings then petered out, replaced by invitations to visit her new commercial weblog venture. She then stopped blogging and eventually removed her personal weblog altogether although a second one under her name remained whose sole purpose is to act as a promotional page. She says she stopped blogging because of a lack of time though she says she will return to blogging "someday" (see Chapter 7 on the way weblogs change over time).

Although these cases of the use of the weblog are primarily professional, they featured a number of personal disclosures. A number of potential explanations for this revelation in an unexpected context are developed in Section 8.3. 


\subsubsection{Dialogic Weblogging - Keeping in touch with friends}

Those interviewed for this study who appeared to be pursuing this form of weblogging were seeking to interact with those who are reading and appeared to value such interactions as ends in themselves (rather than 'necessary evils' or something to purposely ignore as in the case of narrowcasting bloggers). I distinguish them from those practicing 'telelogic' weblogging (see Section 5.3.3) because these bloggers seemed to be intending to use their sites solely or principally to communicate with a limited number of known others. In contrast I will be using the term 'telelogic' to indicate practices that involve reciprocal communication with online others who were not already known to the writer (see earlier discussion in Section 3.3.2).

The desire to stay in contact with friends was a common reason given by interviewees for having a weblog (five of 23 interviewees), especially for those who had widely dispersed friends and family. For example, Jane's use of her LiveJournal described here is typical of this pattern of behaviour.

The main reason [for my weblog] is for keeping up with a community of friends. Almost everybody who is on my friends list is people that I've actually met. Almost all of them at science fiction conventions. I just find it wonderful to be able to ... I don't have to work to keep up with their lives, they don't have to work to keep up with mine and yet when we run into each other we all know what we've been up to and what the most important things that have been happening in our lives are.

Unlike the 'narrowcasting' communicators in Section 3.1, however, she stressed a desire to interact with her readers: "I like the reciprocal aspect to it. I say something, they comment on it, I know my friends are keeping in touch with me."

Like others, she did not use the features LiveJournal provides to limit access only to the online friends that she specifies. For her and for the others who use their weblogs in this way, attitudes towards unintended readers ranged from indifference to suspicion. As Jane said, "I am not particularly secretive about myself - I'm a bit of a show-off and I'm quite happy for anybody who wants to fall across my LiveJournal to fall across my LiveJournal" but while she "has a lot of friends who do strike up a lot of friendships through online communities" it “just isn't particularly my thing".

Linda had a much more exclusive picture of her circle of readers (almost entirely a group of fellow students from the university she attended in Canada). She says she is "very open" with her site "because it is for people that I trust". The thought of strangers posting comments, even anodyne ones ("that they were happy for you or that they were amused") would make her "a bit weirded out" - "my immediate reaction would not be comfort - it would be like... intruding on my little world." What she was seeking was, "more banter and because I am far away and they all live together for the most part it's just a way of including myself in the conversations." 
Frances was different again. Her weblog began as a way to keep in touch with her family and friends overseas but unlike the other two interviewees she began to receive a wider audience (getting between ten and twenty comments per post at the time of interview according to her). Though her posts are among the most personally revealing of any of those interviewed (including, for example, discussion of sexual encounters) - "I pretty much blog my whole life" - in her case she accepted the attention from those she had not already known. "If I was so concerned about people knowing this sort of thing then I would never have a blog", she said. She nonetheless disavowed any suggestion by the interviewer that she might be seeking a dialogue with people other than those she already knew:

The only comments that I - don't worry about but that I look forward to getting are maybe from the people I know really well in real life like my friends and my family. Partly because it's really rare to see say my sister pop up and comment so when she does it's like 'oh my God'. Those are the people I am more interested in commenting rather than people I don't know.

These reported stances toward a blogger's potential indefinite audience can be contrasted with the third form of blogging - telelogic sociality.

\subsubsection{Telelogic Communication}

There are many ways weblog technology can be used by authors, and as we have seen briefly with respect to the uses of tracking tools, most of them arguably do not take full advantage of the technical features that weblogs offer. Weblogs appear to be precisely suited for allowing authors to reach and to interact with people previously unknown to them - a form of communication that has been dubbed telelogic and is often seen as central to blogging practice (see Section 2.4 and Chapter 3.3.2). It appeared to be the primary motivation for the blogging practices of only four of the 23 interviewees in this study, however. One of the ways in which a telelogic orientation reveals itself is when bloggers actively attempt to 'market' their blogs to readers using online means.

One theme that emerged was that where bloggers sought to gain an online audience they were not seeking to maximise numbers or a valuable demographic as a conventional media outlet might but merely to get 'enough' or the 'right kind' of readers. Simon, for example, entered his weblog onto directories and commented on others' blogs in order to bring readers to his own. As a result, he remarked, 'I've got my weblog listed on about twenty other weblogs. There's not much really. It's enough. But they're quite good weblogs." And Quentin spoke of having a link to his blog from "one sort of famous-ish blogger which provides me with just the right number of readers. Not so many that the comments become things I don't like."

And in considering whether and how to promote their sites, four of the interviewees appeared uncertain about how their blogs should be framed and under what circumstances they felt they should be found. Renia said she'd like to get her blog "high up on the Google rating" and said she 
wanted to "be able to reach out to other people a lot easier" but when asked what it is that she would like people to be looking for when they found her blog she gave her blog's name and the titles of postings as an example, which seems to imply wanting to help people already familiar with her blog find it. Donald had experience in internet marketing, and said, "it would be nice for people to be able to find me or discover me," but added that "I don't want them to be particularly searching for it" and he emphasised that, "I don't want people to discover my blog through a search term that they are looking for something in particular." Likewise, Bruce remarked, "I quite like the aspect that people will find it by accident and that's happened on more than one occasion. So I wouldn't go out of my way to tell people about it necessarily." Charles felt when he was considering marketing his site that that he should label it as political but "I didn't see myself as fit to run a political site so to just advertise it as a personal one seemed a bit counter intuitive somehow."

\section{$\underline{\text { Telelogic sociality }}$}

None of those interviewed reported that they set up their weblog in order to get to know people online they did not already know though some discovered subsequently that interacting socially with, and getting to know, new people was an unanticipated benefit (Section 7.2). Online interactions with strangers do sometimes lead to face to face contact and friendships, but in some cases it appears that what is sought is closer to 'quasi-sociality' (Section 5.3.4). When bloggers have little expectation that they will ever meet their readers and when (as is normal) the comments to what they write are very short ${ }^{40}$, one must consider whether this practice really constitutes discussion or is a novel form of phatic communion with an audience which is indefinite but perceived as intimate. This aspect is taken up again in the analysis (Section 8.3).

\section{Practical telelogic communication}

A few of those interviewed sought feedback from unknown others but for practical, not social, purposes. Those encountered in this study for whom this appeared to be a central framing of their practice were artists or writers who sought to improve their work through feedback. Other interviewees who had other primary motivations, nonetheless, occasionally sought advice about personal issues. Isobel, for example, said:

I really do appreciate people actually giving their feedback on the situation you are in because sometimes it just reiterates what you are thinking and sometimes it is completely the opposite and you have to think 'am I thinking about this wrong or am I going about this the wrong way'

\footnotetext{
${ }^{40}$ No statistical analysis of the interviewees' weblogs was performed but a large-scale survey found the median length of a weblog comment was just 31 words. (Mishne and Glance 2006)
} 
Quentin - a journalist - was one of only three (mostly male) interviewees who expressed a desire to engage in debate with his readers, and was the only one to provide an example of his use of this discussion to examine his own views. This expressed attitude, however, which appears consistent with earlier academic framings of weblogging as a tool for self-exploration (see Section 2.4) must be seen in the overall context of his framing of his weblog in the interview. He stressed the site's use as writing practice, depicting the readers as essentially people to practice on rather than partners in discourse - "you need to be able to manipulate people's emotions if you want to be an artist and writer". His distanced relationship to those who read his weblog resembles that of mainstream media journalists to their audiences as discussed in Section 2.6 (unsurprisingly, since he is a journalist), but is, nevertheless, in some respects the most extreme demonstration of this distanced attitude within the sample of interviewees for this study.

As indicated in Section 2.6, journalists may (in their heart of hearts) write largely for themselves but the literature suggests that this tends to be tempered by a perceived need to serve, please and build a public readership that pays their wages. Quentin abandoned his early hopes that the weblog could be a source of work directly - "if you ask me could someone become famous and get renown and enhance their career as a writer through an online weblog I would probably have to say right now I don't think so. So my aim has changed". For him, therefore, the key was not to grow his audience but to maintain "just the right number of readers" - enough to provide him with feedback but "not so many that the comments become things I don't like." In other words, as he said himself, for him his readership was:

more of an exercise in as wide a range of samples - social samples - as possible if you like. Just.. I'm interested in people's knee-jerk reactions to things I write - people I don't know - and that's... so I've not really thought about it in any other way than that.

Since he had not attracted a mass audience which might directly or indirectly generate an income, and since he did not (to his knowledge) have a readership of people who could commission him to write, he seemed to feel that he was free to use his audience instrumentally - if they were to become alienated he would have nothing to lose.

Donald began a blog and stated it would serve as a place to write short fiction and poetry. Although his blog also contained personal postings which appeared to fit a "quasi-social" framing (see Section 5.3.4), his primary expressed purpose was to get feedback on his writing in order to improve it.

I'd like to get people's comments on my work be it 'you've spelled something wrong, this sentence doesn't make sense.' To me it's about getting better at what I like to do which is to write. It's an exercise for me and I invite people to read, think and comment.

Indeed, on the text of the blog itself he frequently invited readers to comment. Despite the claims of reader-orientation, however, it was also clear that for Donald the audience was as much a 
justification for his practice as it was a genuine communicative partner, as will be also be elaborated in Section 5.3.4 under "expression of creativity".

Renia's case was similar, although she wanted readers to comment on the quality of the writing of her personal posts rather than on explicitly fictional works. Perhaps unsurprisingly, however, she found that commenters tended to comment on the substance of what she posted rather than its style: "they tend to take it more as myself - a life thing... when it comes to writing [the writing itself] I keep asking [for feedback] and they won't say."

In addition to the two forms of telelogic practice identified in this study - telelogic sociality and practical telelogic communication - there are a number of other telelogic weblog practices that have been observed in other studies. These include political activity or sharing of annotated topicspecific links aimed at a wider group than one's friends and acquaintances (Section 2.4). However this kind of activity was not observed among those interviewed for this study.

The final perception of weblogging is one that was not foregrounded in the theoretical discussion in Chapter 3. What is designated here as 'self-directed' weblogging is a form that emerged during the course of the analysis of the interview data.

\subsection{4 'Self-directed' weblogging}

To refer to 'self-directed' practices built around a communication medium may seem counterintuitive initially, but the interviewees revealed a wide variety of motivations to start and to continue weblogging that appeared to have only a tenuous connection to communication processes themselves. The existence of this category should not be taken to imply that there are many bloggers whose blogging takes place entirely without reference to an audience - rather it is meant to indicate one pole of a continuum of audience orientations. As noted at the beginning of Section 5.3, bloggers interviewed spoke of orientations towards their audiences which were sometimes inconsistent and mixed and often changed over time.

This category was not initially foreshadowed by the conceptual framework for this study, and there was little empirical discussion in the literature on weblogging bearing on it, reflecting some of the gaps between disciplinary approaches to the development and consequences of emergent internet-based applications. As discussed in Chapter 3, this study is situated firmly within sociological approaches to the dynamics of internet based mediated communication. In fact, however, the framework for this study appears to be insufficiently robust to account for the 'quasitherapeutic' motivation for blogging, a topic more generally addressed with in the psychology or psychoanalytic literatures. In this section the empirical results are discussed. In Chapter 8 these findings are related to theories drawn from these areas providing a basis for future investigation and 
providing a means of enriching our understanding of the communicative process as both a socially embedded set of practices and a strongly intrasubjective phenomenon.

\section{Quasi-therapy}

Five of the 23 interviewed appeared to be using what they wrote in their personal weblogs as a means to feel better about issues and feelings in their lives - as a form of what Harriet described as 'therapy'. Rather than using the weblog to invite comment or, through writing, to enable selfreflection, their dominant use appeared to be purgative. That is, by writing down thoughts or feelings - particularly those that bothered them - the authors could then put these feelings behind them. It appears that those who practiced this 'quasi-therapy' felt it worked more as a palliative than as a cure for what was troubling them. As George put it, "if someone pissed me off or annoyed me generally if I put it down it didn't annoy me any more."

To the extent the interviewees in this study appeared to be conducting quasi-therapeutic practices, they did not generally appear to be seeking responses to their writing from their readers, whether as judge/confessor or interpreter. Some did say they sought advice - perhaps to legitimate the fact that they were using a communicative medium - but generally it emerged that they tended to disregard it unless it suited them, as seen in this testimony from Harriet:

You've still got to remain true to yourself and follow your gut. Just because you are putting your heart out to people doesn't mean you've got to do as they say. I'm not beholden to my commenters.

In any case, consistent with earlier quantitative studies (Mishne and Glance 2006) comments on the sites of those interviewed tended to be brief and superficial, so it seems unlikely that the bloggers could have gained much insight from them.

This form of blogging practice would seem to be potentially the most problematic in its consequences for those who were motivated by it. Of course there is a long history of people from all walks of life keeping self-reflexive diaries in which they may write about matters that could harm themselves or others if made public, but because this form of practice involves by its nature sharing the most sensitive social information it exposes practitioners to greater risks than other forms of personal blogging.

If the writing itself serves as a quasi-therapeutic process, however, why not simply write a paper diary or keep it on your hard disk? George seems to suggest an answer:

For years I tried to type a journal as opposed to write it - just in Word - but there was something really unfulfilling about it... I guess it's because it wasn't tangible perhaps - it was just on the screen ... whereas with blogs you seem to get... you seem to be online on a different format and there's always the possibility that someone was reading it.

This response suggests that the possibility of readership in the abstract - as with the idea a paper notebook might be read by a vague 'posterity' - prevents the practice from feeling 
meaningless and self-indulgent. The shadowy role for the imagined audience in these cases was complicated by an apparent desire among five of 23 interviewees for a post containing the author's point of view or for the emotional state to be read by specific others - particularly if what they wished to convey was too sensitive for face to face communication. George, for example, said:

You get it off your chest and... I guess there's partly the hope that they would read it and understand what went wrong... I think I did indirectly address things in the hope that they read them and realised more perhaps where I am coming from.

Elaine, similarly, noted that when someone said something that upset her, she didn't respond right away but "I answer in my blog [...] and hide it in a debate about something." The "undirected' nature of the weblog medium appeared to allow them the possibility of imagining that the person desired might read it but without the embarrassment of contacting and confronting them directly and without having to fully acknowledge the desire for them to read it. The possibility that many others including family, friends and work colleagues could also be reading tended to be either downplayed or ignored in this context. For Adam, there was also a hint of embarrassment associated with his blog, given that he saw it as being akin to self-help or quasi-therapeutic activity as indicated in this quotation from the interview.

People become like their blogs, and the way in which that's something I've seen, with a lot of people, it drags them down, when it can be something that you could take advantage of. If you're writing yourself as a character, even if you're being truthful, you're never going to be telling the whole truth. So I do think it's a brilliant opportunity to become more like yourself, almost to fine tune, upgrade, come up with a kind of everevolving version two point whatever of oneself. And - to other people that would sound sort of bizarrely occult - but it can also be understood in terms of the kind of self-help book type stuff almost. Except without having to do anything quite as embarrassing as doing the kind of looking in the mirror and saying, "every day, in every way, I'm getting better.'

\section{Quasi-sociality}

'Quasi-sociality' is a term that has been chosen here to describe the most attenuated possible form of social interaction - that is, communication with people not known to the writer, who the writer does not really want to come to know and from whom only phatic responses are expected or desired (see also Section 8.3.3). This dimension of blogging is exemplified by the following quotations from the interviews:

I think in large part I am just happy as long as I get a response. Ah, I mean, sometimes, if I have written something and no one seems to be commenting on it I will have this terrible moment of (draws in breath sharply) but you know, as long as people are commenting on it I don't tend to mind whether it's "You evil man, how could you say that" or "Oh yes, you are so right about everything." It's, you know, it's ... to be a terrible cliché and quote Wilde, it is better to be talked about than not. - Adam

It's just nice to know that there are people out there paying attention to what you're doing. We're all not alone. - Annie

The internet became a channel through which I could meet like-minded people, have a really good conversation for an hour and then not have to worry if I upset them because I would never meet them again. Donald 
This dimension of blogging practice was not expected, given the central place of interactivity in the rhetoric of internet studies generally (Section 2.4.2), and it emerged as a result of the analysis of the interview data. While as discussed earlier in Section 4.3 many of those interviewed expected to mainly to reach a specific set of others who were known before their blogging started a minority clearly meant their weblogs only to reach online others who they do not already know or who they know only online. Renia, for example, made sure her parents did not read it and "my college friends don't know I have one because I'm scared they might seek it out and they will know all my secrets." Isobel likewise found weblogging embarrassing and as she put it, "my offline friends don't really know anything about it. I don't think I want to go around parading the fact that I have a life online as well because I don't think they would be quite ready for my sad and geeky quiet side.”

As noted earlier, however, a desire to reach unknown readers does not necessarily indicate a desire for telelogic communication - ie a meaningful response from one's readers. Four of the 23 interviewees were not aiming at known readers and either did not evince a desire to get to know their readers or appeared to actively want the readers to keep their distance - for example, Donald (see quotation above) or Renia, who often wrote about her depression and even about suicide attempts, but said she did not look for sympathy as a result. If someone offered that, she would "just say I appreciate it - that's it really. I would not really elaborate on it because I don't want sympathy - I just want someone to chat to - friends really." While she does appear in this quotation to be seeking a relationship with those she was sharing her experiences with, it appeared from an analysis of the interview as a whole that neither the 'chat' nor the 'friendship' that she said she sought were of any depth - certainly she did not appear to seek the kind of serious, in-depth interaction that the intensely personal subject matter of her blog would appear to call for.

These bloggers continued blogging although they were getting little or no feedback and in most cases, they did not discuss any significant interactions with those readers. This implies a form of phatic communication but with an imagined sympathetic audience rather than particular individuals who are already known, which is the way phatic communication is traditionally framed. This suggests a need to broaden our conception of the role of phatic communication as will be elaborated in Chapter 8.

\section{$\underline{\text { Blogging as an end in itself }}$}

As discussed in Chapter 2, studies of weblogging have tended to treat it as a means to an end - whether that end is information exchange, social interaction or self-expression. This is also to some extent the case in the sociologically informed theories of communication processes as 
'interactive' and intersubjective (see conceptual framework in Chapter 3). In several cases, however, blogging as a practice appears to be its own intrinsic reward.

One reason for blogging is the pleasure of mastering and tinkering with a new tool. When Betty started her first blog she said she did "very little" with it except to practice, posting 'Oh look at this, I can write in this blog' and changing around its design. Elaine who was writing about the internet at the time she started her blog said she started it for work, but added:

The sort of person that I am I just throw myself into something - get really really involved. It's great - it gives you a role and something to get your teeth into - so you keep your antennae out for new trends on the web and weblogs was a big trend coming out of the States.

For several of those interviewed, more important than the pleasure of blogging as a means of technical exploration was the pleasure of blogging as a form of writing and expression of creativity - as Harriet's example illustrates.

All the way through Uni I got firsts for anything that involved writing anything... I loved the [assignments] where I was writing - I was obviously in the wrong degree... the blog came along and I thought 'this is a great opportunity for me to actually do more of the writing and find out if I really really do like it'. As it turns out I actually still do. - Harriet

The distinction between those using their sites as a media outlet (see Section 4.3.1) and the practices of Harriet and seven of 23 others in the interview sample is that, for the former group, it was an extension of their working lives with a practical end while, for the latter it was an activity that appeared to be more separate from their working lives - often providing what they considered to be their only means of 'scratching the writing itch' and without much if any reported extrinsic value.

This was also the case for George. He had been keeping a paper journal and in addition to its 'cathartic' value, he said "it also seemed like a very productive process - it seems you had something creative at the end of it". He wished he had studied English or creative writing in further education, observing that "what I've got a lot of heart in - a lot of enthusiasm for is writing". Instead, he came to work in financial services. Bruce, likewise, said "I have always enjoyed writing and have always wanted to do more writing creatively... this is a way of doing it", and Renia, who first went online to find a place to publish her poems, started blogging because:

I liked the thought of publishing your thoughts and ideas and writings. I thought it was a really nice way of writing and seeing the world and also I thought it would be a good way of improving my writing skills as well.

As with the quasi-therapeutic webloggers, they could have written in private, but it appears that the fact that there were or could be readers helped to encourage them to continue. All these interviewees mentioned that they enjoyed being able to hear that they had touched or (more usually) amused or entertained their readers - to this extent the (mere) existence of readers appeared to be important but not central. Those of them who were or wished to be artists were clear that this was not for them a form of collaborative artwork or performance. Consistent with Bourdieu's characterisation of artists' attitudes briefly outlined in Section 2.6, they frequently distanced their 
work from its reception, suggesting that they did not wish to 'play to the crowd' - Donald puts this most clearly:

I would like other people to maybe get something out of it but it's certainly for me - I started it for me. I didn't start it really for anybody else and even saying things like "I want people to read this - I want people to comment" - that's for me - it's selfish in that sense. It's not for any other reason. I don't think you do anything creative in the sense of writing or art or music because you want to make somebody else happy or sad. You hope that it will affect them in a way but you certainly always do it for yourself.

Intriguingly, some of those interviewed were using a diaristic form apparently focused on themselves and their lives and thoughts but felt themselves distinct from the persona which they had brought to life through the written performance of their narrative. With Adam and Quentin this was intentional. Quentin's case has been discussed already in Section 3.3 and is treated as distinct from the others mentioned here because his blog seems to have been produced primarily for practical reasons rather than in order to 'scratch a creative itch', though this distinction appears to be blurred - as Section 6.3.3 establishes he wished to advance his career in order to make a living writing the kind of work he would enjoy (which was the kind he produces on the blog). In the case of Adam this appeared to be the case from the beginning, because of the special circumstances around the creation of his blog, which was started by others as a parody of himself. When he took it over he took over the 'voice' as well, saying, "I thought, well, you know, if there is a version of me that is having more fun, why not become him?" and he spoke of an uneasy relationship with the character he had created through his blog: "it's turned into something between a folk devil and an in-joke and if it, I don't know, it's the truth, but it is not the whole truth."

Elaine, Harriet and Isobel also spoke of developing a persona they perceive as separate to their 'real' selves through their writing but in their cases it appeared to be less an intentional act than an unintentional consequence of the writing process, albeit one with sometimes beneficial consequences.

There is a voice there definitely. It has developed while I have been writing it. It is a lot more sharp than I am naturally. A lot more skeptical than I am naturally. And I am not quite sure where that has come from but it has just evolved as I have been writing the blog... I am much braver on the blog than I am when I am talking to people and I am more eloquent as well. - Elaine

You portray this character and this life - obviously it's a real character and it's a real life - you're almost a caricature of your self - and people find something admirable in it. - Harriet

In some ways she is more my real self than I am in some ways... I can be quite shallow sometimes and she can be quite in depth about things and much more in touch with her feelings and much more confident about herself sometimes so in some ways I don't know I feel like I've got a split personality going on... it's horrible... I think the fact that most of the people that read it don't actually know me properly and they've only - if they've met me - they've only seen me out socially and they don't have any sway on my life at all. They don't know my friends, they don't know my family... in that way it's - it means that I can be much more frank about certain things to them - Isobel

\subsection{CONCLUSION}

The relationship implied between communicators and their audiences as outlined by Goffman in relation to face to face communication and elaborated by Meyrowitz, Thompson and Walther 
(Meyrowitz 1985, Thompson 1995b, Walther 1996) in different mediated contexts (see Section 2.2 and Section 3.2.3 and 3.3) appears to differ in a number of ways from the relationships between blogger and audience found in this study.

It is assumed in the writings above that the reaction of those to whom communication is addressed is both vitally important to interpersonal communicators and broadcasters and (therefore) is continually in their minds when communicating. The kinds of mass market weblogging tools used by those interviewed do not, by default, offer users any means of perceiving who is reading what they have written or what their reactions might be unless those readers choose to reveal themselves by addressing the author. Under these circumstances, my reading of the initial conceptual framework for this study suggested that bloggers would be anxious to gather information about who was reading what they wrote, would solicit comments from their readers to gauge their reactions, would attempt, where possible, to use any technical features available to control who could access what they were writing and would tailor the social communications they made to their potential audiences taking into consideration any remaining uncertainty. The results outlined in Sections 4.1 and 2 suggest by contrast that most bloggers interviewed appeared to assume that reactions to what they wrote would be positive without seeking confirmation (and thereby without risking potentially uncomfortable contradictory evidence).

As noted in Section 3.3.2, weblogs appear best suited to enable telelogic communication and are therefore often framed as vehicles for this form of interaction in the literature. It would not be possible to ascertain without knowing who was reading what the actual nature was of the communication practiced by those interviewed, but it seems most likely that all of those interviewed were technically practicing telelogic communication, since their blogs could be read and responded to by an indefinite audience. However, the imagined and/or desired relationship with the audience revealed by those interviewed was varied. Different interviewees (and at different times) appeared to expect varying amounts of interaction with readers and to envisage specific audiences, indefinite audiences and, more rarely, no audience at all.

The 'self-directed' framings of blogging practice encountered in the fieldwork are particularly noteworthy, as they were not foreshadowed by the conceptual framework, although some qualitative weblog studies have noted these uses (see Section 2.4). These will be further analysed in Chapter 8 .

The next chapter, Chapter 6, broadens the focus of attention from the producer-audience relation of blogging practice to encompass the wider social and technical context surrounding blogging practices. It takes as its starting point the assertion often made both in the literatures surrounding blogging and by the interviewees themselves that personal blogging practices take 
place in a context of freedom from influence and examines why this claim appears to have such widespread appeal. It then provides an account of the influences both potential and actual on personal blogging practices, based on the analysis of interview data and an analysis of known or observable structural social and technological mediating factors. 


\section{Chapter 6: It's $m y$ blog - or is it?}

\subsection{INTRODUCTION}

The personal weblog is often depicted both by observers and those who produce them as a free, unconstrained writing space. Indeed, it appears - at least in the discourse of some influential bloggers and many of the academics who study them - that this freedom is central to weblogging practice and a key benefit for practitioners (see Section 2.4). Some bloggers go further, suggesting that it is not merely possible but necessary that bloggers should use this space to express themselves in ways they would not do in other contexts. For example, one high profile blogger, Tony Pierce insists you must "say exactly what you want to say no matter what it looks like on the screen." (Pierce 2004) Another, Mark Bernstein, said in a similar vein, "Write honestly. Don’t hide, and don't stop short" (Bernstein 2002).

This sense that one should write completely freely and honestly appears to be reflected in the observations of several interviewees for this study, although as will be discussed, some bloggers resisted the pressure to conform to this expectation. The prevalence of personally sensitive information in weblogs as reported in the literature (see Section 2.4.3) also appears to suggest that some webloggers do write as if they were unconstrained by conventional social norms. Nonetheless in this chapter, evidence is presented to suggest that the 23 personal webloggers studied here appeared to be operating within or against a web of both social and technical influences both visible and invisible - in fact the idea that one's weblog should be a space of free expression appears to be itself a form of influence.

The chapter starts in Section 6.2 by revealing the sense that the bloggers interviewed for this study appeared to have that their weblogs are and should be considered to be under their control and they are free to do what they like with them. In Section 6.3 with reference to the experiences of those interviewed I demonstrate the ways in which, notwithstanding the actual and perceived freedoms of weblogging, what is produced can be shown to be constrained or influenced ("biased" in Feenberg's terms) in a variety of ways.

One of the ways in which blogging practice may be influenced is the way that the weblog's persistence through time is managed and presented by blogging software. This is part of a larger discussion about weblogs and their relation to time, however, which relates to a separate subresearch question and is explored in Chapter 7, which follows this one.

\subsection{IT'S MY BLOG}

When probed about influences on what they wrote, six of the 23 interviewed repeatedly disavowed such influences and asserted - often vehemently - that their weblog was theirs - under 
their sole control. In Frances' words, “it's your soap box. And you can paint it whatever colour you like", or as Isobel said, "in the end it's my blog and it's my thoughts and feelings and no one's going to change that." Although all of the bloggers in the sample were writing in a space open to anyone to both read and comment, they frequently asserted they had control over this virtual space - findings that have been replicated in other studies (see Section 2.4).

One of the ways that the companies that run blog hosting services promote their products is by claiming they offer users freedom of expression in a controlled space. For example, the first page of the Blogger's "tour of features" at its home page says, "Your blog is whatever you want it to be. There are millions of them, in all shapes and sizes, and there are no real rules." (Blogger n.d.-b).

There are a variety of technical characteristics of blogging (see Section 6.3.1 below) which also appear to encourage blog users to perceive themselves as being in control. Weblogs belong to their authors because they bring them into being, provide them with a title which may provide a stated purpose or focus to the site, and choose (within technical limitations) how the text and images on the site are presented. Moreover, having brought blogs into being the authors can also edit or delete them in part or in full - taking with them anything that had been written there whether by themselves or by third parties ${ }^{41}$. The weblog owners have technical tools they can use to exercise control over whether readers will be able to comment publicly on what they have written (though all of those interviewed chose to allow anyone to comment). Reader comments are in visual terms always subordinate to what the weblog author posts. By default, comments do not appear on the "front page" of weblogs; only a list of the authors' own postings and a link by each giving the number of comments that have been made appear there. Readers who want to see the comments on an individual story have to click on the "comments" link and the comments that then appear follow only after the weblog owner's writings, and these, therefore, tend to frame any subsequent discussion.

As an example of the subordinate role of commenters, Bruce references the contrast between the control he says he has over his LiveJournal and the lack of control that pertains in online discussions elsewhere when he explained that he started his LiveJournal in order to have a space under his control in which he could discuss political issues. He had discussed such issues in the past but had found that interacting in online political spaces run by others was problematic:

When I've been on bulletin boards you get these people coming on and 'trolling' or deliberately trying to start arguments - making personal comments all the time.

\footnotetext{
${ }^{41}$ The two weblog platforms studied - LiveJournal and Blogger - only give users control over visitors' comments by allowing them to delete them, but other weblog software - WordPress and TypePad for example - allows site owners to edit visitor's comments as well
} 
Not only did the authors of weblogs interviewed for this study say that they felt a sense of ownership and control over their weblogs but they were generally adamant that - since the weblog was theirs - they were and should be free to do exactly what they pleased with it. Harriet, for example, explicitly contrasted the (relative) freedom of expression on her blog with the limitations she felt in everyday social interaction.

It's my blog. And it's about how I feel at this particular time. I can't be all singing all dancing cartwheeling. Sometimes I've got to be down. And I think maybe that's one of the things I learned about myself in the blogging. People even in real life - and it does happen sometimes on the blog - expect you to be all singing all dancing cracking the jokes keeping everybody else upbeat and sometimes I just go 'fuck it I don't want to be'. And I'll say it. At work if I'm not wisecracking and all the rest it's '[name] what's wrong you haven't said that much today?' [...] Sometimes I've written a post and yeah you are thinking this sounds like 'poor me'. But sometimes it's just how I feel and there's no point in me going 'I'm feeling bloody marvellous' when in actual fact I feel absolutely dire so now I just say so. And people relate to that as well. And if they don't well tough shit.

Two of the interviewees went even further, asserting, not just that they should be able to say what they wanted but that they felt that they (and other bloggers) were under pressure to be more open in their weblog writing than is normally permitted in everyday social interaction. This seems to be consistent with the framing of blogging as suggested by Frances, who said "my whole life is on there pretty much":

There are really no rules and you can post whatever the hell you like and because it's your site you don't have to - there are no rules so you can say whatever you like and who gives a shit about what that person over there thinks?

Charles insisted, for example, that while his own weblog writing was "my public face", "true blogging" requires you to write "as if nobody's reading". To the extent this is so, the rhetoric of freedom may paradoxically make some writers feel less free to avoid self-disclosure. Kevin, a writer who wanted to use his LiveJournal for self-promotion, also suggested that he felt under pressure to reveal more than he was comfortable with, both because of the example of a friend of his using their LiveJournal "to express frustration" and because of the way he felt his readers had come to consider themselves to be family:

This network of people is family and these are who I share things with and it has changed the dynamic of the interpersonal relationship I think in a large way. Particularly with its growth. But I'm not sure that I'm comfortable with that dynamic as it stands at the moment.

Five of 23 interviewees mentioned that others whose blogs they read were more open than they would be comfortable being themselves. In Chapter 8 I explore the conflict between these norms of openness that emerged early in the development of blogging and the reaction to this which followed both online and off.

Although as discussed above, these webloggers technically had a great deal of control over what was published on their weblogs by others, it appears they rarely exercised that control. The four interviewees who were asked about whether they had considered editing or removing 
comments tended to suggest that they felt bound to extend to others the freedom of speech that they themselves enjoyed, even when they found comments that had been made on their weblogs objectionable. Annie said, for example, "the only time I took a comment down was when a girl called me fat" and Nancy observed that she would not remove comments she did not like because of her commitment to free speech. Harriet, whose blog received between five and twenty comments on each post, was the only interviewee who made explicit on the blog itself her willingness to remove offensive or abusive comments but even she noted that, "I have left every rude, obnoxious comment on there. I think bar one that was distinctly racist I think." Bruce, who created his LiveJournal, in part, in order to have a space that he felt that he could control, once completely blocked someone who he was having a "massive argument" with from accessing his blog. He added, however, that this was not something he did as a rule and that he did not really like doing it. It is possible that it is the feeling of control that the bloggers have over their site that makes them feel powerful enough not to be threatened by dissenting voices.

This perception of control and autonomy may be further reinforced by the physical context of blogging, which tends to present the practice as taking place between bloggers and their computers rather than between the blogger and tens or even hundreds of readers, as will be further developed towards the end of Section 6.3.1.

In summary, it would appear that blogging is strongly coded as being a space under a blogger's control that therefore enables free expression. Nonetheless, through the interviews conducted and observation of bloggers' practices several influences on blogging practice have been identified.

\subsection{BLOGGING BIASES}

As discussed in Section 2.4 and in Section 6.2 above the personal weblog is frequently described in the media and by bloggers themselves as a space of interaction that is relatively - even radically - unconstrained. Six of the 23 interviewees explicitly described their own weblogs in these terms - at least initially during the interviews. Nevertheless as the interviews continued, several of what Feenberg terms "biases", or influences related to a given technological artefact (Feenberg 2008 p. 23), became apparent (see Section 3.4 for a discussion of Feenberg and the relevance of his work to this study and Section 4.4.3 for more on its operationalization). Indeed, the idea that blogging is an unconstrained practice can itself be viewed as a form of implementation bias. In this section, I discuss these biases as they are reflected or embedded in the technology of blogging itself and in the legal, market, and social framing of blogging practices. This division of the relevant biases follows a structure drawn from Lessig's insights (Lessig 1999, Lessig 2006) into constraints 
on online action which was used to operationalise Feenberg's analysis of biases (see Section 4.4.3). Lessig divides constraints into four modalities, illustrated in Table 6.1 below.

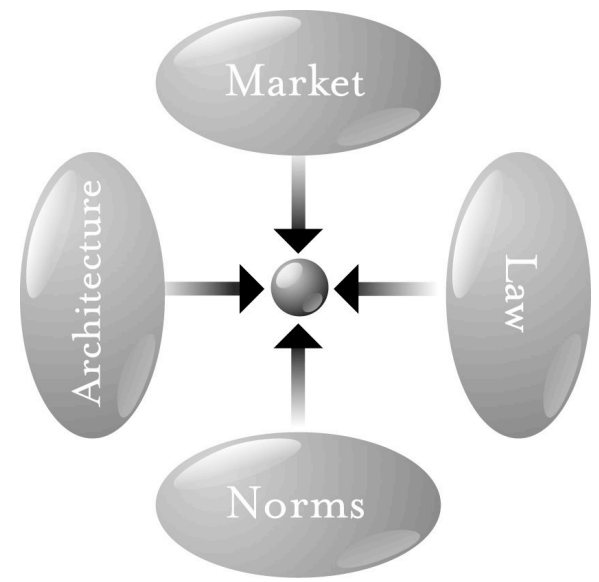

Table 6.1

Constraints on mediated practices reproduced from Lessig (2006 p. 123)

What he refers to as "architecture" in this diagram (and elsewhere also refers to as "code") is what is referred to here and by Feenberg as "constitutive bias" - those biases in behaviour that operate as a direct consequence of the physical design of technological artefacts. The remaining three modalities which will be used below ${ }^{42}$ stem from ways these artefacts have been adopted in particular social contexts and can be seen as three forms of "implementation bias".

\subsubsection{Constitutive bias}

Weblogging is generally characterised by an almost complete absence - for UK users at least - of obvious constraints on what blog owners can write in terms of the technical architectural features that are built into the software used for blogging. By contrast the software underlying other internet discussion fora often automatically rejects postings that contain profanities and may prevent or restrict the use of embedded images or even simple web links ${ }^{43}$. Other web-based communication platforms almost always assume a hierarchical structure where the discussion space is 'owned' by a moderator or host, who can remove (and in many cases edit) any contributor's entries and, if necessary, ban any contributor from that space ${ }^{44}$. The overall design of the web page in which contributors' words are displayed in those contexts is also constrained both by the limitations and characteristics of discussion hosting software itself and by the design choices that any given site's host might make (to the extent the software is customisable). By contrast, weblog software normally

\footnotetext{
${ }^{42}$ Section 6.3.4 "societal bias" corresponds to Lessig's 'norms' in chart 6.1 above.

${ }^{43}$ A typical example is UBB message board software which features a "highly customizable censoring tool" http://www.ubbcentral.com/features.php

${ }^{44}$ Group weblogs with multiple authors can also have this hierarchical structure, though they were excluded from the sample for this study (see Chapter 4).
} 
allows weblog authors to write whatever they like ${ }^{45}$ and gives them control over what others can write - they become (to use the language of software designers) the owner/moderator of their own space (a degree of "ownership" frequently referenced by those interviewed and blogging scholars see Section 6.2 above).

The interfaces of blogging software generally give the blogger wide latitude in defining the desired frame of their blogging practice, starting with the way that such software enables users to loosely classify what it is they are doing. While many earlier services that enabled self-publishing attempted to force users to associate their sites with a particular topic or theme when they created them - see AOL (2008) for example - blogging services do not require this. In the case of LiveJournal, users can associate their profiles (and by inference their associated journals) with 'interests' and can associate their journal with interest-based 'groups' but this is optional and there is space for several to be added. LiveJournal also allows users to 'tag' individual entries by subject but again this is optional and users can have as many tags as they like ${ }^{46}$. In many respects blogging software tends to give organizational primacy to individual posts which are given dates, titles and labels (see also discussion of the technologies of blog reading Appendix A). Thus, enabled by the design choices made by blog services, users of these services are not required to limit the scope of their writing in advance to particular themes, and are also free to change what they are doing with their blogs with each post without explanation (a feature they often took advantage of - see Section 7.2). Tags can be used to present postings by topic, but none of the interviewees took advantage of this and the default presentation of blogs remains reverse chronological.

Bloggers are generally also permitted a great deal of latitude in how their weblog is laid out and displayed. With Blogger one can edit the underlying Hypertext Markup Language (HTML). The extent to which individual bloggers would be able to take advantage of this flexibility depends, however, on their comfort and familiarity with HTML editing. The navigation bar at the top (see image 6.2 below) is also fixed (so readers can always search the archives of a Blogger blog or report offensive content to Google) and if users choose to carry advertising from the parent company, Google, or from other third parties it would have to be displayed in specified ways to earn revenue.

\footnotetext{
45 Although Microsoft has faced criticism for preventing bloggers in China from writing words like "freedom" and “democracy" in postings using its MSN Spaces software (BBC News Online 2005, Dickie 2005) - and, indeed, it appeared to prevent even users elsewhere from using certain profanities in the title of their blog (Jardin 2004).

${ }^{46}$ Blogger now also has this feature though it was not present at the time of the fieldwork (2005).
} 
LiveJournal trades on advanced users' desires to customise their pages, giving increased creative freedom if the user pays or enables LiveJournal to advertise on their pages - but even the least commercial option still provides a degree of creative flexibility ${ }^{47}$

\section{Image 6.2 - Blogger navigation bar from http://peoplereading.blogspot.com/ 17 March} 2008

While the presentation of a weblog's basic elements tends to be flexible, the menu of potential elements and their definition tends to be fixed. This tends to influence in advance the designs considered possible. As noted earlier, the software assumes the central purpose of a blog is the publishing of separate chunks - 'posts' - each of which has a date and (optionally) a 'subject line' attached, and each of which may have comments associated with it. These posts are automatically sorted in date order, with the most recent posting at the top.

The relationship between the bloggers and their readers is also fixed by the software architecture in the sense that - unlike, for example, a wiki where by default all contributors are equal - the comments of readers are generally segregated below what is written by the bloggers themselves and are only visible on the home page to readers who elect to view them ${ }^{48}$. The weblog is in this sense constrained to be an inegalitarian space. The constraints in this case - at least for Blogger users - are not absolute, however, because of their ability to choose to display or not display individual elements and to alter the HTML that controls the layout of the whole page. It is also possible to use weblogging software in ways not anticipated by its designers. Among the interviewees for this study, George was the only person to do this. He wished to produce a number of static pages, each on a different theme, but did not regard himself capable of coding in HTML. He got around this by making each page a different blog, though he was aware that this was counter to the designers' intentions and suggested that the ability he was exploiting for any user to create multiple weblogs "surely won't last".

Users are substantially constrained to work within the technical capabilities offered by the company that hosts their weblog, although thanks to the inter-operability of websites spurred by the 'Web 2.0' movement, it is increasingly possible for more 'web-savvy' users to use third party

47 With LiveJournal if you have chosen their 'free' option and do not choose to carry advertising on their behalf you can choose between 100 layout options. If you do take advertising you can choose between 300 options and if you pay an annual fee of $\$ 19.95$ you can create and use your own custom layout. (LiveJournal n.d.-a).

${ }^{48}$ Those who read blogs using RSS readers are generally not aware of any comments that a post might receive unless they "click through" to see the post on the hosting website (see Appendix A). 
applications to expand the features available ${ }^{49}$. Weblog developers choose the features to implement and despite the continuous addition of features by all major companies, there are still significant differences in what they offer. Most notable at the time that the empirical research for this study was carried out in mid 2005, was the differing levels of control over who can read what is written on a given blog. While LiveJournal users could choose to limit the readership of any given post to registered users they selected ('friends'), Blogger users had no such control available ${ }^{50}$.

This feature of Blogger's software architecture can be understood as a constraint. For instance, in order to reach the readers they wished to reach, the Blogger users interviewed for this study were required to make what they wrote also available to anyone else online. This is not, however, how those who used it experienced this feature. All appeared to take it for granted that blogging entailed openness to any potential reader.

Contrary to expectations, there did not appear to be a substantial difference in attitudes towards privacy between the Blogger users among those interviewed (who had no control over who could read their blogs) and the LiveJournal users (who had access to sophisticated tools for controlling access). However, it may be that this sample of LiveJournal users - chosen because they had a substantial number of public personal posts - was not typical of LiveJournal users as a whole. Unfortunately, no statistics are available to indicate the proportion of LiveJournal sites or postings which are public.

Although as noted above there are few obvious constraints on webloggers' behaviour embedded in the software they use, there are a number of ways in which what they write may be influenced more subtly by the specific architecture of the software.

Weblogs are often described as easy to use - indeed two of those interviewed claimed that they had started weblogs because they felt other means of publishing on the web such as personal home pages were too difficult to use. Nonetheless, there are some weblog features that were not used (or not used as much as the authors would like to) because they were not experienced as easy to understand or to use. Three of the interviewees - including one artist, Phillippa - said they would have liked to have changed the way their weblogs looked but did not know how to do so, and two said they would have wanted to be able to better track their readers.

\footnotetext{
${ }^{49}$ It is possible for users to host weblogs on their own servers or using servers under their control hosted by third parties which offers greater flexibility, but this option requires greater technical sophistication and potential expense and is, therefore, comparatively uncommon. As outlined in Chapter 4, the sample only included users whose sites were hosted by Livejournal or by Blogger, though since they were interviewed in 2005 two bloggers - Tim and Charles - moved their blogs onto their own servers.

${ }^{50}$ Blogger has subsequently implemented optional access control through password protection. While LiveJournal allows users to specify different groups with different levels of access to individual posts, Blogger's access controls are (as of 2008) strictly 'all or nothing' (Blogger 2006).
} 
An author's ability and willingness to use a particular feature was not the only relevant issue in one important respect at least the adoption (or non-adoption) of a feature by potential readers was also apparently relevant. Two interviewees said that while they might have wished to implement some form of restriction over the readership of their weblogs they did not do so because they felt it would exclude those who could not or would not register themselves appropriately to ensure they had access. Charles said, "I can imagine getting to a stage where maybe I would be starting to want to put more personal stuff on it and I actually want it to be less 'any person in the world can look at it' but the problem is that I found things like that or things like MySpace or something never really take off because you can never get the people you need to join them for it to work", and Linda said that while she considered her LiveJournal to be addressed to a small circle of friends she did not use the software's features to secure access "because sometimes there are a few [others] who I do want to see it - if I close it off completely they can't get to it as easily".

The ways in which the specific implementation of weblog authoring software influence what is written can be more subtle and may not always be perceived by the authors themselves. In other contexts, for example, the default settings of software programs have been found to be important in shaping user decision-making ${ }^{51}$. The default privacy setting for LiveJournal entries is 'show this entry to everyone'. Thus if the software required users to choose either to publish a post to all or to a group without a specified default, it is possible that more postings would be private than was the case at the time of the interviews for this study. This is further analysed in Section 8.4. The related implications of these default settings on archived blog postings and on third party indexing of weblog content are discussed in detail in Section 7.3.

The assumed environment of the reader as well as the environment of the weblog writer may be relevant to the way these architectural influences are experienced by webloggers. As discussed in Appendix A, the act of reading weblogs in the 'conventional' way - as web pages one visits periodically using a web browser - is different from reading them through an RSS reader or - if using LiveJournal - as 'friends' journal entries'. In the latter cases, a weblog that is not updated will effectively 'disappear' from its readers' view and may be forgotten, thus effectively encouraging bloggers who are concerned about their readers to update their sites regularly. Only six of 23

\footnotetext{
${ }^{51}$ In one experiment, nearly all subjects $(96.3 \% ; n=134)$ participated when the default action was to participate while if the default was non-participation, fewer than half of subjects participated (Bellman et al. 2001). Defaults have been shown to have important influences on decision making even when the decision is an important one - for example the propensity to donate organs is strongly linked to whether donation is 'opt in' or 'opt out' (Johnson and Goldstein 2003).
} 
interviewees mentioned RSS readers, however. ${ }^{52}$. It is also not clear how many of these interviewees would expect those who are reading their weblogs to be doing so via RSS. One might expect those who are LiveJournal users to feel more pressure to update than Blogger users, because of the 'friend reading' features mentioned above, but the interviewees who expressed feeling such pressure were evenly balanced between those using the two sites.

The typical physical context of blogging discussed in the last part of this section arguably leads to forms of bias that fall somewhere between constitutive and implementation bias. Historically, the communicative modes envisaged by communicators have been strongly linked to the medium they are using or to the communicative situation that they find themselves in (see Chapter 3). If one speaks quietly in an empty room to another person, one does not expect others to know what one says. Conversely, someone addressing a television camera generally expects a wide potential audience. The presence of a television camera does not itself make the eyes of thousands or millions apparent to those appearing on the screen, but even when those televised are not in a studio, there are usually a sufficient number of other cues (additional participants like sound and lighting crew, the necessity to rehearse and possibly repeat what is said) to impart a sense of heightened occasion (and risk) in the production of any televised communication. Of course communicative 'leakage' could always occur - private diaries can be unearthed and published, private utterances can be caught on microphones - but such leakages are generally deemed exceptional and are not normally anticipated (Section 3.2.3). With blogging, however, the communicative context is blurred, both experientially and technologically. In contrast to many communicative situations, the experience of blogging at the moment of posting provides few physical cues about the likely audience that are present in other modes of communication. It may be that without this absence of cues, blogging would be significantly less popular (or more often privacy protected). If typical blogging practices were transposed to an analogous environment offline (perhaps writing a series of notes to your friends while in a pub and leaving them there, permanently), the risks and uncertainties that Goffman suggests we would try to minimise in most interactions would become more apparent.

As remarked upon in some other blogging studies (Section 2.4), the physical experience of posting to a blog - sitting in front of a computer, generally on one's own, and typing onto a screen does not change whether the blogger is writing for him or herself, for friends or for thousands. Each of these possibilities is open for any blog and unless those reading choose to respond or the blogger

\footnotetext{
${ }^{52}$ This was not probed in interviews so the actual number familiar with them could have been higher, but other evidence suggests otherwise - one survey of college students in early 2006 found that over $40 \%$ did not know what an RSS reader was (Hargittai 2006).
} 
chooses to install and use tracking tools, there is no way for the blogger to judge at the moment of production whether he or she is engaging in the online equivalent of writing a diary, conducting a chat in a pub or making an appearance on a televised chat show. As Charles remarked:

because I don't know who the people are who are looking at it and because I can't see them in a way they are not there and in a way it is anonymous and it is just like writing a diary in a bedroom and keeping a lock on it you're not really aware of the fact that people are reading it.

As will be discussed further in Section 8.4, it would be possible for weblog software designers to provide intrusive cues and reminders to users about their potential or actual audiences as they post but they do not do so (see image 6.3 below).

\section{Edit Journal Entries}

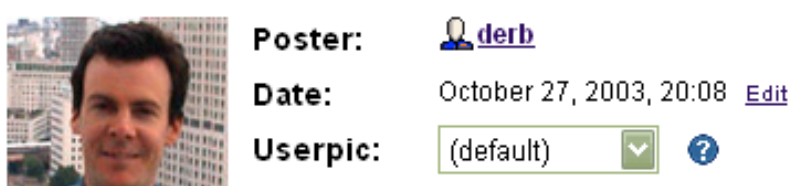

Subject: Where you will find my blogging

\section{More ways to post: Download a Client lim Posting Voice Posting Mobile Posting Create a Poll}

\section{Rich text}

HTML

Is <a href="http://blog.org/">blog.org</a〉 (for more-or-less personal things) and the unofficial <a href="http://groupblog. workasone.net/">Medial LSE Group weblog</a> (for academic reflections). For the moment this is just a way for me to keep up with the private thoughts of some LJ-ing friends...

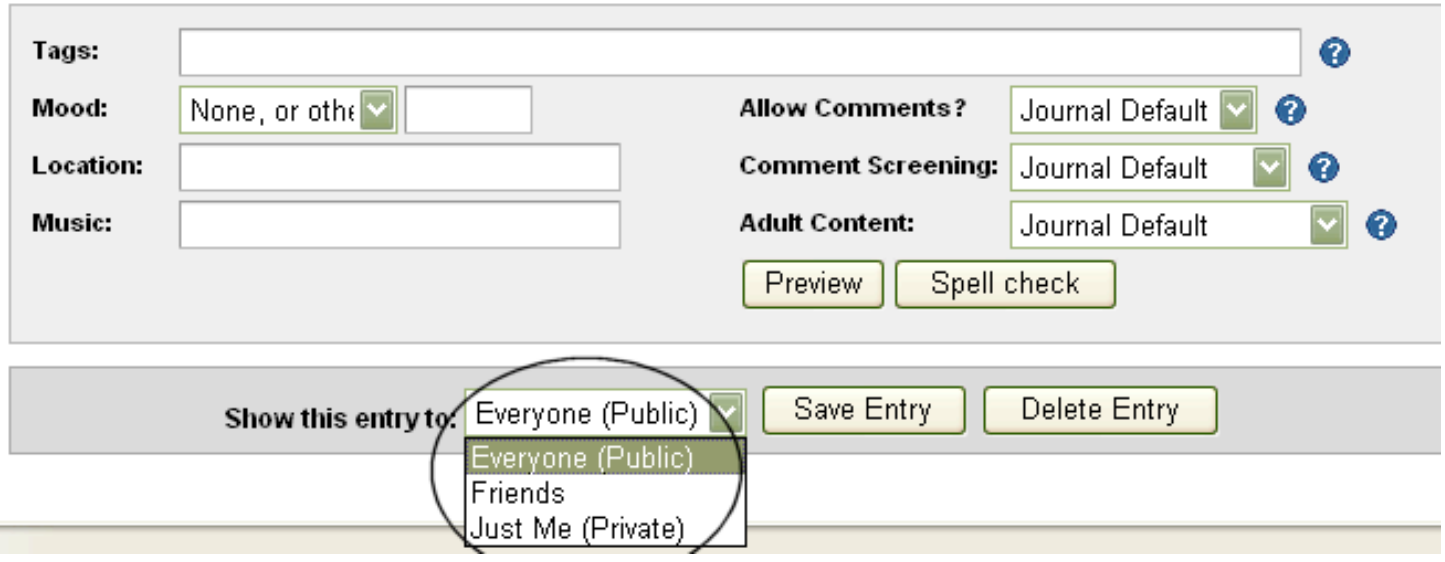




\section{Image 6.3 - Livejournal posting interface - the degree of privacy protection of a posting like this one on LiveJournal is indicated and controlled by this unobtrusive menu (and by default all postings are made completely public). Source: author, 2008}

The weblog writers' interactions with their weblogs are performed using a set of 'authoring' pages which are visually very different from the pages presented to someone browsing their weblogs and are only available to the author and protected by a password. In Goffman's terms (1959) there is a sense here of a privileged 'backstage' (the weblog administration interface) and a 'frontstage' (the weblog itself).

Moreover, blog postings are broadcast instantaneously and from my experience as a blog reader and author ${ }^{53}$ tend to receive the most responses, insofar as they receive any response, within hours or days of their appearance. The more rapid the responses are, the more this might tend to give blogging the rhythm of an oral conversation rather than a written exchange, just as textual "chat" rooms appear to resemble talk although they are mediated through writing. Because of the automatic archiving that blogs provide and the access to those archives provided by search engines, blogging can mix the immediacy of talk with the durability of book publishing. For more on orality and on archiving and blogger perceptions of it, see Section 7.3.

Although the physical environment in which blog authoring takes place was not studied through direct observation in this research ${ }^{54}$, two of the interviewees referred to their desire to keep their weblogging concealed from others in the room with them - either in order to ensure that what is written is private or to conceal the journaling practice itself $f^{55}$. Where the home is shared with others, blogging may be done privately in order to keep the existence of the blog or its nature a secret from other family members. In the case of George, for example, he noted, "there was one time when my parents did accidentally come across it on their PC. Yeah and Mum wanted to read it and Dad stopped her and I was very grateful [laughs]. That would have been quite bad." Renia blogs at home and tries to keep it a secret: "sometimes I have to blog in private when they are not there". The blogging practice's context of physical privacy may make bloggers feel to some extent as if their practice is just shared between them and their computer, and the felt absence of a potentially critical audience may make them feel more able to express themselves openly.

In summary, the architectural form of weblogging sites and the attendant software and the typical physical contexts of blogging suggest that webloggers are likely to be operating in an

\footnotetext{
${ }^{53}$ I am not aware of any research bearing on this question.

${ }^{54}$ Although interviews in the homes of weblog authors were among the original objectives, this did not prove feasible see Section 4.4.2

${ }^{55}$ Five of the 23 interviewees noted that work colleagues were aware of their blogging activities but in the absence of contrary testimony it is assumed that their blog writing in common with other office work is treated by them and by others as if it were not continuously available for scrutiny.
} 
environment that conditions both perceptions of control and perceptions of suitable practices in a variety of ways. The implications of the evidence reported here are discussed further in Chapter 8 .

\subsubsection{Legal bias}

The weblogs of those interviewed, like those of other UK bloggers, are produced within a set of legal constraints. Only two interviewees referred to these constraints, however, and then only in passing. This absence of explicit reference to legal constraints may be explained by the fact that what most of the interviewees wrote or wished to write came nowhere near to a test of the limitations of the legal institutions that they appeared to believe themselves to be governed by. UK bloggers are, nonetheless, at least potentially constrained in what they write by laws governing public written speech - most notably those of libel and breach of copyright (Defamation Act 2001, Copyright, Designs and Patent Act 1988).

Only two of the 23 interviewees expressed concern about the legalities of blogging practice. Kevin mentioned that an acquaintance of his republished some art photos critical of and threatening towards George Bush and, "disappeared from LiveJournal and everybody wanted to know what was going on and then he came back 'sanitised'." It was not clear whether this had any effect on his own unwillingness to post political statements which he attributed to other causes. Quentin, a journalist, observed that he concealed the names of people he wrote about because "if real names are involved or people are identifiable then libel is a potential risk - not much of a risk because the post can simply be deleted but it's not worth the hassle. It's easier to keep it anonymous." None of the others expressed any concern that what they wrote might be reported to governmental or legal authorities, nor did they speak of a fear of legal prosecution. The constraint most felt about discussing what took place in their workplaces was primarily a market constraint (see Section 6.3.3) and seemed to be related to the risk of potentially losing their jobs or harming their employment prospects, and to a lesser extent reflected a social norm against embarrassing or annoying co-workers with whom they would have to interact.

In summary, while in principle those interviewed were legally constrained in what they could write without fear of potential prosecution, this constraint appeared to have little impact on their actual practice - possibly because of a lack of knowledge of the relevant laws, possibly because of a perception that their blogs would not come to the attention of legal authority but most likely because their desired practice would without difficulty fall well within the legal constraints operating in the UK. The importance of legal constraints on blogging in other countries is discussed in Chapter 8.4. 


\subsubsection{Market bias}

As indicated in the discussion of the conceptual framework (Section 3.5), the operation of the market can be seen as a constraint on behaviour. The cost of an activity can, for example, be a potential barrier and in this respect, the proliferation of free weblog hosting services can be seen as removing earlier market constraints on speech, since in contrast to earlier media both online ${ }^{56}$ and off, they levy no charge on publishers regardless of how many readers they reach. In fact, the opposite could be the case - thanks to Google's AdSense programme (http://www.google.com/adsense/) and other competing services, bloggers have the opportunity - at least in principle - to make money from their readers by displaying context-sensitive advertising on their sites.

In the sample of interviewees for this study, however, only one, Harriet (who worked in marketing) had elected to put ads on her site and, although hers was one of the five most popular weblogs among those produced by interviewees with between 250 and 1000 readers a week according to her best estimates, she said she had only earned about $\$ 25$ from her ads ${ }^{57}$. While she was alone among the interviewees in suggesting that one could make money from blogging, citing a friend of hers who had sold some of the pictures she had taken, she evidently did not believe the amounts to be significant, as she also said "you don't obviously obtain money for blogging”, and prefaced her remarks on what you could earn with, "it's not certainly for fame, fortune and glory that you do blogging."

The three interviewees who were asked about the advertising potential of their sites doubted that there could be any and asserted that any money they could make would not interest them. Tim remarked, "Most of the things I post about, which I could possibly make money from, I could make far more money from by doing them." Indeed, one interviewee, Colin, was hostile to the idea that commercial interests could come to affect what he or other webloggers said: "if you got a blogger with twenty thousand readers that's been going for four years, you can sell that domain, you could sell that space, you could sell that online persona. Which I think is horrible.” Thus there is little sign among these personal webloggers that their blogging practice is influenced by a desire or need to make money from their blogging directly.

Instead, two of the interviewees who were also embedded in commercial creative industries saw weblogging as radically free from the influence of the market - for those who feel constrained by market forces in everyday life this appears to be an important characteristic of blogging. Note

\footnotetext{
${ }^{56}$ Some web page hosts limit the amount of accesses to a hosted page that a user may have before they incur a charge. Neither Blogger nor LiveJournal have such a limit.

${ }^{57}$ Though she was UK-based, Google Adsense paid her in dollars.
} 
that the market as these two defined it blurs the boundaries between commercial acceptance and what could be described as a set of institutional norms related to commercial publishing. They referred not to the imperative outside blogging to write to satisfy audiences for advertisers but to the need to write articles that they will be able to sell to editors. Quentin spells this out clearly, for example:

It's a well known fact in journalism that it takes you a while before you write the fun stuff where you get to be a bit creative. People generally have to work on newsdesks or freelance with news features for quite a while. People will reach their 30s before they get to write more creative pieces. Now my worry has always been, well, by the time I'm 30 or older - it's a little while off - [I will have been] not writing, so how well am I going to do when I get to that stage in my career? So I need to try to establish things like tone and what have you.

Elaine similarly noted, "writing my blog gives me a chance to write the way that I want to rather than the way that is required for different publications."

There are other market-related constraints operating on the space of personal weblogging which were not remarked upon by those interviewed because they did not perceive themselves to have been confronted by them. For instance, all of the interviewees for this study appeared to have easy access to a computer connected to the internet, whether at home or at work. In addition, they also had an employment situation that allowed them sufficient leisure to indulge in this activity.

In addition to market-related constraints there are also likely to be ways in which marketbased organizations can influence behaviour, becoming effective indirect shapers of activity. For example, the need to avoid discussing work-related issues on their weblogs was one of the most common self-imposed limitations that emerged in interviews. Ten of 23 interviewees said that their current or potential employers might be hostile to some of what they might wish to write, or to weblogging per se (an eleventh, Simon, said while others might be worried he was not worried about this). Isobel's reaction is typical:

You would never think to blog about life in a [governmental organization]?

No... God no... I do read them. I think they are really interesting. I think... I do like them and I think they are really cool. It's always nice to have an insight into someone else's work but I would never do it because I would probably get found out and it's just not worth it. Even having a freedom of voice to talk about your work and talk about things that annoy you I just don't think it's worth it. Not my job - I couldn't lose my job over it and that's ultimately what would happen if I got found out - Isobel

Rather than negotiating their practice and establishing guidelines with their employers, these interviewees appeared to prefer not to draw their blogs to the attention of those within the organization who might seek to influence their practice. Two interviewees mentioned unprompted the case of Joe Gordon, a British blogger who had been fired around the time of interview (2005) by a UK bookshop chain for writing about his work (Pollitt 2005). The reluctance of bloggers to seek formal permission from their organizations was in this context therefore understandable. It may be that they would have found it difficult to get a decision and they might reasonably have expected 
employers to impose restrictions ${ }^{58}$. It may be that the perception of such restrictions would impede the sensation of the freedom that many (five of 23) interviewees said they valued.

In summary, blogging does seem to provide a means of publishing that is less constrained by the ability to afford access than previous media forms like print publishing and some interviewees also valued their perception that it is free of the institutional pressures that accompany publication in other media. There are, however, other indirect market-related influences on practice which interviewees identified - notably the perceived necessity to avoid writing about work-related topics on their blogs because of the potential threat posed to their income should employers object to what they wrote.

\subsubsection{Societal bias}

The last form of influence encountered by webloggers which will be outlined here is socially enforced norms of behaviour. The number of norms potentially in operation is expected to be a reflection of the ambiguous nature of the communicative space of the weblog. As discussed in Chapter 3 and Section 5.3, the weblog is sometimes envisaged as a space for interpersonal communication, sometimes as an online analogue of earlier offline print forms like a newspaper or magazine column or a paper diary, and sometimes as a new space with its own emerging communicative norms. These framings of the space are not exclusive - interviewees often described themselves as being governed or influenced by different norms at different times and these were found to come into conflict and to change over time (see Chapter 7). In this section, we consider emergent norms of weblogging as a new online form, the application of norms derived from other textual forms to blogging practices, and the relationships between weblogging and 'offline' social norms.

\section{Emergent norms of weblogging as a new online form}

At the time of the fieldwork for this study (2005) weblogging was a phenomenon that only recently had been discovered by the media and the general public in the UK. Nonetheless, for some of my interviewees, norms of expression and behaviour peculiar to the space of blogging already appeared to have become apparent. These 'local' norms were not perceived as being universal or

\footnotetext{
${ }^{58}$ Efimova and Grudin have produced the only academic case study I have found of workplace weblogging and its governance (2007). They found, "early bloggers felt that legal and public relations representatives wanted to shut them down. In an open internal panel discussion in June 2003, a legal representative benignly encouraged bloggers uncertain about the wisdom of publishing particular content to seek guidance. Four months later, however, a contractor was dismissed for what many considered a relatively minor disclosure in a blog." Since they were studying Microsoft, however, (a company in which weblogging could be expected to be an early and acute issue) their findings are hard to generalise. The Chartered Institute of Personnel and Development in the UK has issued brief guidance for employers about blogging in the workplace, all of it negative in tone - "employers may need to specify in their Internet and email policy that blogging is unacceptable use." (CIPD 2007)
} 
rigid. In particular, there was a marked contrast in several cases between what the interviewees observed as being common behaviour in this online space and what they suggested 'should' occur. Before examining the norms themselves several ways in which such norms might have been encountered by the interviewees are briefly outlined.

One possible way in which bloggers might come to perceive norms of blogging practice is through media representation of such norms. Mass media coverage specifically about blogging practice in 2005 was limited in most of the 'mainstream' media in the UK - broadcast or mass media print publications - but three of 23 interviewees mentioned that it was the coverage of blogging in The Guardian newspaper that encouraged them to start a blog themselves - two of them citing, in particular, its coverage of the Baghdad-based blogger 'Salam Pax ${ }^{, 59}$. Two other interviewees, by contrast, were put off blogging altogether at first because of the way they felt it had been framed by the media. Betty remarked, for example, "my initial reaction was, "why would I do this?' Because initially it was very much publishing links of things that you found on the internet." And Bruce only started blogging when his friends persuaded him that it was not "either extremely serious political projects like the kind of things you are reading about happening in the States" or "the sort of very self-promotional things that you read about on the news of a woman who puts up cameras all over her house and is telling you everything about herself that maybe you didn't want to know."

Articles about personal weblogging in the mainstream media in the UK around the time of the fieldwork for this study tended to range between prurient interest in the more sensational blogs (like that of a UK-based prostitute, Belle De Jour (Woods and Hellen 2004)), puzzlement about such bloggers' motivations, and derision (for example, "nowadays millions of people publish their innermost thoughts as internet blogs, safe in the knowledge that no one will ever read them" (Browning 2006)). See also the pictures below (Images 6.4 and 6.5), both from The Guardian:

\footnotetext{
${ }^{59}$ Salam al-Janabi at http://dear_raed.blogspot.com/. His blogging around the time of the second Gulf war received widespread attention in the UK press and in the Guardian in particular, which gave him a column and later published his blog in book form.
} 


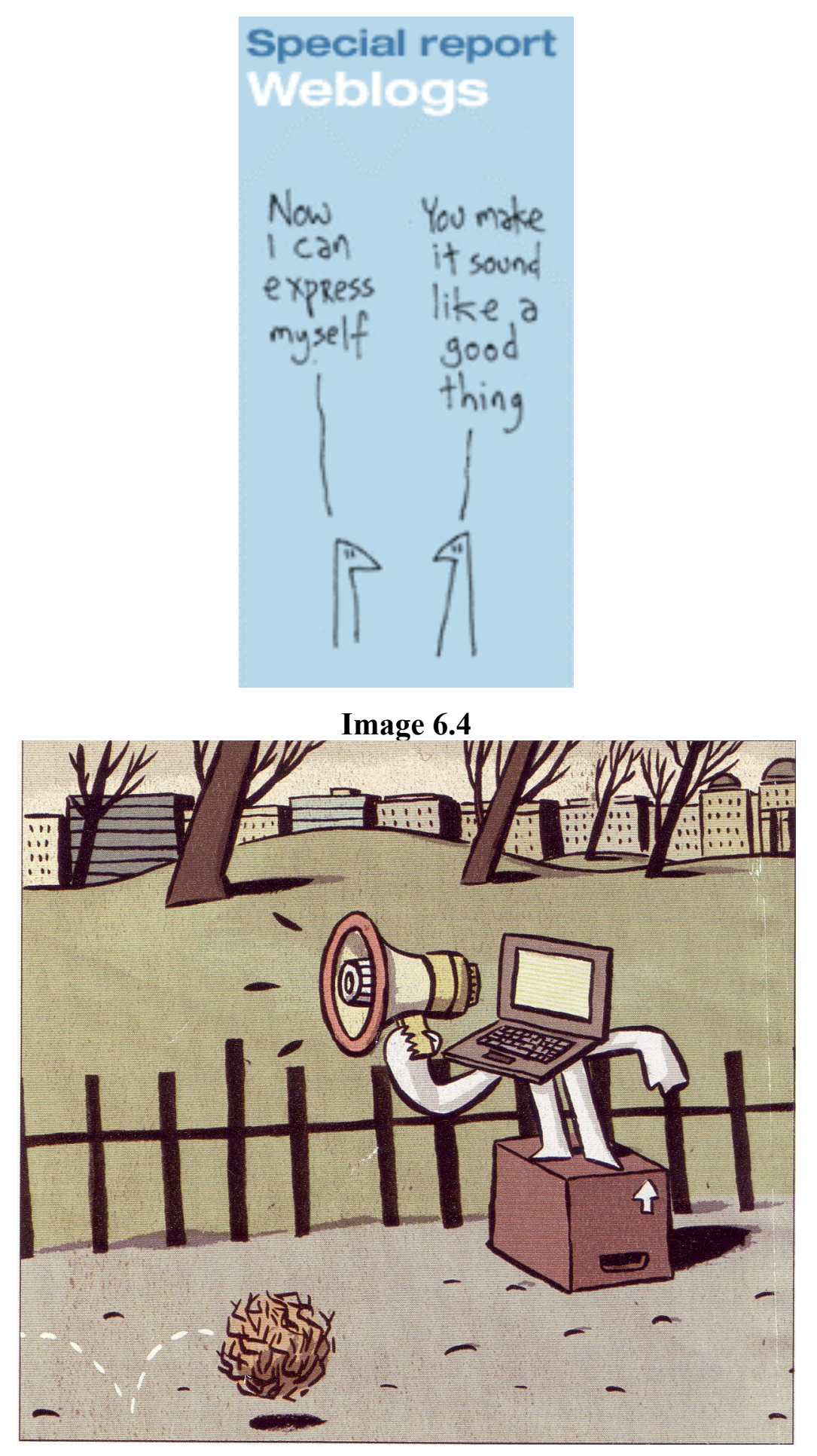

Image 6.5 (Accompanying Browning 2006)

As Colin noted, the media occasionally drew distinctions between different weblog services based on their perceived user demographics and the norms that they thought were followed on those services (which might in turn serve both to reinforce those norms and to encourage potential users to seek out or avoid a service based on the media depiction of that service).

I think it's interesting that Live Journal, the perception of it is that it is more aimed at the teen-age market. Although [many of the] people who use it are adults. So Blogger blogs are serious, LiveJournals are teen-age angst... If you look at references to blogs on BBC news.co.uk, they will show Blogger.com and a few of the others. They don't use Live Journal. 
In addition to mass media framings of blogging, there was limited evidence that interviewees might have been influenced by online writings - often on weblogs themselves - that explicitly attempt to set out rules of conduct for weblog practice. There have been many attempts across a variety of sites to set out such rules. Rebecca Blood's early blogging on weblog ethics which is also available in book form is one prominent example (Blood 2002), as are the weblog postings from Tony Pierce and Mark Bernstein (Pierce 2004, Bernstein 2002) quoted in Section 6.1 above. The extent to which these early normative pronouncements were directly influential in shaping blogging practice is unclear. Of those interviewed for this study, Frances was the only one to mention being influenced by one of these normative texts. However several more may have been indirectly influenced by reading bloggers who had read those texts and whose blogging was shaped by them to some degree. ${ }^{60}$

This third form of influence - the perception of norms apparently followed by the weblogs read by the interviewees - is one that was more apparent in the interview data. Of the 15 bloggers interviewed for this thesis who responded to a survey question about the number of weblogs they had read ${ }^{61}$, only three claimed not to have read any, and Doug claimed to read between 50 and 100 in a week. Among the 12 survey respondents who said they do read weblogs, eight said they regularly read the personal weblogs of friends. While it seems likely that most British bloggers would have been practicing blogging for not much more than a year at the time of this research ${ }^{62}$, the sample was (unintentionally) skewed towards more experienced bloggers - half of whom had been blogging for at least two years. They would therefore have been potentially exposed to and influenced by these norms for longer than the average UK blogger.

Six of the 23 interviewed for this study made some reference to the way in which the example of others' blogging practices informed their own weblogging practice. Annie remarked, "I usually blog at least once a day because I like to read people who post once a day", and said she admired a friend's site which had "really proper writing and everything and there was a point where I did want to write properly and make it really poetic." For Bruce the influence of others' practice was evident:

...by that stage I had read a few of my friends' and you began to see certain patterns emerge. Telling you anecdotes really - people putting up anecdotes about odd, quirky things that happened. And there is no

\footnotetext{
${ }^{60}$ It has been established at least in the US that weblog writers are more likely to be weblog readers as well - $90 \%$ of US bloggers in a recent survey said they had read someone else's blog, compared with $39 \%$ of all internet users who said they had done so (Lenhart and Fox 2006).

${ }^{61}$ This refers to the survey which was used to recruit a broad range of bloggers for interview. The question about number of blogs read was added after pilot interviews so not all interviewees were presented with it (see Chapter 4 for more methodological details).

${ }^{62}$ It is difficult to establish this as no statistics were collected in the UK on weblogging before 2005. In the US, the prevalence of weblogging appeared to rise from 2\% of online users in Mar-May 2003 (Lenhart et al. 2004) to 9\% by late 2005 (Pew Internet \& American Life Project 2007), however the margins of error in these Pew surveys mean the size of blogging's expansion is hard to gauge.
} 
shortage of that really when you live in London. So that was probably the first longish entry that I wrote - an anecdote.

A number of weblog-specific norms governing what bloggers felt they could write emerged in interviews $^{63}$. The norm suggesting that one should be as open as possible online, disregarding the normal constraints of face to face interaction with strangers, has already been suggested in Section 6.2. As noted there, one of the interviewees, Kevin, discussed being uncomfortable about the pressure he felt to be more open online, and four others mentioned seeing others' blogs which disclosed more than they were comfortable with. On the other hand, five of the interviewees talked about choosing this form of communication because they perceived it enabled the free expression of feelings or revelation of facets of themselves that they would find difficult to express face to face.

George said, for example, "I think I did indirectly address things in the hope that they [friends] read them and realised more perhaps where I am coming from" and Charles said, "I guess I like the idea of somebody who meets me in the pub and doesn't know I'm gay going to the website and finding out so it saves me the conversation saying I am which I invariably hate".

Alongside the 'openness' norm and related to it is the norm that suggests that one should be truthful in one's accounts about one's self. For example, Renia, whose blog discussed some of the most personal material including self-harm and a suicide attempt, appeared to feel this most strongly. She said,

"I tend to try to leave it as much as I can because I think it might be wrong to alter it just because I am a bit embarrassed.

If you did something you were really ashamed of would you blog about it?

I would tell them, yeah. I would say 'look this is what I did'. I would try to put it in a slightly good light but I wouldn't hold back - I would tell them the truth.

And Harriet remarked, "if you're going to write about yourself - I try to be honest with my posts - not just being honest about myself but about what I'm doing - because otherwise what's the point?". Six of the interviewees also alluded to the importance of not writing anything too trivial excessively trivial content was seen as a common problem among personal weblogs. Indeed, blogging about one's cat or about what one had for breakfast seemed to be the 'gold standard' of triviality. Three of those interviewed mentioned their desire to avoid reading about cats and two disparaged breakfast-related blog entries. One interviewee, Quentin, said he thought the prevalence of trivial blog entries "has given blogging a bit of a bad name". This may be in part because he was a journalist and understood the practice chiefly in journalistic terms (see next Section 4.4.2). Bruce

\footnotetext{
${ }^{63}$ I have attempted to isolate norms which appear to be specific to blogging practice from those which are more broadly held social norms (those I discuss in section 3.4.3) but the borders are not always clear cut. I only discuss here norms that relate to what bloggers felt themselves able to write in their postings, but there are numerous other blogging norms mentioned in passing - most notably those around who would be made a LiveJournal 'friend' (see Appendix A for a definition of 'friend' in this context).
} 
was aware of a norm against trivial blog content but chose to resist it. He remarked, "if you have been looking at my journal ... sometimes it can be stupidly trivial..." and he later justified this:

"Maybe this sounds weird but being able to write about things that are silly or foolish or show that you have got trivial interests or whatever - I'm quite proud of that. I don't want to know or associate with people who wouldn't want to know or associate with me because of that. And this is one of the things that are very nice about LiveJournaling or weblogging is that here is an environment where I can say 'hey I really like Dr Who' and I don't have to worry about everyone going [derisive sound]" 64

Here, as with the norm of openness it is clear that there are clashing norms of behaviour in operation in blogging. Clearly for many blogging licences them to write about trivia, but this has contributed to a counter-movement, to which several of those interviewed appear to subscribe. This is consistent with the findings of interviews by Fono and Raynes-Goldie about LiveJournal 'friending' practices, which concluded that, "there are enough people engaging in certain normative behaviors such that they could be identified as norms. However, there do not appear to be any norms or sets of norms which the majority of the user population agrees upon." (Fono and RaynesGoldie 2006)

One norm mentioned in some blogging studies (see Section 2.4) and implied in most definitions of blogging (see Appendix A) is the need to update one's blog regularly - a perceived obligation which may also be influenced by the way blogging technology is designed as has been discussed in Section 6.3.1. For Isobel this seems to clash with the norm against writing trivia:

If I haven't updated for a while I will put something really stupid in - I'll put a photo in - I've done that quite a lot recently - just put a load of photos in - or I'll write something really meaningless and trivial but it will mean people still know I'm alive and that I am still blogging but I've got other stuff to do.

Kevin expresses the requirement to update in similar terms:

I will feel a twinge every couple of days and say 'oh I haven't posted anything I really should just to make sure that people know that I'm alive and not in a plane crash somewhere'

Charles appears to believe that this obligation to update would only come into force if his audience were to grow to a certain size:

The idea of developing an audience of people somewhere on the other side of the world who likes what I have to say and wants to see what I am going to say next week is something I find deeply scary because I wouldn't want to get that kind of sense of actual responsibility.

Alongside these norms is the idea that one should not post items that are too long. Quentin, for example, said, "I would generally assume that a golden rule of blogging is 'keep it short", and Harriet noted, “Don't write insanely long posts if there's no particular reason to and even then they should never be really insanely long posts. I am very conscious of the length of posts.” Betty echoes this and adds that she feels that she should not put more than one picture per posting in her blog because "I just think that's rude". Although she adds in this case, "as people increasingly have

\footnotetext{
${ }^{64}$ This interview took place just as a new Dr Who series was beginning to attain mass popularity, but clearly some stigma was still attached to watching at the time.
} 
broadband, it becomes less and less of an issue." The 'shortness' norm may again be linked to and reinforced by the way blogging sites are structured (see Section 6.3.1).

Taken together the major thrust of these norms suggest a felt obligation not to displease the audience and a desire to entertain readers - often by amusing them. Annie said her definition of a good blog post is, "something that makes me laugh. If I think it's funny then I'm going to leave it up there." George said his "humorous slant on things" would make people enjoy his blog, and Phillippa said that while the focus of her blog was on her art, she would consider other more personal topics if they were sufficiently funny: "if something terribly amusing were to happen then I might put it because it's funny and makes people laugh."

Although the perceived norms of blog reading practice are beyond the scope of this study, four of those interviewed did remark on one such norm - that visitors to their site should be polite and respectful in their response to it. This may be of particular importance insofar as it might tend to encourage bloggers to assume a favourable response to what they have written (see Section

\title{
5.2.2). Phillippa remarked, for example:
}

I think most people are pretty polite and if they don't like it they just move away. If they don't like it who's going to waste time writing a... why would you do that?

And Frances elaborates:

\begin{abstract}
there seems to be this kind of unwritten code of ethics with blogging and commenting on other people's blogs and that's basically if you don't... if you really strongly disagree with what someone says then go ahead and comment and say that you disagree but don't ever be rude about it. If you don't like what you're reading then go to the next blog but don't waste your time here insulting me. I suppose it's kind of like if you walked into my house and you said, "you know your curtains really fucking suck" then I would say "get the hell out if you don't like looking at them". So that's part of it. But I think most people who read blogs know that and I've had very few negative comments as well.
\end{abstract}

In summary, interviewees revealed several social norms influencing blog writing that appeared to be emergent norms specific to blogging. The next section outlines some weblogging norms that appear to be related to norms associated with earlier textual practices.

\section{Weblog norms derived from other mediated practices}

While the interviewees for this study frequently asserted the novelty of weblogging as a practice, they also not infrequently appeared to frame it either as analogous to or in contrast to earlier textual forms. The most often-cited analogous form was the diary ${ }^{65}$ - perhaps not surprisingly, since personal weblogging has often been described since its inception as online diary writing (see Appendix A on definitions of blogging). Six of the 23 interviewed stated that they saw

\footnotetext{
${ }^{65}$ There is some ambiguity here as of course there can be several uses for paper diaries just as there are several uses for weblogs - for Simon, it appears it would be something like a commonplace book - to "help me keep track of the changing world. New attitudes to things or new ways of doing things" whereas for George a diary was more of a means of venting emotions.
} 
their weblog as a straightforward substitute for a paper diary - at least at the beginning of their practice, although Colin, Elaine and Isobel remarked that the growing awareness of an audience changed their practice (see Chapters 5 and 7). Others recognised the discursive connection between blogging and diary writing but maintained their blog did not fit this pattern. Bruce, for example, said:

I never kept a diary as a child. I never kept one of these very detailed intimate personal diaries and I have always tended to work that sort of stuff out just through talking to people rather than writing it down. I am as I say quite aware that blogging is a public activity really and I think that it brings with it certain... even if it is quite trifling... it brings a certain amount of responsibility about what you write with it.

And Harriet remarked, 'I wasn't necessarily keeping a diary - I don't even like to call it a diary really. I wasn't doing it for... I wanted to see if I could build up an audience.” As in Harriet's case, the principal diaristic norm referenced in these cases is the contemporary expectation that paper diaries should not be read by others ${ }^{66}$. It may be that this association of weblogging with the practices of paper diary writing contributes to the norm of openness and honesty identified above as a weblog-specific norm to the extent bloggers see their blogs as being read only by themselves.

By contrast, three of the interviewees, two of them journalists, referred to their weblogs as being analogous to a newspaper column. As Elaine explained it, this appeared to refer to a particular kind of personal column that had become popular in the UK, combining personal anecdotes with commentary on news and current events. She mentioned Julie Burchill and Melanie Phillips as typical authors - Quentin cited Will Self, PJ O'Rourke, Hunter S Thompson and Auberon Waugh. The relevant norm here appears to be that what is produced may contain some personal content but - in contrast to weblog-specific norms - it need not be entirely truthful as the reader will accept that it is the voice of a persona. It is seen as being aimed at pleasing the reader - often at amusing them - and it should therefore be well written.

When Quentin was asked whether "someone who knows you well would recognise you - the 'real' you - from what you write on the blog?" he replied, "I would hope not... my online persona is a great deal crueller and opinionated and arrogant and boastful and all sorts of things which I can't be in my day to day life. And the trick is making that horrible unpleasant online person in some way captivating."

Elaine explained the relationship between her own views and those expressed on her blog this way:

Suddenly the [pseudonym] voice takes over and I can be quite sharp and quite cutting and sometimes I think 'ooh I am not sure I really meant that - that's a bit harsh but it sounds good so I will leave it. Not that it makes

\footnotetext{
${ }^{66}$ Though as Bloom and Blodgett relate, paper diaries were and are sometimes shared with others in particular contexts (Blodgett 1988, Bloom 1996)
} 
me sound good but that the words sound good - you know what I mean, it's slightly different. And I am sure a lot of newspaper columnists are like that as well.

The relationship between Elaine's self-perception and her writing was examined in Chapter V, Section 3.4.

In summary, the evidence suggests that where the framing of a novel practice like blogging is still being defined, the practice is sometimes compared to more familiar existing practices like newspaper column production in order to provide a basis for establishing norms. The next and last sub-section considers how blogging practices might be influenced by social norms that are not specific to mediated communication.

\section{$\underline{\text { Weblogging and social norms of unmediated interaction }}$}

Whatever the perceived freedoms of expression afforded by the weblog as a technology and encouraged by some of the rhetoric surrounding the practice, there were occasions when the interviewees acknowledged some amount of self-censorship which appeared to be associated with their perceptions of social norms governing everyday unmediated communication. The first such norm was a perceived stigma attached to computer use and blogging in particular, which influenced the decision to blog and whether to tell others about it. Other instances were associated principally with perceptions of the political environment and of the permissibility of intimate modes of expression.

Two of the interviewees in this study, both of them women, were clearly concerned that computer use in general and blogging in particular were seen as 'sad' and geeky by non-blogging peers. They suggested that this, in turn, often encouraged them not to let the rest of their social circle know about their blogging practice, even when they felt it was actually something beneficial to them, which in turn may have helped to reinforce the sense of it as a marginal practice.

I started doing blogs when I was in my first year of university - 2000 - I've been blogging for five years which makes me very sad. - Isobel ${ }^{67}$

Isobel's defensiveness about blogging appeared to be particularly strong, even though (or perhaps because) she was an exceptionally early adopter of the practice and had been an active chatroom participant before that. Though she said that, "I think it [blogging's reputation] is getting better", she nonetheless asserted that:

I think that the perception of blogs has always been that they are done by kind of geeky people and they talk about IT stuff or their role playing games or whatever it is that they talk about... I wouldn't have classed myself as a blog kind of a person. I think basically geeks or people who were slightly odd and have some very strange backgrounds used it - I don't know what they used it to do - that's kind of perception that I've always had of it except when I started when it was very cool - naturally.

67 "Sad" in this context means socially inept, not unhappy. 
Frances's belief that blogging is "still seen by a lot of people as one of those 'you're such a net geek' things" is remarkable insofar as it appears contradicted by her own experience. She said when people do discover in conversation that she has a blog, "they said 'oh, they're the in thing these days aren't they?' And 'what's your blog about'? ... So I think it's me who still sees it as net geekery. I don't think it's so much other people." George, on the other hand, seemed to perceive that blogging was framed as cool by the media: "blog became a real buzzword last year didn't it and I think one of the American newspapers said that that was the word of the year - blog."

With respect to the political environment and the space for debate potentially created by weblogs, the authors of weblogs predominantly consisting of political content and commentary were excluded from the sample for this study. However, personal weblogs containing some political comment were included in the sample (see Section 4.4.1). Although weblogging is one of the few public practices where 'ordinary people' are encouraged to express themselves politically, and although the interviews took place shortly after the ' $7 / 7$ ' bombings in London which killed 52 people, there was very little discussion of the politics of the bombings or other political issues on their blogs (though several wrote functional entries of the "yes I am all right" variety around that date, and some made gestures of defiance towards the terrorists which were more reflexive than political).

Some of this may be due to a lack of political engagement but of the 15 of 23 bloggers who mentioned politics in the course of their interviews, ten alluded to having strong political views. Of these, however, only four said they expressed those views regularly on their weblog ${ }^{68}$. None suggested that this was because weblogs were not the place to raise political matters. On the contrary as suggested earlier in this section, one of the interviewees - Bruce - regarded weblogging initially as being primarily political and none of the interviewees appeared to be surprised to be asked about political uses for weblogging.

Strikingly, then, we have a sample of bloggers with political opinions and a space they have framed as 'free' which is also understood as being appropriate for political speech, yet many of the interviewees did not use it for this purpose. Even those who did occasionally write political posts expressed some reservations about their practice. The reasons advanced for non-participation of this kind were consistent with the observations of others who have studied the social norms surrounding political involvement in everyday life (Bourdieu 1991, Bourdieu and Wacquant 1992 p. 146, Eliasoph 1998).

\footnotetext{
${ }^{68}$ As discussed in Chapter 5, only one, Simon, said he used the weblog as a means of critically examining his own views by receiving feedback - the other three (Bruce, Charles and Colin) expressed their political views in a more broadcast or monologic way - or at least were not interested in having their views challenged.
} 
The most recurrent of these was that participation in the political sphere requires specialist knowledge and skills and that the interviewees claimed that they either lacked the energy or the ability to acquire them. Charles started his blogging viewing himself as a 'political blogger' - 'it's an area where I feel comfortable extemporising a lot about my opinions and feelings so I get a chance to really engage with it - the medium and with the writing process - without going into too much of a personal place emotionally". However, his interest in political blogging had faded by the time of interview. He commented as follows, suggesting the internalised limits to the effectiveness of his political blogging:

I never was confident enough that I was going to keep doing political stuff - every time I did political stuff I kind of thought afterwards "what a waste of time" because I didn't think anyone was reading it and someone was always doing it better somewhere else - I don't think I've got [inaudible] so I think setting up something that was dedicated to my political opinion would always seem a bit geeky and a bit sort of arrogant. I'm not $\mathrm{Kos}^{69}$ - you know what I mean - I'm not like some insider with loads of knowledge and political blogging is unbelievably time-consuming because you are so much more careful about what you write.

He appears to want to assert his identity as a political person, "if you had a good browse of it [my blog] you'd know I was interested in politics, you'd know I was left wing and into trendy causes like opposing the war in Iraq and poverty in Africa and climate change" but without feeling confident enough to back his assertions in detail:

"surprisingly given the amount I publicise them I am not super-confident of my political beliefs either... I'm restricting it to issues where there doesn't seem to be much of a question, like I don't know anyone who really actively opposes the 'Make Poverty History' campaign."

He had not always been this reticent as he indicated that he did 'offline' campaigning in his student years against tuition fees. His level of political engagement or confidence may have changed over time, as he suggests:

Until two or three years ago I did have more of a political network and I shed it because it was hard work because they kept expecting me to go to protests and demonstrations and running meetings and blah blah blah. And I think partly it [blogging] does function as a substitute. It gives me a way to feel that I am promoting these causes that I believe in without the responsibility of entering into dialogue with people.

After the interview his blogging practice appeared to have shifted and as of the end of 2008 his blog is now predominantly a political one again.

Donald also initially depicted his blog as being at least partially political: "I am going to tell you that I'm not happy with Mr Bush and I'm not happy with Blair. I'm going to tell you that I'm not happy it's raining today or whatever it is that I happen to be blogging," but though like Charles he was politically engaged, 'I've lived in trees, I've done the road protesting, I've written for people like Schnews", there was in fact little political discussion on his blog. Like Charles he said, "there are enough people out there doing it [writing politically] and doing it a lot better than me... I

\footnotetext{
${ }^{69} \mathrm{http}: / /$ www.dailykos.com/ - a high profile US political weblog by Markos Moulitsas Zuniga
} 
haven't got the time to dedicate myself to one cause which I think when you get political you really need to." Phillippa echoed this in her own account:

Although I have very strong feelings about political things I for the most part leave it out of my weblog because I think there's already enough of that out there already and I'm not going to add much to the pot... I don't think I would start a political weblog. There are people who are far more articulate and educated than I am in those things and I just think I would be leaving myself wide open for just a lot of hassle and life is too short.

In contrast, Linda's stance was less self-critical. She did not imply that she would not be capable of blogging about her "very keen" interests in politics, but did appear to see political engagement as an unwanted effort - she "wouldn't write about major political stuff unless it was really personal and bothering me", because "I look at the LiveJournal as a step away from work or anything where I have to think heavily. It's recreation.” Isobel's self-critical stance was apparently inhibiting her from blogging politically. This was remarkable, given that she was employed in press relations at a government organization:

I don't think I am very good at it [political blogging]. You have purely political blogs who talk about George Bush ... it was all very intellectual and very deeply thought out arguments about this or that and I think I'd be a little scared to do that because I don't think I'm confident enough to write like that. I don't think I could argue well enough. There's the election coming up... If I was going to blog about how I was going to vote or why I think people should always use their vote which I believe very strongly in I don't think I could because although I know what my arguments are I don't think I'd be very good at writing them down and putting them coherently enough that people would understand what I was trying to get at but I find the same when I am arguing with people about politics or I am arguing with people about literature or whatever it is which is disturbing because I managed to do it in university quite convincingly and got a degree because of my analytical arguments.

Here an additional constraining factor seems to emerge which is the valorization of the written form. The belief that writing is more difficult than speaking and that statements or arguments made in written form must be better thought through than those made orally appears to be discouraging political self-expression.

In addition to offline social influences there appeared to be market constraints on political speech for two of the interviewees. Bruce had a job which did not allow him to make public political statements, so he said, "where I'm going to really write my political opinion on something then I would tend to filter that and make it a post that only my friends could read" ${ }^{\text {"70 }}$. Isobel who worked in media relations for a governmental organization said that she avoided direct references to her workplace, but this was not the reason she offered for avoiding political discussion.

The emergence of the weblog form and, particularly the association of this medium with politics in the media, seems likely to have encouraged some people who would not normally voice political views to express them online - indeed it appears to be one of the few everyday spaces for online communication where political expression is considered normal. Nonetheless these

\footnotetext{
${ }^{70}$ In fact he had numerous political posts which he had neglected to filter, and he was subsequently asked by his employer to make his journal 'friends only' as a result (see also Chapter 6).
} 
interviews suggest that the social norms against political expression which are active in other communicative contexts also inhibit such expression on personal weblogs.

Another indicator of the presence of offline social norms influencing blogging practice is the found in the interviewees' perceptions about social norms for intimate expression. It is not only in respect to political expression that the bloggers in the sample acknowledged the influence of their readers in particular and social norms in general. As discussed in Section 4.1 some bloggers appeared to resist what they saw as a pressure to be open, but others perceived the 'freedom' of this space as a potential opportunity to voice aspects of their lives that were troubling them. In the quotes which follow one can see the tension between the desire to take advantage of the potential seemingly offered by this communicative context for unconstrained speech and concern about potentially negative reactions based on conventional social norms:

I avoid writing anything about love and sex and stuff like that, because again, that is one of the things where people write something and then someone else gets offended about what was written about or about the fact that nothing was written about them, or whatever, and it is just too tiresome for words. Also, that sort of stuff is generally only of interest to the people involved, and as a rule I try and write something which will be of at least potential interest to anyone. - Adam

Betty remarked:

I avoided posting about how miserable I was... I have thought 'people don't want to hear that. I'm not going to write that.' - Betty

And Elaine commented:

I'm sure that people don't want to read about my crappy experience of depression really - they would much rather read about what I thought of 'Charlie and the Chocolate Factory'. - Elaine

Surprisingly, none of the interviewees remarked that they were concerned that readers might disapprove of intimate expression. Rather, they seemed to be concerned that their readers would not find such material interesting or entertaining (consistent with the expressed norm that blogs should be entertaining or funny outlined above). Although the phrasing of the reason for this perception was similar among the different interviewees, the reasons for readers not to find what they said 'interesting' differed. For bloggers like Kevin, his blog, despite occasional discussion of 'private' issues, was essentially perceived as being a public space. As a result he suggested that intimate revelations would not be situationally appropriate -"if I'm talking to somebody about [personal] stuff it will happen by email or it will happen by phone or face to face. I can't see why people would be interested for a start." Phillippa, a middle-aged artist, said that she felt that the art world, in particular, was often resistant to online self-revelation: "I think it goes back to the idea that if you expose too much of yourself or too much of how the work was made or something like that then you are taking the magic away." 
For Nancy, a 19-year-old student who writes fan fiction, and Elaine, above, there was a sense that unlike Phillippa, Kevin and Adam, they might wish to receive emotional support through expressing difficult feelings but that they were afraid that it might not be offered:

Ultimately although my friends do care if I'm upset and stuff they would rather read an optimistic post than a negative post so if I'm going to be all emotional and stuff I'll usually try to save it for a real life conversation or something. Occasionally I make emotional posts but not so often... Because people aren't really interested in reading about that sort of thing and it's - not to do my friends down because I'm sure they would be supportive and stuff if I was feeling upset but I know from my personal experience that it can be a bit awkward around someone who is just being really emotional all the time and after a certain point it does become a bit hard to take them seriously.

As for Elaine, she said that she reads others whose journals are at times more emotionally revealing, but that this had not encouraged her to post herself - rather the reverse. She did not appear to have much sympathy for them or enjoy such postings herself:

There are a lot of teenagers on LiveJournal all talking about their teenage angst. You know - 15 year olds. And they are all saying things like 'my mum wouldn't buy me a book that I wanted to buy - God. my life is terrible'. After a bit it's a bit like 'ok. Get over yourself.

Elaine's situation is complex and her attitude towards her readers appears to be conflicted. On the one hand (as shown in section 4.2.2), she claimed that she does not write with her readers in mind. On the other hand - perhaps because of her professional practice as a journalist, she did claim to take pains over her writing:

I am also a disciplined editor and I am quite hard on myself about what my blog... if I go back and see an entry which is not very well written - even if it is an entry from last year which no-one will ever read - I will spend a while editing it and if I still can't get it right I'll just delete it.

Here too she suggested that this is something she does for herself rather than for the audience. Nonetheless, the sense that what she writes has to be well-received by an audience seemed to limit what she writes to some extent:

There are days when all I want to write about on the blog is how much I... is my experiences of depression and this that and the other. But I don't because I know that there are thousands of other people out there writing blogs like that and they are probably really boring and I'm not sure that anybody really wants to read that.

She appears in this quotation to acknowledge that it is not uncommon for weblogs to contain revelations like those she would like to make, but she does not seem to value those blogs herself and did not wish her blog to be among their number.

In summary, despite the formal and rhetorical freedom of expression associated with blogging practice, several of those interviewed revealed limitations to both political and emotional expression on their blogs that appeared consistent with and derived from social norms in everyday life.

\subsection{CONCLUSION}

This chapter has outlined some of the biases influencing personal blogging practice that were revealed by this research and which tend to challenge the dominant framing of personal weblogging as a practice free from the legal, financial and social constraints of other forms of communication. Norms that are emergent and appear specific to personal weblogging practice - for example, the 
bias towards openness and honesty of expression - are shown to sometimes conflict with preexisting social norms which are applied in this new context - for example, norms against excessive self-revelation in everyday conversation. These observations will be considered in greater detail in Chapter 8 in the light of the explanations suggested by the conceptual framework. In the next chapter I discuss the uses to which the weblog form has been put by the authors in the sample, how these appear to have changed over time, and the differing perception and importance placed on the availability of blogs through time. The next chapter is the final contribution setting out the empirical findings of the field research. 


\section{Chapter 7: Blogs and blogging through time}

\subsection{INTRODUCTION}

This chapter is presented in two halves. The first half reveals how in the case of those interviewed blogging practices can often change over time. The second half examines how the content of these blogs may persist over time, thus potentially preserving in the same context different blogging practices, and how and to what extent this characteristic of blogging technologies is accounted for by bloggers. The discussion in this chapter is responsive to the aspects of the conceptual framework in Chapter 3.5 that deal with the temporal aspects of blogging. The aim is to provide a basis for an assessment in Chapter 8, firstly, of the conflicting claims in the literature over the extent to which bloggers value the archival function inherent in blog technology and secondly of the extent to which bloggers perceive the potential risks to their current self presentation from reading of earlier blog postings outside their intended temporal context ('secondary reception') and their willingness and ability to act on any concerns by retrospectively editing their blogs.

A weakness of most of the studies of weblogging undertaken as of the end of 2008 is that they are not conducted using a longitudinal research design. Data are normally collected at a single point in time, whether through interviews or surveys (or where data is collected over a longer period as with ethnographic studies, changes which occurred over time are not highlighted). However, as suggested by the insight offered by the conceptual framework for this thesis, time appeared likely to be a central dimension of weblogging practice. This is intuitively the case, given that the date and time of a weblog posting are generally presented at the top of each post and that weblogs are nearly all archived from their beginnings in date order. As a result, while the age and 'lifespan' of most web publications is indeterminate, the date weblogs were last updated is readily visible and, by convention, they need to be continually updated to avoid the risk of being considered by readers as having been 'abandoned' (see the perceived obligation to update mentioned in Section 6.3.1 and Section 6.3.4 and the section on reader contexts in Appendix A).

While personal blogs can have a natural beginning and end and they can be focused on a single aspect of a blogger's life or personal issue (as with a pregnancy-centric blog, for example, or one related to a journey), the blogs of the bloggers I interviewed were much more loosely-structured - even when they began with a particular topic in mind. As will be outlined in Section 7.2, they generally began without a strong motivating impulse or clearly articulated purpose, drifted from topic to topic and even from one central framing to another, and finished without a conclusion often without warning - in response to changes in the author's motivation, in their life stage or, in some cases, due to concerns raised by a change in their perception of their readers. This finding is 
potentially important both in itself and insofar as it results in blogs which record in their archives different blogging practices with potential consequences for the consistency of bloggers' online self-presentation.

While home pages and social network profiles to a large extent allow users to continually update what they have written so that it presents a self consistent with what is desired at the present moment, doing so on a blog site would be significantly more difficult for several reasons which will be developed in Section 7.3. This section outlines the differing attitudes towards the archiving of their blogs manifested by the bloggers interviewed.

\subsection{Changing BLOGging PRACTICE THROUgh TIME}

As outlined in Section 6.3.1, bloggers can start their blogs without committing themselves to a theme, they can write about multiple topics, change the topics they write about over time and post at irregular intervals, all without clashing with norms embedded in the blogging software itself or (seemingly) with reader expectations.

The temporal aspect of bloggers' motivations was elicited as discussed in the methodology (see Chapter 4) by inviting interviewees to reflect on how their blogging practices changed as their life circumstances changed and as their experiences of blogging - continuous and discontinuous matured. Although based on self-reports, and therefore subject to the varied processes of recall about their imagined communicative environments online there were often clear distinctions between early and later periods evident in the interview data. In addition, after the initial interviews, some changes in the way bloggers framed their practices appeared to have occurred that were reflected through changes in the blogs themselves and the reasons behind these apparent changes were probed via follow-up emails to selected interviewees.

While 12 of 23 of those interviewed expressed a purpose for their blog at the start and continued more or less down that path, the remainder either claimed to have had no clear purpose to begin with and to have discovered one along the way, or said that they had found their practice developing in directions they had not anticipated. Three principal reasons for changes in blogging practice over time were identified - changes in bloggers' imagined relations with their readers, changes in bloggers' motivations; and changes in their circumstances.

\subsubsection{Changed relation to readers}

A common way in which a blogging practice can change over time is a shift in the perceived nature of the relationship of the bloggers to their readers. Four of those interviewed appear to have shifted the focus of their blogging to recognise the existence of audiences they had not anticipated. At first Colin, Elaine and Isobel claimed that they had blogged as if nobody was reading what they 
wrote. Colin recalled changing his blogging practice twice in response to shifting conceptions of his readership:

It started as a diary. It was a, "this is what I have done." And it very quickly became, "I'm writing a diary but people are reading it." The moment you start to have comments on it, it actually shifts - or for me it shifted the way that I approached it. Suddenly I'm not writing something for me to read. I'm writing for my friends. And I think it was about six months in I started seeing people there I didn't know. And I'm writing for an audience. And there is a paradigm shift during that period - Colin

With the first comments he said that he began to write not for himself but for his friends and, within six months, he found what he was writing was also being read by others he did not know. He then discovered that some work colleagues also had LiveJournals which caused him to be more cautious about commenting about his work. Similarly, Isobel started by viewing her blog as akin to a personal diary but came to feel "pressurised to write for the people actually reading it". As she put it:

When I first started posting it was very much an online diary to myself. And then as it kind of grew and as more people started reading it I think I started writing it for them.

Elaine said she started her blog as a purely personal writing exercise and although she quickly gained readers she continued to treat it as if it were only being read by herself until two factors intervened - she went freelance and was approached by a professional blogger who encouraged her to see her weblog as something she could market to potential clients. Annie's blog at the time of interview was conversational in tone and included content (notably about her drinking) which she acknowledged could cause her family or an employer concern. Several months after the interview, she removed all her archives and began blogging exclusively about her work, and then removed her blog entirely. When asked what had happened she explained:

Initially I stopped blogging as it was being used against me, and I was being 'e-stalked' by various people - I was putting too much information out on the internet. Then since I had some success with visibility on the internet, I thought I would use the blog to further my career - this didn't work. So I just retired the idea altogether.

\subsubsection{Changed motivations}

The interviewees also reported changes in their practice because their initial motivation was not satisfied or was overtaken by another. Charles reported that he began his blog with political links, then changed to a more personal diary format when he moved temporarily to the US because he felt he needed a way to keep in touch with those he left behind and wanted to chronicle what happened there. In the period post-interview he returned to predominantly political blogging but with intermittent personal posts. Donald said that it took him too much time to write stories:

Originally it was just up there to post stories. That's why I started it. But slowly but surely the stories have dropped off and the opinions come through although the odd story does go up.

His move away from stories could also have been a reaction to his own evaluation that his stories were not getting commented on while more opinionated pieces were. "People don't go to 
blogs necessarily to read two or three thousand word epic poems or something - they go there to get snapshots of people's lives and I think I maybe misunderstood what the point of my blog was going to be at that point". That said, in his weblogging practice after the interview he returned to posting short stories, interspersed with occasional personal comments. Quentin, as noted above, claimed that he had started his blog thinking he could build a readership and perhaps emulate the success of other bloggers in attracting an audience and building a journalistic brand which he could capitalise on. He came to realise early on that attracting an audience big enough to make a living from or to interest a mass media outlet was not a realistic target. Instead, he adjusted his expectations. He said he no longer sought a "huge" audience - instead, he looked for an audience large enough to provide him with good feedback on his ideas and his writing style. He addressed his blog to, "maybe 15 or so friends who are other bloggers" and a sufficient number of other readers to ensure "about five to ten comments [per blog entry] which is ideal for me". After the interview he abandoned the blog altogether, however.

Phillippa began her blog with practical, work-related aims in view, but while "I was trying to be quite serious about it in the beginning... it started to relax pretty quickly - within a month I would say" - led in part by the example of another artist whose blog she found - Ivan Pope (http://www.ivanpope.com/).

He's quite open on his blog - he just puts it out there and says this is what I'm doing and this is what stage it's at, this is what I'm thinking and these are the things that annoy me or whatever it is and I love that - I love his transparency and I thought ' $\mathrm{OK}$ - why not? What have I got to lose?

She appeared to find that the purely practical benefits she sought originally - archiving and promoting her work - were overtaken by the pleasures of interaction with others from across the world. In fact, even before the interview, her artwork very seldom appeared on her LiveJournal at all.

\subsubsection{Changed circumstances}

There is also evidence in the interview data that changes in life circumstances can lead to changes in blog content. Almost anything can, it seems, be used as the basis of a personal weblog entry, but four of the bloggers (all of them women) tacitly or explicitly made discussion of their relationships - particularly their unsatisfactory relationships - a central feature of their blogging practice and, when those relationships changed, it caused the owners to dramatically shift their blogging practice, or to abandon it altogether.

For example, Isobel had recently formed a steady relationship at the time of interview and it was clear in the context of the interview that it was this fact that meant "things were becoming stable" in her life, just as she noted earlier in the interview that she increased her blogging as she 
reached her early 20 s because there “was more personal stuff going on like there was 'him' or whoever else I happened to be madly in love with at the time". As she said:

A couple of weeks ago - a month ago. I thought, "is there actually any point in carrying on because things are quite stable now. I don't have exciting and thrilling new things to write about because I am very settled. Is there any point in continuing? ... I can see it petering out - it's just a question of when. I am not sure when it will but I am sure it will at some stage - probably in the next year... - Isobel (who abandoned her blog shortly after the interview but started another at a different address but with similar content a year later).

Harriet's blog was the only one among the interviewees with a stated theme - her dissatisfaction with men. In practice, this was not by any means the only theme explored on the blog, but when she found a man and then had a child, she eventually elected to put a formal end to her original blog in favour of a blog of relationship advice and a motherhood-related blog that continued the previous blog in style and content but with a different framing more suited to her new circumstances (though she later also re-started her original blog).

Frances also said that she had considered stopping her blog during a period when she found herself happy in a relationship because she felt less need to write to vent her worries and frustrations. She was also uncomfortable in talking about how happy she was (because others might be more sceptical) and in discussing problems (because the reactions of others might magnify her perception of these problems). She foreshadowed this when she was interviewed:

I suppose if I suddenly found a boyfriend or got married or won the lottery and decided to travel around the world then maybe it might get scaled back ... because then there'd be no drama and nothing to write about if everything was smooth sailing.

Phillippa started a new weblog at a new address (and on a new platform - Blogger instead of LiveJournal) because she did not wish her estranged partner to be able to continue to read it.

Representative surveys in the US and UK find that blogging appears to decrease with age (Dutton and Helsper 2007, USC Annenberg School Center for the Digital Future 2008). There are several possible explanations for this. Firstly, to the extent that blogging is an attempt to communicate with imagined peers, the lower internet penetration and use of older people may cause older people to assume their peers are not potential readers. Secondly, it has been suggested that generations who have grown up with the internet are more comfortable with online revelation (see Section 8.3.2), The interview data suggests a third possibility - that the desire to tell stories about one's self may be related to one's life stage (and people earlier in their lives without family responsibilities may have more free time available for such activities).

Although this was not mentioned as a factor by interviewees, it would appear reasonable that blogging practices may change over time as the features of the enabling technologies change. For example, as noted in Chapter VI Section 4.4, Betty remarked that she considered it rude to put up several pictures on a single blog posting because it would make the page slow to download, but added that, in the context of increasing broadband adoption, this might change. In part, because of 
this increasing adoption of broadband, blog services and third party sites have made it easier to post both still images and video on weblogs, which may change the mix of content provided over time. As broadband-connected smartphones become increasingly prevalent, the physical context of blogging may also change, from being predominantly a computer-based, stationary activity to a mobile one (some potential consequences of recent and projected changes in blogging technologies will be suggested in Chapter 9).

In summary, many of the bloggers interviewed appeared to change their blogging practice over time because of changes in the way they perceived their audiences, changes in the motivations to blog, changes in their circumstances and potentially because of changes in the underlying technologies. Even when blogging practice changed significantly these changes often did not result in a change of 'venue', nor was there often a formal demarcation between different practices.

\subsection{THE PLACE OF ARCHIVING IN BLOGGING PRACTICE}

The fact that blogs incorporate a visible archive of all postings is one of the key defining features of blogging technology. However, just as academics' framings of the importance of blog archives are varied (see Section 2.4) the attitudes towards such archives varied among those interviewed. Six of 23 said that they valued the existence of these archives and re-read them from time to time - the rest seldom mentioned them. Two interviewees whose attachments to their archives appeared to be particularly strong are Frances and Phillippa. Frances said she re-read old entries "just because I'm stuck in a really really boring job" and that "I like to go back and read it and think, 'that was really well written and I really expressed what I was feeling at the time." And Phillippa, an artist, said she valued being able to look back at her creative thought process - "it's a huge asset to my work, I think" but this perceived benefit was not entirely practical or work-related - it appeared tied to a more personal appreciation of the value of memory. She compared the archiving function of the blog to the "stacks of sketchbooks" she had in her studio and said, "they're lovely and I do love them. The feel of them and looking at the pages and everything but if you're on the road or something like that you can't just carry them all with you".

Two others also spoke of the practical benefits of the recording and archiving of more personal material - the use of a blog as a form of "outboard memory" (Doctorow 2002). George said, “you can go through your life and have 101 stories but what's the point if you don't document them - they might as well not exist." And Simon spoke of his blog as an "experiment" to "help me keep track of the changing world. New attitudes to things or new ways of doing things" - a form of permanent record "lest the world forget", or to himself, even of trivial things like "an account of my trip to WH Smith". 
Doug, by contrast, said looking back was "very rare" - in part, because finding a particular post in the past was "a real effort" - you would have to "dig and dig and dig" - at least until the advent of tagging (see Appendix A for an explanation). Whatever these bloggers said about their attachment to their archives, it was not clear whether these bloggers actually re-visited their archives often or whether it was largely the knowledge that they would be available to them that they felt was important.

A further six of the interviewees claimed that their archives contained material that they were ashamed of. Betty, for example said she does not like to look back at hers because of this:

I would curl up with embarrassment if I were to go back. ... I did revise the one I had way back originally. And it was horrifying. I sounded like an over excited five year old. ... It's like hearing one's self recorded.

Marie had a weblog she wrote when she was 13 which was abandoned and then disappeared and she said it was "sad" but "it's like reading things which you've written and you think to yourself 'oh my God how could I have written that?' so I wasn't particularly upset to have lost all that."

Whatever their embarrassed feelings about old postings, however, six of those interviewed said that they should stand by what they had said and were reluctant either to edit or delete old postings. Charles was concerned that some of his earlier postings did not reflect his current political views but said he would not edit them:

because I think it would be somehow dishonest. I mean something that's on there from two years ago is what I was thinking at the time and it would seem meaningless to go back and change it and then publish it as still being then and it would also seem meaningless to go back and post it now given that most of the time the issue has moved on or whatever and is no longer relevant.

As we have seen George, who was fired after his weblog was discovered by his employers, nonetheless said he could not bear to remove it. Harriet noted that although what she had posted about previous relationships might endanger future ones, "I think my fingers don't post if I can't stand by it. I may live to regret that sometime.” And Renia - who was 17 at the time of first interview and whose blog mentions a suicide attempt and episodes of self-harm among other issues, said nonetheless, "I tend to try to leave it as much as I can because I think it might be wrong to alter it just because I am a bit embarrassed." Annie said she did sometimes take down postings she regretted making but, “it doesn't happen very often - usually I leave it up. I hate it when people don't leave their posts up. I like to go back and read." She did remove her weblog a few months after being interviewed, however.

Some simply suggested that the task of editing would be too onerous - Bruce said that after he heard of someone else having been fired for blogging he became more cautious about postings that would breach his work contract but he hoped that people would not read back and find his more contentious writing and he "never actually got around" to editing his older postings. In 2008, he was 
approached by his employer and at that point he was able to use a 'mass editing' tool in LiveJournal to make his whole journal friends-only. This tool is not available for the majority of LiveJournal users who do not pay a subscription to the service (Livejournal 2008) - and having maintained a journal since 2003 he had produced approximately 500 postings. Betty considered trying to delete the old postings that she found embarrassing but "realized it would be an enormous job" and abandoned the task. The only person who mentioned large-scale retrospective editing of his archives was Doug, who did it at the request of a now-estranged LiveJournal 'friend' who asked him to remove links between her journal and his.

Consistent with the observation in Section 5.2.2 that those interviewed ranged widely in their perceptions of the likelihood that others were reading, their perception of the likelihood that others would read their archived postings also varied.

Simon appeared to hope that in future historians might read blogs like his to learn about life today (though he is "quite ashamed" of some of the postings he has made which are "very trivial and of no value to anyone, probably").

One thing about weblogs is that they might be an interesting reflection of our society in the future. Maybe for a social historian. Um. And there are people who are archiving websites before they disappear. So the sites like The Way Back Machine, yeah and so on. So I hope in the future, people will still be able to see all this electronic information.

Most other interviewees, however, when they spoke about their archives at all, appeared to view them as of interest only to themselves. Renia, for example, said, "When I am 30 or older I will think 'how did I get from there to there?' and I would see. It would be good to see how it goes along - how it all worked in the end."

Annie appeared to believe that nobody would read through her archives - at least not in their entirety - although she said she enjoyed reading the archived postings of others. When she discovered that at least one blogger was willing to read her blog in its entirety she was surprised and somewhat perturbed:

There was a guy advertising a LiveAid ticket for free as long as he came and stayed... I said 'read my blog to see if you want to do it' so he read my entire blog. The entire thing. Really creeps me out. He came down and he was awesome - a really cool guy - but he knew everything about me and I was just like 'woah'. I didn't really think anyone would pay that much attention to go all the way back through it and really really read it.

Betty in part justified not editing her old posts because "I don't think anyone would scroll back and read it all", although she had noted earlier in the interview that "people who are acquaintances of yours begin to have quite an intimate knowlege of what's going on in your life", and Charles left up his early political postings (albeit 'filed away' separately from his then-current blog) because "I couldn't see why anybody would want to" read them. For Harriet this is a source of occasional frustration - "I appreciate that not everybody has been reading [my blog] since the 
beginning but sometimes people do comment on things that if they even read back two posts they would have the whole story." And for Phillippa this piqued her vanity:

I think it's more the egotistical thing of 'I thought that was a particularly good piece of writing and I want it to be set in stone for whatever it was and then having to realise that well it's not. It's a live document - it's changing all the time and moving on and so does the world so that's just the way it is. So I had to let go of that quickly. Because when you write something - you would know as a journalist or a writer - if you write a book then you have this object. You've got this book - it's there and can be passed around and read again or whatever. Whereas with this it can be accessed definitely but it probably won't be.

Elaine repeatedly stressed that her blog was produced primarily as a writing exercise for herself, so she said that she did go back, read and re-edit old entries, but said in the case of year-old entries that she did so believing no-one will ever read them. It appears clear from this that these interviewees are focused on what in Section 3.3.3 is termed 'primary reception' - the time that a particular posting is made - rather than on 'secondary reception' - subsequent readings outside of the original temporal context.

When interviewees' perceptions of blogging practice changed radically, they did not therefore attempt to systematically re-edit what they had written to reflect this change - they stopped blogging on their present sites, either leaving their archived text online or attempting to have the text removed or hidden. A few then started new blogs elsewhere.

Among those interviewed (who were active bloggers to begin with, hence a disproportionately engaged sample), six of 23 appeared to have abandoned blogging since their interviews (last checked in July 2008), and six had moved their blogs to different places or added passwords in order to start anew. Frances moved her blog without indicating the new address in order to be able to speak freely "out of earshot" of an ex-partner who read her existing blog. Others were posting very irregularly - Renia posted 128 times in 2005, 40 times in 2006, five times in the first three months of 2007 and once in January 2008. Both Frances and Harriet have repeatedly announced their intention to stop blogging only to re-commence it. Elaine also announced an end to her blog, leaving it visible for a time with the announcement, then closed the site entirely, though she too said she intends to start blogging again.

Even when blogs are abandoned, however, they can have an 'afterlife'. Of the eleven blogs by the bloggers interviewed that subsequently appeared to have been permanently abandoned or hidden from public view, most or all of the archives of five remained visible at the time of writing. When George was dismissed from his job he made the blogger archives of what he posted harder for a casual browser to find and started a new blog with a similar name. He said during the interview that he could not bring himself to remove the archives completely, however. Of the sites where the archives appear to have been deliberately hidden from public view or removed, the two LiveJournal sites were inaccessible to the public, but two of the four blogger sites which had been closed are 
archived partially or fully via archive.org. In these cases, their content does not appear in casual web searches but anyone who knows what the addresses of their weblogs were can see what they had said. It is also possible (if unlikely) that readers of any of these weblogs may have used one of the many free tools available to archive web pages onto their hard disks for their private use.

The way in which archives like archive.org operate is seldom discussed in the press or online outside specialist circles. Only one interviewee, Simon, spoke of the existence of such third party archives and it is not likely that many bloggers are aware of how to manipulate their weblogs in order to keep their sites from being archived in this way. When asked about her attitude towards such archival sites or caches, Frances said, “I wasn’t actually aware you could request cached content to be removed". Site authors can request that their site should not appear in their indices using the accepted technical code for this purpose ${ }^{71}$ but Blogger does not alert its users to the existence of such third party archives or provide detailed instructions for its users to implement the changes to their blog that would be required in order to protect their entries. On LiveJournal the relevant privacy setting is one of 19 on a lengthy page and defaults to allowing archives access to postings that are not otherwise marked as being private. In addition, requesting that search engines should not index pages does not guarantee that they will not be indexed - it is a convention that is not always followed. Even privacy protection functions provided by websites designed to prevent access to pages from anyone other than authorised users are not always effective (Thomas 2008).

The lack of emphasis on archives among some of those interviewed could be linked to the uncertainty over whether blogging practice bears a closer relation to orality or written speech which was alluded to in previous research (see Section 2.4). This was not directly probed in the interviews, but in the case of at least one interviewee, Isobel, blogging was clearly framed as an oral activity. She said she was not happy to pursue political arguments on her blog because, "if I had to actually sit down and write a coherent argument about why I believed X, Y and Z. It would just ruin the sort of spontaneity."

To partially substantiate the blurring of the framing of blogging between orality and written forms that was suggested in some blogging literature, I counted the frequency of appearance of the words "I wrote" (24 times) when associated with weblogging in the interview transcripts and compared this with the frequency of "I said" and "I talked" (15 times altogether). Twice both oral and written framings appeared to be used at the same time, which seems to highlight the ambiguity in bloggers' perceptions of their practice. Harriet mentioned "a recent post where I talked about

\footnotetext{
${ }^{71}$ See http://www.robotstxt.org/ for more about how this works.
} 
forgiveness" and Betty said she had decided, "I would write... and it would be, not formal exactly but careful about you know, how I talked about other people."

To the extent that blogging is experienced as oral, it may also be perceived as sharing speech's normal properties of transitoriness and this may consequently also concentrate the producers' attention on primary rather than secondary reception of their blogs.

In Chapter 5 it was noted that many bloggers appeared to orient their practice in relation to an imagined and somewhat idealised audience, and to overlook - possibly deliberately - other unintended audiences. Similarly, the evidence outlined in this section appears to suggest that many bloggers either overlook the possibility that their archives will be read by anyone other than themselves (possibly because blogging seems more an oral than a written practice) or they imagine such reading as taking place in a distant future time by themselves or by a well-disposed posterity.

\subsection{CONCLUSION}

In the first half of this chapter (Section 7.2), it emerged that a substantial minority of those interviewed had changed their attitude towards their blogging practice after starting blogging sometimes more than once. However, there were a number of cases in which these changes did not result in the changes to bloggers' blogs that might be inferred from the conceptual framework. In particular, bloggers did not attempt to edit their past blog postings to make them consistent with changed framings of blogging practice, even when past postings embarrassed them. And, even when they abandoned their blogs altogether, they often left the text of those blogs online rather than seeking to have them removed.

The examination of interviewees' attitudes towards their blogs' archives in the second half of the chapter (Section 7.3) provides two chief potential explanations for this behaviour. Firstly, it appeared that several perceived a norm that they should not edit past entries which may also have influenced bloggers not to attempt to remove weblogs from view that they were 'finished with'. This may also be related to the sense that weblogs are an open-ended project - some appear to have finished blogging since they have not posted for several months, but they evidently did not feel they needed to formally announce an end. Even such an announcement does not appear binding - several bloggers posted that they were finishing and then re-commenced blogging without further explanation. Perhaps because of this open-endedness, bloggers appear reluctant to take the final step of removing their blogs completely. At the time of the fieldwork, any such decision would be final and irrevocable (Blogger n.d.-a, Livejournal 2007) ${ }^{72}$.

\footnotetext{
${ }^{72}$ It is now possible to remove one's blog from public view without deleting it altogether, but in the case of LiveJournal, this would by default involve changing the privacy status of each post individually and this option was not available for Blogger users at the time that fieldwork was being conducted. The relevant web pages explaining how to
} 
Secondly, it appeared that they generally did not expect readers to read the archives of their blogs - they appeared to be focused on their blogs' 'primary reception' or, to a lesser extent, on their own reading at some point in the future. Thus, it may not have appeared necessary for them to make later posts consistent in content or style with earlier ones. This focus on the present may be related to a perception of blogging as an oral rather than a written form which has been tentatively identified. The implications of these findings in the light of the suggestions derived conceptual framework will be further explored in Section 8.5. 


\section{Chapter 8: Further Analysis}

\subsection{INTRODUCTION}

In this chapter, the principal findings from the three preceding empirical chapters will be considered in the light of the over-arching research questions this thesis addresses:

How do personal webloggers understand this practice and how does the practice relate to its social and technical context?

In Section 8.2 the implications of these findings as a whole will be outlined in relation to the insights derived from the conceptual framework outlined in Chapter 3. In Sections 8.3 through 8.5 the findings will be discussed in further detail in relation to the three sub-research questions that emerged from the conceptual framework and which were addressed in chapters 4 through 6.

Chapter 5 was responsive to the first research sub-question:

How are the readers of such sites imagined by the producers and how does this imagination shape the authors' practice? In particular, to what extent do they feel in control of their interactions, what do they feel might threaten their control over social information exchanged and how do they manage such threats?

The first half of that chapter outlined the information that was, or could be, made available to personal blog producers that they could draw on to picture their readers. It went on to examine through analysis of interview data, the extent to which bloggers sought such information and what their impressions of their audiences actually were. The second half of the chapter outlined the variety of relationships to their readers that were desired by the bloggers interviewed. The extent to which they felt in control of their interactions was tackled in Section 6.2, and aspects of the control of social information were tackled in Section 6.4 (and also - in relation to the archives of their blogs - in Section 7.3). The analysis of these findings is in Section 8.2 below.

Chapter 6 was primarily responsive to the second research sub-question:

What are the principal sources of constitutive and implementation bias in personal weblogging, and how are they perceived and encountered in practice by personal bloggers?

The first part of that chapter (Section 6.2) outlined the impression of control over their environment and of freedom from constraint which bloggers appeared to share. It then set out some of the ways in which personal blogging practice could, nonetheless, be influenced (or 'biased' to use Feenberg's terminology (Feenberg 2008)). Section 6.3 was divided into four sub-sections. It first tackled "constitutive" bias embedded in the technology itself. Secondly, it tackled "implementation" bias which derives from the interaction between technology in use and its social context, drawing primarily on an analysis of the interview data. Following a schema suggested by Lessig (1999, 2006), possible sources of implementation bias were subdivided into three principal contexts - the legal context, the market context and societal norms. Some of the latter appear to be 'local' norms specific to blogging practice, some seem to have been derived by analogy with other 
media practices and others are norms in place in wider society which impinge on blogging practice. The analysis of these findings is in Section 8.3 below.

Chapter 7 was primarily responsive to the third research sub-question:

How do personal bloggers understand and negotiate the space-time interpolations inherent in their practice?

In the first half of that chapter, the principal temporal aspects of blogging practice were briefly outlined and the propensity among the bloggers interviewed to change their blogging practice through time was analysed. In the second half, bloggers' expressed attitudes towards their archives were outlined. To return to the other two sub-questions this chapter also included a discussion of their (lack of) willingness to alter their archives in order to exercise control over the potentially inappropriate release of social information and some of the biases which hight help to explain the relationships to temporality which were found. The analysis of these findings is in Section 8.4 below.

\subsection{COMPLICATING MEDIATED INTERACTION}

This research was, in part, inspired by the desire to solve an apparent puzzle, which was (and still is) being raised by journalists and policy-makers - why do personal webloggers choose to share potentially sensitive information about themselves with a broad audience across the internet? This question is in itself too broad for an academic study of this kind. As noted in Section 3.1, however, our knowledge of how personal webloggers understand their practices is as yet at an early stage. Thus, to provide a foundation for future enquiry, the core research questions this study addresses are "how do personal webloggers understand their practices?" and (because both this understanding and the practices themselves are potentially shaped by contextual factors) "how does the practice relate to its social and technical context?"

There appear to be a number of unspoken presuppositions behind questions about why it appears webloggers choose to share social information online. Chief among these (as outlined in Section 2.4.2) is the assumption that personal webloggers have a desire to communicate with an indefinite audience and that they select weblogging as a communicative means because of the technical features that enable this form of communication. The inclusion of symbolic interactionism in the conceptual framework for this study was important in helping to unravel this as it recognises that communicative situations do not have an inherent meaning or essence but, instead, are arrived at in a negotiated fashion. Similarly, as I outline in Section 3.3.2, Thompson's analysis of mediated and unmediated interaction is based on imagined, intended and anticipated relationships not on actual ones. Thus, this study focused on how personal webloggers understand their practices, thereby ensuring that these assumptions would be open to question and could be examined using the empirical evidence produced for this study. 
A number of factors have come to light as a result of the analysis in the preceding chapters that add complexity to our understanding of personal blogging as an interaction. First, it seems that a desire for interaction itself or a desire to reach an audience are not always central to blogging practice. For some of those interviewed for this study, the practice of writing or the pleasure of tinkering with a new tool were central - at least as an initial motivator (Section 5.3.4).

This finding was not envisaged in the light of the conceptual framework but it is consistent with a number of findings in other contexts. In an ethnographic study of home computer purchasers in the late $80 \mathrm{~s}$, for example, Murdock found that for many "the pleasures they offered derived not from particular applications but from the possession of the technology itself and from solving the problems involved in getting it to perform" (Murdock et al. 1992 p. 152) and Aune characterised some computer users she studied as explorers, saying of one of them, "he expressed a relationship to the computer as more than a tangible tool. The computer itself was a goal." (Aune 1996 p. 103). This was also found by Rosenstein, Bober and Hine in their separate studies of personal home page creators (Bober 2004, Hine 2000 p. 93, Rosenstein 2000 pp 56-57). More recently, Thumim found in her study of 'ordinary people' involved in institutional digital storytelling projects that several of them participated, not in order to reach an audience (at least not primarily), but because of a desire to learn new skills, engage with new technologies and because of the stimulus it gave them to practice something of essentially private value - as when one interviewee spoke of "the opportunity the workshop gave him to delve into family history and, by that route, also personal identity, for his own interest." (Thumim 2007 p. 202). An ethnographic study of young US internet users found that, while they enjoyed 'hanging out' online in order to interact with their friends, they also occasionally valued what the researchers termed "messing around" and "geeking out" using digital technologies - practices that are primarily exploratory and "only loosely goal directed" (Ito et al. 2008 p. 23).

Until recently, the idea that the creativity involved in the writing process itself could be the primary motivation for weblogging practice has not been extensively studied, but evidence to support this has begun to emerge. A poll of US webloggers revealed that the single most popular reason offered (by 52\%) for weblogging was "to express yourself creatively" (Lenhart and Fox 2006) - a motivation that was also noted in Menchen Trevino's interviews with webloggers (Menchen Trevino 2005 p. 9). Potentially linked to this is the symbolic power associated with media participation. This may include the sense identified by Couldry (2000) that those depicted by the media feel that they become thereby somehow 'important' and the sense of empowerment that Rodríguez (2001) suggests can come through media production (although as amateur media production online becomes more common, this may itself dilute the sense of 'specialness' associated with media production). 
Second, to the extent interaction is important in personal weblogging, different bloggers seek a variety of different forms of interaction. Although 'telelogic' interaction with unknown others may be blogging's most distinctive affordance, it did not appear to be the central form of interaction sought by most of those interviewed for this study. The largest single group of interviewees framed their interactions as being with known others rather than with an indefinite audience.

Third, bloggers in this study often did not appear to be completely aware of all of the relevant technical characteristics or features of the blogging medium they had chosen and in some cases were not able to use certain features they might find desirable either because of lack of knowledge or social bias. Moreover, in their day to day practice they appeared to attend to the features most relevant to their intended use and to overlook or underplay other features that facilitated unintended interactions. Two unintended kinds of interactions identified in this study are the reading of postings by unintended others and the reading of postings outside their intended temporal context (which I have termed 'secondary reception'). Both represent a potential threat to what Goffman might term the blogger's Umwelt or their informational and conversational preserve because, as noted in Section 3.3.1, the sensitivity of the release of social information can stem from its removal from its original context as well as from the nature of the information itself.

Three explanations for the apparent indifference to such threats among the bloggers studied are advanced in Section 8.3 which follows. The first is that, because they enjoy the practice as they have framed it, the interviewees avoided seeking evidence that would seem to threaten that framing. As Goffman remarks, various communications about the self can be by-passed or downplayed:

Facts are of the schoolboy's world - they can be altered by diligent effort but they cannot be avoided. But what the person protects and defends and invests his feelings in is an idea about himself, and ideas are vulnerable not to facts and things but to communications. Communications belong to a less punitive scheme than do facts, for communications can be by-passed, withdrawn from, disbelieved, conveniently misunderstood and tactfully conveyed. (Goffman 1967 p. 43).

The second explanation is that the interviewees in this study did not regard the social information they provided on their blogs as being sensitive. The third explanation is that the medium seemed to shield them from perceiving unfavourable reception of their provision of social information. This last may be partly attributable to the fact that the interviewees did not receive impressions that would be 'given off' in face-to-face or other mediated interactions and partly because social conventions around blog reading do not seem to encourage readers to give anything other than positive feedback. In addition, the bloggers in the sample tended to overlook the persistence of their blog postings through time. This may be because although some were aware that their weblogs are archived through time, the archived posts disappear from the 'front page' of their blogs and therefore from their attention, or because they tended to suggest (in part based on their own experience of blog reading) that blog readers do not read archives. 
Overall, this study suggests that a focus on thinking and self-awareness in the construction and maintenance of blogging practices in previous blogging studies - two "facts" about human beings that Maines characterises as central to symbolic interactionist thought (Maines 2001 p. 3) may lead researchers to overlook other contextual factors that may influence blogging interactions. The bloggers interviewed for this study were indeed self-aware and thinking, and often presented coherent accounts for their blogging practices. Nonetheless, there is evidence from the analysis of the interviews and through comparison of the interviewees' accounts with the evidence in their blogs of their practice, that their blogging was not always conducted with deliberate attention to all of the relevant factors that they identified as important in their accounts of their activity. For example, while they often professed awareness (and sometimes concern) that many of their weblog postings could be read by anyone online, they also tended to suggest that their everyday practice is governed by a narrower conception of their readership - limited to friends and well-disposed strangers $^{73}$. As Maines also observes (ibid., p. 3), interactionists centrally see human activity as occurring in contexts. This study points out an important corollary to this in the case of blogging contexts can be consciously chosen and manipulated (as when a blogger chooses to make a post 'friends only' instead of public) but they can also influence practice more subtly - a process which is mainly examined in Chapter 6 using Feenberg's technological 'bias' framework. For example, the bloggers' social context can influence what is perceived as appropriate blogging behaviour, as when politically-engaged people choose not to blog about their political interests because they are not experts - see Section 6.3.4 - and the design of the blogging software's user interface can influence bloggers' perceptions of their audiences - see Section 6.3.1.

The analysis of the empirical evidence in this thesis suggests that while personal blogging appears to be centrally an inter-subjective practice, its importance to those who are involved in the practice can be primarily intra-subjective. To the extent this is the case, blogging may be 'about' the writing itself as a process, or about interactions with others that are, and are at some level intended to be, primarily imagined. A typical example of the latter might be a blogger writing a posting with friends in mind who may imagine sympathetic interest, but may have no particular friend or friends in mind and what he or she desires and expects may not be a 'given' response but an imagined sympathy 'given off'. As Goffman suggests in his analysis of everyday talk, "The response we often seek is not an answer to a question or a compliance with a request but an appreciation of a show put on.” (Goffman 1986 [1974] p. 546).

\footnotetext{
${ }^{73}$ For the many users of LiveJournal who use the privacy controls available to direct their personal communications only at specified people this is unproblematic (at least to the extent that they use such controls successfully), but those interviewed were chosen because their personal revelations are visible to all Internet users.
} 


\subsection{THE IMAGINED AUDIENCE}

The first sub-research question guiding this study was:

How are the readers of personal weblogs imagined by the producers and how does this imagination shape the authors' practice? In particular, to what extent do they feel in control of their interactions, what do they feel might threaten their control over social information exchanged and how do they manage such threats?

As noted in Section 3.3.1, some degree, or perception, of control over social information and, in particular, over the kind of sensitive social information the revelation of which might be problematic - is seen by Meyrowitz (1985) (interpreting Goffman) as essential for social interactions. The bloggers selected for study were precisely those whose situation appeared most problematic in this regard. It is not clear how representative those chosen are of personal webloggers as a whole ${ }^{74}$. As personal bloggers those interviewed were providing social information, but since they were publishing that information on publicly-accessible web pages, they appeared to have no control over who would read it and in what context ${ }^{75}$. What seems to explain their willingness to share such information in this way?

\subsubsection{Selective audience perception}

This brings us to the weakness of Goffman's approach to symbolic interaction touched upon in Section 8.2 above - his apparent lack of interest in accounting for self-deception in the framing of an interaction. In his analysis, participants in an interaction can be deceived by others about what is going on or mistaken but there is little space in his work for self-deception. To the extent he does discuss this in Frame Analysis it is in two principal contexts - in the extreme case of mental illness (Goffman 1986 [1974] p. 111), and where distractions and onlookers are "disattended" (Goffman 1986 [1974] pp 202-210 and 225). This latter case appears to be the closest to the situation of several of the bloggers interviewed but as there are important differences between the disattention practiced in the examples given by Goffman and that appear to be practiced by some of the bloggers interviewed. Distractions may appear to be disattended in ceremonial and theatrical contexts but participants continue to be aware of (for example) an interruption to a performance, conspiring to appear to ignore it. In the case of onlookers to a scene or accident, I would argue it is implicit in Goffman's analysis that these are disattended but tolerated because what is taking place does not include the revelation of sensitive social information. He briefly mentions the case of bystanders to

\footnotetext{
${ }^{74}$ In the case of LiveJournal users in particular, no information is available on the extent to which they successfully use the tools available to them to control access to personal postings. While at the time this fieldwork was performed in 2005 Blogger users were not offered similar tools, a basic password protection function has been subsequently offered. It is again not clear to what extent Blogger users now resemble the Blogger users interviewed.

${ }^{75}$ The LiveJournal bloggers in this sample had tools with which they could control access to personal posts, and some used these for certain postings, but those whose blogs formed part of the sampling frame were chosen because they had published social information without using the tools at their disposal to restrict its availability. The degree to which they also published social information on their blogs which was available to selected groups - LiveJournal 'friends' - was not probed in the interviews and not available to the author via their websites.
} 
informal talk alongside the above two cases but such bystanders who eavesdrop on such talk are deemed to be taking "improper advantage" of their proximity (Goffman 1986 [1974] p. 224). The case of some of the personal webloggers interviewed in this study is more complex. They appear to disattend their audiences not merely formally but actually, and they tolerate potential bystanders to their informal talk even though potentially sensitive social information is being shared and even though (by the act of reading) such bystanders would be clearly eavesdropping.

The relative lack of attention given to this issue by Goffman is to some extent understandable in the case of face to face interaction when, under normal circumstances at least, the question of who can be and is intended to be heard by whom is clear (see discussion of the vulnerability of framings to misconstruction in Section 3.2.3). But as discussed in Section 5.2.2 it is the nature of the weblogging practice performed by those interviewed and others like them that there is room for ambiguity about who, if anyone, is reading. While this was a reason for anxiety for some of the bloggers interviewed (as the conceptual framework would suggest), most appeared to derive comfort from not being confronted by their audience. It is apparent that while all of those interviewed were aware at some level that anyone who was online could read much or all of what they wrote, they generally chose to say that they believe that only those they would wish to read it would come across it. A similar attitude held among authors was observed in a different context more than a century ago, by Nathaniel Hawthorne:

When he casts his leaves forth upon the wind, the author addresses, not the many who will fling aside his volume, or never take it up, but the few who will understand him, better than most of his schoolmates and lifemates. Some authors, indeed, do far more than this, and indulge themselves in such confidential depths of revelation as could fittingly be addressed, only and exclusively, to the one heart and mind of perfect sympathy; as if the printed book, thrown at large on the wide world, were certain to find out the divided segment of the writer's own nature, and complete his circle of existence by bringing him into communion with it. (Hawthorne $1850 \mathrm{pp} \mathrm{1-2)}$

As will be noted in Section 9.5, this perception was a two edged sword - encouraging personal creativity in some instances (because it provided an imagined appreciative audience) but also, occasionally, opening blog creators to potential harm when the unanticipated audience reacted in unexpected ways.

Why and how then did the bloggers interviewed come to assume that their audiences were sympathetic? In principle, webloggers can gather more information about the nature and reactions of their audiences than producers using traditional mass media like radio and television (see Section 5.2.1) - one reason why scholars coined the term "telelogic" to describe computer mediated communication (Ball-Rokeach and Reardon 1988). Most weblogs (and all of the weblogs in this sample) provide opportunities for readers to respond to what is produced. Moreover, free services are available that can enable bloggers to evaluate (albeit imprecisely) how many readers they have 
and where they come from ${ }^{76}$. Among the bloggers studied however the information flow from readers to personal weblog producers was limited. Instead of finding this to be a source of anxiety and seeking to increase their knowledge of readers, as my interpretation of interactionist theory (see Sections 3.2.3 and 3.3.1) initially suggested, those interviewed were often found to be selective about the feedback they were attentive to. To the extent this occurred they appeared to imagine their audience in a way that enabled them to continue their practice comfortably.

Unlike the situation of face to face or audio or video-mediated synchronous communication, weblogs do not confront the blogger with social information 'given off' by blog readers. Expressions of disapproval or incomprehension by readers, for example, would have to be deliberately composed and sent to a blog's producer by email or as a comment on his or her blog to be perceived - something that did not appear to occur frequently according to those interviewed. As discussed in Section 2.2, early CMC studies, e.g. (Sproull and Kiesler 1986), stressed the importance of disinhibition effects (they observed a greater propensity to "flame" others when using email than when in face to face interaction). If this tendency had been present in this study, this willingness - even eagerness - to expose disapproval might have acted as a brake on selfdisclosure. Walther (1992) points to a potential explanation for the lower than expected incidence of flaming in the experience of bloggers by reference to the implications of continued interaction over time. This, he suggests, tends to produce increasingly rich impressions of others and thus to inhibit hostile reactions. This finding might be applicable to weblog reading, since blogs can persist over years. Some respondents in this study suggested that there is a norm among weblog readers including themselves - not to be critical in comments on others' weblogs (see Section 6.3.4), consistent with suggestions made in a few qualitative blogging studies (see Section 2.4).

Even on the occasions when the interviewees reported negative feedback, they also reported that they tended to disregard it. To the extent that critical commenters were reported to be strangers, their comments were not seen as relevant to the bloggers' practices for three principal reasons. Firstly, the reactions of strangers were seen as limited to the virtual context and were not perceived to spill over into the interviewees' everyday lives. This appears to imply that, for some bloggers at least, online interactions are perceived as occurring in a kind of safe 'backstage region'. Secondly and relatedly, strangers commenting on behaviour described in an individual posting were perceived to lack the contextual information about the rest of the bloggers' (interviewees') lives which might explain their actions, so their judgements were not seen as relevant or of concern.

\footnotetext{
${ }^{76}$ See Appendix A for more detailed information on the technical features of blogging and the ecosystem of third party sites which provide additional services.
} 
Lastly, for several interviewees, actual (as opposed to imagined) responses did not appear to be relevant to their blogging practice, which appeared to be predominantly self-directed. This is an important contrast to the assumptions of many academics, journalists and practitioners that audience response is central to blogging practice (Section 2.4.2).

\subsubsection{Changing norms of social information disclosure?}

One possible alternative explanation for bloggers' disclosures is that they did not consider the social information they published to be sensitive and therefore felt it did not require control ${ }^{77}$. The degree of perceived sensitivity of social information was not tackled directly in the interviews for this study as it was considered that probing using examples from the bloggers' own sites might be intrusive, might make interviewees uncomfortable and would, in any case, result in data that would be difficult to use in the light of ethical issues associated with sharing such examples (see Section 4.3.2). This possible explanation was, however, addressed indirectly by some of the interviewees who said they did indeed exercise control over the amount of social information they were willing to share in line with the insights derived from the conceptual framework (see Section 6.3.4) - one reading of these responses might be that the interviewees exercised discretion because they were concerned at the potential consequences of reading of their texts by unknown others. This interpretation must be treated with caution, however, as in several cases the cautious attitude expressed by these interviewees was not consistently followed through in the interviewees' blogging practices. Bruce, for example had a LiveJournal and was therefore able to control access to specific posts on his weblog. He spoke of his concern to ensure that nothing appeared on his blog that was political. Nevertheless, several such postings had been made without using the access controls, whether by accident or design ${ }^{78}$. While bloggers may express concern about who is reading their blogs if asked, the evidence in this study suggests that some may not sustain the attitude of caution they express because they are not visibly confronted with their potential audience as they post (Section 6.3.1) - this points to a potential weakness in survey-based research into privacy-related practices.

Another possible explanation for self-revelatory behaviour is that bloggers might recognise that some of the social information that they publish is sensitive but they are more willing than previous generations to share such information openly. An increased willingness to expose the self may be linked to what Giddens (1990) has suggested is an increasing pressure in modern society to

\footnotetext{
${ }^{77}$ The issue of whether the social information provided is actually sensitive is a different one that cannot be answered with the methods used here.

${ }^{78} \mathrm{I}$ am not aware of research on stated privacy attitudes and actual privacy behaviour in the context of blogging but there is a discussion of contradictions between attitudes and behaviour in other contexts in Section 2.5.1.
} 
share intimate life details in a variety of contexts in order to build relationships with others. Similarly, Bauman has asserted that services (like blogs) that enable internet-mediated identity work are, at the same time, being used by their developers to exploit a commercially-driven need for consumers to "commoditize" themselves (Bauman 2007 p. 111). A more pragmatic reason for sharing social information may simply be that the events of bloggers' lives and their reactions to them are the materials closest to hand for would-be writers - as Goffman put it, "although a performer can run out of lively traditional materials, he cannot want for one particular out-of-frame resource - his own current effort to stage a performance." (Goffman 1986 [1974] p. 388) As noted in Section 4.3.2, when approached for an interview most respondents in this study stated a desire to be identified in this research and many were even willing that extracts from parts of their website not normally visible to browsers without permission should be made available in the course of this research. This, in itself, would appear to indicate a higher willingness to reveal sensitive information publicly among personal webloggers than academic researchers have tended to expect from the general public.

Broad societal changes that may be influencing a willingness to share social information online may be complemented by changing social norms associated with particular media forms such as the weblog and the genres of the self-revelatory printed diary column, reality TV or chat show. Several of those interviewed (Section 6.3.4) who said they had chosen to limit what they shared suggested that this was in contrast to the behaviour of other fellow bloggers and that it ran counter to what they perceived to be a social norm of openness particular to weblogging. Both of the professional journalists interviewed for this study saw their weblogs - initially at least - as being broadly similar to the newspaper columns of journalists, e.g. Julie Burchill, who write about their daily lives. Many scholars and commentators have remarked on the increasing prevalence of personal revelations in the mass media (including mass mediated revelations based on weblog postings and social network sites). This prevalence, it is suggested, renders self-exposure more acceptable (Calvert 2000, Kitzmann 2004, Rosen 2005, Shattuc 1997). A “fascination with exposure" is one of the suggested features of the advent of television that Meyrowitz also hypothesized (Meyrowitz 1985 p. 311). Subsequently, researchers studying what they term "digital natives" (those who have grown up using online tools) suggest similarly that "they who live so much of their lives in networked publics, are unlikely to come to see privacy in the same terms that previous generations have, by and large" (Palfrey and Gasser 2008 p. 82). Using Meyrowitz's claims of the development of a "sidestage" region of performance in response to increased revelation of social information in response to television (Meyrowitz 1985 pp 47-48), it could also be argued that in the long term the privacy-related behaviours of bloggers and others will shift 
unconsciously as they become used to the ubiquitous sharing of what was once backstage information.

Many journalistic accounts of personal weblogging appear to accept these arguments and suggest or, at least tacitly, assume that if potentially sensitive material is shared online without protection, its producers must be intending it to be shared, and shared widely (Barker 2005, Cha 2001, Chaudry 2007, Nussbaum 2007). Several scholars also take this line (Rettberg 2008, Van Dijck 2004). From among such scholars I quote Paccagnella (1997), who states:

Conversation on publicly accessible IRC channels or messages posted on newsgroups are not equivalent to private letters (while private, one-to-one e-mail messages of course are); they are instead public acts deliberately intended for public consumption.

And Sorapure who in her study of personal home pages asserts (2003 p. 10):

Audience and purpose are clearly important to online diarists, since these writers obviously and intentionally are creating public documents. Even if no one other than the author reads the diary, it is available on the Web for others to read, and is to some extent put on the Web precisely for others to read.

The results of this study suggest that these scholars are in danger of confusing what the writers are actually doing and what they are intending to do at any given moment in their practice. They also overlook the possibility, as raised in Chapter 7, that even if a blogger decides to reduce the amount of social information in their postings, they may not necessarily hide or remove earlier revelatory blog postings as a result because editing one's blog retrospectively violates other perceived norms of authenticity or may simply appear too difficult, so willingness to disclose social information that is demonstrated in archived material may not reflect an author's present attitudes.

Some of those interviewed did state that they had a greater willingness than most to disclose social information about themselves - for example in the case of one interviewee, Frances, who said:

My whole life is on there pretty much. And there's some really personal, personal stuff on there - there's photos of my neighbourhood on there and if you wanted to you could pretty much pinpoint exactly where I love but it just doesn't really bother me. If I was so concerned about people knowing this sort of thing then I would never have a blog.

In her case, however, she revealed that this willingness to reveal social information was longstanding and that blogging was just one more way in which it was manifested. Most CMC theories posit that online communication tends to encourage self-disclosure (see Section 2.2), and there was some evidence from the analysis of the interviews performed in this study that supports this view, but the interviews did not probe bloggers' communicative practices prior to or outside of their use of $\mathrm{CMC}$ so it is not clear whether and to what extent their blogging practice differed from or influenced their other communicative practices. 


\subsubsection{The varying roles and importance of the audience}

Another aspect of blogging practice that emerged and challenged explanations derived from the conceptual framework and much prior literature, is the intended relationship between the bloggers and their readers. Using a typology of blogging interaction outlined in Section 5.3, while there were several bloggers whose practice appeared to be predominantly telelogic in accordance with the technology's features, the purpose of several bloggers studied appeared to be primarily monologic or self-directed - interaction was either unsought and/or unanticipated, or was intended to be with a generalised imagined sympathetic audience, rather than with specific people. As outlined in Section 5.3.1 and 5.3.4, these framings of personal blogging can be grouped into six principal categories (see Table 8.1 below). The narrowcast group included those keeping friends up to date by broadcasting selected details from their everyday lives or expressing their views without wanting or expecting them to be challenged and those for whom their blog was acting as a conventional media outlet, framing the technology as being analogous to the mass media they are familiar with. Others appeared to be self-directed - at least to the extent they were using blogging as a form of quasi-therapeutic 'venting' (without thought of a reader's response), as a form of quasisociality where their blogs were formally aimed at strangers but where a favourable or at least interested attitude in the reader appeared to be assumed and where an expressed response was not necessary; or where their primary use appeared to be as an end in itself - as a habit or where the act of blogging itself was its own reward.

\section{Minimally-interactive forms of blogging practice Narrowcast}

Keeping friends up to date

Expressing views

Acting as a conventional media outlet

\section{Self-directed}

Quasi-therapeutic

Quasi-social

End in itself

\section{Table 8.1}

The self-directed framings of blogging practice that suggest that blogging can be envisioned in other ways than as a form of interpersonal interaction are of particular interest. Quasi-sociality (which was coined in this study in Chapter 5 to describe the most attenuated forms of imagined contact with unknown readers) is related to what Thompson calls "mediated quasi-interaction" (Thompson 1995c) and what Horton and Wohl refer to as "para-sociality"(Horton and Wohl 1956), 
i.e. the relationship television viewers feel they have with individuals they watch on the screen. Quasi-social blogging can be seen as a mirror image of this relationship - just as the viewer or reader of a television programme may have an imagined relationship with those they see, based on the persona that is given or given off during that performance, so the producer of a message may imagine a relationship with those who receive it and may anticipate a para-social response on the part of the recipients. The interviewees' accounts suggest that to the extent this occurs this response is imagined to take the form of interest in the events of the blogger's life and sympathy with any problems expressed. While some 'quasi-social' communication can contain significant personal revelations and information, much of it appears to be phatic in nature (see Section 6.3.4 for discussion of the norms for and against 'trivial' content). Yet (as noted in Section 3.3.2) traditional formulations of phatic communion suggest that it links a speaker to known others. What appears to be occurring in the perception of some of those interviewed is a form of phatic communication with an imagined and indefinite peer group of sympathetic others.

The internet provides a number of outlets for such quasi-social behaviour - chatrooms, messageboards and mailing lists may appear to fulfil such a role, for example. Several of those interviewed had participated in such forums before starting their blogs. But for those wishing to talk about themselves and receive support or validation - either for their practice as writing or for the life they depict - the other forms of CMC mentioned above that provide spaces for sharing social information with unknown others appear to present three key difficulties. Firstly, the frame of the interaction is defined by a third party - chatrooms and discussion boards tend to be given a set topic and off-topic conversation may be ignored or criticised. Secondly, the writer's postings are competing for attention with those of others. And finally, unless the would-be communicator has themselves set up the communicative space, the norms of conversation and formal controls in these spaces will be set and controlled by others - not always in the communicator's favour. The personal weblog appears to address all three of these issues - the owner has control over the topic, comments are generally made in relation to what the owner writes (though commenters may also comment on others' comments) and even without comments, readers are assumed to be attending primarily to what the site owner has to say (see also Section 6.2). The owner can establish his or her norms and may refuse to publish comments (though in practice most commenters appear to have internalised the norm that they should be polite or supportive (Karlsson 2005) - see also Section 6.3.4.

\subsubsection{Alternative academic framings for the audience's role}

Two additional frames for the analysis of personal blogging interaction have been suggested in the literature (Chapter 2) - which were not included in the conceptual framework at the outset of this study. The first, suggested by studies of home page creation and weblogging (Chandler 1998, 
Germann Molz 2006, Rosenstein 2000) is that personal blogging enables self-examination through interaction with others and serves as an instance of a Foucauldian technology of the self (Foucault $1988 b)^{79}$. Self-examination was not frequently mentioned as an objective among those interviewed in this study. It did seem to emerge, however, as an unintended consequence of some blogging practice. Some suggest that all blog writers seek feedback on themselves and what they write. Serfaty, for example, claims, "online diaries explicitly search for an audience and in so doing turn themselves into a collaborative project" (2004 pp 39-40). Among the bloggers interviewed, to the extent self-examination did occur it seemed to take place in the process of writing as an intrasubjective practice rather than through interaction. This is illustrated by the following quotation from Bruce:

It makes me think about my life a lot more. Before I did it - partly because of the job I was doing and the stage I was in my life I felt I was kind of drifting around a lot. I still feel like that but writing about my life and writing about things it makes you reflect about your life a lot more.

The second potential frame which might be offered as an explanation for personal blogging is that it can be used by marginalised people to represent themselves and their marginalised characteristics to a wider public. This possibility is suggested by numerous studies of talk shows and reality television which suggest this is one of the principal reasons people elect to appear on them (Abt and Seesholtz 1994, Dovey 2000, Gamson 1998, Grindstaff 1997, Priest 1995, Priest 1996). A few of those interviewed for this study belonged to groups that may be considered marginalised - non-whites and non-heterosexuals - indeed, one participant in the study began her blog profile by describing herself as a black lesbian. Neither she nor the other interviewees, however, seemed to evince a desire, or reported that they felt an obligation, to represent their lives to others as examples of minority group members.

It is perhaps notable that none of the interviewees connected what they were doing with reality television or talk radio and television, though a connection has been drawn between personal weblogs and these confessional genres (Jacobs 2003). This may be because at the time of interviews these weblogs were primarily textual and tools were not yet available to enable the easy sharing of audio or video content or perhaps because consumption of or participation in these media genres can be stigmatised.

In summary, it appears that most of the personal bloggers interviewed relied on limited information to establish the nature of their audiences and what their reactions to their blogs might be. Contrary to expectations raised at the outset of this study, this did not appear to concern them.

\footnotetext{
${ }^{79}$ Defined by Foucault as processes "which permit individuals to effect by their own means or with the help of others a certain number of operations on their own bodies and souls, thoughts, conduct, and way of being, so as to transform themselves in order to attain a certain state of happiness, purity, wisdom, perfection or immortality." (1988b p. 18)
} 
They did not generally strive to gather more information and reduce their uncertainty - instead they appeared happy to assume a sympathetic audience and it appears that both constitutive and implementation biases of blogging practice helped to sustain this view. Although this may be sufficient to explain a willingness to share sensitive information online, it is also possible that some bloggers do not believe, or are not aware, that what they are revealing might be sensitive information. The extent to which this is the case among webloggers generally, or whether the definition of what constitutes sensitive information is itself shifting, is outside the scope of this study.

Another unanticipated result is that narrowcast or self-directed practices were identified in which the relationship with the audience itself (whether positive or negative) appeared to be of peripheral importance. To the extent blogging was self-directed in particular, the act of blogging itself appeared to be its own reward and its communicative aspect appeared either to be irrelevant or merely a means of retrospectively rationalising the practice. The practice observed of phatic communication with an audience whose identities were not known, suggests a need to re-evaluate the meanings and purposes of phatic communication.

\subsection{THE WIDER CONTEXTS OF BLOGGING INTERACTION}

While Thompson (1995b) and Meyrowitz (1985) point to key features of mediated communication in their work (Section 3.3), they tend to treat the mediating technologies as givens with fixed parameters or constraints rather than as features that influence a process of mediation. Feenberg's (2008) theoretical lens provides a way to place the micro-level interactions analysed by Thompson (in some aspects of his work) and by Meyrowitz in the wider context of selected social and economic forces so as to provide a meso-level understanding of the interplay between technological, social and economic factors that seem to influence blogging practices. These forces, to use Feenberg's terminology, constitute "biases". They can be divided into constitutive biases that are directly related to technical characteristics of blogging, and implementation biases that relate to the manner in which blogging technologies are adopted in a social context.

As explained in Section 3.6, the second set of sub-questions guiding this study were:

"What are the principal sources of constitutive and implementation bias in personal weblogging and how are they perceived and encountered in practice by personal bloggers?"

Feenberg maintains that the biases of technologies tend to be invisible to their users. As noted in Section 6.2, most of the bloggers interviewed and many academic and media commentators appear to have framed blogging practice as radically unconstrained, which tends to support Feenberg's view. However, on deeper probing, the interviewees generally either revealed directly or acknowledged tacitly that a number of norms influence their practice. 
One of the findings that therefore emerges from this study is that when a technology is relatively new, some of the biases of its use in practice may be visible at first because they have not yet become part of everyday social practice ${ }^{80}$. This is particularly striking when 'local' norms that emerge alongside a new technology come into conflict with pre-existing norms that may be threatened by them. The norm of "openness" identified in this study is one example of this - the local norm that personal bloggers should feel themselves free to (or even obligated to) reveal social information clashes with the wider social norms that dictate continued concealment.

During the interviews the origins of the blogging-centric norms that emerged were not probed. However, it appears that there are three principal routes through which blogging-centric norms may begin to be established. First, there is the potential influence of norms bloggers might have perceived as being followed by those whose blogs they read, (Section 6.3.4). The second potential source of perceived norms is bloggers' assimilation of characterisations of the internet and of blogging practice in the mainstream media. Of particular relevance is the framing of the internet as a space that is - and to some extent should be - outside the control of governments and corporations. An early example of this view is the Declaration of the Independence of Cyberspace by John Perry Barlow, which asserted, "we are creating a world where anyone, anywhere may express his or her beliefs, no matter how singular, without fear of being coerced into silence or conformity" (Barlow 1996). It was unclear as a result of the analysis of the interview transcripts to what extent media depictions of the internet were encountered by the interviewees or had been instrumental in framing their blogging practice as being relatively socially unconstrained, as interviewee perceptions of the media's characterisations of blogging were not probed and seldom emerged unprompted.

Lastly, bloggers could discover emerging blogging norms by reading online writings particularly on weblogs - that attempt to set rules of conduct for weblog practice, as outlined in Section 6.3.4. The manner in which these early blogging pundits appear to insist that openness is not only possible but a requirement suggests the lingering influence of what Turner $(2005,2006)$ describes as 'New Communalism' and what Curran describes as the 1980s counterculture which have been passed on by influential early contributors to online spaces like The Well (2003 pp 244-

${ }^{80}$ As Shirky puts it in another context:

It is a curiosity of technology that it creates new characteristics in old institutions. Prior to the spread of moveable type, scribes didn't write slowly; they wrote at ordinary speed, which is to say that in the absence of a comparable alternative, the speed of a man writing was the norm for all publishing. After moveable type came in, scribes started to write slowly, even though their speed hadn't changed; it was simply that they were being compared to something much faster. (Shirky 2008 p. 156) 
248). Many of the early managers of The Well were veterans of The Farm ${ }^{81}$, where - in the words of one of them - "everyone was expected to 'say what they saw' about anyone else. Your mind had to be an open book. A mental nudist colony." (Coate 1987).

Regardless of the way in which their awareness of blog-related social norms emerged, it was clear that most of the interviewees saw openness as a common, and sometimes even a normative, attribute of blogging. To a limited extent (as was argued in Section 6.2) there is a constitutive bias enabling openness because of the way in which blogging technology tends to shield bloggers from an active perception of their readers. However, it appears that the implementation bias towards openness (which may in part have its roots in West Coast countercultural attitudes) may be the more important factor in shaping this aspect of personal blogging practice.

This bias seemed to have become visible precisely because it clashed with pre-existing social norms of discretion in the social context of those interviewed here. Several of those interviewed said that in their own practice they resisted the openness bias that they detected in other blogs. Misunderstandings and over-reactions that result and come from or spill over into LiveJournal have attracted their own websites and groups devoted to mocking such activities ${ }^{82}$. It may also be that the suspicion and hostility towards online emotional expression, which to some extent was echoed by the interviewees' comments in this study, are a reflection of the British cultural norm of the 'stiff upper lip'. Certainly, it is important to note that while these clashes and others provide examples of potential clashes in other contexts they cannot be assumed to be characteristic of personal bloggers more widely - rather, they are the product of the particular social contexts that those interviewed found themselves in. For example, those sampled were all based in and around London and thus in an urban context, and are likely to be exposed to British social norms. When considering the bias toward openness in blogging understood by those interviewed, it seems likely that it will be temporary. While the practice of personal blogging (and those who read such blogs) was part of a subculture which attracted little public attention it was arguably possible for its local norms to differ from general social norms without conflict. On the one hand, thanks in part to increased media exposure, the British public is becoming increasingly aware of (and often concerned by) the revelation of sensitive social information in blogging practices. Traditional media outlets already 'police' the online profiles of celebrities and more widely circulate what they reveal. Increasingly, 'ordinary people' whose blog postings or social networking profiles attract attention may be

\footnotetext{
${ }^{81}$ The Well is a San Francisco-based bulletin board system that started in 1985 and attracted numerous virtual community pioneers including Howard Rheingold and the founders of the Electronic Frontier Foundation (EFF). The Farm is a Tennessee-based commune founded in the 1970s.

${ }^{82}$ The most popular of these was http://www.ljdrama.org/. It is now offline but has been archived at http://web.archive.org/web/20060812042238/http://www.ljdrama.org/.
} 
exposed to ridicule not just via the kind of 'grassroots' information sharing that brought Star Wars Kid unwanted attention (BBC News Online 2006b) but also via websites like Gawker.com ${ }^{83}$ which are commercial enterprises with mass media-sized audiences ${ }^{84}$ and increasing influence in the mass media and online (Gawker appears as a "news source" on Google News and Yahoo News, for example). As a result the assumption (revealed in the analysis of interviews in this study) that those able to read one's postings adhere to a 'local' norm that encourages or at least tolerates openness may be increasingly inaccurate and this may increase awareness of potential risks in sharing ${ }^{85}$ among the kind of bloggers identified in this study. The practice of personal blogging may thereby lose some of its local autonomy and norms around self-disclosure may become closer to those of wider UK society thus reducing or eliminating that form of bias. In that case, personal blogging might remain, but the sensitivity of social information shared publicly might decline, and/or bloggers might increasingly demand and use privacy protection tools to control access to that personal information.

On the other hand, some argue that practices may continue to allow blogging to retain its own separate norms by segregating blogging from other everyday contexts:

It's possible, of course, to imagine a norm developing that allowed blogs to be considered and intermediate space between the public and the private. Perhaps people might eventually agree that it's just not proper to discuss in public what they read on a blog, just as it wasn't proper for the servants in 18th century England to report what they learned while serving their masters. (Rosen 2005 p. 169) ${ }^{86}$

This would be consistent with Goffman's observation that people are generally tactful and agree to pretend not to have noticed actions that would cause the observed to lose face. Lastly, as noted in Section 8.2 above, still others like Palfrey and Gasser (2008) suggest that blogging and other mediated practices that encourage openness may gradually encourage those who encounter them to practice greater openness in other contexts.

To the extent that this case is illustrative of technological bias more generally, one way or another, it appears that gaps between technologically-influenced norms and general social norms will narrow and conflicts that make biases visible will gradually be resolved; the biases will become once more "self-evident" (Feenberg 1999 p. 88).

This finding may have important implications for Feenberg's arguments. It is difficult to mobilise efforts to reform the way technologies are designed and how they are framed by their

\footnotetext{
${ }^{83}$ See (Tate 2008) for an example of Gawker's public pillorying of a private individual.

${ }^{84}$ Gawker claims it had an average of $3.1 \mathrm{~m}$ readers a month as of March 2009 (see http://www.quantcast.com/gawker.com/traffic)

${ }^{85} \mathrm{~B} \log$ reading is still a minority practice, but it is a growing one - Pew surveys of American Internet users indicate the proportion that have ever read blogs has risen from 17\% in Feb 2004 to 33\% in May 08. (Pew Internet \& American Life Project 2008)

${ }^{86}$ Although Rosen is sceptical that this would actually occur.
} 
producers and users as he would seek to do if technology's biases remain invisible - this study suggests that intervention, if this is deemed necessary, would be most effective at an early stage while biases both positive and negative remain visible. These interviewees suggest it is not merely the biases of blogging that are brought into sharp focus when they clash with existing social norms - the norms which those biases confront are also exposed for debate as a result. For example, the threat which the bias towards openness in mediated practices like personal blogging appears to pose to norms of privacy in other contexts has led Brin (1998) to suggest that rather than opposing potential changes in privacy norms, there is an opportunity to rethink those norms.

While some of my respondents did provide evidence that they were aware of and resisted some of the biases in blogging, to some extent this apparent visibility may have been as a result of the research process itself - it is possible that by asking questions relating to some of these biases, I made them visible to my respondents. For example, in asking them how they felt about making what they posted available to a broad range of internet users I might have encouraged them to reflect for the first time on how this practice might clash with existing social norms. There is also some evidence that certain blogging biases might invisibly influence blogging practice over the long term even when they have been rendered visible and then resisted for a time, as, for example, when Annie recognised that the openness of her blog might damage her relationship with her family but she continued to blog about sensitive issues (see Section 5.3.1).

There were several potential biases that did appear to be largely invisible, though their very invisibility makes them difficult to substantiate (insofar as interviewees were frequently not aware of being influenced by them, the analysis of their accounts and blogging practices only provides indirect evidence). Such biases include those against long posts or against posting on politicallyrelated subjects. As discussed in Section 6.3.4, several of the interviewees suggested that it is normal for bloggers to comment on political issues (consistent with the perceived bias towards freedom from conventional limitations to discussion on blogs that they identify). When some interviewees were asked why they did not blog politically, however, despite their own political interests, familiar social norms delegating political discussion to experts (Eliasoph 1998) were the predominant explanation that emerged. This bias against political participation was invisible to the respondents, however, as they seemed to have internalised this norm. This is consistent with an analysis I performed (Brake 2008a) of Pew statistics about weblogging collected through a random dial survey in the US in mid-2006 (Lenhart and Fox 2006). This showed that not only is blogging already skewed towards the college educated $-39 \%$ of bloggers contacted had college degrees compared to $28 \%$ of the US population aged 25 and over at the time (US Census Bureau 2006) - 
but that political blogging is even more so $-59 \%$ of those sampled who blogged primarily about politics $(\mathrm{N}=16)$ had college degrees ${ }^{87}$.

The privacy-related biases embedded in the technology supporting the blogging services under examination here are also invisible in normal blogging practice. One striking example of such a bias is manifested in the default settings in blog software that invariably expose weblog postings automatically to the widest possible audience and for an indefinite period (see discussion in Section 6.3.1 and discussion of archiving in Section 7.3). Even LiveJournal, which has the most sophisticated privacy features of any mass market blogging tool, defaults to publishing every posting publicly and allowing search engines to index them. For those who frame weblogging as publishing this would appear to be normal, but in the case of the personal weblog, it could be framed instead as an inter-personal interaction and this would seem to entail a different set of norms governing public exposure.

A comparison of LiveJournal with email software is illustrative. Both enable users to target individuals or groups with messages, but while a new draft email starts with an empty to: field and tends to treat group emails as a special case (sometimes even preventing users from emailing to more than a limited number of addresses at once), LiveJournal starts by assuming the blogger wants to reach everyone who is connected to a network or, if not everyone, then all those in the blogger's list of 'friends'. Limiting access to groups or specific named individuals is possible but requires one to specify these in user settings. The definition of groups with different levels of access and the maintenance of such groups as relationships change - potentially across several different sites - can become an unmanageably complex task. As Palfrey and Gasser suggest:

It's too much to expect any Digital Native to manage a hundred relationships with a hundred companies and other institutions that hold data about her. There is nothing standard about their privacy policies (not that she reads them anyway). And in any event they invariably involve the right to change at the sole discretion of the company. (Palfrey and Gasser 2008 p. 69)

As noted in Section 6.3.1, most forms of privacy protection require the potential recipient of a protected message to register him or herself in some way, so some interviewees were reluctant to use such tools because of the chance of excluding some readers they wished to have.

Weblog software could be configured in such a way that users would be forced to choose at the point of publishing a post, a specific group or groups to whom the post is to be targeted or to choose 'anyone on the internet'. Similarly, weblog software could be configured to search for swearwords or descriptions of controversial behaviour (just as it is already configured in some countries to look for politically sensitive topics - see (Dickie 2005)) and the software could be

\footnotetext{
${ }^{87}$ This stratification may be even more pronounced in the UK than in the US since in the UK political blogging has not achieved anything like the prominence it has in the US.
} 
programmed to ask users "are you sure you wish to post this?" Weblog providers could collect information about the people reading a blogger's postings using web log analysis software and this could be displayed prominently to the blogger and related to the sensitivity of the information revealed at the time of posting (e.g. "this post contains references to drug use. The last such post was read by 16 friends and 30 others, including your mother. Would you like to make it 'friends only' before posting?"). Measures targeting under-16s with intrusive warnings about potentially dangerous behaviour have already been implemented by some social network sites in response to concerns raised by parents and the media about sexual predators - see for example image 8.2 below. This study suggests a much wider variety of potential risks inherent in the use of blogging (and other tools) and that these risks are common to any age group ${ }^{88}$.

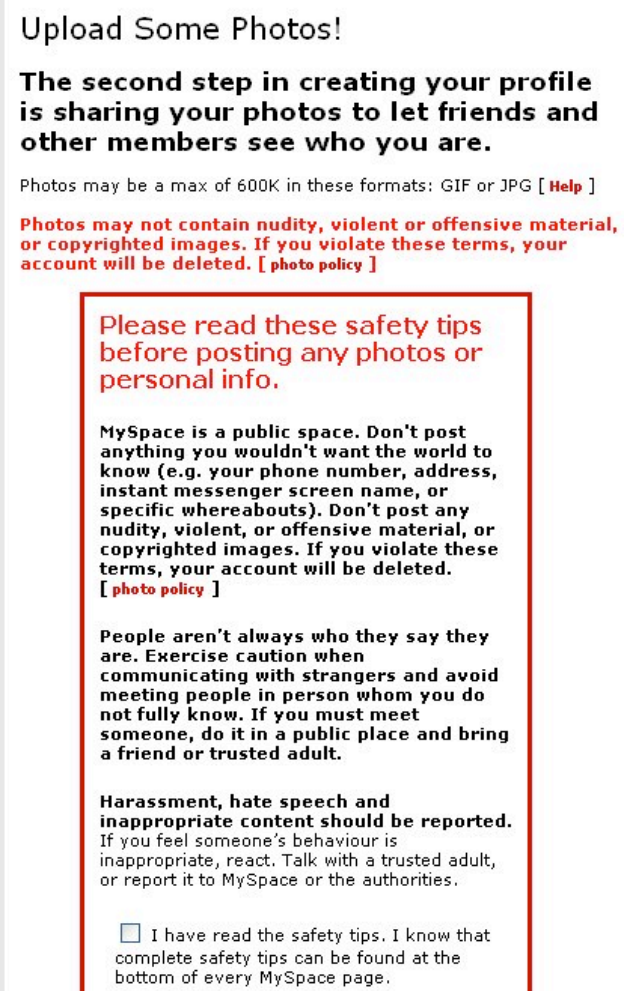

Image 8.2 - MySpace warns users who are under-18 to exercise caution when posting information about themselves online (though its default setting strongly encourages them at the same time to provide a picture of themselves). Source: MySpace, 2008.

Drawing attention to the potential risks of blogging in this way might discourage bloggers from starting a blog or continuing to post. The absence of features like these might therefore be the

\footnotetext{
${ }^{88}$ The harms encountered by those interviewed in this study are briefly outlined in chapter 9.5 .
} 
result of a commercial decision on the part of weblog service providers ${ }^{89}$. Another potential explanation is that the early designers of weblog software services were steeped in the West Coast counter-cultural ethos of self-disclosure and that this initial design orientation has not been challenged by users.

The results of this study suggest that the constitutive biases of blogging technology work in two different ways - biases can directly affect how a technology is used - as for example the default settings in LiveJournal appear to encourage users to make their postings public (Section 6.4.1). Constitutive biases can also, however, indirectly affect a technology's use because of the way that it encourages users to perceive (or to overlook) certain features and uses. As discussed in Section 6.3.1, one of the aspects of the physical context of blogging is the interface which does not provide physical cues comparable to those we are accustomed to in face to face interaction to indicate the potential or actual audience for a blog posting.

It should be noted that the claim here is not that the biases uncovered in this study are universal or comprehensive. Instead, the study offers a snapshot of the most visible biases (and some insight into the 'invisible' biases) at the time of the research (2005) among the UK-based bloggers interviewed. Other biases might become evident in a study of bloggers in a different context. While the legal environment in the UK does not generally constrain most webloggers, for example, it is important to note that internet users in other countries often operate under much more severe systems of formal repression and control (Committee to Protect Journalists 2007, Deibert et al. 2008, Kalathil and Boas 2002, Loewenstein 2008, Reporters Without Borders 2004). In several countries weblogging is blocked outright or intermittently (Gharbia 2007) and, where blogging is technically possible, bloggers have to exercise care in order to avoid topics that their government might take exception to.

In summary, while the notion that weblogging practice is free from social and technical influence is widespread, this merely supports Feenberg's assertion that bias is often invisible and indeed can itself be considered a bias influencing blogging practice insofar as it is believed. While there are several respects in which blogging is, indeed, more free from influence than other forms of mediated expression, this study has identified both constitutive and implementation biases bearing on the practices of those interviewed. Some appear to be invisible to those interviewed as Feenberg suggests but others are not (yet) invisible because these 'local' norms appear to clash with other norms and in so doing bring both kinds of norms into sharper relief.

\footnotetext{
${ }^{89}$ The creator of Facebook has publicly stated that he wants to "stretch" Facebook users boundaries of public and private and make them "comfortable with things they aren't yet comfortable with" (Thompson 2008).
} 


\subsection{BLOGGING AND BLOGS THROUGH TIME}

The third research sub-question, chiefly addressed in Chapter 7, was:

"How do personal bloggers understand and negotiate the space-time interpolations inherent in their practice?"

In the first part of that chapter the propensity of blogging practice to change over time was noted and some explanations were advanced - bloggers' relationship to their imagined readership changes, their motivation to continue blogging changes and they themselves change over time. The analysis of the interview transcripts suggests a challenge to received views with respect to blogging's relationship to time. As discussed in Section 8.2 above in the context of the presumed desire of bloggers to reveal themselves to a broad audience, it is often implied that if a communicative practice's technical characteristics are well-understood then those who practice it must be intending to take advantage of those characteristics. The analysis conducted in this study suggests by contrast that unsought or perceived undesirable technical characteristics of the weblog can be overlooked by users, deliberately ignored or simply put up with. For example, in Section 8.2 above it has been noted that although the sample for this research was constructed so that all the personal bloggers interviewed had blogs containing social information that was publicly available, public availability was not necessarily sought or even welcomed by these bloggers. The orientation of bloggers towards the temporal aspects of their practice was similar. As noted in Section 7.3, although it seems to be clear that weblogs automatically archive all the content that producers write, making it readable for an indefinite period (and they all include by default a keyword search function), blogger attitudes in the sample toward the existence of this archive were mixed and both their awareness of the potential reception of their archived postings at a future date and their willingness to edit their archives to protect their self-presentation appear to be subject to both technological and social biases. Constitutive bias seems to emerge primarily because the sheer volume of text produced in the course of months or years of blogging makes producers feel it would be impractical to make alterations. Where a blog's contents were felt to pose a significant challenge to the producer's current self-presentation the only solutions that were perceived to be practical were to change the status of the blog by removing it entirely, by making it 'friends only' or by moving it elsewhere. Any of these would be seen as a draconian solution to any but the most problematic releases of social information. The influence of social norms was discerned because some bloggers said they felt it would be wrong to edit past entries.

Some interviewees for this study did value the archival function provided by weblogging, although for differing reasons, as one might expect given the differing attitudes towards potential readers that have been identified. Some spoke of the usefulness of blog archives as a benefit to themselves; relatively few spoke of the benefit of the archival function for future readers. However, 
many interviewees appeared to have given little thought to the archives of their blogs at all, suggesting that they would be of little interest to most of their readers and reporting that they seldom looked at their archives themselves. Despite the persistent nature of the weblog as an artefact, it appears that (in Thompson's terms (1995b pp 92-95)) the 'anchor frame' of the space time framework for most of the bloggers interviewed is the moment of posting. This also lends implicit support to the assertion by some scholars that blogging can be experienced as an oral practice (see Section 2.4.1).

While for some the availability of an ongoing archive represents an opportunity to reflect on their own personal journeys, the manner in which archives that include social information about a weblog's author persist through time can represent a threat to what Goffman describes as the need to maintain face by presenting an image that is internally consistent (1967 p. 6). The self presentation that has been archived may be inconsistent with a current self-image maintained in other contexts or that which is currently expressed on the blog (or both). The acceptability of the expressions preserved therein can depend on the temporal context in which they were originally situated - personal views can change as do societal mores. I have not uncovered research into the ways in which blog readers may interpret and take into account the blend of past and present postings they encounter in their reading, and this study did not include questions dealing with this point, but there is reason to suggest that 'secondary reception' of blog postings (see Section 3.3.3) may be particularly problematic. It is noteworthy that while old paper notebooks, photographs or video recordings often provide a number of subtle visual and/or aural cues that place them in the past, weblog postings may provide very little in the way of such cues aside from the posting date printed at the top. While an old web page may reveal its age through a dated layout, when a blog's layout is updated, all of the earlier postings are generally retrospectively updated with the same visual style. Though in some cases archived blog postings will be accessed via links on the home page to the blog's archives sorted by date, thus placing what is read in a temporal context, old blog postings can also be found via search engines or linked to directly via their 'permalinks', thus minimising contextual cues to the age of the posting encountered (and potentially presenting a single posting from the past as representative of the author's current attitudes or behaviour if read in isolation from other subsequent postings).

Weblog postings, once made, can be edited by the producer or removed at any point and it was expected at the outset of this study that bloggers might continuously or periodically modify or remove archived material in order to maintain a consistent self-presentation as the conceptual framework suggests would take place. This did not appear to occur frequently, however. The analysis of the interview data and the weblogs themselves suggests that a small amount of 
retrospective modification did take place, but generally only when grammatical or spelling mistakes were spotted. Interviewees showed little awareness of the possibility that what they wrote might also be archived by third party sites in the ways outlined in Appendix A.

The manner in which the text of weblogs persists through time is principally a function of design decisions by weblog service providers and by the developers of the search engines which index them. One can envisage other design decisions and other potential consequences. For example, weblog providers could, by default, request that archives of postings be automatically purged from search engines after a certain interval of time has elapsed unless a blog owner chooses otherwise, or providers could give tools that would make it easier for users to hide large numbers of postings at once using certain criteria (their date or the presence of keywords, for example). It may be argued by weblog providers that most users do not demand such functions, but it can also be argued that weblog software tends to shield users from the awareness of the consequences of their actions and that they might be more concerned if they were more aware of the risks involved.

In summary, while temporal aspects of blogging like its archive can appear central if one is focused on the weblog as a technology or artefact, and blogging practitioners might therefore be assumed to value such archives, those interviewed showed differing levels of active awareness of the archival aspects of blogging - potentially influenced by biases in the technology - and differing attitudes towards what they did perceive - in part influenced by 'local' social norms.

\subsection{CONCLUSION}

This research has examined weblogging practices through two lenses - as interactions in relation to both a real and an imagined audience and as a set of uses of a technological artefact whose design and use are influenced by the social, political and economic context. Each of these lenses has suggested a variety of potential influences on the personal weblogging practices of those interviewed that interact with and reinforce, or appear to conflict with, each other. Taking the willingness to make social information on the internet available to an indefinite audience as an example, this could be explained theoretically using an interpretation derived from interactionist theory - that in the absence of contrary feedback, blog producers feel that they are reaching only those they wish to be reading their blogs and they assume favourable reactions to what they say. This absence of feedback is not, however, a necessary consequence of blogging practice but involves particular choices by the designers of blog software and bloggers' assumptions of favourable reactions is, in part, enabled by the social norms of blog readers' behaviour. The interactional space has been shown to be a technologically shaped space with certain characteristics and limitations, but an analysis that stopped with an exploration of the nature of those characteristics and their likely implications for the perception of mediated interactions would have 
overlooked the fact that the designers and users of blogging technology are socially embedded. As revealed in the study both design and use patterns and practices differ across the variety of social circumstances provided in the sample.

While the richness of feedback available about the reactions of blog readers that web log analysis tools provide could not approach that available in face to face interaction, this chapter suggests that different approaches to the design of weblogging sites could provide more social information about readers or frame the interaction differently (by displaying reader comments and weblog author posts in the same way instead of hierarchically, for example). I have suggested that the particular characteristics of weblogging software stem, in part, from Californian counter-cultural norms that emerged in the 1970s and that early user behaviour consistent with these norms may have encouraged the production of norms of openness that are particular to the forms of personal weblogging examined in this study. These norms have been shown to conflict with other situated norms of self-disclosure that have been developed primarily through face-to-face interaction and three alternative possible resolutions for the resulting tensions have been advanced.

Chapter 9 that follows is the last chapter in this thesis. It will highlight the key empirical findings and theoretical insights, and reflect on the implications of this study for future research and for public policy. 


\section{Chapter 9: Conclusion}

\subsection{INTRODUCTION}

This chapter highlights the main findings arising from this study, looks forward to future research avenues, suggests policy recommendations and points to some of the wider social implications of the emergence of blogging and other social information sharing services. Section 9.2 provides an overview of the main findings and considers them in light of the existing literature. Section 9.3 focuses on the strengths and weaknesses of the conceptual framework developed to guide the empirical study. It also reflects on the methodology for this study, suggesting approaches that may be valuable in future research. Section 9.4 outlines new avenues for research that could extend the work undertaken here and reflects on the applicability of this research to the study of SNS. Section 9.5 offers some policy recommendations based on a synthesis of some of the risks and opportunities that were found to have been encountered by the bloggers interviewed for this study and on my awareness of trends emerging in online social information sharing. The conclusion, Section 9.6 summarises the key contributions of this study.

\subsection{THEORETICAL INSIGHTS AND KEY EMPIRICAL RESULTS}

The research questions this study sought to address were, "how do personal webloggers understand this practice and how does the practice relate to its social and technical context?" The analysis has revealed that while personal weblogs may appear similar both in technical characteristics and in subject matter, the understandings and meanings constructed by blog creators themselves of their writing practices are various. While those interviewed tended to construct their accounts of the communicative context of their blogging based on what they know of their readers and the technology's characteristics, it seems that their understanding is sometimes incomplete. Moreover, the practices at any given time of bloggers may be based on the perceptions they have of the situation at the moment of writing, rather than on the accounts they give in another context. Those immediate perceptions may be based on the meaning blogging has for them and on ideas they have of the norms and perceptions of readers more than they are based on observation and reflection. This is illustrated, for example, in the case of the relationship with the archives of their writing observed among several of those interviewed. They were aware to some extent of the persistence of what they wrote but they tended to write primarily with a sense of their immediate audience rather than of their future one. Similarly, they appeared to write with a sense of personal freedom, although when prompted they were either aware of, or revealed, a variety of social and technical contextual influences. 
The central work of this thesis has been to gain insight into some of the varied meanings that bloggers ascribe to the practice of personal weblogging. The theoretical framework for this study was informed by the perspectives drawn from the tradition of symbolic interactionism in the sociological field. Insight into these meanings emerged through an analysis of the texts generated by in-depth face to face interviews illuminating the perceptions of the social interactions that surround some blogging practices and the way in which these interactions are interpreted.

One insight that emerged from the analysis is that although, superficially all the personal bloggers in the sample were engaged in communication that is similar in content and in features (the revelation of social information to or with, in John Thompson's language, an indefinite audience, i.e. an audience whose size and composition are unspecified) the meanings of this communication appeared to differ markedly among those who were practicing it.

As observed in Section 3.3.2, the technological features of blogging appear to favour its use in order to engage in interactions with an indefinite audience (as opposed to - what is referred to in Section 5.3.3 as 'telelogic' communication. Most academics and professional practitioners suggest that this is how it is used and often that this 'should' be the manner in which blogging is practiced. A few of those studied did appear to be blogging in a telelogic manner from the start - more found themselves increasingly aware of and attentive to indefinite audiences as their practice developed and as they attained larger readerships than they at first anticipated.

Nonetheless this study suggests that while personal bloggers like those studied here might are often aware that blogging is positioned as an interactive practice open to any reader, blogger practices vary considerably in their orientation towards potential and actual audiences.

The most common form of orientation toward the audience practiced by the bloggers interviewed was 'dialogic' blogging - where the imagined and desired audience appeared to be primarily a small group of friends and/or family members known to the blogger in other contexts. This form of blogging is consistent with many other characterisations of blogging practice and with symbolic interactionist theory though as discussed in Section 8.3.1 the form of 'disattention' practiced by such bloggers towards unsought readers is somewhat different.

The remaining two forms of audience orientation observed in this study appear to challenge to a greater extent the way earlier scholars have applied ideas drawn from the symbolic interactionism to theoretical development in the study of computer mediated communication, including blogging.

Firstly, some personal blogging practices appear to be monologic in intention - that is, the bloggers in question appear to be aiming what they say at a particular audience but appear not to be strongly interested in receiving feedback from that audience (in the form of comments or email) and sometimes even appear not to want such feedback. This throws into question the presumed 
importance of gauging the reaction of the audience in order to present one's self appropriately, an assumption that runs through much of Goffman's work, and of others such as Walther who have applied it in studies of computer mediated communication (Section 2.2).

This study offers insight into this apparent inconsistency - the narrowcasting (monologic) bloggers identified in this study did seem to have a sense of the reaction of the audience despite not seeking to enter into dialogue with them - it was simply a largely imagined response, based not primarily on observation but on a mixture of assumption and wishful thinking. An optimistic assessment of the social context of blogging as perceived by these bloggers is reinforced by the use of social conventions of tact by blog readers (see Section 5.2.2 for evidence from this study and Section 2.4 for other studies which have noted this). The characteristics of blogging technologies allow such bloggers to construct an imagined social context without perceiving contradictory information for two reasons. Firstly, 'given off' unfavourable reactions to what they have written that would be available in face to face interaction are not accessible and secondly the presence of readers other than those envisaged is not apparent to them at the moment of posting even when they might be intermittently aware of the existence of such readers. As shown in Section 6.2, a few of the bloggers interviewed drew a distinction between the kind of interaction and communicative norms they expected from those who visited their blogs and those they expected in online forums which they perceived to be a more hostile environment. However, examining the space of interaction in a technical way as many earlier studies of computer mediated communication have done, it appears that there is no technical reason why other fora should be more hostile, i.e., both web-based message boards and their blogs are online spaces without access boundaries enabling anonymous or pseudonymous interaction.

Goffman's work does not thoroughly address this issue. This may be because in the face to face interactions he examines, it is less open to communicators to imagine their own communicative context since the nature of the audience and their reactions are apparent at least superficially and are, to some extent, unavoidable. Nonetheless, as noted in Chs 2.2 and 8.2, there are places in Goffman's work where he does address the selective evaluation of audience response, notably in Interaction Ritual where he notes communications can be disbelieved and conveniently misunderstood (Goffman 1967 p. 43), and in Frame Analysis where he notes that the presence of onlookers can be deliberately 'disattended' (Goffman 1986 [1974] p. 225) ${ }^{90}$. He also addresses the idea of tact that enables such 'misunderstandings' to take place. Most importantly given this study's findings, he briefly addresses the presumption of benevolence, or at least neutrality, that often

\footnotetext{
${ }^{90}$ The apparent gaps in Goffman's conception of disattention are discussed in section 8.3.1.
} 
characterises our attitudes to passing strangers (Goffman 1971a p. 320). It seems that this presumption explains the perception of many of the bloggers interviewed for this study that their unknown audiences are benign.

The second insight relates to the manner in which narrowcast, dialogic and telelogic bloggers appear to construct their social context. A gap identified in my review of the relevant studies is that they generally do not take into consideration the imagined social context of interactions when examining the implications of the mediation of such interactions by computer technologies. The implications of anonymity for communicative behaviour in the context of a political messageboard on the 'open internet' might, for instance, be quite different from the behavioural implications of anonymity on a messageboard on the same topic in an experimental setting, within a workplace or on an individual's weblog, even if those messageboards were also visible on the 'open internet'. My study suggests that bloggers often perceive their blogs as a suitable space for the sharing of social information because of their sense that their blog is under their control, even when (as in the sample researched here) from a technical perspective the texts they produce are as exposed to public view and, therefore, are susceptible to out-of-context consumption. As noted in Section 3.2.2, Goffman maintains that our framings of interactions are generally accurate and both errors and uncertainties tend to be quickly resolved. In this case, however, it appears that although it would be difficult for bloggers to gain a reasonably accurate perception of the interactions around their postings, rather than seeking information to enable the resolution of uncertainty about the communicative situation they find themselves in - particularly about who might read their texts in the present or in the future - some bloggers imagine themselves to be in a safe context and do not look for signs that this assessment is inaccurate. In this case, errors in the interpretation of the frame for the blogging situation can persist over long periods of time - that is, a communication that is available to a very large potential audience indefinitely may be framed by a blogger as being speech-like ephemeral communication to a small group of friends or even akin to an internal monologue.

Thirdly, focusing on what Thompson terms the temporal 'anchor frame' (see Section 3.3.2) of the blogging interaction reveals that the propensity of blog producers in this study to focus on their blog's 'primary reception' - the reading of their postings immediately after their publication appears to contribute to a sense of control over the context of reception. If a blog posting does not appear to have attracted unwelcome attention within a few hours or days, it is likely to be forgotten and the potential future consequences of its continued availability may be overlooked. This points to the importance of considering temporality when analysing communication practices that are mediated. 
A fourth insight which was not expected in the light of the initial conceptual framework for this study and which is only rarely alluded to in previous studies, is that for a minority of bloggers interviewed - those who were primarily 'self-directed' (Section 5.3.4 and Section 7.3) - the audience for their practice appeared not to play a central role. In each of the three sub-categories of 'self-directed' blogging identified the existence of an audience was acknowledged, and formed part of the (self-) justification for participating in the practice, but the analysis of the interview data suggested that to the extent blogging practices are self-directed, bloggers have little or no desire to influence that audience and have little interest in receiving a response - the imagined presence of an audience in such cases appears to be sufficient. There is little in Goffman's work that would seem to address this form of imagined interaction. This finding is consistent with a broader symbolic interactionist perspective, however, as one of the core tenets of that framework is the centrality of participants' construction of situations. Although the theorists in this tradition tend to stress that this construction is done jointly with others, Mead, whose work was important in the historical development of symbolic interactionism, developed the concept of the "generalized other" (Mead and Morris 1967 [1934]) - an imagined composite observer - and some of the bloggers interviewed in my study could be producing their blogs for the benefit of such an observer. This observation may have implications for studies of mass media production - as noted in (Section 2.6), some research in this area suggests self-directed (and peer-directed) motivations and imagined contexts of production. However, this is often treated as a failure or as an incapacity to envisage audiences, while this research suggests there may be an element of resistance to an awareness of the audience, in part because of their potential negative reactions.

A few of those engaging in 'quasi-sociality' choose to share highly personal topics - others indulged in a form of phatic communication. This appears to suggest a new role for phatic communication, which has been described variously as a way to establish bonds between people or to communicate the social identity and state of mind of speakers. For those who engaged in 'quasisociality' in this study, the imagined audience appears to provide them with the feeling of being tied to a sympathetic community online, centred around their blogs and (by implication) themselves, in a relationship cemented by their phatic utterances.

For those engaged in 'quasi-therapy', being able to vent their frustrations and reveal their weaknesses in what they seemed to feel is a safe context appeared to be rewarding even though they may not receive (or desire) critical feedback, support or absolution. Lastly, for those engaged in 'blogging as an end in itself', it was the process of blogging itself, whether as a form of writing or as a form of engagement with a new tool, which appeared to be the primary motivation. 
There is a tension between the emphasis on agency drawn from symbolic interactionism and the emphasis on structure which is characteristic of Feenberg's work and medium theory as represented by Meyrowitz and to a lesser extent by Thompson as they have been presented in the conceptual framework for this study. In Chapter 6, this tension was illustrated by the conflict between the sense that the bloggers interviewed appeared to have that blogging practice was (and often should or even must be) un-constrained and the evidence based both on their testimony and on the analysis of the features of blogs. Their blogging practices were shown to be subject to a variety of influences. How the balance between structure and agency is struck in blogging practices is likely to vary from individual to individual, and assessment of the strength of the influences (biases) outlined is problematic because, as noted in Section 8.4, the workings of these biases may be partially invisible to those involved in the practice.

Although the analysis related to biases (chiefly in Chapter 6) did not yield many surprises, this study takes into consideration a broad range of technological and social influences on blogging practice. To the extent these are considered in the existing literature, they are generally considered individually rather than in the round. Where influences on blogging practice have been considered by earlier scholars, only those which appear to be specific to blogging have been explored, for example, emergent norms of blogging behaviour like giving credit for sources of links. This study has demonstrated the importance of widening the perspective to include pre-existing norms and biases that, nonetheless, appear to influence blogging practices, for example, the influence of norms related to political expression.

One difficulty encountered in applying this part of the conceptual framework for this study with respect to the wider implications of the technical features and biases is that Feenberg does not specify the key sources of bias. Lessig's work $(1999,2006)$ was introduced (see Section 3.4.3) to provide categories that enabled this study to concentrate on some of the biases that were visible to the interviewees or which appeared through comparison of their statements about their practices with the evidence of those practices in blog form. It is likely that bloggers in other situations encounter other biases. The analysis in this study is helpful in alerting researchers to the importance of being alert to potential biases of this kind as a context for the practices studied. In the present study these insights about bias helped to explain other findings. For example, it is suggested in Section 6.4.1 that various constitutive biases contribute to bloggers' sense of control over their blogging space that, from a Goffman-informed perspective, might appear to be threatening, since for bloggers like those interviewed, who write largely without using privacy controls, reception is possible - if not likely - by an indefinitely large audience, both in the present and in the indefinite future. 
The inclusion of pre-existing norms alongside emergent 'local' blogging norms in the analysis helped to illuminate conflicts that may occur among these norms when they differ. This manifested itself, for example, in the conflict between the perceived 'local' norm of openness in blogging practice and the broader social norms around privacy and appropriateness of disclosure (Section 6.3.4). Indeed, such norms often seem to become visible precisely when they differ from those adhered to in other contexts.

These theoretical insights were underpinned by a number of key empirical findings. It emerged that, while most of the personal webloggers interviewed had a vision of their audiences, this vision was not generally informed by a continuous assessment or monitoring of their environment: instead it was primarily imagined. These bloggers' visions of their audiences seemed to assume that they were made up of the kinds of readers that were desired. If they wanted to be read by their close friends they tended to assume their blog reached only them; if they only wanted to be read by strangers they assumed their close friends would not find it. To the extent that unforeseen readers were envisaged, it was generally supposed that they would be well-disposed toward the writer and that unsympathetic readers would simply look for something else. A few of those interviewed felt initially that their blogs were aimed at and consumed by themselves alone. Though this impression usually changed once readers began to comment, one interviewee (Elaine) said she was reluctant to acknowledge to herself that her blog had readers even when she began to receive comments, even though she had written about the creation of her blog and given its address in a magazine (Section 5.2.2). This observation may be linked to the fact that several interviewees revealed that they were primarily blogging because they liked the process (whether the process of writing, of venting their feelings or of mastering a new technological tool) rather than because of blogging's communicative features. A range of norms potentially influencing blogging practice has been outlined, including norms of writing regularly, avoiding lengthy entries, being open and honest, and entertaining readers, most of which are consistent with those outlined in other studies. One unexpected norm conflict that emerged was a clash between the norm that encourages political expression on weblogs and pre-existing social norms that inhibit political expression by nonexperts. It also appeared that while the content of blogs is generally archived indefinitely both on the blog sites themselves and on third party sites, this technical characteristic did not seem to have an important role in the practice as seen by the bloggers interviewed. They seldom thought that others would read a substantial proportion of their archived writings and, even when they liked the idea of having an archive of prior postings, they said they seldom returned to read them. They sometimes seemed to see blogging as akin to an oral, near-synchronous practice, rather than as a practice whose product lingers through time. 
In Chapter 2 I drew attention to a number of gaps in the literature on computer mediated communication, home pages, weblogging and social network sites. Two principal gaps were addressed in this study. First, as noted in Chapter 2, the imagined social context is often undertheorised in studies of mediated communication. Its importance was primarily revealed in Chapter 5 and Section 8.3 in my analysis of the varied relationships between personal bloggers and their readers and how those relationships are envisaged. In Chapter 7, the importance of imagination in forming the meaning of blogging practices was further analysed by focusing on the meanings and significance of the blog's archives for bloggers. Second, studies of blogging practice tend to focus more on the possibilities blogging appears to offer for unfettered communication and selfexpression rather than on constraints or influences on blogging. To the extent that influences on blogging have been considered, they have tended to be limited to discussion of particular blogspecific social norms. In Chapter 6 and Section 8.4 the influence of everyday social norms on personal blogging practice was integrated into my analysis. Other influences - market, legal, and technological - were also outlined to demonstrate the usefulness of incorporating a broader context when analysing mediated practices.

\subsection{THEORETICAL AND METHODOLOGICAL REFLECTIONS}

In the conceptual framework outlined in Section 3.5, some uncertainty was noted about how personal bloggers would frame the interactions that they are participating in, given the ambiguity of their communicative situation and the lack of information they generally would have about who they would be communicating with and their reactions. It emerged that, given this uncertainty, the bloggers studied here framed their communicative contexts in a variety of different ways. While, for some, the communicative ambiguity created some anxiety and caution, as Goffman and Meyrowitz's work would lead one to expect, others appeared to value the ambiguity because it enabled them to frame their blogging practice to themselves as being in the context they would like. The conceptual framework - drawing in particular on Thompson - suggested that personal weblogs might be monologic, dialogic or telelogic in the way they are framed by the bloggers themselves. The analysis in this study suggested that all three of these possible orientations towards the audience were observed among those interviewed. In addition, a fourth, unanticipated framing of blogging practice emerged insofar as a variety of 'self-directed' practices were identified. While all blogging practices potentially involve communication with others, it is apparent that inter-personal communication is not inherently central to blogging practice. The bloggers' framing of their practice was not always fixed but instead might shift, either in response to external evidence as when bloggers were contacted by others who had read what was to the author a 'self-directed' blog, or in response to changing motivations (see Chapter 7). My study suggests that, for bloggers like 
those interviewed, while their practice extends through time and leaves persistent archives, the subjective anchor frame of their blogging practice tends to be the moment of blogging itself and a short time immediately afterwards when comments on the posting tend to be made. These findings suggest that personal blogging practices can have a variety of meanings, that these meanings can change over time and that while the technological characteristics of blogging and the interactions bloggers have with their readers can influence the meanings bloggers attach to their practices, they do not preclude other possibilities.

As noted in Section 2.4, and in Section 4.2, the research design for this study and the research methodology were unusual in the field of weblog studies insofar as interviews have been employed rather than surveys or textual analysis. In addition, the diversity of the sample in terms of age and educational achievement represents a departure from most other weblog-related interview studies. This is not to say however that the sampling method provided anything close to a representative group of bloggers - there are a number of ways in which it differed from what is known or believed about personal bloggers. Despite the efforts made to stratify the sample by class the result did not reflect the diversity of class among bloggers that has been identified in surveys. This may have been because the sampling method favoured those bloggers who were more active in their blogging practice. While London was chosen as a space offering considerable cultural diversity, the sample interviewees share a single legal and governmental framework underlying their blogging practices which means that great care should be taken in generalising the results of this study beyond the UK, and then only to places whose legal and governmental regimes are relatively liberal. Also, a less urban group might have different communicative purposes and might encounter different communicative norms in their everyday offline interactions. Lastly, the sample was constructed from among bloggers whose blogs were substantially available to public view both by necessity given the use of search engines to attempt to reach a diverse group and because of the desire to analyse self-presentational difficulties that could result from the public availability of potentially sensitive personal information. It is not clear, however, how representative the interviewees were in this respect - in particular nothing is known about the extent to which other LiveJournal users do use the privacy options available to limit access to their postings.

The variety of the sub-practices this study revealed within the category of personal weblogging makes it difficult to make strong claims about any particular sub-practice. Lastly, these observations are necessarily situated in time, reflecting the technological biases and social norms which pertained in mid-2005. Since that time, blogging sites have developed a number of new features and it is possible that social attitudes towards personal blogging practices have also changed. 
The bloggers interviewed were generous with their time and appeared to be open and reflexive in answering the questions posed, but, as noted in Chapter 3, the irregular timing of blogging practice meant it was not possible to speak to the bloggers as they performed their blogging, so their testimony and my questioning was necessarily retrospective. Thus their recall may have been selective and their accounts might have been still richer had they been given 'in the heat of the moment', although the passage of time may have allowed them to provide more considered responses. Having decided on a qualitative approach to the subject, the decision not to attempt closer ethnographic engagement with the lives of those studied (which many symbolic interactionists favour) was a difficult methodological choice. It is tempting to suppose that greater closeness to the lives of those studied, if this could have been achieved, would have yielded deeper insights. Set against this, however, as outlined in Chapter 3, there were practical reasons to take the stance that I did. It did not appear that I could find a 'natural' way to enter the lives of a broad range of bloggers so any such study would most likely have had to be of people similar in age and background to myself (a weakness identified in prior blogging studies). Interviewees who would have come to feel they knew me might also have begun to censor their responses to questions because of our ongoing relationship. I am satisfied that I was able to achieve a good enough rapport with those interviewed to elicit useful responses thanks to my own experience as a blogger and a familiarity prior to the interviews with the interviewees' blogging practice derived from the reading of their blogs.

This research has focused on blogging as a predominantly textual practice, but even in 2005 there was evidence of a shift towards the publishing of still images (whether on their blogs or on specialist photo websites) among some of those interviewed. With the growth of YouTube and of other video-related services, it appears that blogging and related practices may be increasingly multimedia, which will considerably complicate content analyses. One way to improve content analyses of blogs in general might be through triangulating such analyses using interviews. For example, future researchers could look for patterns of speech and presentation on blogs that appear to encourage interaction and interview the creators of those blogs to ask what their intended relationships with readers might be. Where interviewee responses differed from expectations, this information could be used to refine the textual analyses.

\subsection{DIRECTIONS FOR FUTURE STUDY}

As noted in Section 4.3, this research aimed to provide insight into the variety of personal weblogging practices and the sample was chosen to provide interviewees who were diverse in their backgrounds and practices. Now that a preliminary typology of personal blogging practices has been developed in this study, however, there is scope for future researchers to concentrate on sub- 
forms of personal blogging of particular interest - one such form that seemed to challenge received views about blogging and about producer/audience relations is 'self-directed' blogging practice (see Section 5.3.4 and Section 8.3). An interview-based study focused on those whose practice seemed strongly self-directed could provide additional insights. If survey instruments were developed that could reasonably reliably group blogger respondents into the identified sub-groups, the influence of various socio-demographic characteristics on the choice of particular kinds of blogging practice could also be assessed.

It was beyond the scope of this research to embark on a representative survey of personal webloggers (although as noted in Chapter 4 a survey was conducted, it was primarily designed as a means of creating of a stratified sample not as an end in itself). Questions inspired by some of the findings in this study could be adapted to a questionnaire format for future survey research. This would provide valuable data for triangulation of the results of this research and quantitative data might help to persuade policy-makers to act on any normative recommendations emerging from this and future studies.

This thesis has provided initial insights into a variety of biases influencing blogging practices, focused particularly on those that were highlighted as a result of analysis of the interview data or which appeared relevant to the particular practices which emerged. There is scope, however, to undertake analyses of any of the individual potential influences that were highlighted in this study a number of approaches to such research are suggested below.

Several of the constitutive biases suggested in Section 6.3.1 might be demonstrable experimentally either in laboratories or through naturalistic experiments. For example, the size of text boxes displayed on-screen could be varied to test the extent to which this affects users' willingness to post longer or shorter items (or the average length of blog posts on sites which offer different sized text boxes but are otherwise similar could be compared).

With respect to the market bias features discussed in Section 6.3.3, little is known as yet about organizational and professional cultures and their relationship with blogging and other online practices beyond a few case studies of technology firms ${ }^{91}$. There may be pressures to use one's blog to market one's self or one's organization, potentially using elements of social information to 'personalise' one's presentation (see discussion in Section 8.3), but at the same time, companies have been keen to protect themselves from 'inappropriate' employee revelations (BBC News Online 2004, Hanscom 2003, Pollitt 2005). There is some evidence that personal revelations on

\footnotetext{
${ }^{91}$ A selection of papers on blogging practices in business is available here: http://blog.mathemagenic.com/2008/12/15/research-papers-on-business-blogging/
} 
blogs (and social network sites) may be viewed with concern by potential employers (CIPD 2007, YouGov 2007).

There is also scope for research into the potential social biases discussed in Section 6.3.4 (and further analysed in Section 8.4). In particular, there seem to be a number of social norms that relate specifically to blogging and there are a number of ways in which the origins of these could be probed, one of which is outlined below.

As noted in Chapter 8, the social attitudes of the developers of weblog services could influence norms of blogging practice both directly, through the assumptions made in the software about the user's desired practices and, indirectly, both by their own examples as blogging pioneers and through their marketing activities. Studies focused on the shared cultures of the creators of blogging services (or SNS and other web 2.0 sites) would be invaluable.

This research has concentrated on the practice of weblogging as seen by the weblog writer. This could be supplemented by studies of weblog reading practices. A better understanding of how and why personal blog texts are found, read and interpreted and a better appreciation of the extent to which they are archived by readers and/or circulated outside their original context without the author's knowledge could help to establish the nature and extent of risk bloggers encounter in publishing social information.

In recent years a profusion of options for online self-publishing has arisen, loosely grouped together as "social software". Together, they are being used by a large and growing cross-section of the online population - according to Pew, in May 2008 14\% of the US online population had ever created their own weblog, while 29\% had used social networking sites (SNS) (Pew Internet \& American Life Project 2008) ${ }^{92}$. This percentage may rise further if those using photo sharing services and other "social software" services are taken into account.

Some of the insights and theoretical frameworks from this study may be of use in analysing other social software uses, though the sheer variety of services available means caution must be employed, as these new applications typically differ from personal blogging services in a number of relevant ways, some of which are briefly summarised below.

With respect to control over social information, social networking sites often encourage (or to the best of their abilities - demand) that the information published is attributable to an identifiable person ${ }^{93}$, and they encourage users to provide pictures of themselves, while weblogs

\footnotetext{
${ }^{92}$ A proportion of users of social networking sites may not themselves have created profiles on them, however.

93 "In consideration of your use of the Site, you agree to (a) provide accurate, current and complete information about you as may be prompted by any registration forms on the Site" (Facebook 2008)
} 
may be published by individuals pseudonymously or anonymously ${ }^{94}$. Because of this, and because of concerns raised by the large numbers of minors on such sites, they (and other social software sites) often offer a broader range of privacy controls than most weblogging software.

The risks surrounding revelation of social information in unforeseen temporal contexts 'secondary reception' - as outlined in Chapter 3.3.3, may also be significantly lower in social networking profiles as compared to blogs because of the differing approaches SNS take to archiving past material. In general, they are focused on 'primary reception' of social information - while changes to profiles are often broadcast to a users' 'friends', the archives tend not to be as extensive and easy to find and search as the archives of blogs (although the SNS owners and their business partners may have greater access than members of the public).

\subsection{POLICY IMPLICATIONS}

The aim of this study was to gain a better understanding of how the space of blogging practice is (co-)constructed. While it was not designed to assess the scale of benefits and harms encountered by personal bloggers, it uncovered a number of ways in which blogging practices were experienced as beneficial or harmful which may be relevant for policy.

Two chief benefits of blogging practice emerged. The first was a feeling of connection to a supportive community. This community might be imagined or real and, while for many of those interviewed it was thought to be made up of those they knew already in other contexts, there was a minority who felt or found that their blogs connected them to new people who they might or might not then wish to meet. For several of those interviewed this appeared to be an important factor sustaining their continued blogging. Studies of SNS use have suggested it can enhance the social capital of its users (Ellison et al. 2007), and this study also suggests that users may benefit in similar ways from the ability to both maintain relationships with existing friends and gain new ones.

The second benefit attested to by several of the bloggers interviewed was that blogging provided an outlet for their desire to write. Two linked factors emerged. Firstly, blogging provides a potential audience, which is often assumed to be appreciative (largely because of the norm of supportiveness in commenting $)^{95}$. Secondly, bloggers often seem to feel more free to express themselves as they wish using this medium than they might in other online spaces because of the control they feel they have. Given the importance of literacy in society today, personal blogging

\footnotetext{
${ }^{94}$ Although weblog software generally also prompts new users to provide such information, it appears norms of profile accuracy and completeness are less strong for blogging than for SNS.

${ }^{95}$ A recent study of teenagers' writing practices indicates that they "very much enjoy the writing they do to communicate with their peers" (Lenhart et al. 2008 p. 51) because "they choose their own topics, do not need to use any particular writing conventions, can write and get feedback quickly, and are typically not being judged" - all potentially characteristics of blogging practice. (ibid, p. 62).
} 
would appear to have potential educational use to encourage both creativity and the practice of writing skills, if the technology's use were integrated into educational curricula (with appropriate warnings and safeguards).

A number of harms also emerged in the course of this research, although analysis of these fell outside the scope of this study. These were associated with: a) harm to relationships with friends and family; b) upset associated with online encounters with strangers; and c) employment and reputational risk. Altogether one or more of these harms affected six of the 23 people interviewed. One of them even lost his job as a result of his blogging activity. Much of the popular concern about negative consequences of the revelation of social information online has concentrated on the danger posed to young people by online sexual predators but the evidence of other bloggingfocused studies (Mitchell et al. 2008, Ybarra et al. 2007) suggests such risks are rare except among young people who also engage in other risky behaviours both on and offline. While society has a particular responsibility to help and advise young people, the harms that were encountered by interviewees of all ages warrant further research into the prevalence of such harms across the whole population of bloggers - little such research exists and none is available with a UK context ${ }^{96}$. If the harms outlined above proved to be widespread there may be a role for education and, potentially, for governmental intervention.

A key finding of this study is that bloggers may well be aware, in principle, that their practice exposes them to potential harm (particularly from unintended readers), but the evidence of those interviewed suggests a tendency to assume that the readers of their blogs are mostly sympathetic. It would appear that when outlining risks educators and policy makers need to take the perceptions (and misperceptions) of bloggers into account.

Given some bloggers' tendencies to under-estimate or disregard blogging dangers, information and social pressure alone may be insufficient to minimise harm. An additional approach would be to use 'constitutive bias' (or, put in another way, to counter existing constitutive biases) to influence behaviour by putting pressure on blog software providers to encourage more responsible default settings in their software and to provide more (and more obvious) tools that would enable users to better gauge their level of risk. Web-based services can provide producers with a great deal of information about the size and nature of their audiences - more in some ways than 'mass media' organizations have had access to - but while such data may be gathered for the benefit of weblog

\footnotetext{
${ }^{96}$ An early Neilsen//NetRatings survey found $9.5 \%$ of US bloggers surveyed said they had been in trouble because of something they had written on their blogs (Buchwalter 2005). The only other survey on blogging harms found to date was also early in the practice's diffusion and relied on a convenience sample but found " $36 \%$ of respondents have gotten in trouble because of things they have written on their blogs" (Viegas 2005)
} 
services themselves, little of it is made available to the users of their services and information on real and potential audiences is not generally made visible at the moment of posting, which, the evidence of this study suggests, is when it is most needed.

\subsection{CONCLUSION}

This study has pointed to several aspects of blogging practice that have been underemphasised in previous research. Among these are an apparent lack of interest in understanding the size and composition of their audiences observed among several of the bloggers interviewed. This appears to reflect and to contribute to their mental construction of the audience for their work as being made up of sympathetic readers. Blogging appeared to be more a self-directed than an interactive practice for several personal bloggers studied. Most bloggers asserted initially at interview that they felt their blogging practice was free and under their sole control but it emerged that what they wrote appeared to be subject to influences both technical and social, and both visible and invisible to them. Lastly, despite the manner in which blogging technologies archive all that is written, bloggers' primary focus appeared to be on the moment of posting and its immediate aftermath.

Many scholars have tended to argue that personal blogging has an undifferentiated meaning for its practitioners and that blogging practice is mainly the product of a continuing process of reflexive negotiation between the blogger, his or her audience and the features of blogging software. This study has provided a more complex and nuanced understanding of the interplay between blogger, audience, blogging technology and wider social norms and practices, on which, it is hoped, future studies of weblogging can build. 


\section{Appendix A: Blog technologies \& definitions}

\section{BLOGGING DEFINED}

While the terms weblog and weblogging (the practice of producing a weblog) have passed into the language alongside the contractions 'blog' and 'blogging', there remains some ambiguity about their definition, and considerable imprecision in the definition of some of the sub-practices within it (sometimes termed 'genres'). The most inclusive definitions refer to the most frequently encountered technological characteristics of blogging (although it should be noted that because of the variety of blog software platforms and practices, none of these characteristics is universal).

Technological definitions of blogs agree that they contain multiple entries or "posts" arranged in reverse chronological order. Although the earliest blogs pre-dated technologies used to automate the posting process, there is also a consensus that blogging now involves the use of specialised software to generate pages whether on one's own computer or (more commonly) as a service provided by a weblog hosting company (December n.d.). As 'Web 2.0' services evolve and adopt this format in a variety of ways this definition increasingly includes a large variety of disparate technologies and an even larger assortment of practices. Most social network sites offer some form of blog-like functionality, although such features are often not explicitly labelled by the services as a blog (see image A.1 below). 


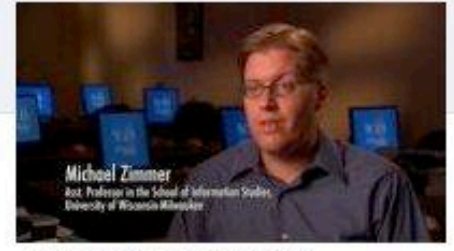

View Photos of Michael (10)

Send Michael a Message

Poke Michael

Information

Networks:

Wisconsin Milwaukee Academic Staff

NYU Graduate 2007

Notre Dame Graduate 1994

Yale Graduate

Relationship Status:

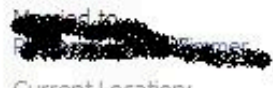

Current Location:

Milwaukee, WI

Website:

http://michaelzimmer.org

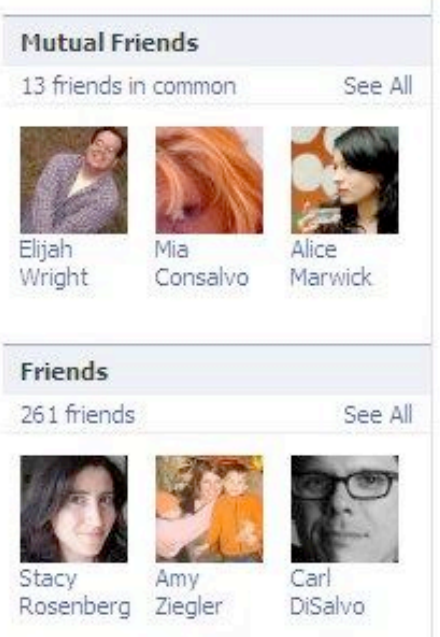

Michael Zimmer thinks the prez better get to work. 18 tours ago

\begin{tabular}{ll|l|l|l|l|}
\hline Wall Info Photos & \\
\hline
\end{tabular}

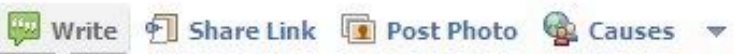
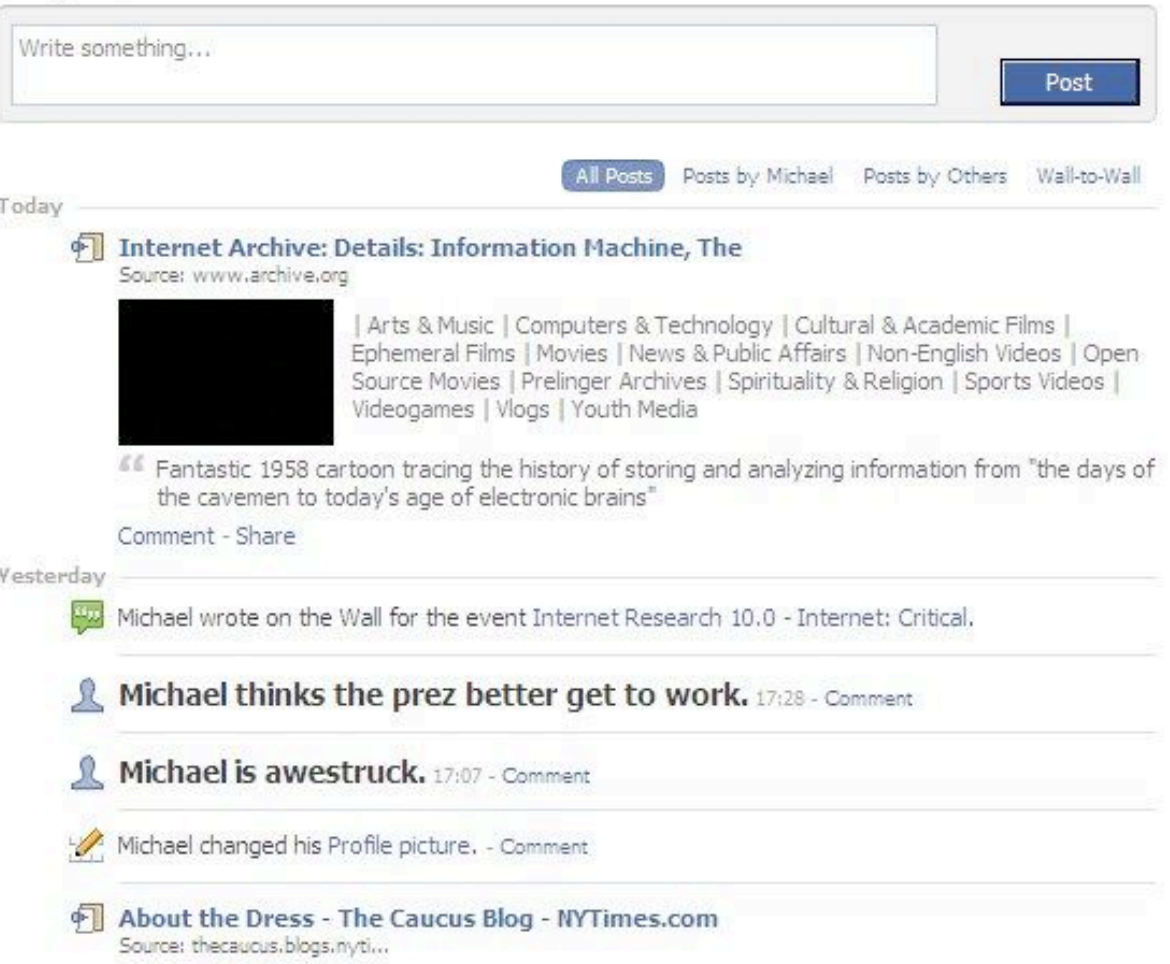

Michelle Obama chose a embroidered laced yellow coat and matching dress by the designer Isabel Toledo for the inauguration. The outfit is an unconventional choice in one sense-in its sparkle, it seems very dressy for the hour....

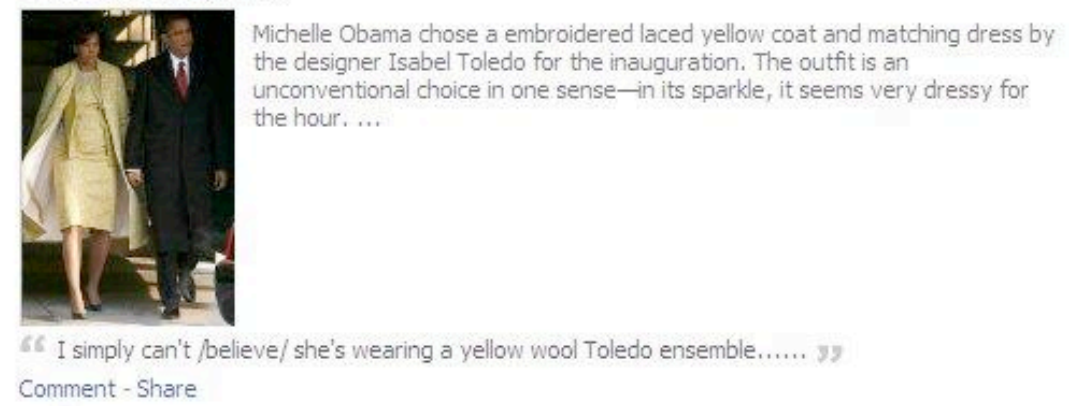

Image A.1 - Facebook's wall for each user includes a chronologically-ordered list of their recent Facebook-hosted activities and statements, bearing some resemblance to a blog in form and content. (Published with permission, 2008)

Additionally, a number of specialised sites have emerged that enable particular forms of blogging, though again they do not always self-identify as blogging platforms. For example Flickr.com offers blog-like functionality but is primarily focused on still pictures, YouTube.com does this but is focused on moving images and Twitter.com does this but only allows users to send up to 140 characters in each post (see images A.2-4 below). 


\section{flickr}

Home The Tou

Sign Up

Explore

Search eszter's photostream

Search

\section{eszter's photostream pro}

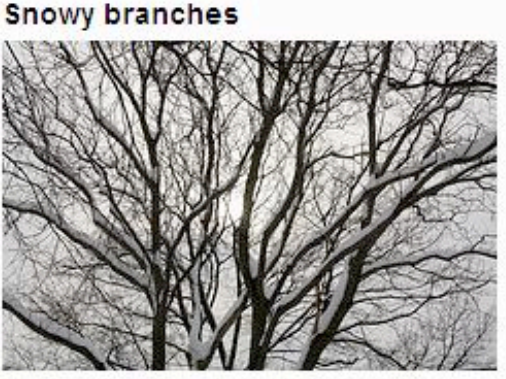

이 (-) (5) Some rights reserved

Uploaded on Jan 19,2009

2 comments

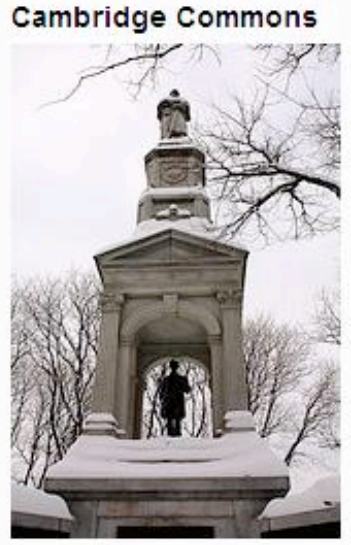

이 (3) (2) Some rights reserved

Uploaded on Jan 19,2009

0 comments

Snowy branches

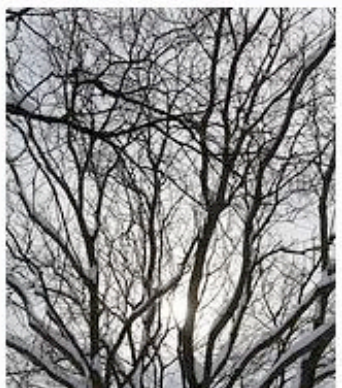

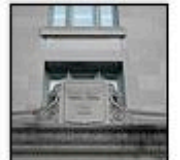

Harvard

17 photos

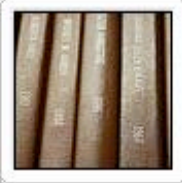

My senior thesis (1996)

9 photos

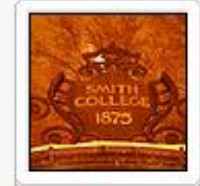

Smith College Jan '09

98 photos

Image A.2 - Flickr displays a user's pictures in reverse chronological order as a blog does with postings. 
Videos | Favourites | Playlists | Groups | Friends | Subscribers | Subscriptions

\begin{tabular}{|l|l|}
\hline Iessig & \multicolumn{1}{|c|}{ Subscribe } \\
\hline & $\begin{array}{l}\text { Iessig } \\
\text { Joined: } 14 \text { January } 2006 \\
\text { Last Sign In: } 4 \text { days ago } \\
\text { Videos Watched: } 1,055 \\
\text { Subscribers: } 422 \\
\text { Channel Views: } 8,386\end{array}$ \\
\hline Name: Lawrence \\
Age: 47 \\
City: San Francisco, CA \\
Hometown: Williamsport, PA \\
Country: United States \\
Occupation: law professor \\
Companies: Creative Commons, Stanford Law S... \\
Website: http:/lessig.org blog \\
\hline
\end{tabular}

Connect with lessig

\section{$\triangle$ Send Message \\ Eld Comment \\ $\Rightarrow$ Share Channel \\ ¿3. Block User \\ f욜 Add as Friend \\ 1 Google Add to iGoogle}

http:iruk.youtube.comilessig

Embed This Channel:

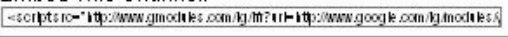

\section{Recent Activity}

(C) lessig subscribed to bravenewfilms ( 2 months ago)

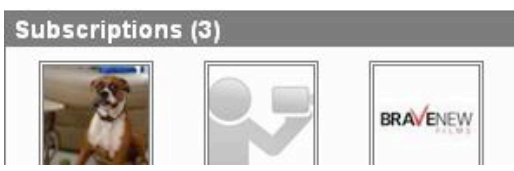

Image A.3 Youtube displays a user's posted videos in chronological order (though the browser can change the way they are sorted)

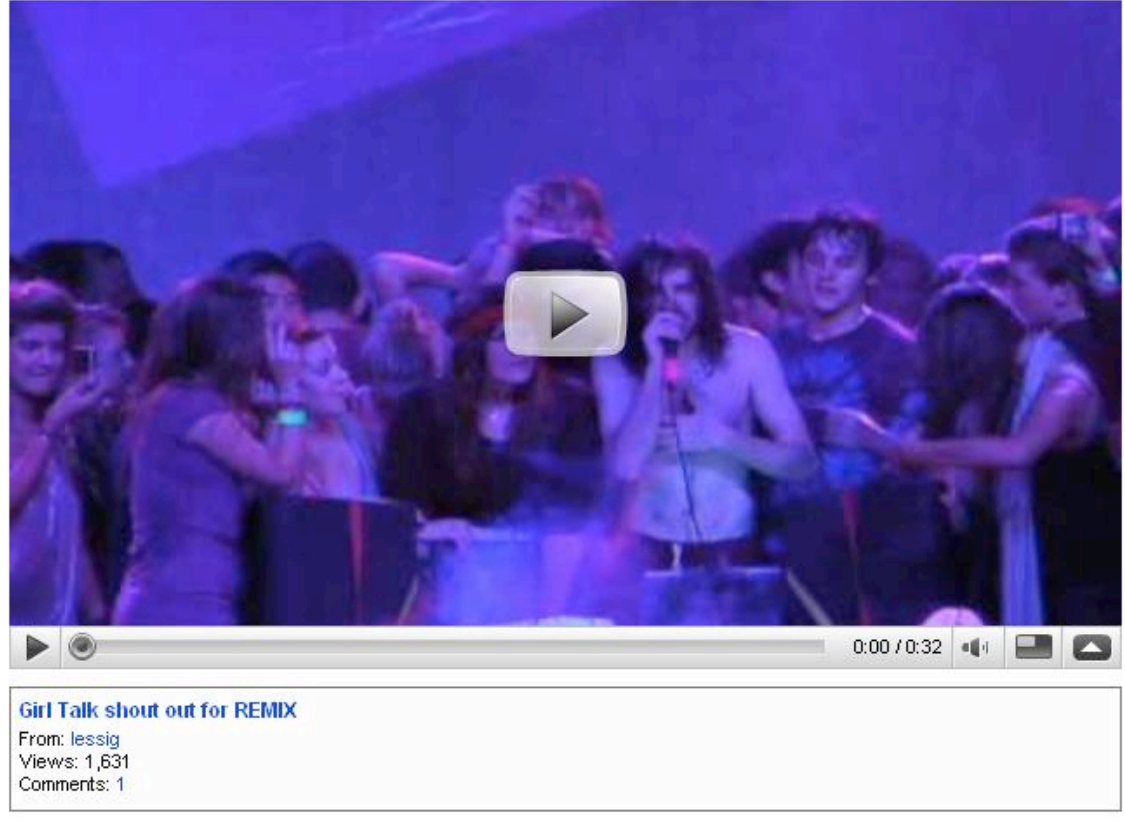

Videos (16)

Videos | Most Viewed | Most Discussed

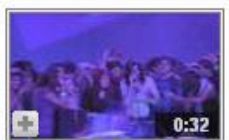

Girl Talk shout out

for REIMIX

2 months ago

1,631 views

lessig

ॠ市市入

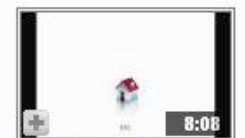

8 minutes on

Proposition 8

2 months ago

(5i views

lessig

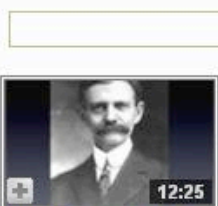

Palin's experience

in just 12 mi...

3 months ago

12,844 views

lessig

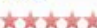

Subscribe to lessig's videos 


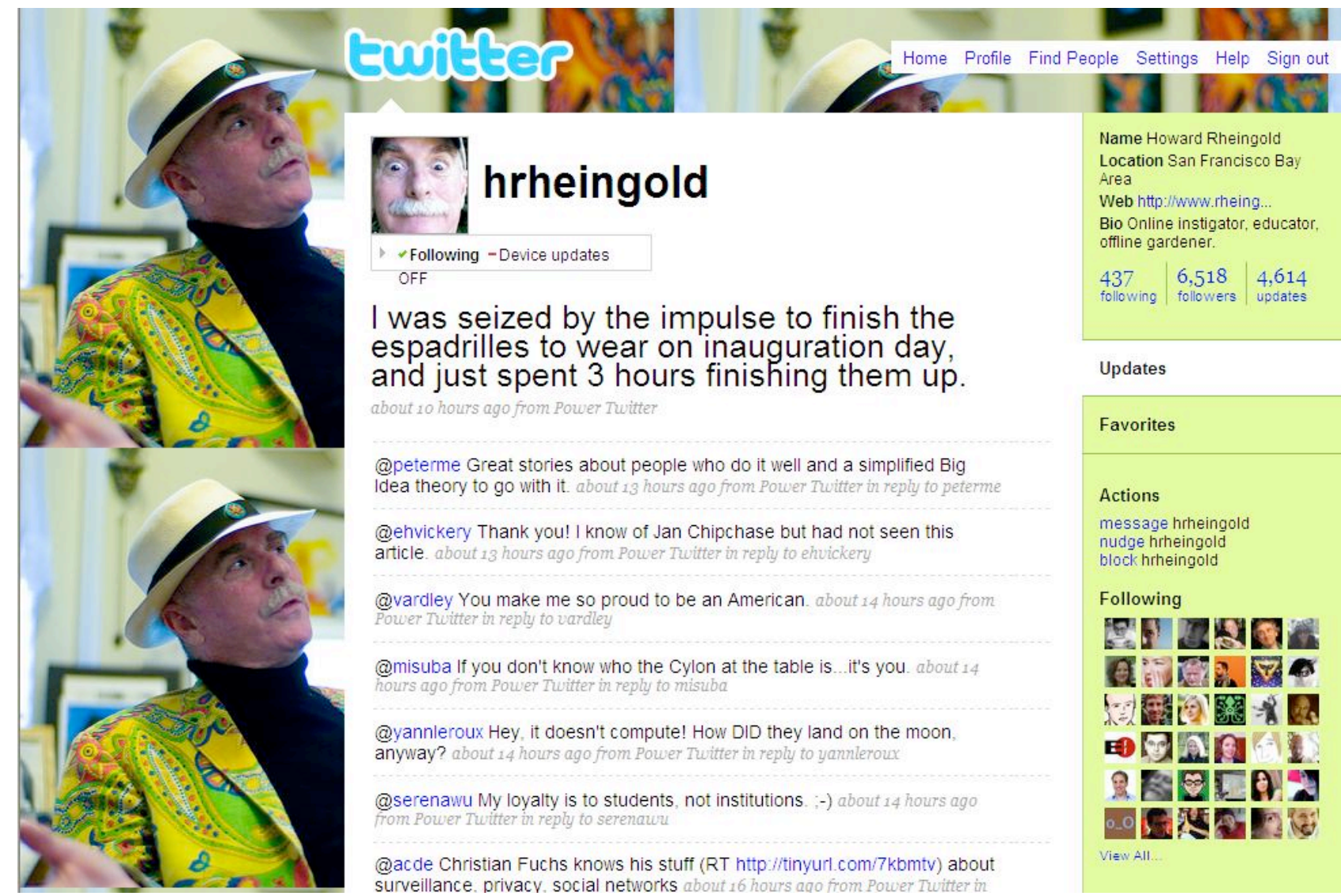

Image A.4 Twitter blurs the lines between instant messaging, emailing and blogging, but as with blogs twitter updates are displayed in reverse chronological order, and twitter posts are available as RSS feeds. Twitter use is sometimes termed "micro-blogging"

Many definitions of blogging describe it in terms of kinds of practice enabled by blogging use - some recognise these as sub-practices, others claim that all blogging fits particular behavioural patterns and some of these contain within them tacit normative assumptions about how this malleable set of tools should be used.

The most common assertion is that blogs are frequently updated (December n.d., Herring et al. 2004, Hourihan 2002, Walker 2005). This assertion is not supported by statistical evidence although an influential early small-scale content analysis offered some backing (Herring et al. 2004), a larger 2006 survey from Pew found $46.4 \%$ of US bloggers posted every few weeks or less often (Brake 2009).

Another common defining use-based definition is that blogging is frequently or invariably characterised by links to other websites (Killoran 2002a, Rettberg 2008) - even the Oxford English Dictionary definition says blogs usually offer links to other sites. This definition is sometimes used to differentiate blogs from web diaries, for example, "Links are vital to the genre; take the links out of a weblog and you are left with a web diary, a much more introverted and private form of writing" (Mortensen and Walker 2002 p. 265). Related to this is the view that webloggers are tied into a 
community of fellow bloggers and engaged in an ongoing dialogue with them and with commenters on their weblogs.

Of particular concern for this study is the definition of personal weblogging, which can also be referred to as the writing of web diaries or web journals. Although there have been several studies which use one or more of these terms there are few attempts to define it. Scheidt, drawing on Fothergill's definition of (paper) diaries (1974), says that diary weblogs are blogs, "whose posts explore their producer's inner terrain and life as it is lived it in the first person" (Scheidt $2008 \mathrm{p}$. $15)$.

\section{THE BLOGGING 'ECOSYSTEM' - BLOG-RELATED SERVICES}

\section{Contexts of consumption}

\section{"Conventional"}

Weblogs can be consumed like other sites by choosing to visit their home pages and navigating from there. This may be the most common way they are read, but because of the way in which blogs are constructed there are several other ways the content of blogs can be found which changes both the layout and the content that readers encounter.

Blog sites can also be found via searches for terms using 'conventional' search engines. Depending on a blog author's settings and the features of blogging software, search engines may direct readers to a page with a single post, a set of posts around the same time or a set of posts on the same theme.

\section{$\underline{\text { Blog search }}$}

Several search engines have emerged that are focused specifically on indexing weblogs. These index blog texts as individual posts rather than indexing the entirety of the pages in which the posts are embedded, tend to focus explicitly on the most recent entries, often ordering matching posts by date, and they tend to assert the 'authority' of individual posts by providing indications of the number of other weblogs which have linked to a given posting (see for example image A.5 below). 


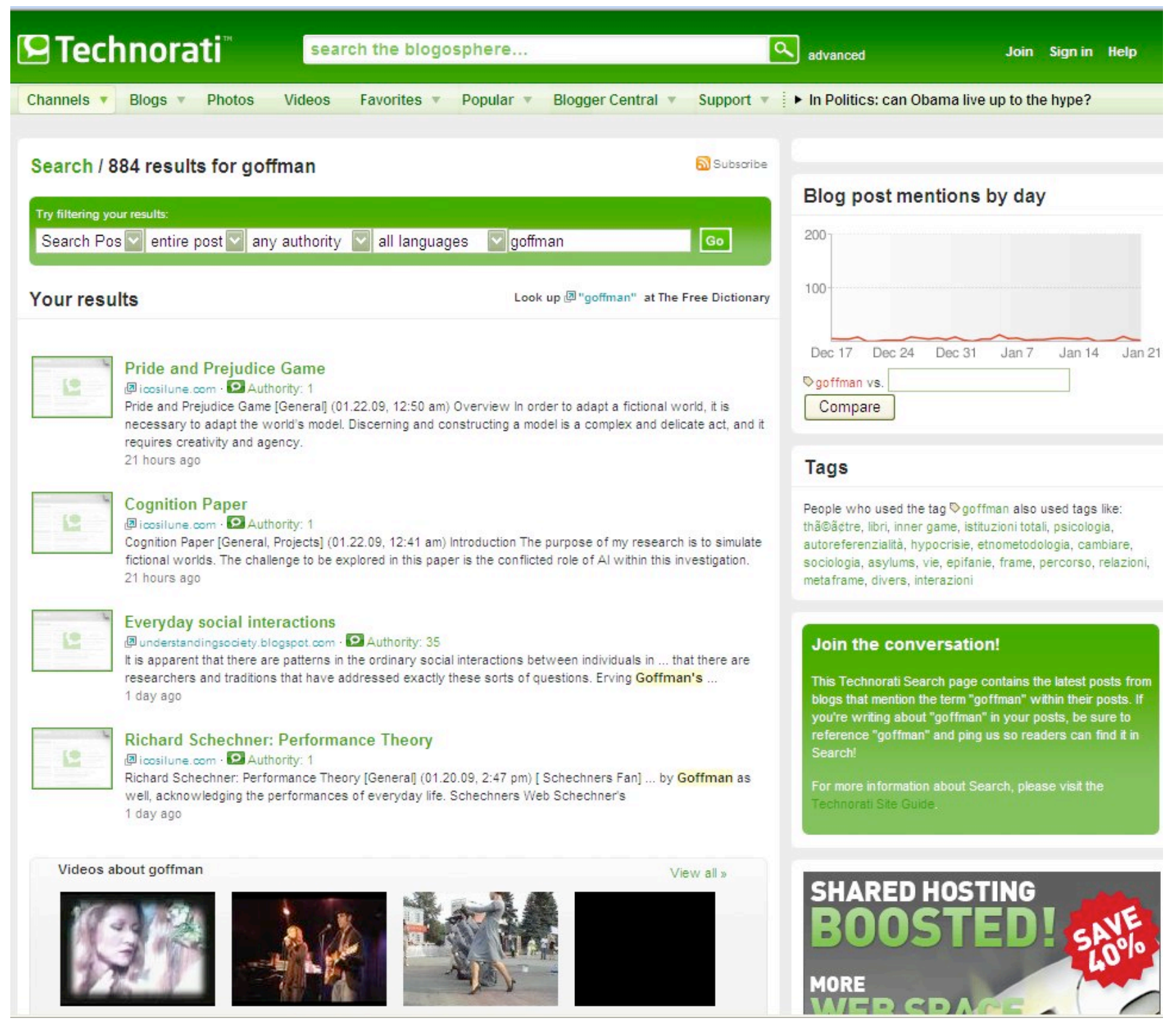

Image A.5 - The results of a search using Technorati blog search are sorted by recency first and are also given an "authority" ranking (blogs that fall below a certain authority can be excluded from view)

$\underline{\mathrm{RSS} \text { feeds, RSS reading and 'friends page' reading }}$

Nearly all weblog services (and a variety of other 'Web 2.0' services) automatically produce what is called an "RSS feed" as well as the pages viewed by ordinary web browsers. This feed consists of the content of the individual posts plus accompanying descriptive data which can then be passed on to other 'Web 2.0' services for display or other forms of processing. Tools called variously RSS readers or news readers or aggregators or viewers are used to allow individual users to more conveniently read and search all of the weblogs and other RSS-using sites they normally read. These enable such users to group such sites by subject area and automatically alert them when new items are posted - image A.6 is an example of such a reader. 


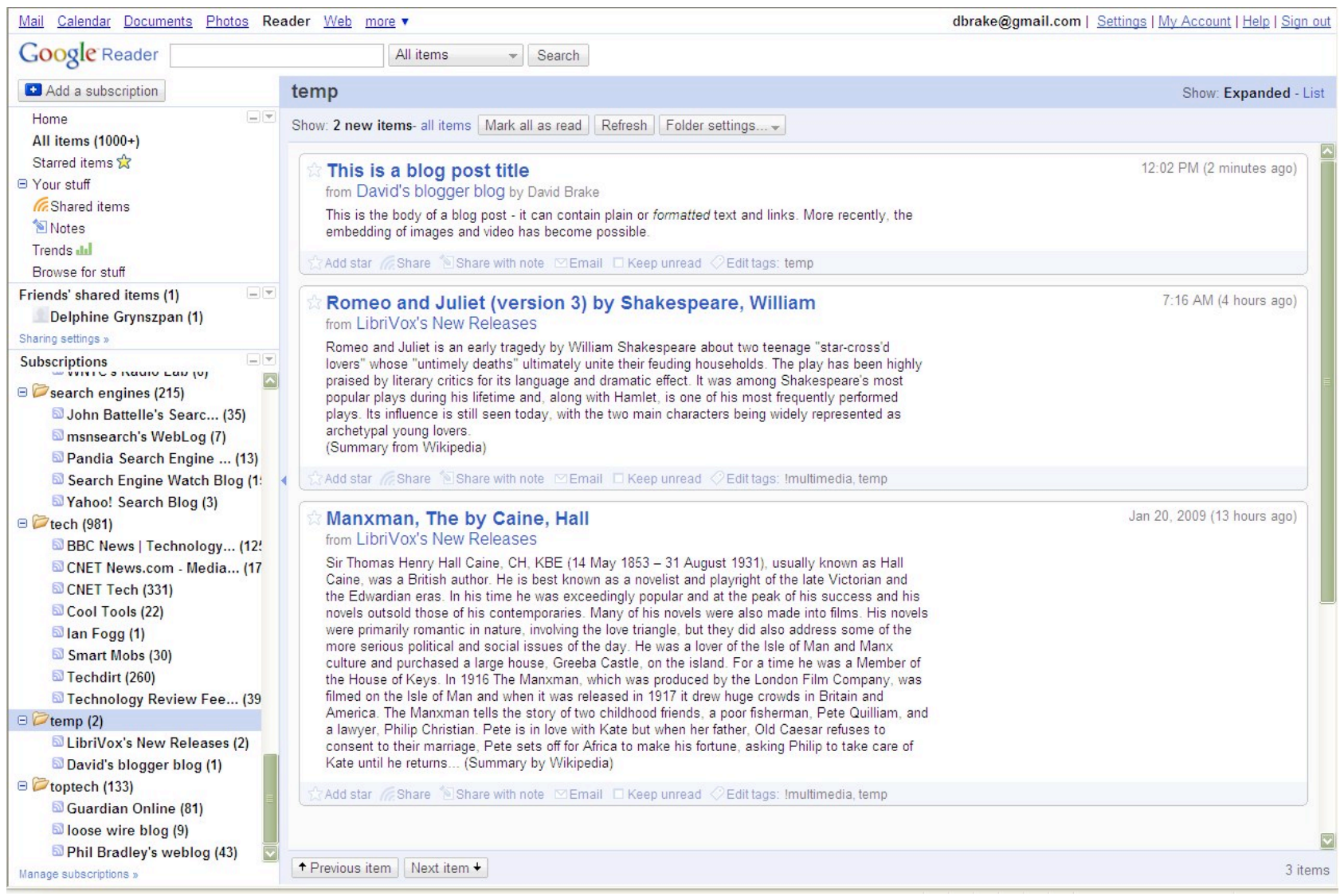

\section{Image A.6 - Google Reader is one of many RSS readers available. Note how text from different blogs is re-contextualised and reformatted.}

Because a variety of 'Web 2.0' services provide RSS feeds, these can be mixed together by users themselves (or by third parties) to provide a picture of a user's online activities across several sites (see image A.7 below). 


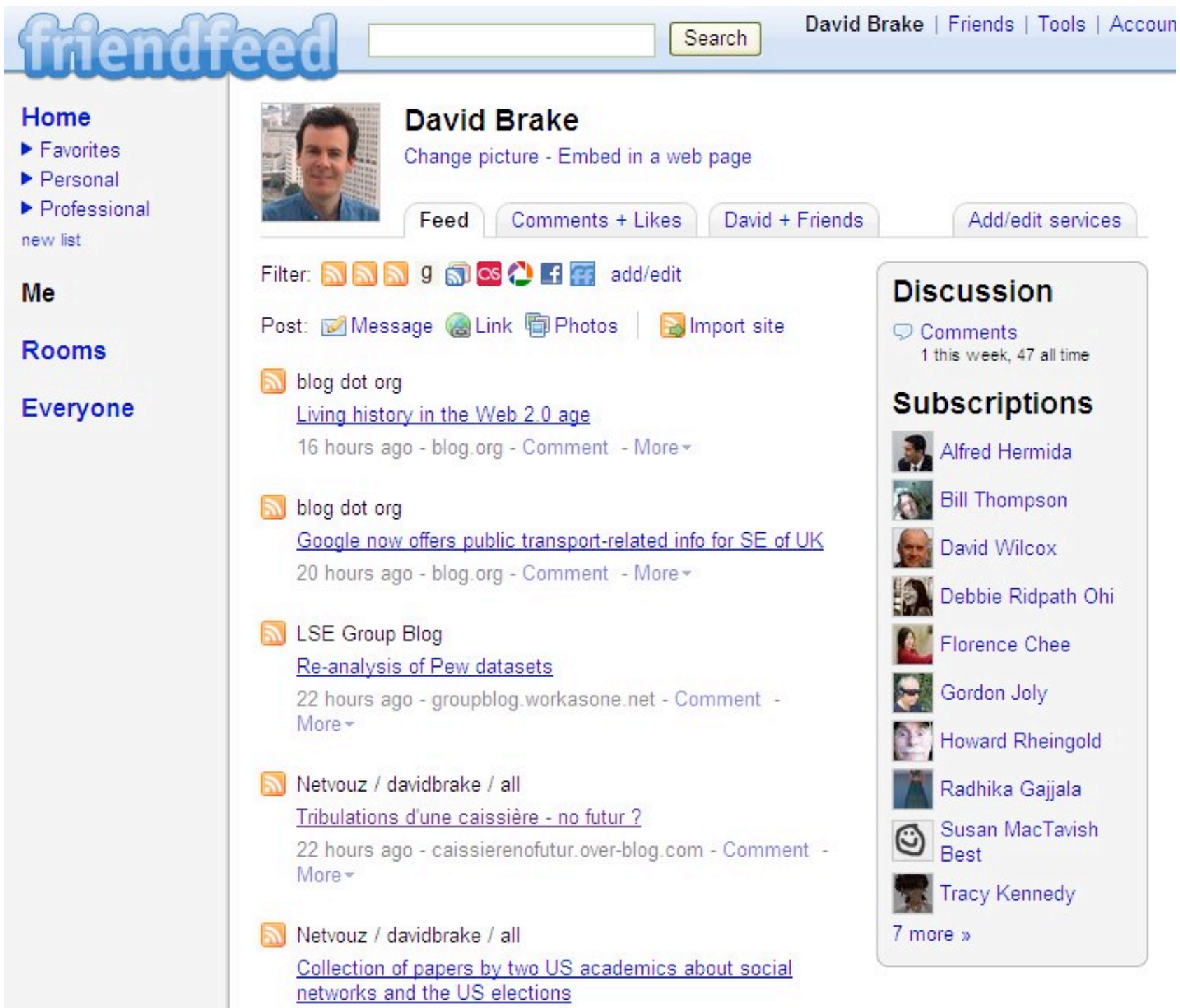

\section{Image A.7 - This site brings together recent public web activity by the author across two weblogs and eight other sites.}

LiveJournal, which was developed before RSS was designed, has a feature called the "friends page". This works in a similar way to RSS readers in that it brings together postings from several different sites - in this case it provides a reverse chronological listing of the recent postings of a user's LJ friends - but does not facilitate mixing of these posts with other posts from outside LiveJournal.

$\underline{\text { Archiving }}$

In addition to the archives of blogs which are under a blog producer's direct control, there are or could be numerous other archives for a variety of purposes. The website providers may retain copies of the text (while LiveJournal suggests they delete journal files once an account is deleted, Blogger removes posts from public view in these circumstances but may retain some text in backup files ${ }^{97}$ ). Search engines routinely archive the pages they index so even if a website has been

\footnotetext{
${ }^{97} \mathrm{http}: / /$ www.blogger.com/privacy, http://www.livejournal.com/legal/privacy.bml
} 
removed, pages from it can be searched for and retrieved, although only the latest version of a web page before its removal is normally saved in this way. RSS readers represent another way weblogs may be archived. Both online and offline readers generally retain the text of RSS feeds and sometimes associated images for later keyword searching by their users - even when the original text disappears both from the originating blog site itself and from its RSS feed.

The Wayback Machine at http://archive.org/ is the most ambitious public internet archiving project as it attempts to archive a broad range of sites across the world. It stores multiple snapshots of web pages through time and makes its archive publicly available (see image A. 8 below).

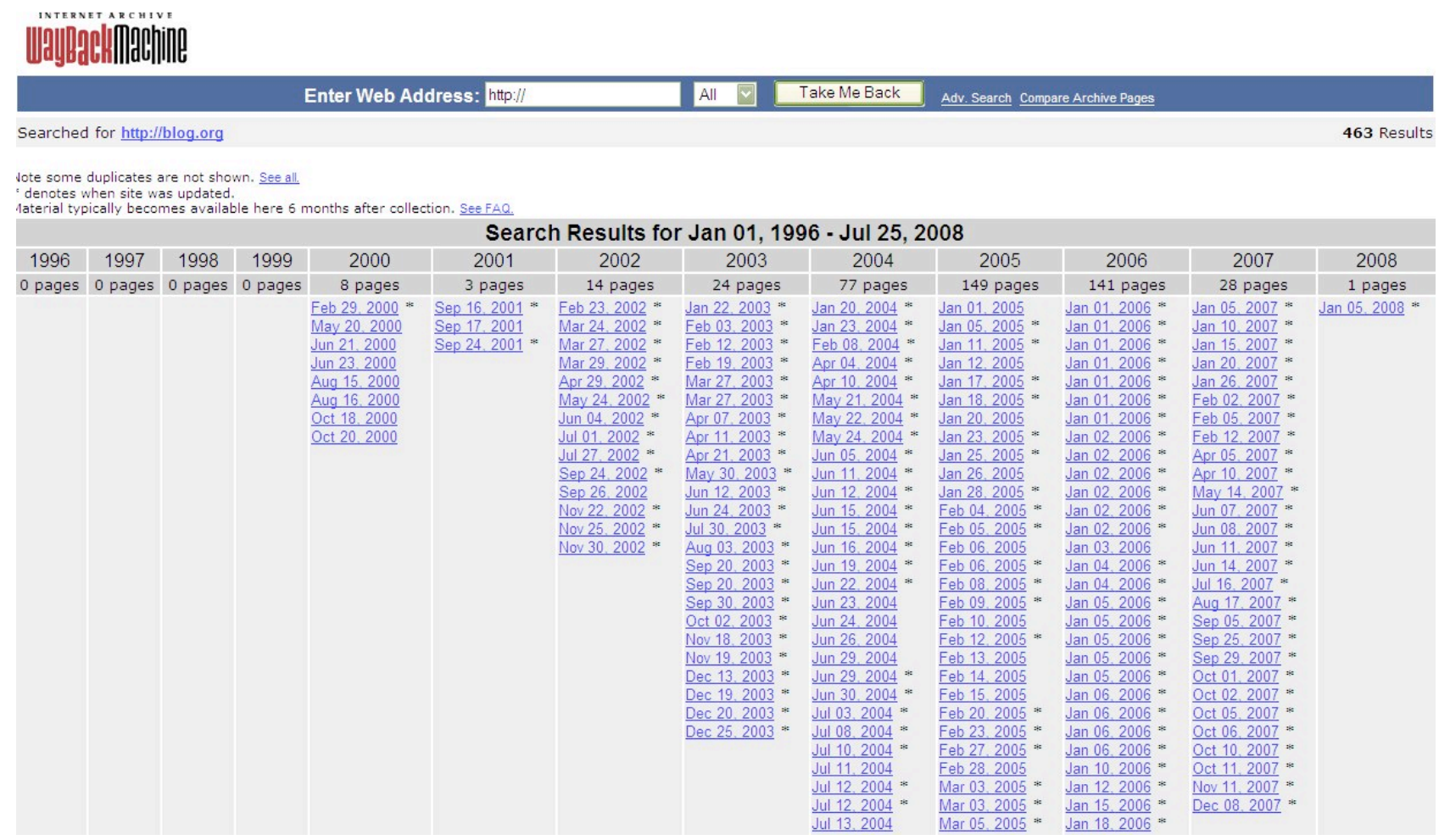

Image A.8 - The Wayback Machine has multiple copies of my weblog dating back 7 years.

Though the archive was not keyword searchable at the time of writing - one has to know the address of the website one is looking for to access its archive - a third of the index was searchable using an experimental tool called "Recall Search" between September 2003 and September 2004, and if the developers of this site obtain sufficient resources it might become keyword searchable again in future. It also provides an easy-to-use tool which allows readers to compare one version from the archive with another, making it easy to see (for example) which parts of a user's postings they may have elected to remove (see image A.9 below). 


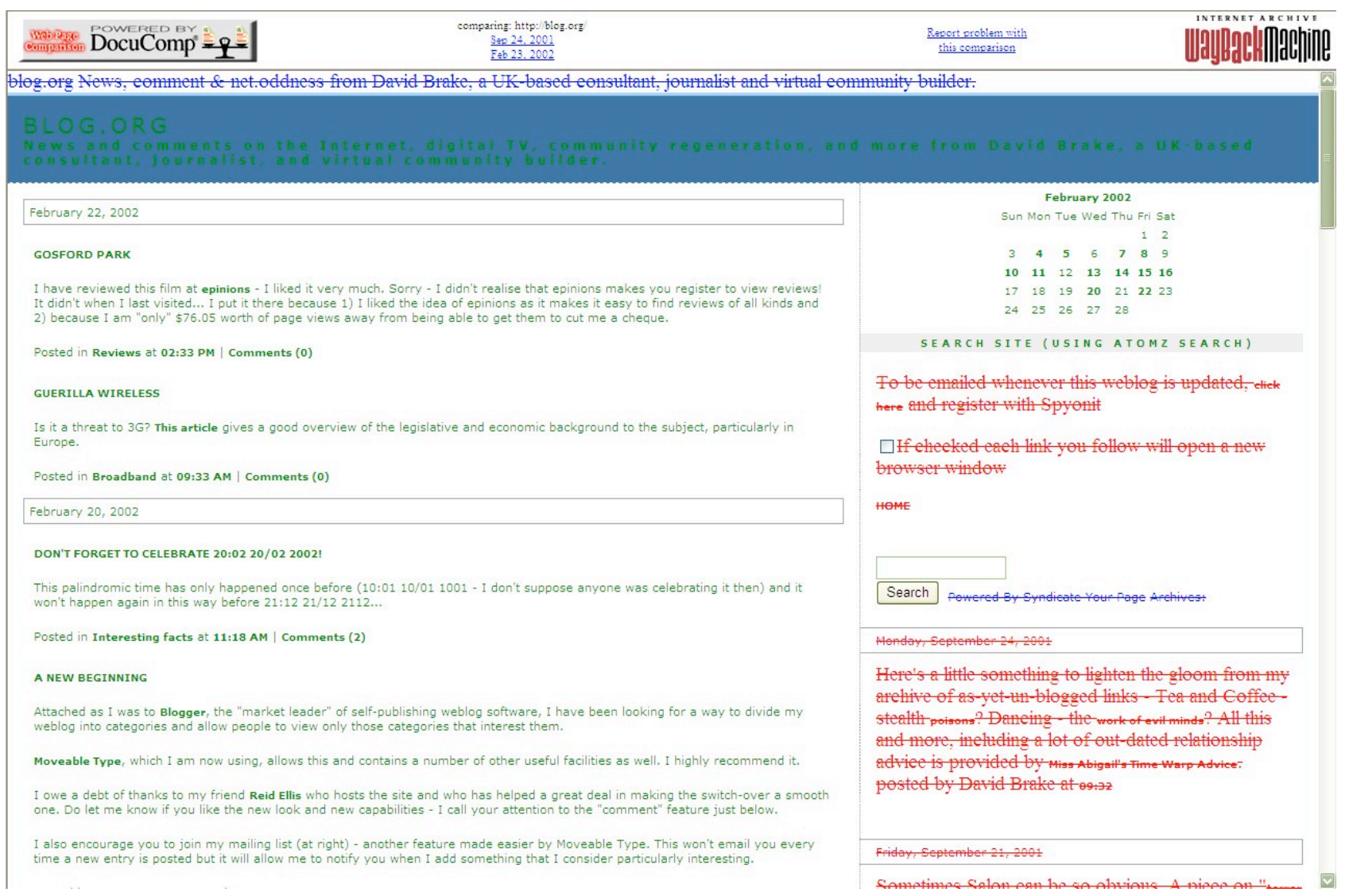

Image A.9 - The WayBack Machine's comparison feature reveals page elements of my weblog that changed between 2001 and 2002.

The extent to which national governments and intelligence agencies maintain their own archives of web pages or might request information on removed pages from search engines is not known. In general, the extent of the present and future availability of publicly-accessible web pages is not clear. There was no discernable pattern to indicate which of the abandoned websites from those examined in this study would be archived in the Wayback Machine, for example, and search engines do not specify when or whether they will index a publicly-available page.

\section{Additional functionality}

While each weblogging platform has its own features, there are numerous third party websites offering additional features for those who want them and who have the technical capability to add them ${ }^{98}$. The principal features found to be added in this study in 2005 were the embedding of photographs hosted on third party sites and the use of third party traffic analysis tools which can reveal the number of people who visited a given site, which pages they looked at and (to a limited extent) their countries of origin, among other data (see image A.10 for an example). More recently

\footnotetext{
${ }^{98}$ In the case of the two technology platforms used by those in this study, Blogger and LiveJournal, the main way this is accomplished is through embedding of third party HTML code in the master templates of users' websites. More advanced weblogging services like WordPress and MoveableType have a "plugin" capability which makes it easier for users to add features.
} 
numerous services have sprung up to enable blogs (and personal web pages) to display information from other web applications automatically - for example bloggers may include a feed of their recent postings to Twitter, of books that they have reviewed on Shelfari or of videos that they have viewed or created on YouTube.

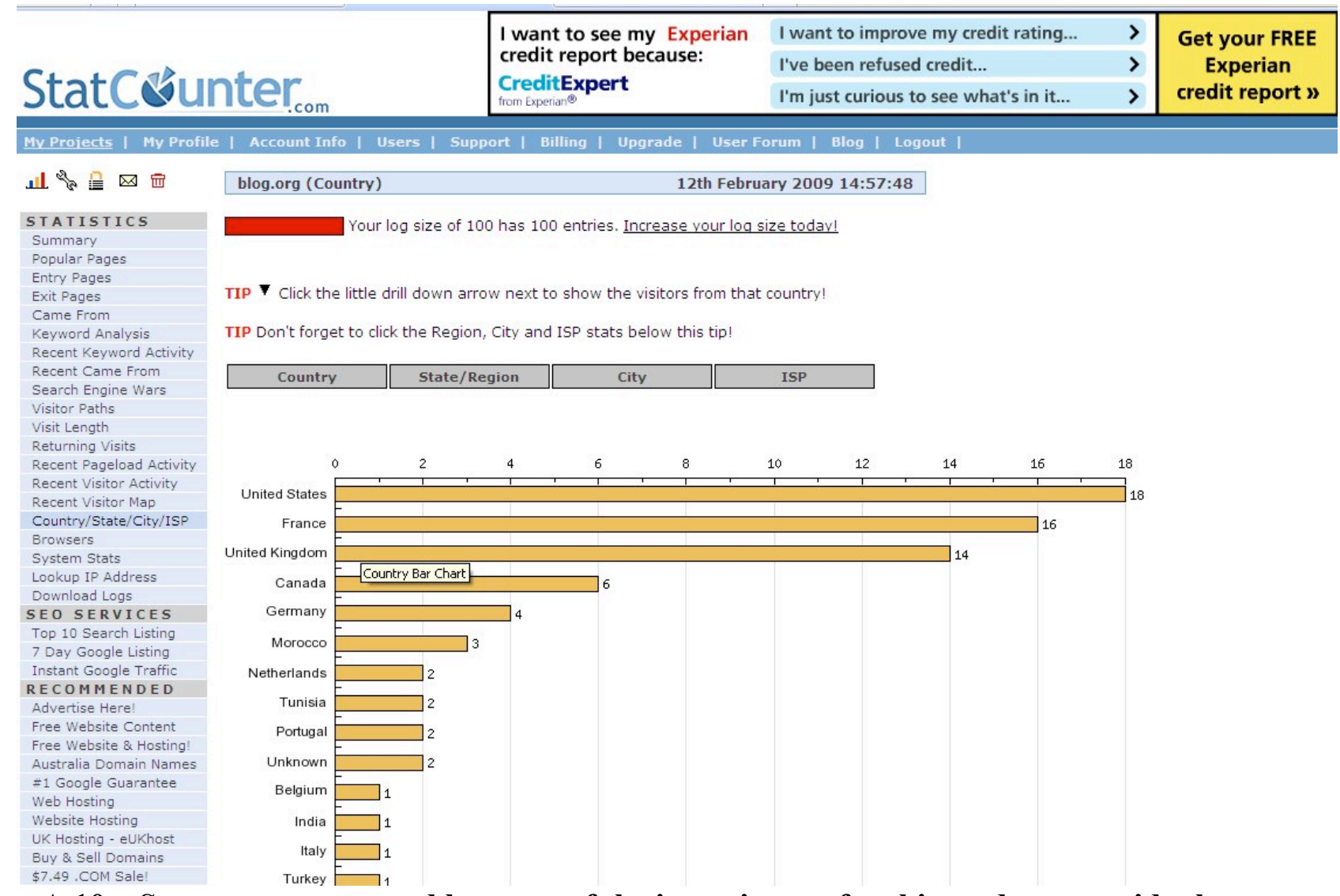

Image A.10 - Statcounter was used by some of the interviewees for this study to provide them with details about visitors to their sites like their numbers and location.

\section{Glossary}

Blogroll - A fixed list of sites, usually other blogs, which a blog user chooses to highlight alongside their postings.

"Friend" - In the context of LiveJournal use practices this refers to any other LiveJournal user who has been given the rights to view posts that would otherwise be private or to a user whose LiveJournal postings are added to the speaker's "friend updates" page.

Profile - Frequently blog sites (and other services) include a "profile" page which users are encouraged to fill in when they start using their blogs with space for the user's picture, contact details and any other information they choose to share. This tends to undermine the anonymity of blogging, though bloggers who choose to can leave out or falsify what is presented. 
RSS feed - RSS stands for "really simple syndication" - it is a special form of XML (an HTML-like text format) that describes postings to blogs and other sites in such a way that these postings can be accessed as independent units by other applications and services and searched or displayed in contexts outside of the pages they were originally placed on.

RSS reader - Any piece of software or service which allows a user to read and search multiple RSS feeds.

Tagging - The practice of assigning keywords to individual blog postings (and other online content) to enable the original author or other users to categorise that content.

Image A.11 (below) illustrates the key elements of a weblog page. 


\section{DAVID'S BLOGGER BLOG}

TUESDAY, JANUARY 20,2009

This is a blog post title

This is the body of a blog post - it can contain plain or formatted

text and links. More recently, the embedding of images and video

has become possible.

POSTED BY DAVID BRAKE AT 8:12 AM O COMMENTS

LABELS: A_TAG ANOTHER_TAG

Subscribe to: Posts (Atom)
AN EXAMPLE "BLOGROLL"

The blog of David Brake academic, consultant $\mathrm{A}$ journalist

LSE Group Blog

BLOG ARCHIVE

$\nabla 2009$ (1)

$\boldsymbol{\nabla}$ January (1)

This is a blog post title

$*$

ABOUT ME

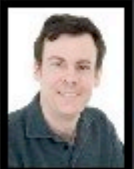

DAVID BRAKE

I am an academic,

Internet consultant and

journalist. My academic group weblog is

Media@LSE.

VIEW MY COMPLETE PROFILE

Image A.11 An annotated screenshot showing how different typical blog page elements are organized. The "subscribe to" text links to the blog's RSS feed 


\section{Appendix B: Interview Consent Form}

This consent form outlines my rights as a participant in the study of personal weblogging conducted by David Brake, Doctoral student at the London School of Economics.

I understand that

Taking part in this study is entirely voluntary.

It is my right to decline to answer any question that I am asked.

I am free to end the interview at any time.

I consent to the recording of this interview.

It is customary for participants to be anonymous, however I may have my name and/or web address(es) included if I choose. If I do choose anonymity, my name and identity will remain confidential in any publications or discussions and will not appear on any tapes or transcripts resulting from the interview.

[ ] I would like you to publish my web address.

[ ] I would like you to publish my name.

Inclusion of text from participants' websites alongside the interviews themselves would help this research, however use of this text may make it possible (using a search engine) for readers to find participants' websites even if their addresses are not published.

[ ] I am happy to have short excerpts from my public website published.

[ ] I am happy to have short excerpts from "friends only" portions of my website published.

I HAVE READ THIS CONSENT FORM. I HAVE HAD A CHANCE TO ASK QUESTIONS CONCERNING ANY AREAS THAT I DID NOT UNDERSTAND.

(Signature of Interviewee)

(Printed name of Interviewee)

(Date)

You may decline to participate in this study. You may end your participation in this study at any time. Maintaining your anonymity if you request it is a priority and in that case every practical precaution will be taken to disguise your identity. I will not allow anyone other than the research advisor to hear any audiotape of your voice or review a transcript of this interview. All materials generated from your interview (e.g., audiotapes and transcripts) will remain in my direct physical possession.

(Signature of Interviewer and Date) 


\section{Appendix C: Introductory email}

$\mathrm{PhD}$ researcher interested in your blog

I am a student at the University of London (LSE) researching personal webloggers and the people who read their blogs/journals. I would be grateful if you would answer a short questionnaire about your blog, which I found through a search for blogs in London. It should take only about five minutes to complete.

This is a survey for non-commercial academic purposes only. No information that could be used to identify you will be used without your permission, and responses to this questionnaire will only be published in summary form.

If you have any questions now or after you have completed the questionnaire please contact me by replying to this message.

Here is a link to the survey:

[SurveyLink]

Thanks in advance for your participation! 
Appendix D: Survey web form

[Available on request] 
Page 217 
Page 218 


\section{Appendix E: Interview protocol}

\section{General/open questions}

Did you have a journal of some kind before you took yours online? Do you maintain it still? Do you show it to anyone else? How do you differentiate what goes in each journal?

Why did you start this site?

If other people suggested - what arguments did they use? Why agreed?

What did you think it would be like?

Why do/did you continue?

How long do you spend on it?

What might cause you to stop?/Why did you stop?

Can you think of times when having an online journal was particularly important to you? Tell me about them.

Can you think of times when having an online journal was a problem for you? Tell me about them. In what ways is this autobiographical practice important to those performing it?

Is there anything about your personal journal that is important to you that you would like to add?

Do you re-read your old journal entries after they have been published?

If so, how does it make you feel? Do you feel you have changed?

Have you changed or removed an entry after completing it? Why?

Do you read other personal journals? Do you contact their authors?

To what extent are your peers online?

\section{Relationship of the weblog with the self}

What was going on in your life when you decided to start your online journal?

Would someone who read all of your online journal have a good picture of the kind of person you are? [If not] What would they miss?

Is that a deliberate choice? Something you find hard to express or don't want to express?

Is your journal mainly about a particular part of your personality?

Is this a side of yourself that mainly comes out online?

Do you 'craft' your posts or do they just 'come out'?

Have there been significant events that have happened during blogging that you haven't blogged about? Why not?

Do you keep a 'stock' of postings in case you don't have something to say on a particular day?

\section{Perception of audience}

Do you have a mental picture of the people who read you?

What kind of people are they?

Have you been surprised by finding that a particular person or kind of person reads your site?

What kind of people would you tell about your site?

What kind of people would you expect to know about your site before you met them?

[If some postings are only readable by a limited group]

When and why did you decide not to make some of your posts public?

How do you decide what group can read a posting?

How do you decide when to add or remove people from your list of readers?

Why have you/haven't you included your name and identity on your site?

Are there people who know you that you wouldn't want to read your site?

Why do you think people read your site?

Do you have an idea of how people might see you from your blog?

Do you think about what they might be looking for as you write?

What do you look for in the weblogs you read? 
[When writing personal items] Do you change what you write with them in mind?

[If they make changes] What kind of changes do you make? Do you aim to make your account more artistic? More interesting? Less revealing [of embarrassing details]? To make yourself appear better/smarter?

Do you keep track of the number and kind of visitors you get?

How popular would you say your site is?

How do you feel about that?

How much do you know about your readership aside from their numbers?

Do you try to reach additional readers? [If so how - by registering with search engines, by word of mouth, by linking to other popular sites?]

Do you use other people's real names?

Have you found yourself upset about what other people have said about you on their blogs?

\section{Role of interaction}

How much contact do you have from people who read your site?

Roughly what proportion is from people you only know because of your journal?

Roughly what proportion is public (e.g. comments) and what is private (e.g. email)?

Are there things you write with particular readers in mind that other people wouldn't understand?

If weblog is strongly personal - who outside of your audience would you talk to about these issues?

How much feedback did you expect in the beginning?

Do you wish it was more? Or less?

What kind of people write you?

Do you think they are they typical of your readers?

What kind of things do they write about?

Are readers generally supportive? Hostile?

How do you feel about what they say?

What kinds of comment do you like? Do you not like? [Probe for examples]

Have you changed what you write because of them?

Have their comments changed the way you feel about yourself/your actions? [probe for examples]

\section{Tech/Genre}

Do you think there is a typical kind of reader of personal sites? A typical producer?

How did you come up with the design of your site?

Did you look at books? Magazines? Design-related sites? Other similar sites?

How did you choose what you were going to write about? Has that changed? Why?

Do you feel there is a certain way people expect journal sites to look? Or a way they feel they should look like?

Is there a sort of content and/or practice that people expect from journal writers? (e.g. full disclosure of personal details, no erasure of past postings)

Does your site follow this convention?

How do you decide what to write about? What counts as 'blog-able'?

Do you post things sometimes because there's a 'meme' going around or because a particular topic is in the news rather than because it is interesting to you?

Are there any additional technical features you wish you had on your site? Why? (Forget for the moment what the tech allows)

What keeps you from doing it? [not knowing how? Not having the time? Cost? Tech doesn't allow it?]

Are there features on your site you would prefer not to have?

Why are they there? [Don't know how to remove them/ people expect them] 
In particular, is your site open to all because you want it to be or because it would be inconvenient or difficult to restrict its readership? If you could restrict the readership what group would you choose? 


\section{Appendix F: Interviewee Profiles}

Based on questionnaire responses

Educational attainment

\begin{tabular}{|l|r|r|r|r|}
\hline & Frequency & Percent & Valid & \multicolumn{2}{|c|}{ Pumulative } \\
& Percent & Percent \\
\hline Vocational & 2 & 8.7 & 8.7 & 8.7 \\
A level & 4 & 17.4 & 17.4 & 26.1 \\
BA & 8 & 34.8 & 34.8 & 60.9 \\
Postgrad & 9 & 39.1 & 39.1 & 100.0 \\
Total & 23 & 100.0 & 100.0 & \\
\hline
\end{tabular}

Self-described social class

\begin{tabular}{|l|r|r|r|r|}
\hline & \multicolumn{2}{|c|}{ Freque } & Valid & $\begin{array}{c}\text { Cumula } \\
\text { ncy }\end{array}$ \\
& Percent & Percent & Percent \\
\hline Working class & 13 & 13.0 & 13.0 & 13.0 \\
Middle & 6 & 56.5 & 56.5 & 69.6 \\
Upper middle & 1 & 26.1 & 26.1 & 95.7 \\
Other & 23 & 4.3 & 4.3 & 100.0 \\
Total & 100.0 & 100.0 & \\
\hline
\end{tabular}

\section{Gender}

\begin{tabular}{|c|c|c|c|c|}
\hline & $\begin{array}{l}\text { Freque } \\
\text { ncy }\end{array}$ & Percent & $\begin{array}{l}\text { Valid } \\
\text { Percent }\end{array}$ & $\begin{array}{l}\text { Cumula } \\
\text { tive Percent }\end{array}$ \\
\hline $\mathrm{M}$ & 11 & 47.8 & 47.8 & 47.8 \\
\hline $\mathrm{F}$ & 12 & 52.2 & 52.2 & 100.0 \\
\hline Total & 23 & 100.0 & 100.0 & \\
\hline
\end{tabular}




\section{Occupation}

\begin{tabular}{|c|c|c|c|c|}
\hline & Frequency & Percent & Valid Percent & $\begin{array}{l}\text { Cumulative } \\
\text { Percent }\end{array}$ \\
\hline Administrative & 1 & 4.3 & 4.3 & 4.3 \\
\hline Artist & 1 & 4.3 & 4.3 & 8.7 \\
\hline artist, educator & 1 & 4.3 & 4.3 & 13.0 \\
\hline Author & 1 & 4.3 & 4.3 & 17.4 \\
\hline $\begin{array}{l}\text { Business Analyst, Writer, } \\
\text { DJ }\end{array}$ & 1 & 4.3 & 4.3 & 21.7 \\
\hline $\begin{array}{l}\text { Charities Communications } \\
\text { Officer }\end{array}$ & 1 & 4.3 & 4.3 & 26.1 \\
\hline Civil servant & 1 & 4.3 & 4.3 & 30.4 \\
\hline $\begin{array}{l}\text { Client Manager for a large } \\
\text { publisher. }\end{array}$ & 1 & 4.3 & 4.3 & 34.8 \\
\hline copywriter & 1 & 4.3 & 4.3 & 39.1 \\
\hline finance & 1 & 4.3 & 4.3 & 43.5 \\
\hline Freelance journalist & 1 & 4.3 & 4.3 & 47.8 \\
\hline IT, technical consultant & 1 & 4.3 & 4.3 & 52.2 \\
\hline Journalist & 2 & 8.7 & 8.7 & 60.9 \\
\hline $\begin{array}{l}\text { Librarian working for an } \\
\text { accountancy firm }\end{array}$ & 1 & 4.3 & 4.3 & 65.2 \\
\hline $\begin{array}{l}\text { Makeup Artist for Film, } \\
\mathrm{TV} \text {, and Stage an }\end{array}$ & 1 & 4.3 & 4.3 & 69.6 \\
\hline $\begin{array}{c}\text { Marketing } \\
\text { Communications in the public s }\end{array}$ & 1 & 4.3 & 4.3 & 73.9 \\
\hline office clerk & 1 & 4.3 & 4.3 & 78.3 \\
\hline PhD student & 1 & 4.3 & 4.3 & 82.6 \\
\hline Senior Computer Operator & 1 & 4.3 & 4.3 & 87.0 \\
\hline Software engineer & 1 & 4.3 & 4.3 & 91.3 \\
\hline Student & 1 & 4.3 & 4.3 & 95.7 \\
\hline Writer & 1 & 4.3 & 4.3 & 100.0 \\
\hline Total & 23 & 100.0 & 100.0 & \\
\hline
\end{tabular}




\section{Age group}

\begin{tabular}{|c|c|c|c|c|}
\hline & $\begin{array}{l}\text { Freque } \\
\text { ncy }\end{array}$ & Percent & $\begin{array}{l}\text { Valid } \\
\text { Percent }\end{array}$ & $\begin{array}{l}\text { Cumula } \\
\text { tive Percent }\end{array}$ \\
\hline $16-24$ & 6 & 26.1 & 26.1 & 26.1 \\
\hline $25-34$ & 9 & 39.1 & 39.1 & 65.2 \\
\hline $34-49$ & 6 & 26.1 & 26.1 & 91.3 \\
\hline $50-64$ & 2 & 8.7 & 8.7 & 100.0 \\
\hline Total & 23 & 100.0 & 100.0 & \\
\hline
\end{tabular}

\section{Self-described race}

\begin{tabular}{|c|r|r|r|r|}
\hline & \multicolumn{2}{|c|}{ Freque } & Valid & Cumula \\
& ncy & Percent & Percent & tive Percent \\
\hline 0 & 1 & 4.3 & 4.3 & 4.3 \\
White & 17 & 73.9 & 73.9 & 78.3 \\
Mixed & 1 & 4.3 & 4.3 & 82.6 \\
Black & 1 & 4.3 & 4.3 & 87.0 \\
other & 3 & 13.0 & 13.0 & 100.0 \\
Total & 23 & 100.0 & 100.0 & \\
\hline
\end{tabular}

On a scale of one to five how well would a regular reader of your weblog get to know you?

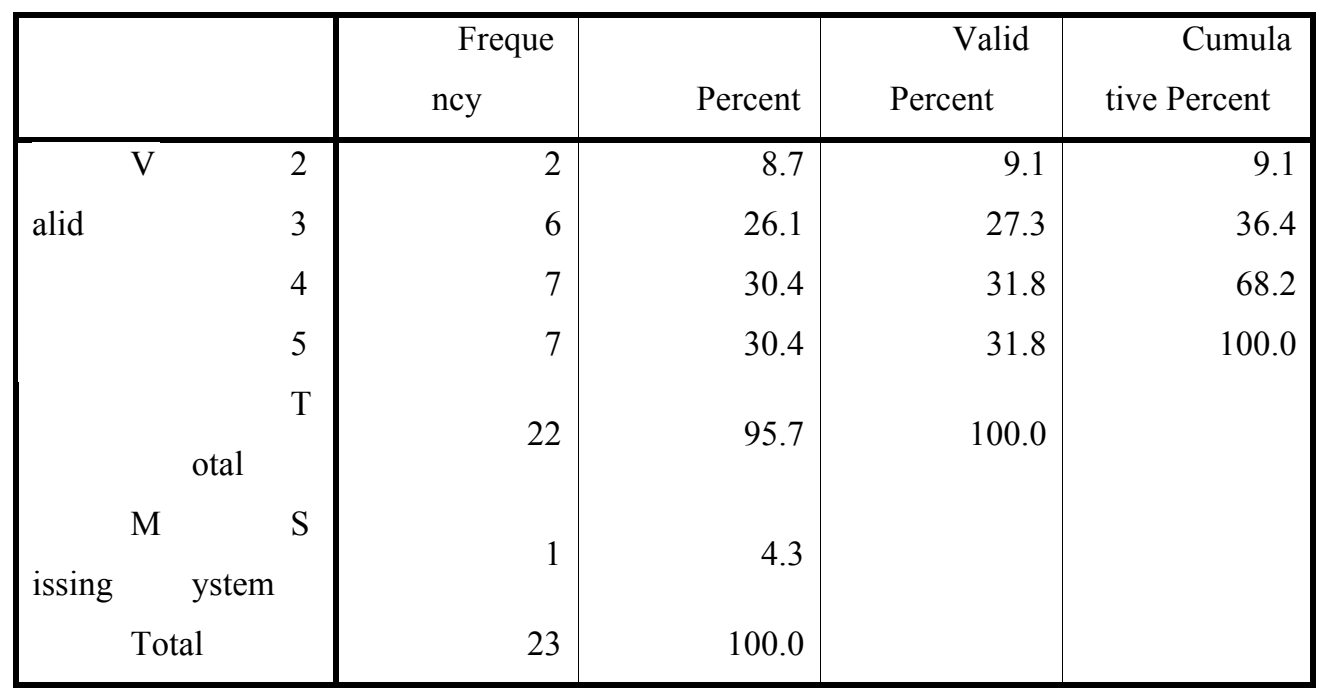


Roughly how many people do you think visit your weblog in an average week?

\begin{tabular}{|l|r|r|r|r|}
\hline & $\begin{array}{r}\text { Freque } \\
\text { ncy }\end{array}$ & Percent & $\begin{array}{r}\text { Valid } \\
\text { Percent }\end{array}$ & $\begin{array}{r}\text { Cumula } \\
\text { tive Percent }\end{array}$ \\
\hline none & 1 & 4.3 & 4.3 & 4.3 \\
$4-10$ & 4 & 17.4 & 17.4 & 21.7 \\
$11-50$ & 6 & 26.1 & 26.1 & 47.8 \\
$51-250$ & 7 & 30.4 & 30.4 & 78.3 \\
$251-1000$ & 5 & 21.7 & 21.7 & 100.0 \\
Total & 23 & 100.0 & 100.0 & \\
\hline
\end{tabular}

Roughly how many comments or weblog-related emails do you get in a typical week?

\begin{tabular}{|c|c|c|c|c|}
\hline & $\begin{array}{l}\text { Freque } \\
\text { ncy }\end{array}$ & Percent & $\begin{array}{l}\text { Valid } \\
\text { Percent }\end{array}$ & $\begin{array}{l}\text { Cumula } \\
\text { tive Percent }\end{array}$ \\
\hline none & 1 & 4.3 & 4.3 & 4.3 \\
\hline One or two & 5 & 21.7 & 21.7 & 26.1 \\
\hline $3-5$ & 4 & 17.4 & 17.4 & 43.5 \\
\hline $6-20$ & 7 & 30.4 & 30.4 & 73.9 \\
\hline $21-100$ & 5 & 21.7 & 21.7 & 95.7 \\
\hline$>100$ & 1 & 4.3 & 4.3 & 100.0 \\
\hline Total & 23 & 100.0 & 100.0 & \\
\hline
\end{tabular}

On a scale from 1 to 5 how important to you are the comments you get from readers?

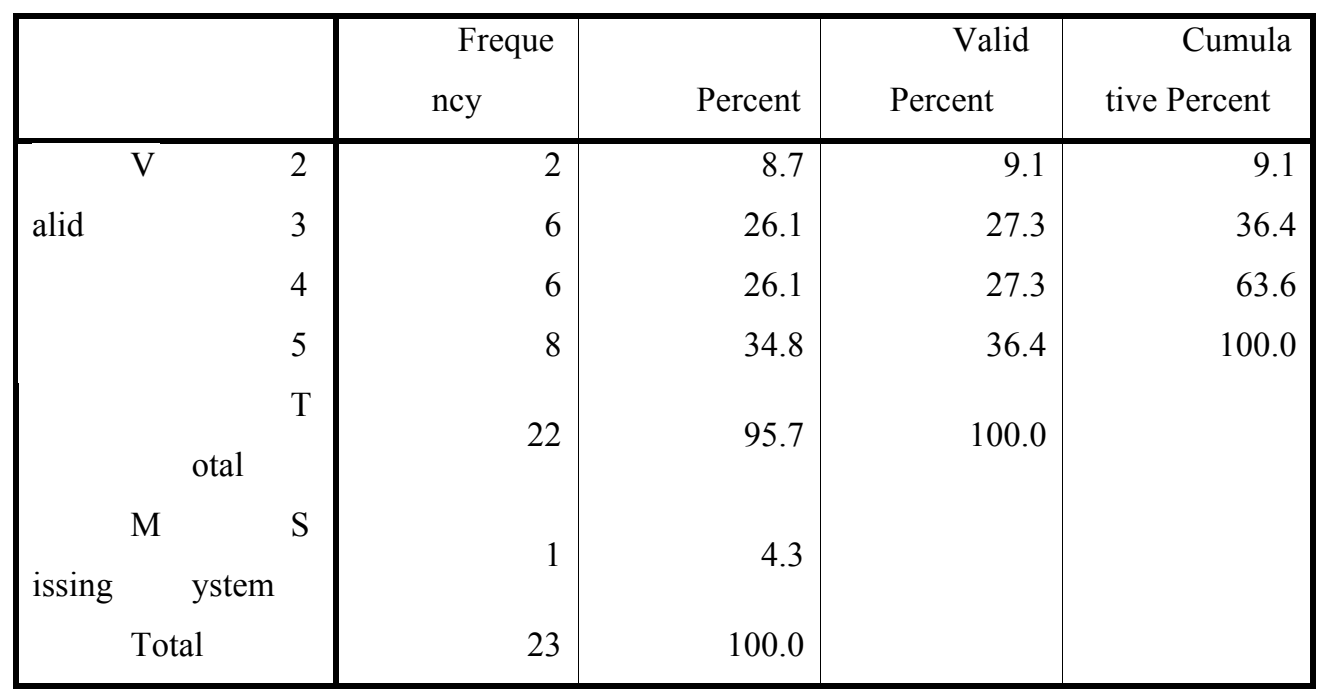




\section{Bibliography}

Abt, V. and M. Seesholtz (1994) The Shameless World of Phil, Sally and Oprah: Television Talk Shows and the Deconstructing of Society, J Popular Culture, 28 (1), 171-191.

Acquisti, A. and E. F. Gross (2006) Imagined Communities Awareness, Information Sharing, and Privacy on the Facebook Presented at Privacy Enhancing Technologies Workshop. Cambridge, UK. http://www.heinz.cmu.edu/ acquisti/papers/acquisti-gross-facebook-privacy-PET-final.pdf.

Acquisti, A. and J. Grossklags (2005) Privacy and Rationality in Decision Making, IEEE Security and Privacy, http://www.heinz.cmu.edu/ acquisti/papers/acquisti.pdf

Amir-Ebrahimi, M. (2004) Performance in Everyday Life and the Rediscovery of The "Self" In Iranian Weblogs, Bad Jens, 7 http://www.badjens.com/rediscovery.html

Ang, I. (1990) Desperately Seeking the Audience, Routledge, London.

AOL (2008) AOL UK Hometown Last accessed: 29 Dec 2008 [service withdrawn in Oct 08 but interface is archived] Last updated: 6 Jan 2008

http://web.archive.org/web/20080106232148/http://hometown.aol.co.uk/

Armstrong, H. B. (2002) Collecting Unemployment Last accessed: May 25th 2004 Last updated:

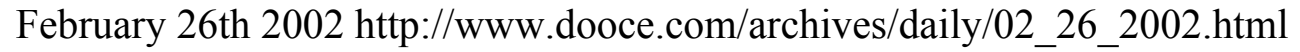

Atkinson, P. and W. Housley (2003) Interactionism: An Essay in Sociological Amnesia, SAGE, London.

Aune, M. (1996) The Computer in Everyday Life: Patterns of Domestication of a New Technology. In: Lie, M. and K. H. Sørensen (eds.) Making Technology Our Own?, Scandinavian University Press, Oslo; Boston, pp. 91-120.

Bakardjieva, M. (2005) Internet Society: The Internet in Everyday Life, SAGE, London.

Ball-Rokeach, S. J. and K. Reardon (1988) Monologue, Dialogue, and Telelog: Comparing an Emergent Form of Communication with Traditional Forms. In: Pingree, S., R. P. Hawkins and J. M. Wiemann (eds.) Advancing Communication Science: Merging Mass and Interpersonal Processes, Sage Publications, Newbury Park, Calif., pp. 135-161.

Barker, O. (31 July 2005) Web Spins Personal Laundry. USA Today, http://www.usatoday.com/life/lifestyle/2005-07-31-web-dirty-laundry_x.htm.

Barlow, J. P. (1996) A Declaration of the Independence of Cyberspace Last accessed: 25th Jan 2004 Last updated: February 8, 1996 http://www.eff.org/ barlow/Declaration-Final.html

Bauer, M. and B. Aarts (2000) Corpus Construction. In: Bauer, M. and G. Gaskell (eds.) Qualitative Researching with Text, Image and Sound: A Practical Handbook for Social Research, SAGE, London, pp. 19-37.

Bauer, M. and G. Gaskell (2000) Qualitative Researching with Text, Image and Sound: A Practical Handbook for Social Research, SAGE, London.

Bauman, Z. (2001) The Individualized Society, Polity Press, Cambridge, UK; Malden, MA.

Bauman, Z. (2007) Consuming Life, Polity Press, Cambridge.

BBC News Online (2004) US Blogger Fired by Her Airline Last accessed: 6 February 2009 Last updated: 3 November 2004 http://news.bbc.co.uk/1/hi/technology/3974081.stm

BBC News Online (2005) Microsoft Censors Chinese Blogs Last accessed: 27 April, 2006 Last updated: 14 June 2005 http://news.bbc.co.uk/1/hi/technology/4088702.stm 
BBC News Online (2006a) Most Britons 'Are Working Class' Last accessed: 5 May, 2006 Last updated: 4 May, 2006 http://news.bbc.co.uk/1/hi/uk/4974460.stm

BBC News Online (2006b) Star Wars Kid Is Top Viral Video Last accessed: 10 September 2008 Last updated: 27 November 2006 http://news.bbc.co.uk/1/hi/entertainment/6187554.stm

Beck, U. and E. Beck-Gernsheim (2001) Individualization: Institutionalized Individualism and Its Social and Political Consequences, Sage, London.

Bellman, S., E. J. Johnson and G. L. Lohse (2001) To Opt-in or Opt-Out? It Depends on the Question, Communications of the ACM, 44 (2), 25-27.

Bernstein, M. (2002) 10 Tips on Writing the Living Web Last accessed: 7 November, 2007 Last updated: 16 August $2002 \mathrm{http} / /$ www.alistapart.com/articles/writeliving/

Bijker, W. E., T. P. Hughes and T. J. Pinch (Eds.) (1990) The Social Construction of Technological Systems: New Directions in the Sociology and History of Technology, The MIT Press, Cambridge, Mass.; London.

Bijker, W. E. and J. Law (1992) Shaping Technology/Building Society: Studies in Sociotechnical Change, MIT Press, Cambridge, Mass.

Blodgett, H. (1988) Centuries of Female Days: Englishwomen's Private Diaries, Rutgers University Press, New Brunswick, N.J.; London.

Blogger (2006) How Do I Control Who Can View My Blog? Last accessed: 2 April 2009 Last updated: n.d. http://help.blogger.com/bin/answer.py?answer=42673

Blogger (n.d.-a) How Do I Delete a Blog? Last accessed: 2 April 2009 Last updated: n.d. http://help.blogger.com/bin/answer.py?hl=en\&answer=41387

Blogger (n.d.-b) What Is a Blog? Last accessed: 2 April 2009 Last updated:

http://www2.blogger.com/tour_start.g

Blood, R. (2000) Weblogs: A History and Perspective Last accessed: 31 March, 2008 Last updated: 7 Sep 2000 http://www.rebeccablood.net/essays/weblog_history.html

Blood, R. (2002) Weblog Ethics. In: The Weblog Handbook: Practical Advice on Creating and Maintaining Your Blog, Basic Books, New York City.

http://www.rebeccablood.net/handbook/excerpts/weblog_ethics.html

Blood, R., et al. (2003) Weblogs and Journalism, Nieman Reports, 57 (3), 61-98.

http://www.nieman.harvard.edu/reports/03-3NRfall/V57N3.pdf

Bloom, L. Z. (1996) I Write for Myself and Others': Private Diaries as Public Documents. In:

Bunkers, S. L. and C. A. Huff (eds.) Inscribing the Daily: Critical Essays on Women's Diaries, University of Massachusetts Press, Amherst, pp. 23-37.

Blumer, H. (1937) Social Psychology, Man and Society: A Substantive Introduction to the Social Sciences,

Blumer, H. (1969) The Methodological Position of Symbolic Interactionism. In: Blumer, H. (ed.) Symbolic Interactionism; Perspective and Method, Prentice-Hall, Englewood Cliffs, N.J., pp. 1-60.

Bober, M. (2004) Young People Online: Emerging Meanings in the Production and Consumption of Web Based Content. PhD. Manchester Metropolitan University.

Bourdieu, P. (1977) Outline of a Theory of Practice, Nice, R.) Cambridge University Press, Cambridge. 
Bourdieu, P. (1979) Public Opinion Does Not Exist. In: Mattelart, A. and S. Siegelaub (eds.) Communication and Class Struggle: 1. Capitalism and Imperialism, International General International Mass Media Research Center, New York, Bagnolet, France, pp. 124-130.

Bourdieu, P. (1991) Language and Symbolic Power the Economy of Linguistic Exchanges, (English translation 1991.) (trans. Raymond, G. and M. Adamson) Polity in association with Basil Blackwell, Cambridge.

Bourdieu, P. (1993a) The Field of Cultural Production: Essays on Art and Literature, Johnson, R.) Polity Press, Cambridge.

Bourdieu, P. (1993b) Sociology in Question, Sage, London.

Bourdieu, P. (1996) The Rules of Art: Genesis and Structure of the Literary Field, Polity Press, Cambridge.

Bourdieu, P. and L. J. D. Wacquant (1992) The Purpose of Reflexive Sociology (the Chicago Workshop). In: Bourdieu, P. and L. J. D. Wacquant (eds.) An Invitation to Reflexive Sociology, University of Chicago Press, Chicago, pp. 62-215.

Bowman, S. and C. Willis (2004) We Media: How Audiences Are Shaping the Future of News and Information, http://www.hypergene.net/wemedia/weblog.php

boyd, d. (2004) Broken Metaphors: Blogging as Liminal Practice Last accessed: 13 Dec 2004 Last updated: 12 Dec 2004 http://www.danah.org/papers/BrokenMetaphors.pdf

boyd, d. (2006) A Blogger's Blog: Exploring the Definition of a Medium, Reconstruction, 6 (4). http://reconstruction.eserver.org/064/boyd.shtml

boyd, d. (2008a) Why Youth (Heart) Social Network Sites: The Role of Networked Publics in Teenage Social Life. In: Buckingham, D. (ed.) Youth, Identity, and Digital Media, Chicago, pp. 119-142. DOI:10.1162/dmal.9780262524834.119

boyd, d. (2008b) Taken out of Context: American Teen Sociality in Networked Publics. University of California, Berkeley. http://ssrn.com/abstract=1344756

boyd, d. and N. B. Ellison (2007) Social Network Sites: Definition, History, and Scholarship, Journal of Computer-Mediated Communication, 13 (1). DOI:10.1111/j.1083-6101.2007.00393.x

Brady, M. (2006) Blogs: Motivations Behind the Phenomenon Presented at Information Communication \& Society. York, UK.

Brake, D. (2008a) Re-Analysis of 2006 Pew “Digital Footprints” Survey

http://pewinternet.org/PPF/r/65/dataset_display.asp

Brake, D. (2008b) Shaping the 'Me' in Myspace: The Framing of Profiles on a Social Network Site. In: Lundby, K. (ed.) Digital Storytelling, Mediatized Stories: Self-Representations in New Media, Peter Lang, New York, pp. 285-300.

Brake, D. (2009) Re-Analysis of 2005 Pew “Bloggers Callback” Survey http://www.pewinternet.org/PPF/r/60/dataset_display.asp

Branaman, A. (1997) Goffman's Social Theory. In: Goffman, E. and C. C. Lemert (eds.) The Goffman Reader, Blackwell, Malden, Mass.; Oxford, pp. xlvi-lxxxii.

Bratteteig, T. (2008) Does It Matter That It Is Digital? In: Lundby, K. (ed.) Digital Storytelling, Mediatized Stories: Self-Representations in New Media, Peter Lang, New York.

Brin, D. (1998) The Transparent Society: Will Technology Force Us to Choose between Privacy and Freedom?, Addison-Wesley, Reading, Mass. 
Browning, G. (16 December 2006) How To... Blog. The Guardian, p. 12

Bruns, A. and J. Jacobs (2006) Uses of Blogs, Peter Lang, New York.

Buchwalter, C. (2005) The Blog Universe: Influencers, Early Adopters and Online Tenure Rolled into One Presented at Word of Mouth Marketing Association.

http://www.womma.org/metrics/pres/womma_research_buchwalter.pdf.

Burns, T. (1977) The BBC: Public Institution and Private World, Macmillan, London.

Cadle, L. (2005) A Public View of Private Writing: Personal Weblogs and Adolescent Girls.

Bowling Green State University. http://www.scribd.com/doc/353334/A-Public-View-of-Private-

Writing-Personal-Weblogs-and-Adolecent-Girls

Calvert, C. (2000) Voyeur Nation: Media, Privacy, and Peering in Modern Culture, Westview Press, Boulder, Colo.

Castells, M. (2007) Communication, Power and Counter-Power in the Network Society, International Journal of Communication, 1, 238-266.

Cha, A. E. (Sunday, September 2, 2001) Dear Web Diary, So Much to Tell! Teens Tell Secrets, Get Gifts, Attract Nuts, Scare Mom. Washington Post, p. 1 http://www.washingtonpost.com/ac2/wpdyn/A30916-2001Sep1?language=printer.

Chadwick, B. A., H. M. Bahr and S. L. Albrecht (1984) Social Science Research Methods, PrenticeHall, Englewood Cliffs, N.J.

Chambers, I. (1990) A Miniature History of the Walkman, New Formations, 11, 1-4.

Chandler, D. (1998) Personal Home Pages and the Construction of Identities on the Web Last accessed: 22 August Last updated: Apr 192000

http://www.aber.ac.uk/media/Documents/short/webident.html

Chandler, D. and D. Roberts-Young (1998) The Construction of Identity in the Personal Homepages of Adolescents Last accessed: 19 September 2007 Last updated: 19 April 2000 http://www.aber.ac.uk/media/Documents/short/strasbourg.html

Chaudry, L. (2007) Mirror, Mirror on the Web. In: The Nation.

http://www.thenation.com/doc/20070129/chaudry

Cheung, C. (2004) Identity Construction and Self-Presentation on Personal Home Pages:

Emancipatory Potentials and Reality Constraints. In: Gauntlett, D. and R. Horsley (eds.)

Web.Studies: Rewiring Media Studies for the Digital Age, Arnold, London.

Chin, A. (1997) Making the World Wide Web Safe for Democracy: A Medium-Specific First Amendment Analysis, Hastings Communications \& Entertainment Law Journal, 19 (2).

http://democracyweb.com/law/www.htm

CIPD (2007) Internet and Email Policies. Chartered Institute of Personnel and Development. http://www.cipd.co.uk/subjects/hrpract/general/webepolicy.htm?IsSrchRes=1

Coate, J. (1987) Life on the Bus and Farm: An Informal Recollection Last accessed: 2 April 2009

$\mathrm{http}: / /$ cervisa.com/stories/farm.txt

Committee to Protect Journalists (2007) Journalists in Prison in 2007. Committee to Protect

Journalists,. http://www.cpj.org/Briefings/2007/imprisoned_07/imprisoned_07.html

Conniff, M. (2005) Just What Is a Blog, Anyway? Last accessed: 18 Nov 2005 Last updated: 29 Sep 2005 http://www.ojr.org/ojr/stories/050929/

Cooley, C. H. (1902) Human Nature and the Social Order, Scribner, New York. 
Couldry, N. (2000) The Place of Media Power: Pilgrims and Witnesses of the Media Age, Routledge, London.

Culnan, M. J. and M. L. Markus (1987) Information Technologies. In: Jablin, F. M. (ed.) Handbook of Organizational Communication: An Interdisciplinary Perspective, Sage, Newbury Park, Calif.; London, pp. 420-443.

Curran, J. and J. Seaton (2003) Power without Responsibility: The Press, Broadcasting, and New Media in Britain, (6th) (trans. Routledge, London.

Danet, B. (2001) Studies of Cyberpl@Y: Ethical and Methodological Aspects. Ethics Work Group, Association of Internet Researchers. http://atar.mscc.huji.ac.il/ msdanet/papers/ethics2.pdf

December, J. (n.d.) Studying Blogs (Web Logs) Last accessed: 2 April 2009 Last updated: unknown http://www.december.com/cmc/study/blogs.html

Deibert, R., J. Palfrey, R. Rohozinski and J. Zittrain (2008) Access Denied: The Practice and Policy of Global Internet Filtering, Mit Press, http://opennet.net/accessdenied

Delwiche, A. (2005) Agenda-Setting, Opinion Leadership, and the World of Web Logs, First Monday, 10 (12). http://firstmonday.org/issues/issue10_12/delwiche

Dennis, A. and P. J. Martin (2005) Symbolic Interactionism and the Concept of Power, The British Journal of Sociology, 56 (2), 191-213.

Denzin, N. K. (1992) Symbolic Interactionism and Cultural Studies: The Politics of Interpretation, Blackwell Publishers, Cambridge, Mass.

Dewey, J. (1896) The Reflex Arc Concept in Psychology, Psychological Review, 3 (3).

http://www.brocku.ca/MeadProject/Dewey/Dewey_1896.html

Dickie, M. (10 June 2005) Microsoft Bans 'Democracy' for China Web Users. Financial Times,

Digital Marketing Services (2005) Blog Trends Survey.

DiMaggio, P., E. Hargittai, C. Celeste and S. Shafer (2004) From Unequal Access to Differentiated Use: A Literature Review and Agenda for Research on Digital Inequality. In: Neckerman, K. (ed.)

Social Inequality, Russell Sage Foundation, New York, pp. 355-400.

http://www.eszter.com/research/c05-digitalinequality.html

Doctorow, C. (2002) My Blog, My Outboard Brain Last accessed: 21 February 2008 Last updated:

31 May 2002 http://www.oreillynet.com/pub/a/javascript/2002/01/01/cory.html

Doostdar, A. (2004) “The Vulgar Spirit of Blogging”: On Language, Culture, and Power in Persian Weblogistan, American Anthropologist, 106 (4). http://www.swiss.ai.mit.edu/6.805/admin/adminfall-2005/weeks/doostdar-vulgar_spirit_of_b.pdf

Döring, N. (2002) Personal Home Pages on the Web: A Review of Research, Journal of ComputerMediated Communication, 7 (3). DOI: 10.1111/j.1083-6101.2002.tb00152.x

Dovey, J. (2000) Freakshow: First Person Media and Factual Television, Pluto Press, London, Sterling, Va.

Du Gay, P., et al. (1997) Doing Cultural Studies: The Story of the Sony Walkman, Sage in association with The Open University, London; Thousand Oaks [Calif.].

Dutton, W. H., C. di Genarro and A. M. Hargrave (2005) The Oxford Internet Survey (Oxis) Report 2005: The Internet in Britain. Oxford Internet Institute, University of Oxford.

http://www.oii.ox.ac.uk/research/oxis/oxis2005_report.pdf 
Dutton, W. H. and E. Helsper (2007) The Internet in Britain: 2007. Oxford Internet Institute, University of Oxford. http://www.oii.ox.ac.uk/microsites/oxis/

Efimova, L. and J. Grudin (2007) Crossing Boundaries: A Case Study of Employee Blogging. Presented at Fortieth Hawaii International Conference on System Sciences (HICSS-40), Hawaii.

Eliasoph, N. (1998) Avoiding Politics: How Americans Produce Apathy in Everyday Life, Cambridge University Press, Cambridge, England; New York.

Ellison, N., C. Steinfield and C. Lampe (2007) The Benefits of Facebook 'Friends': Social Capital and College Students' Use of Online Social Network Sites, Journal of Computer-Mediated Communication, 12 (4). DOI:10.1111/j.1083-6101.2007.00367.x

Ellul, J. (1965) The Technological Society, Cape, London.

Epstein, E. J. (2000 [1973]) News from Nowhere: Television and the News, I.R. Dee, Chicago.

ESRC (2005) Research Ethics Framework. Economic and Social Research Council. http://www.esrc.ac.uk/ESRCInfoCentre/opportunities/research_ethics_framework/

Ess, C. and AoIR ethics working committee (2002) Ethical Decision-Making and Internet Research: Recommendations from the Aoir Ethics Working Committee. Association of Internet Researchers. http://www.aoir.org/reports/ethics.pdf

Facebook (2008) Facebook Terms of Use Last accessed: 12 September, 2008 Last updated: 7 June $2008 \mathrm{http}: / / \mathrm{www}$. facebook.com/terms.php?ref=pf

Farrell, H. J., E. Lawrence and J. Sides (2008) Self-Segregation or Deliberation? Blog Readership, Participation and Polarization in American Politics. SSRN. http://ssrn.com/paper $=1151490$

Feenberg, A. (1991) Critical Theory of Technology, Oxford University Press, New York, Oxford. Feenberg, A. (1999) Questioning Technology, Routledge, London.

Feenberg, A. (2002a) Democratic Rationalization: Technology, Power, and Freedom, Dogma, http://dogma.free.fr/txt/AF_democratic-rationalization.htm

Feenberg, A. (2002b) Transforming Technology: A Critical Theory Revisited, Oxford University Press, New York; Oxford.

Feenberg, A. (2008) From Critical Theory of Technology to the Rational Critique of Rationality, Social Epistemology, 22 (1), 5-28.

Ferguson, R. and B. Griffiths (2006) Thin Democracy? Parliamentarians, Citizens and the Influence of Blogging on Political Engagement, Parliament Affairs, 59 (2), 366-374.

Fisher, B. M. and A. L. Strauss (1979) Interactionism. In: Bottomore, T. B. and R. A. Nisbet (eds.) A History of Sociological Analysis, Heinemann Educational, London, pp. 457-498.

Flick, U. (2000) Episodic Interviewing. In: Bauer, M. and G. Gaskell (eds.) Qualitative Researching with Text, Image and Sound: A Practical Handbook for Social Research, Sage, London, pp. 75-92.

Flick, U. (2006a) Coding and Categorizing. In: Flick, U. (ed.) An Introduction to Qualitative Research, (3rd ed) Sage, London, pp. 295-319.

Flick, U. (2006b) An Introduction to Qualitative Research, (3rd ed) (trans. Sage, London.

Flick, U. (2006c) Narratives. In: Flick, U. (ed.) An Introduction to Qualitative Research, (3rd ed) (trans. Sage, London, pp. 172-188. 
Fono, D. and K. Raynes-Goldie (2006) Hyperfriends and Beyond: Friendship and Social Norms on Livejournal. In: Consalvo, M. and C. Haythornthwaite (eds.) Internet Research Annual Volume 4, Peter Lang, New York. http://k4t3.org/publications/hyperfriendship.pdf

Fothergill, R. A. (1974) Private Chronicles: A Study of English Diaries, Oxford University Press, London; New York.

Foucault, M. (1986) The Care of the Self: The History of Sexuality, Penguin, Harmondsworth.

Foucault, M. (1988a) The Ethic of Care for the Self as a Practice of Freedom. In: Bernauer, J. W. and D. M. Rasmussen (eds.) The Final Foucault, MIT Press, Cambridge, Mass.; London, pp. 1-20.

Foucault, M. (1988b) Technologies of the Self: A Seminar with Michel Foucault, Hutton, P. H.) Tavistock, London.

Foucault, M. (1997a) Ethics of Concern for the Self as a Practice of Freedom. In: Foucault, M. and P. Rabinow (eds.) Ethics: Subjectivity and Truth, Allen Lane [The Penguin Press], London, pp. 281-301.

Foucault, M. (1997b) Self Writing. In: Foucault, M. and P. Rabinow (eds.) Ethics: Subjectivity and Truth, Allen Lane [The Penguin Press], London, pp. 207-222.

Froomkin, A. M. (2000) The Death of Privacy?, Stanford Law Review, 52

http://personal.law.miami.edu/ froomkin/articles/privacy-deathof.pdf

Froomkin, A. M. (2003) Habermas@Discourse.Net: Toward a Critical Theory of Cyberspace, Harvard Law Review, 116 (3), 1461-1543.

Gamson, J. (1998) Freaks Talk Back: Tabloid Talk Shows and Sexual Nonconformity, University of Chicago Press, Chicago, Ill.

Garfinkel, S. (2000) Database Nation, O’Reilly, Cambridge.

Gellner, E. (1970) Concepts and Society. In: Wilson, B. R. (ed.) Rationality, Blackwell, Oxford, pp. $18-50$

Gergen, K. J. (1991) The Saturated Self: Dilemmas of Identity in Contemporary Life, Basic Books, New York.

Germann Molz, J. (2006) 'Watch Us Wander': Mobile Surveillance and the Surveillance of Mobility, Environment and Planning A, 38 (2), 377-393.

Gharbia, S. B. (2007) Access Denied Map: Mapping Web 2.0 Censorship Last accessed: 22 November 2008 Last updated: 13 November 2007

http://advocacy.globalvoicesonline.org/2007/11/13/access-denied-map-mapping-web-20censorship/

Giddens, A. (1987) Erving Goffman as a Systematic Social Theorist. In: Social Theory and Modern Sociology, Polity in association with Blackwell, Cambridge, pp. 109-139.

Giddens, A. (1990) The Consequences of Modernity, Polity in association with Blackwell, Cambridge.

Giddens, A. (1991) Modernity and Self Identity: Self and Society in the Late Modern Age, Polity Press in association with Basil Blackwell, Cambridge.

Gillmor, D. (2004) We the Media, http://www.oreilly.com/catalog/wemedia/book/

Gitlin, T. (1994) Inside Prime Time, (2nd) Routledge, London. 
Gitlin, T. (1998) Public Sphere or Public Sphericules. In: Liebes, T. and J. Curran (eds.) Media, Ritual and Identity, pp. 168-174.

Gitlin, T. (2003) The Whole World Is Watching: Mass Media in the Making \& Unmaking of the New Left, University of California Press, Berkeley, CA.

Goffman, E. (1959) The Presentation of Self in Everyday Life, Anchor Books, New York.

Goffman, E. (1961) Asylums: Essays on the Social Situation of Mental Patients and Other Inmates, (1st) (trans. Anchor Books, Garden City, N.Y.

Goffman, E. (1963) Behavior in Public Places: Notes on the Social Organization of Gatherings, Free Press of Glencoe; Collier-Macmillan, New York; London.

Goffman, E. (1967) Interaction Ritual: Essays in Face-to-Face Behavior, The Penguin Press : Aldine, London; Chicago.

Goffman, E. (1968) Stigma: Notes on the Management of Spoiled Identity, Penguin, Harmondsworth.

Goffman, E. (1971a) Relations in Public: Microstudies of the Public Order, Allen Lane, London.

Goffman, E. (1971b) The Territories of the Self. In: Goffman, E. (ed.) Relations in Public:

Microstudies of the Public Order, Allen Lane, London, pp. 28-61.

Goffman, E. (1979) Gender Advertisements, Harper \& Row, New York.

Goffman, E. (1981) Forms of Talk, Blackwell, Oxford.

Goffman, E. (1983) The Interaction Order: American Sociological Association, 1982 Presidential Address, American Sociological Review, 48 (1), 1-17. http://www.jstor.org/stable/2095141

Goffman, E. (1986 [1974]) Frame Analysis: An Essay on the Organization of Experience, (Northeastern University Press) (trans. Northeastern University Press, 1986, Boston, Mass.

Google (2004) Blogger Brings More Voices to the Web Last accessed: 23 February 2006 Last

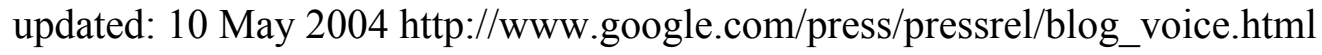

Gouldner, A. W. (1971) The Coming Crisis of Western Sociology, Heinemann, London.

Graves, L. (2007) Emergence, Affordance, Determinism: News-Related Blogs as a Case Study in Technological Effects Presented at International Communications Assocation. San Francisco.

Grindstaff, L. (1997) Producing Trash, Class and the Money Shot. In: Lull, J. and S. Hinerman (eds.) Media Scandals: Morality and Desire in the Popular Culture Marketplace, Polity Press, Oxford, pp. 164-202.

Gubrium, J. F. and J. A. Holstein (2002) Handbook of Interviewing Research: Context and Method, Sage, Thousand Oaks, California, London.

Gumbrecht, M. (2004) Blogs as 'Protected Space'. In: World Wide Web Conference, New York. http://www.blogpulse.com/papers/www2004gumbrecht.pdf

Gurak, L. J., et al. (Eds.) (2004) Into the Blogosphere: Rhetoric, Community, and Culture of Weblogs. http://blog.lib.umn.edu/blogosphere/

Habermas, J. (1970) Technology and Science as 'Ideology'. In: Toward a Rational Society: Student Protest, Science, and Politics, Boston, [Mass.].

Haddon, L. (2007) Roger Silverstone's Legacies: Domestication, New Media \& Society, 9 (1), $25-$ 32. 
Hafner, K. and M. Lyon (1996) Where Wizards Stay up Late: The Origins of the Internet, Simon \& Schuster, New York.

Halavais, A. (2005) Blogging in the Plural Last accessed: 18 November 2005 Last updated: 28 October $2005 \mathrm{http}: / /$ alex.halavais.net/?p=1281

Hannerz, U. (2003) Being There... And There... And There!: Reflections on Multi-Site Ethnography, 4 (2), 201-216.

Hanscom, M. (2003) Of Blogging and Unemployment Last accessed: May 25th 2004 Last updated: Oct 27th 2003 http://www.michaelhanscom.com/eclecticism/2003/10/of_blogging_and.html

Hargittai, E. (2006) Just a Pretty Face(Book)? What College Students Actually Do Online Presented at Beyond Broadcast. Harvard Law School. http://results.webuse.org/uic06/.

Hargittai, E. and A. Hinnant (2008) Digital Inequality: Differences in Young Adults' Use of the Internet, Communication Research, 35 (5), 602-621.

Harrison, A. E. (2001) Where Are They Now? MA. Georgetown.

http://www3.georgetown.edu/grad/cct/8604.html

Hawthorne, N. (1850) The Custom-House. In: The Scarlet Letter: A Romance, Ticknor, Reed \& Fields, Boston, pp. 1-54. http://etext.lib.virginia.edu/toc/modeng/public/Eaf135.html

Heidegger, M. and W. Lovitt (1977) The Question Concerning Technology, and Other Essays, Harper and Row, New York; London.

Henning, J. (2005) The Blogging Geyser. Perseus Development Corp,.

http://web.archive.org/web/20050413050512/http:/www.perseus.com/blogsurvey/geyser.html

Hermida, A. (2008a) The BBC Goes Blogging: Is 'Auntie' Finally Listening? Presented at Online Journalism Symposium. Austin, TX. http://reportr.net/2008/04/05/examining-the-role-of-blogs-inbbc-news/.

Hermida, A. (2008b) How the MSM Is Tackling Participatory Journalism Last accessed: 1 June Last updated: 24 May 2008 http://reportr.net/2008/05/24/how-the-msm-is-tackling-participatoryjournalism/

Herring, S., L. A. Scheidt, S. Bonus and E. Wright (2004) Bridging the Gap: A Genre Analysis of Weblogs. In: Hawaii International Conference on Systems Science, Hawaii. http://www.ics.uci.edu/\%7Ejpd/classes/ics234cw04/herring.pdf

Herring, S., L. A. Scheidt, E. Wright and S. Bonus (2005) Weblogs as a Bridging Genre, Information, Technology and People, 18 (2), 142-171. http://www.blogninja.com/it\&p.final.pdf

Herring, S. C. (2004) Slouching toward the Ordinary: Current Trends in Computer-Mediated Communication, New Media \& Society, 6 (1), 26-37.

Hevern, V. (2000) Alterity and Self-Presentation Via the Web: Dialogical and Narrative Aspects of Identity Construction. In: First International Conference on the Dialogical Self, Katholieke Universiteit Nijmegen, The Netherlands.

Hevern, V. W. (2004) Threaded Identity in Cyberspace: Weblogs \& Positioning in the Dialogical Self, Identity, 4 (4), 321-335.

Hiltz, R. S., K. Johnson and M. Turoff (1986) Experiments in Group Decision Making:

Communication Process and Outcome in Face to Face Versus Computerized Conferences, Human

Communication Research, 13, 225-252. 
Himmer, S. (2004) The Labyrinth Unbound: Weblogs as Literature. In: Herring, S., I. Kouper, L. A. Scheidt and E. L. Wright (eds.) Into the Blogosphere: Rhetoric, Community, and Culture of Weblogs. http://blog.lib.umn.edu/blogosphere/labyrinth_unbound.html

Hine, C. (2000) Virtual Ethnography, Sage, London.

Hlebec, V., K. L. Manfreda and V. Vehovar (2006) The Social Support Networks of Internet Users, New Media \& Society, 8 (1), 9-32.

Hodkinson, P. (2007) Interactive Online Journals and Individualisation New Media \& Society, 9 (4), 625-650.

Horrigan, J. B., J. Boase, L. Rainie and B. Wellman (2006) The Strength of Internet Ties. Pew Internet \& American Life Project. http://www.pewinternet.org/PPF/r/172/report_display.asp

Horton, D. and R. R. Wohl (1956) Mass Communication and Para-Social Interaction: Observations on Intimacy at a Distance, Psychiatry, 19 (3) 215-229.

Hourihan, M. (2002) What We're Doing When We Blog Last accessed: 31 March, 2008 Last updated: 13 Jun 2002 http://www.oreillynet.com/pub/a/javascript/2002/06/13/megnut.html

Indiana University Information Technology Services (2006) In Unix, How Do I Make Plan and Project Files That Will Show up When People Finger My Account? Last accessed: 9 April, 2006 Last updated: 11 May, 2005 http://kb.iu.edu/data/afky.html

Innis, H. A. (1950) Empire and Communications, Clarendon Press, Oxford.

Innis, H. A. (1951) The Bias of Communication, University of Toronto Press, Toronto.

Ito, M., et al. (2008) Living and Learning with New Media: Summary of Findings from the Digital Youth Project. The John D. and Catherine T. MacArthur Foundation.

http://digitalyouth.ischool.berkeley.edu/report

Jacobs, J. (2003) Communication over Exposure: The Rise of Blogs as a Product of Cybervoyeurism. In: ANZCA 03, Brisbane.

James, W. (1950 [1890]) The Principles of Psychology, Dover, New York.

Jardin, X. (2004) Msn Spaces: Seven Dirty Blogs Last accessed: 16 September 2008 Last updated: 2 December 2004 http://www.boingboing.net/2004/12/02/msn-spaces-seven-dir.html

Jogin, T. (2003) Winer Watcher Last accessed: 12 October 2008 Last updated: 15 July 2003 http://jogin.com/weblog/archives/2003/07/15/winer_watcher

Johnson, E. J. and D. Goldstein (2003) Do Defaults Save Lives?, Science, 302 (5649), 1338 - 1339.

Kalathil, S. and T. C. Boas (2002) Open Networks, Closed Regimes: The Impact of the Internet on Authoritarian Rule, Carnegie Endowment for International Peace, Washington, D.C.

Karlsson, L. (2005) It Is as If the Diary Form in Itself Is Preventive: Reading Diary Weblogs. In:

Consalvo, M., M. Allen and Association of Internet Researchers. (eds.) Internet Research Annual. Volume 3, Peter Lang, New York.

Kendall, L. (2003) Diary of a Networked Individual: Interpersonal Connections on Livejournal. In: Association of Internet Research 4.0, Toronto.

http://aoir.org/members/papers42/Kendall_2003aoirpaper.pdf

Kendall, L. (2007) Shout into the Wind, and It Shouts Back: Identity and Interactional Tensions on Livejournal, First Monday, 12 (9). http://www.firstmonday.org/issues/issue12_9/kendall/index.html 
Kennedy, H. (1999) Identity Construction in a Virtual World: The Homepage as Auto/Biographical Practice, Auto/Biography, 7 (1/2), 91-98.

Kiesler, S. and L. Sproull (1992) Group Decision Making and Communication Technology, Organizational behavior and human decision processes, 52, 96-123.

Killoran, J. B. (2002a) Homepage, Homebound; Web Log, We Blog: Web Genres for Personal Civic (Dis-)Engagement. In: Rhetoric Society of America, Las Vegas.

http://myweb.brooklyn.liu.edu/jkillora/research/2002rsa.html

Killoran, J. B. (2002b) Under Constriction: Colonization and Synthetic Institutionalization of Web Space, Computers and Composition, 112, 1-19.

Killoran, J. B. (2003) Homepages, Blogs, and the Chronotopic Dimensions of Personal Civic (Dis)Engagement. In: Hauser, G. A. and A. Grim (eds.) Rhetorical Democracy: Discursive Practices of Civic Engagement, Lawrence Erlbaum, Mahwah, N.J.

Kitzmann, A. (2003) That Different Place: Documenting the Self within Online Environments, Biography-an Interdisciplinary Quarterly, 26 (1), 48-65.

Kitzmann, A. (2004) Saved from Oblivion: Documenting the Daily from Diaries to Web Cams, P. Lang, New York; Oxford.

Kvale, S. (1996) Interviews: An Introduction to Qualitative Research Interviewing, Sage, London.

Lally, E. (2002) At Home with Computers, Berg, Basingstoke.

Landry, C. (1985) What a Way to Run a Railroad: An Analysis of Radical Failure, Comedia, London.

Lash, S. and J. Friedman (1991) Modernity and Identity, Blackwell, Oxford; Cambridge, Mass.

Latour, B. (1987) Science in Action: How to Follow Scientists and Engineers through Society, Open University Press, Milton Keynes.

Latour, B. (1996) Aramis, or, the Love of Technology, Harvard University Press, Cambridge, Mass.

Laver, J. (1975) Communicative Functions of Phatic Communion. In: Kendon, A., R. M. Harris and M. R. Key (eds.) Organization of Behavior in Face-to-Face Interaction, Mouton, The Hague; Chicago.

Leiby, R. The Hill's Sex Diarist Reveals All (Well, Some). Washington Post, p. 3 http://www.washingtonpost.com/wp-dyn/articles/A48909-2004May22.html.

Lenhart, A. (2006) Unstable Text: An Ethnographic Look at How Bloggers and Their Audience Negotiate Self-Presentation, Authenticity and Norm Formation. Master of Arts in Communication, Culture and Technology. Georgetown University.

http://lenhart.flashesofpanic.com/Lenhart_thesis.pdf

Lenhart, A., S. Arafeh, A. Smith and A. R. Macgill (2008) Writing, Technology and Teens. Pew Internet \& American Life Project. http://www.pewinternet.org/PPF/r/247/report_display.asp

Lenhart, A. and S. Fox (2006) Bloggers: A Portrait of the Internet's New Storytellers. Pew Internet \& American Life Project. http://www.pewinternet.org/PPF/r/186/report_display.asp

Lenhart, A., J. B. Horrigan and D. Fallows (2004) Content Creation Online. Pew Internet \& American Life Project. http://www.pewinternet.org/reports/toc.asp?Report=113

Lessig, L. (1999) The Law of the Horse: What Cyberlaw Might Teach, Harvard Law Review, 113 (2), 501-549. 
Lessig, L. (2006) Code: And Other Laws of Cyberspace :Version 2.0, (Rev. ed) Basic Books (The Perseus Books Group), http://codev2.cc/

Li, D. (2005) Why Do You Blog: A Uses and Gratifications Inquiry into Bloggers' Motivations. Marquette University. http://www.whyyoublog.net/doc/Li_Dan_Aug_2005.pdf

Li, D. and G. Walejko (2008) Splogs and Abandoned Blogs: The Perils of Sampling Bloggers and Their Blogs, Information, Communication \& Society, 11 (2), 279-296.

Lie, M. and K. H. Sørensen (1996) Making Technology Our Own?: Domesticating Technology into Everyday Life. In: Lie, M. and K. H. Sørensen (eds.) Making Technology Our Own?:

Domesticating Technology into Everyday Life, Scandinavian University Press, Oslo; Boston, pp. 130 .

LiveJournal (2004) User Statistics Last accessed: 3 Dec 2004 Last updated: 2 Dec 2004 http://www.livejournal.com/stats.bml

Livejournal (2007) How Do I Delete/Undelete My Journal or Community? Last accessed: 09

November 2008 Last updated: 10 May, 2007

http://www.livejournal.com/support/faqbrowse.bml?faqid=16

Livejournal (2008) How Do I Make All My Journal Entries Friends-Only, Private, or Public? Last accessed: 6 August 2008 Last updated: 24 June 2008

http://www.livejournal.com/support/faqbrowse.bml?faqid=120\&q=edit + journal + privacy\&lang=

LiveJournal (n.d.-a) Features by Account Type Last accessed: 2 May, 2007 Last updated: unknown http://www.livejournal.com/site/accounts.bml

LiveJournal (n.d.-b) What Is Livejournal? Last accessed: 23 April, 2007

Livingstone, S. (2008) Taking Risky Opportunities in Youthful Content Creation: Teenagers' Use of Social Networking Sites for Intimacy, Privacy and Self-Expression, New Media \& Society, 10 (3), 393-411.

Loewenstein, A. (2008) The Blogging Revolution, Melbourne University Press, Carlton, Vic.

LSE (2003) Research Ethics Policy. London School of Economics.

http://www.lse.ac.uk/collections/researchAndProjectDevelopmentDivision/research_ethics_policy.h tm

Lüders, M. (2005) Becoming More Like Friends: The Significance of Personal Media in Social Networking Processes Presented at First European Communication Conference. Amsterdam.

Maines, D. R. (2001) The Faultline of Consciousness: A View of Interactionism in Sociology, Aldine de Gruyter, New York.

Malinowski, B. (1923) The Problem of Meaning in Primitive Languages. In: Ogden, C. K. and I. A. Richards (eds.) The Meaning of Meaning: A Study of the Influence of Language Upon Thought and of the Science of Symbolism, pp. 296-336.

Marcus, G. E. (1995) Ethnography in/of the World System: The Emergence of Multi-Sited Ethnography, Annual Review of Anthropology, 24, 95-117.

Markham, A. N. (2004) Internet Communication as a Tool for Qualitative Research. In: Silverman, D. (ed.) Qualitative Research: Theory, Method and Practice, (2nd ed) (trans. SAGE Publications, London, pp. 95-124. http://faculty.uvi.edu/users/amarkha/writing/silvermandraft.html

Marvin, C. (1988) When Old Technologies Were New: Thinking About Electric Communication in the Late Nineteenth Century, Oxford University Press, New York. 
McLuhan, M. (1962) The Gutenberg Galaxy: The Making of Typographic Man, Routledge \& K Paul, London.

McLuhan, M. (2001) Understanding Media: The Extensions of Man, Routledge, London.

Mead, G. H. and C. W. Morris (1967 [1934]) Mind, Self, \& Society from the Standpoint of a Social Behaviorist, University of Chicago Press, Chicago.

Menchen Trevino, E. (2005) Blogger Motivations: Power, Pull, and Positive Feedback Presented at Association of Internet Researchers 6.0. Chicago, Ill.

http://blog.erickamenchen.net/2005/06/28/blogger-motivations-power-pull-and-positve-feedback/.

Meyrowitz, J. (1985) No Sense of Place: The Impact of Electronic Media on Social Behavior, Oxford University Press, Oxford; New York.

Miller, H. and J. Arnold (2001) Self in Web Home Pages: Gender, Identity and Power in Cyberspace. In: Riva, G. and C. Galimberti (eds.) Towards Cyberpsychology: Mind, Cognitions and Society in the Internet Age, IOS Press, Amsterdam.

Miller, J. and B. Glassner (1997) The 'inside' and the 'Outside': Finding Realities in Interviews. In: Silverman, D. (ed.) Qualitative Research: Theory, Method, and Practice, Sage Publications, London, Thousand Oaks, Calif., pp. 99-112.

Miller, V. (2008) New Media, Networking and Phatic Culture, Convergence, 14 (4), 387-400.

Mishne, G. and N. Glance (2006) Leave a Reply: An Analysis of Weblog Comments. In: WWW2006, Edinburgh. http://staff.science.uva.nl/ gilad/pubs/www2006-blogcomments.pdf

Mitchell, K. J., J. Wolak and D. Finkelhor (2008) Are Blogs Putting Youth at Risk for Online Sexual Solicitation or Harassment?, Child Abuse \& Neglect, 32 (2), 277-294.

Miura, A. and K. Yamashita (2004) Why Do People Publish Weblogs? An Online Survey of Weblog Authors in Japan. In: Morgan, K., C. A. Brebbia and D. Almorza (eds.) Human Perspectives in the Internet Society: Culture, Psychology and Gender, WIT Press.

Mortensen, T. (2004) Dialogue in Slow Motion: The Pleasure of Reading and Writing across the Web Presented at Blogtalk 2. Vienna. http://tilsett.hivolda.no/tm/blogtalk2004.doc.

Mortensen, T. and J. Walker (2002) Blogging Thoughts: Personal Publication as an Online Research Tool. In: Morrison, A. (ed.) Researching ICTs in Context, InterMedia, pp. 249-272. http://www.intermedia.uio.no/konferanser/skikt-02/docs/Researching_ICTs_in_context.pdf

MSN (2006) Blogging Britain: Inside Britain's Blogging Phenomenon. MSN. http://www.telegraph.co.uk/news/graphics/2006/07/21/blogging.pdf

Murdock, G., P. Hartmann and P. Gray (1992) Contextualizing Home Computing, Resources and Practices. In: Silverstone, R. and E. Hirsch (eds.) Consuming Technologies: Media and Information in Domestic Spaces, Routledge, London; New York, NY, pp. 146-160.

Murphy, E. and R. Dingwall (2001) The Ethics of Ethnography. In: Atkinson, P. and A. Coffey (eds.) Handbook of Ethnography, SAGE, London.

Nardi, B., D. Schiano and M. Gumbrecht (2004a) Blogging as Social Activity, or, Would You Let 900 Million People Read Your Diary? In: ACM conference on Computer supported cooperative work Chicago, Ill.

Nardi, B., D. Schiano, M. Gumbrecht and L. Swartz (2004b) 'I'm Blogging This': A Close Look at Why People Blog http://www.ics.uci.edu/\%7Ejpd/classes/ics234cw04/nardi.pdf 
Nie, N. H., A. Simpser, I. Stepanikova and L. Zheng (2004) Ten Years after the Birth of the Internet, How Do Americans Use the Internet in Their Daily Lives? Stanford Center for the Quantitative Study of Society. http://www.stanford.edu/group/siqss/

Nielson/NetRatings (2006) A Community Uprising. Nielson/NetRatings. http://www.nielsennetratings.com/pr/pr_060206_uk.pdf

Nussbaum, E. (2004) My So-Called Blog. In: New York Times Magazine, January 11, 2004. http://www.nytimes.com/2004/01/11/magazine/11BLOG.html

Nussbaum, E. (2007) Say Everything. In: New York Magazine, February 12, 2007 (http://nymag.com/news/features/27341/index.html

Ong, W. J. (1982) Orality and Literacy: The Technologizing of the Word, Methuen, London.

Paccagnella, L. (1997) Getting the Seat of Your Pants Dirty: Strategies for Ethnographic Research on Virtual Communities, Journal of Computer-Mediated Communication, 3 (1).

DOI:10.1111/j.1083-6101.1997.tb00065.x

Palfrey, J. and U. Gasser (2008) Born Digital: Understanding the First Generation of Digital Natives, Basic Books, New York.

Pew Internet \& American Life Project (2007) Internet Activities Last accessed: 2 April 2009 Last updated: December 2007 http://www.pewinternet.org/Data-Tools/Download-Data/Trend-Data.aspx

Pew Internet \& American Life Project (2008) Usage over Time Last accessed: 11 August 2008 Last updated: May 2008 http://www.pewinternet.org/Data-Tools/Download-Data/Trend-Data.aspx

Pierce, T. (2004) How to Blog Last accessed: 5 August 2008 Last updated: 16 Jun 2004 http://www.tonypierce.com/blog/2004/06/how-to-blog-by-tony-pierce-110-1.htm

Plummer, K. (1996) Symbolic Interactionism in the Twentieth Century: The Rise of Empirical Social Theory. In: Turner, B. S. (ed.) The Blackwell Companion to Social Theory, Blackwell Publishers, Oxford; Cambridge, Mass, pp. 223-251.

Point Topic (n.d.) Broadband Density Last accessed: Feb 2006 Last updated: n.d. http://www.pointtopic.com/home/bbn/sample.asp

Pollitt, M. (23rd Feb 2005) Careless Blogs Cost Jobs. The Independent, p. 11 http://news.independent.co.uk/world/science_technology/article12329.ece.

Pool, I. d. S. (1977) The Social Impact of the Telephone, M.I.T. Press, Cambridge, Mass.; London. Postmes, T., R. Spears and M. Lea (1998) Breaching or Building Social Boundaries? Side-Effects of Computer-Mediated Communication, Communication Research, 25, 689-715.

Priest, P. J. (1995) Public Intimacies: Talk Show Participants and Tell-All Tv, Hampton Press, Cresskill, N.J.

Priest, P. J. (1996) 'Gilt by Association: Talk Show Participants' Televisually Enhanced Status and Self Esteem. In: Grodin, D. and T. R. Lindlof (eds.) Constructing the Self in a Mediated World, Sage Publications, Thousand Oaks.

Rainie, L. (2005) The State of Blogging. Pew Internet \& American Life Project. http://www.pewinternet.org/PPF/r/144/report_display.asp

Reed, A. (2005) 'My Blog Is Me': Texts and Persons in UK Online Journal Culture (and Anthropology), Ethnos, 70, 220-242.

Reporters Without Borders (2004) Internet under Surveillance: Obstacles to the Free Flow of Information Online. Reporters Without Borders. http://www.rsf.org/rubrique.php3?id_rubrique=433 
Rettberg, J. W. (2008) Blogging, Polity, Cambridge; Malden, MA.

Reynolds, L. T. (1990) Interactionism: Exposition and Critique, (3rd) (trans. General Hall, Dix Hills, N.Y.

Robson, C. (2002) Interviews. In: Real World Research: A Resource for Social Scientists and Practitioner-Researchers, (2nd) (trans. Blackwell Publishers, Oxford, UK; Madden, Mass., pp. 269-291.

Rodríguez, C. (2001) Fissures in the Mediascape: An International Study of Citizens' Media, Hampton Press, Cresskill, N.J.

Rose, N. (1999) Governing the Soul: The Shaping of the Private Self, Routledge, London.

Rosen, J. (2004) The Weblog: An Extremely Democratic Form in Journalism. In: Lebkoswky, J. and M. Ratcliffe (eds.) Extreme Democracy: The Book, Lulu.com.

http://extremedemocracy.com/chapters/Rosen_weblog.pdf

Rosen, J. (2005) The Naked Crowd: Reclaiming Security and Freedom in an Anxious Age, (1st) (trans. Random House, New York, NY.

Rosenstein, A. W. (2000) Self-Presentation and Identity on the World Wide Web: An Exploration of Personal Home Pages. PhD. The University of Texas at Austin.

http://web.archive.org/web/20030423193923/http://www.polysemy.com/awr/dissertation/awr_webi dentity.pdf

Scannell, P. (1996) Radio, Television, and Modern Life: A Phenomenological Approach, Blackwell, Oxford, UK; Cambridge, Mass., USA.

Schaap, F. (2004) Links, Lives, Logs: Presentation in the Dutch Blogosphere. In: Gurak, L., S. Antonijevic, L. Johnson, C. Ratcliff and J. Reyman (eds.) Into the Blogosphere: Rhetoric, Community, and Culture of Weblogs. http://blog.lib.umn.edu/blogosphere/

Scheidt, L. A. (2008) Diary Weblogs as Genre. Indiana University. http://professionallurker.com/linked/2008/quals/diary_weblog_genre.pdf

Schiano, D., B. Nardi, M. Gumbrecht and L. Swartz (2004) Blogging by the Rest of Us. In: CHI 2004, Vienna, Austria. http://home.comcast.net/ diane.schiano/CHI04.Blog.pdf

Schmidt, J. (2006) Blogging Practices: Empirical Findings for the German-Speaking Blogosphere Last accessed: 21 March, 2006 Last updated: 21 March, 2006 http://www.bamberggewinnt.de/wordpress/archives/420

Schmidt, J. (2007a) Blogging Practices in the German-Speaking Blogosphere "New Communication Media" Research Centre.

http://www.ssoar.info/ssoar/files/2008/239/fonkpaper0702.pdf

Schmidt, J. (2007b) Blogging Practices: An Analytical Framework, Journal of Computer-Mediated Communication, 12 (4), 1409-1427.

Schütz, A. and F. Machilek (2003) Who Owns a Personal Home Page? A Discussion of Sampling Problems and a Strategy Based on a Search Engine, Swiss Journal of Psychology, 62 (2), 121-129.

Senft, T. (2008) Camgirls: Celebrity \& Community in the Age of Social Networks, Peter Lang, New York, NY.

Serfaty, V. (2004) The Mirror and the Veil: An Overview of American Online Diaries and Blogs, Rodopi, Amsterdam. 
Shank, G. (1993) Abductive Multiloguing: The Semiotic Dynamics of Navigating the Net, The Arachnet Electronic Journal on Virtual Culture, 1 (1).

http://www.ibiblio.org/pub/academic/communications/papers/ejvc/SHANK.V1N1

Shattuc, J. (1997) The Talking Cure: TV Talk Shows and Women, Routledge, New York; London.

Shepherd, A. (2003) Correlations from Oxford Internet Survey Questions Relating to Web Page Creation 23 May to 28 June 2003. (Personal communication).

Shirky, C. (2008) Here Comes Everybody: The Power of Organizing without Organizations, Penguin Press, New York. http://www.herecomeseverybody.org/

Siapera, E. (2008) The Political Subject of Blogs, Information Polity: The International Journal of Government \& Democracy in the Information Age, 13 (1/2), 51-63.

Sifry, D. (2006) State of the Blogosphere, August 2006 Last accessed: 7 August, 2006 Last updated: 7 August, 2006 http://www.sifry.com/alerts/archives/000436.html

Silverstone, R. (1985) Framing Science: The Making of a BBC Documentary, British Film Institute, London.

Silverstone, R. (2006) Domesticating Domestication: Reflections on the Life of a Concept. In: Berker, T., M. Hartmann, Y. Punie and K. Ward (eds.) Domestication of Media and Technology, Open University Press, Maidenhead, pp. 229-248.

Silverstone, R. and L. Haddon (1996) Design and the Domestication of Information and Communication Technologies: Technical Change and Everyday Life. In: Mansell, R. E. and R. Silverstone (eds.) Communication by Design: The Politics of Information and Communication Technologies, Oxford University Press, Oxford; New York, pp. 44-74.

Simon, H. A. (1982) Models of Bounded Rationality, MIT Press, Cambridge, Mass.

Simpson, J. A. and E. S. Weiner (1989) The Oxford English Dictionary, (2nd ed). Clarendon, Oxford.

Sorapure, M. (2003) Screening Moments, Scrolling Lives: Diary Writing on the Web, Biographyan Interdisciplinary Quarterly, 26 (1), 1-23.

Sproull, L. and S. Kiesler (1986) Reducing Social Context Cues: Electronic Mail in Organizational Communications, Management Science, 32 (11), 1492-1512. http://www.jstor.org/stable/2631506

Stern, S. (2008) Producing Sites, Exploring Identities: Youth Online Authorship. In: Buckingham, D. (ed.) Youth, Identity, and Digital Media, Chicago, pp. 95-117.

Stone, G. P. and H. A. Farberman (1970) Social Psychology through Symbolic Interaction, GinnBlaisdell, Waltham, Mass.

Su, N. M., Y. Wang and G. Mark (2005) Politics as Usual in the Blogosphere. In: Social Intelligence Design, http://blogsurvey.blogspot.com/2005/06/blog-survey-findings.html

Sunstein, C. R. (2007) Republic.Com 2.0, Princeton University Press, Princeton.

Swartz, D. (1997) Culture \& Power: The Sociology of Pierre Bourdieu, University of Chicago Press, Chicago.

Tate, R. (2008) Her Royal Highness of Princeton Last accessed: 10 September 2008 Last updated: 13 August 2008 http://gawker.com/5036818/her-royal-highness-of-princeton

Taubman, G. (1998) A Not-So World Wide Web: The Internet, China and the Challenge to Nondemocratic Rule, Political Communication, 15 (2), 255-272. 
Thomas, O. (2008) Paris Hilton, Lindsay Lohan Private Pics Exposed by Yahoo Hack Last accessed: 3 July 2008 Last updated: 3 June 2008 http://valleywag.com/5012543/paris-hiltonlindsay-lohan-private-pics-exposed-by-yahoo-hack

Thompson, C. (2008) Brave New World of Digital Intimacy. In: New York Times Magazine, 7 September 2008. http://www.nytimes.com/2008/09/07/magazine/07awareness-t.html

Thompson, J. B. (1995a) Communication and Social Context. In: The Media and Modernity: A Social Theory of the Media, Polity Press, Cambridge, UK, pp. 10-43.

Thompson, J. B. (1995b) The Media and Modernity: A Social Theory of the Media, Polity Press, Cambridge, UK.

Thompson, J. B. (1995c) Self and Experience in a Mediated World. In: The Media and Modernity: A Social Theory of the Media, Polity Press, Cambridge, UK, pp. 207-234.

Thorseth, M. (2008) Reflective Judgment and Enlarged Thinking Online, Ethics and Information Technology, 10 (4), 221-231.

Thumim, N. (2007) Mediating Self-Representations: Tensions Surrounding 'Ordinary' Participation in Public Sector Projects. London School of Economics and Political Science.

Tufekci, Z. (2008) Can You See Me Now? Audience and Disclosure Regulation in Online Social Network Sites Bulletin of Science, Technology and Society, 28 (1), 20-36.

Turkle, S. (1996a) Life on the Screen: Identity in the Age of the Internet, Weidenfeld \& Nicolson, London.

Turkle, S. (1996b) Parallel Lives: Working on Identity in Virtual Space. In: Grodin, D. and T. R. Lindlof (eds.) Constructing the Self in a Mediated World, Sage Publications, Thousand Oaks, pp. 156-175.

Turner, F. (2005) Where the Counterculture Met the New Economy: The Well and the Origins of Virtual Community, Technology and Culture, 46 (July 2005), 485-512.

Turner, F. (2006) From Counterculture to Cyberculture: Stewart Brand, the Whole Earth Network, and the Rise of Digital Utopianism, University of Chicago Press, Chicago.

Uexküll, J. V. (1957 [1934]) A Stroll through the Worlds of Animals and Men. In: Schiller, C. H. (ed.) Instinctive Behavior, International Universities Press, New York.

US Census Bureau (2006) Educational Attainment in the United States: 2006. US Census Bureau. http://www.census.gov/population/www/socdemo/education/cps2006.html

USC Annenberg School Center for the Digital Future (2008) The 2008 Digital Future Report. USC Annenberg School Center for the Digital Future. http://www.digitalcenter.org/

Vaisman, C. L. (2006) Design \& Play: Weblog Genres of Adolescent Girls in Israel, Reconstruction, 6 (4). http://reconstruction.eserver.org/064/vaisman.shtml

Valenzuela, S., N. Park and K. F. Kee (2008) Lessons from Facebook: The Effect of Social Network Sites on College Students' Social Capital Presented at 9th International Symposium on Online Journalism Austin, TX.

Van Dijck, J. (2004) Composing the Self: Of Diaries and Lifelogs, fibreculture, (3).

http://journal.fibreculture.org/issue3/issue3_vandijck.html

Van Dijck, J. (2007) Mediated Memories in the Digital Age, Stanford University Press, Stanford, CA. 
Viegas, F. (2005) Bloggers' Expectations of Privacy and Accountability: An Initial Survey Journal of Computer-Mediated Communication, 10 (3). DOI:10.1111/j.1083-6101.2005.tb00260.x

Voiskounsky, A. E. (1997) Telelogue Conversations, Journal of Computer-Mediated Communication, 2 (4). DOI:10.1111/j.1083-6101.1997.tb00194.x

Walker, J. (2005) Final Version of Weblog Definition. In: Herman, D., M. Jahn and M.-L. Ryan (eds.) The Routledge Encyclopedia of Narrative Theory, Routledge, London.

http://jilltxt.net/archives/blog_theorising/final_version_of_weblog_definition.html

Walker, K. (2000) "It's Difficult to Hide It": The Presentation of Self on Internet Home Pages, Qualitative Sociology, 23 (1), 99-120.

Wall, M. (2005) 'Blogs of War': Weblogs as News, Journalism, 6 (2), 153-172.

Walther, J. B. (1992) Interpersonal Effects in Computer-Mediated Interaction - a Relational Perspective, Communication Research, 19 (1), 52-90.

Walther, J. B. (1996) Computer-Mediated Communication: Impersonal, Interpersonal, and Hyperpersonal Interaction, Communication Research, 23 (1), 3-43.

Waskul, D. (1996) Ethics of Online Research: Considerations for the Study of Computer Mediated Forms of Interaction Last accessed: 1st September 2004 Last updated: n.d.

http://venus.soci.niu.edu/ jthomas/ethics/tis/go.dennis

Wellman, B. and A. Quan-Hasse (2004) How Does the Internet Affect Social Capital? In:

Huysman, M. and V. Wulf (eds.) Social Capital and Information Technology, MIT Press, Cambridge, Mass. http://www.chass.utoronto.ca/ wellman/publications/index.html

Williams, R. and D. Edge (1996) The Social Shaping of Technology, Research Policy, 25 (6), 869899.

Winkin, Y. (1988) Erving Goffman: Les Moments Et Leurs Hommes, Minuit, Paris.

Winner, L. (1977) Autonomous Technology: Technics-out-of-Control as a Theme in Political Thought, Cambridge, Mass.

Winston, B. (1998) Media Technology and Society: A History: From the Telegraph to the Internet, Routledge, London; New York.

Woods, R. and N. Hellen (14 March 2004) Who Is 'Belle De Jour', the High-Class Hooker Whose Web Diary Is Set to Be a Literary Sensation? Sunday Times, p. 23

Ybarra, M. L., K. J. Mitchell, D. Finkelhor and J. Wolak (2007) Internet Prevention Messages:

Targeting the Right Online Behaviors, Archives of Pediatrics \& Adolescent Medicine, 161 (2), 138145.

YouGov (2007) What Does Your Netrep Say About You? A Study of How Your Internet Reputation Can Influence Your Career Prospects. YouGov. http://www.viadeo.com/netrep/

Young, I. M. (1990) Justice and the Politics of Difference, Princeton University Press, Princeton, N.J.

Young, I. M. (1996) Communication and the Other: Beyond Deliberative Democracy. In: Benhabib, S. (ed.) Democracy and Difference: Contesting the Boundaries of the Political, Princeton University Press, Princeton, N.J., pp. 120-136. 